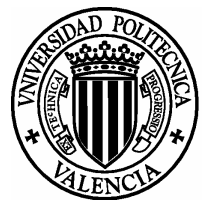

UNIVERSIDAD POLITÉCNICA DE VALENCIA DEPARTAMENTO DE QUÍMICA

\title{
Inmunoensayos en medios orgánicos para el análisis en línea de plaguicidas
}

TESIS DOOTORAL

Presentada por: José Penalva Villegas 


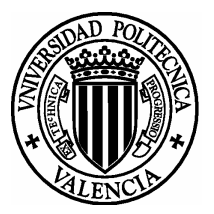

\section{UNIVERSIDAD POLITÉCNICA DE VALENCIA DEPARTAMENTO DE QUÍMICA}

\section{Inmunoensayos en medios orgánicos para el análisis en línea de plaguicidas}

Memoria presentada por José Penalva Villegas

para optar al Grado de Doctor en

Ciencias Químicas

Valencia, Septiembre 2000 


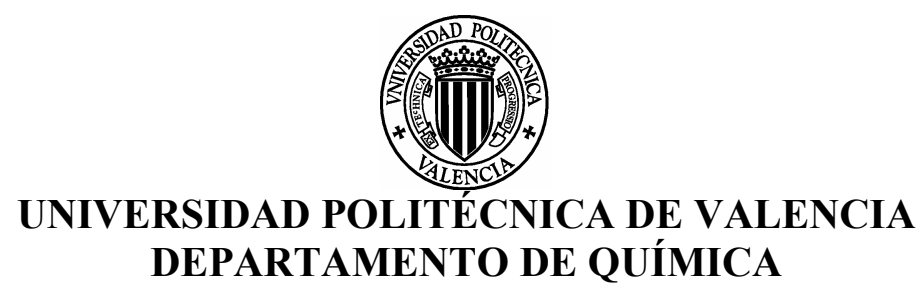

Ángel Maquieira Catalá, Catedrático de Química Analítica de la Universidad Politécnica de Valencia,

Rosa Puchades Pla, Catedrática de Química Analítica de la Universidad Politécnica de Valencia

CERTIFICAN: Que las investigaciones recogidas en la presente memoria “Inmunoensayos en medios orgánicos para el análisis en línea de plaguicidas", que presenta D. José Penalva Villegas, Licenciado en Ciencias Químicas, han sido realizadas bajo nuestra dirección y cumplen con las normas en vigor en cuanto a calidad científica y volumen de trabajo. Por ello, autorizamos su presentación para ser defendida como Tesis Doctoral.

En Valencia a 4 de Septiembre de 2000

Fdo. Ángel Maquieira Catalá

Fdo. Rosa Puchades Pla 
"La oscuridad nos envuelve a todos, pero mientras el sabio tropieza en alguna pared, el ignorante permanece tranquilo en el centro de la estancia"

A. France

"Ciencia es el arte de crear ilusiones convenientes, que el necio acepta o disputa, pero de cuyo ingenio goza el estudioso, sin cegarse ante el hecho de que tales ilusiones son otros tantos velos para ocultar las profundas tinieblas de lo insondable",

\section{Karl Gustav Jung}




\section{Ascadecimientos}

En el momento de escribir la Tesis Doctoral en la que se recogen los resultados obtenidos a lo largo de varios años, es imposible sustraerse a los recuerdos y personas que han influido enormemente en este periodo. Por tanto, me gustaría expresar mi más sincera gratitud a:

Mis directores, Ángel Maquieira Catalá y Rosa Puchades Pla, quienes además de aceptar la dirección de esta Tesis, me han apoyado en todo momento.

A todos mis compañeros y amigos: Miguel Ángel, Sergi, José Antonio, Paqui, Patricia, Lucía, Paloma, Fernando G., que han sabido crear un ambiente de trabajo muy agradable a lo largo de estos años.

A Ángel Montoya, Director del Laboratorio Integrado de Bioingeniería, Antonio, Juanjo y Maria José, por su colaboración en la realización de esta Tesis.

A los grupos de Barcelona, Departamento de Química Ambiental del CID-CSIC y Departamento de Química Orgánica Biológica de la Universidad de Barcelona, por el suministro de inmunorreactivos.

A la empresa AGBAR, Aguas de Barcelona, por suministrar desinteresadamente las muestras de agua utilizadas en esta Tesis.

A los profesores de la Unidad Docente de Química Analítica: M $^{\mathrm{a}}$ Dolores Climent, M ${ }^{\mathrm{a}}$ Dolores Esteve, Julia, Marichu, Susana y Fernando.

A mi familia por el constante apoyo recibido a lo largo de los años y a May que ha supuesto un constante estímulo y apoyo necesario para la conclusión de esta Tesis.

A mis compañeros/as de INDALVA S.L. por el ánimo recibido en la última fase de esta Tesis.

Por último, al Ministerio de Educación y Cultura por la concesión de una Beca para Formación de Personal Investigador, sin la cual no hubiera sido posible la realización de esta Tesis.

Gracias a todos. 


\section{Indice}

1. Introducción 1

1.1. PRODUCTOS FITOSANITARIOS. PERSPECTIVA HISTÓRICA Y 1 PROBLEMÁTICA

1.2. ANÁLISIS DE PRODUCTOS FITOSANITARIOS 5

1.2.1. Métodos oficiales de análisis de productos fitosanitarios 5

1.2.2. Métodos inmunoquímicos de análisis 11

1.2.2.1. Producción de anticuerpos $\quad 12$

1.2.2.2. Clasificación de los inmunoensayos $\quad 15$

1.2.2.3. Características analíticas de los formatos de ensayo 18 competitivos

1.2.2.4. Aplicación de las técnicas inmunoquímicas al análisis de 20 residuos de productos fitosanitarios en aguas y alimentos

1.3. INMUNOENSAYOS Y MEDIOS ORGÁNICOS

1.4. DISOLVENTES ORGÁNICOS 34

1.4.1. Elección de disolventes para bioensayos en medios orgánicos 36

1.5. INMUNOSENSORES. TIPOS

1.5.1. Inmunosensores en flujo 45

1.5.1.1. Soportes de inmovilización de inmunorreactivos 46

1.5.1.2. Modos de inmovilización $\quad 47$

1.5.1.3. Reversibilidad y reusabilidad $\quad 48$

1.6. PRODUCTOS FITOSANITARIOS OBJETO DE ESTUDIO 49

1.6.1. Carbaril 49

1.6.2. 1-Naftol 51

1.6.3. Irgarol 1051

1.7. OBJETIVOS

2. Materiales y métodos 56

2.1. REACTIVOS 56

2.2. INMUNORREACTIVOS

2.3. INSTRUMENTACIÓN 
2.4.1. Método del anhídrido mixto $\quad 60$

2.4.2. Método del éster activo $\quad 62$

2.5. SOPORTES DE INMOVILIZACIÓN DE INMUNORREACTIVOS 64

2.6. MÉTODOS DE INMOVILIZACIÓN 65

2.6.1. Inmovilización de anticuerpos sobre CPG alquilaminado 65

2.6.2. Inmovilización de anticuerpos sobre gel de agarosa (GAHz) 67

$\begin{array}{ll}\text { 2.6.3. Inmovilización de haptenos } & 67\end{array}$

2.6.3.1. Inmovilización sobre CPG 68

2.6.3.2.Inmovilización sobre gel de agarosa derivatizado (GASc) 68

2.7. PRUEBAS PRELIMINARES. SELECCIÓN DE VARIABLES 69

2.8. DESCRIPCIÓN DE LOS EQUIPOS UTILIZADOS EN EL DESARROLLO 72 DE LOS SISTEMAS SENSORES

$\begin{array}{ll}\text { 2.8.1. Formato directo } & 74\end{array}$

2.8.2. Formato indirecto 76

$\begin{array}{ll}\text { 2.8.3. Formato de captura } & 78\end{array}$

2.9. SISTEMAS DE DETECCIÓN EMPLEADOS EN EL DESARROLLO DE 81 LOS INMUNOSENSORES

2.9.1. Inmunosensores con detección fluorescente 81

2.9.1.1.Inmunosensores con detección fluorescente con resolución 81 temporal

2.9.1.2. Conjugación complejo de Tb-hapteno. Formato directo 84

2.9.1.3.Conjugación del complejo de Tb-anticuerpo secundario. 84 Formato indirecto

$\begin{array}{ll}\text { 2.9.2. Inmunosensores con detección luminiscente } & 87\end{array}$

2.10. DISOLVENTES ORGÁNICOS 89

2.11. TRATAMIENTO DE MUESTRAS 90

$\begin{array}{ll}\text { 2.11.1. Muestras vegetales } & 90\end{array}$

$\begin{array}{ll}\text { 2.11.2. Muestras de agua } & 91\end{array}$

3. Resultados y discusión 93

3.1. SISTEMA MODELO. CONDICIONES DE PARTIDA 93

3.2. ESTUDIO DE DISOLVENTES ORGÁNICOS 93

3.3. ESTUDIOS PRELIMINARES: SELECCIÓN DE VARIABLES 95

3.3.1. Ensayos de actividad 96

3.3.2. Ensayos de competición 98

3.3.3. Reversibilidad de las reacciones anticuerpo-antígeno y regeneración de 100 
inmunosoportes

3.4. DESARROLLO DE INMUNOSENSORES PARA EL SISTEMA MODELO 102

3.4.1. Optimización del inmunosensor. Formato directo 103

3.4.1.1. Ensayos de competición en formato directo 107

3.4.2. Optimización del inmunosensor. Formato indirecto 110

3.4.3. Optimización del inmunosensor. Formato de captura 113

3.4.4. Recapitulación 116

3.5. ESTUDIO DE REACTIVIDAD CRUZADA 117

$\begin{array}{ll}\text { 3.5.1. Formato directo } & 118\end{array}$

$\begin{array}{ll}\text { 3.5.2. Formato indirecto } & 118\end{array}$

$\begin{array}{ll}\text { 3.5.3. Formato de captura } & 119\end{array}$

3.6. COMPARACIÓN CON LOS SISTEMAS EN MEDIO ACUOSO 120

3.7. ANALISIS DE MUESTRAS REFORZADAS 121

$\begin{array}{ll}\text { 3.7.1. Inmunosensor en formato de captura } & 122\end{array}$

3.7.1.1. Análisis de vegetales frescos y procesados 122

3.7.1.2. Análisis de muestras líquidas 127

$\begin{array}{ll}\text { 3.7.2. Inmunosensor en formato directo } & 129\end{array}$

3.7.2.1. Análisis de muestras vegetales 129

3.7.2.2. Análisis de aguas $\quad 130$

3.7.3. Inmunosensor en formato indirecto 131

3.8 DESARROLLO DE INMUNOSENSORES PARA CARBARIL BASADOS 133 EN ANTICUERPOS POLICLONALES

3.8.1. Desarrollo de inmunosensores en formato directo 133

3.8.2. Desarrollo de inmunosensores en formato indirecto 138

3.8.3. Desarrollo de inmunosensores en formato de captura 139

$\begin{array}{ll}\text { 3.8.4. Recapitulación } & 141\end{array}$

3.9. ESTUDIO DE REACTIVIDAD CRUZADA 142

3.9.1. Formato directo 142

3.9.2. Formato indirecto 143

$\begin{array}{ll}\text { 3.9.3. Formato de captura } & 143\end{array}$

3.10. ANÁLISIS DE MUESTRAS REALES 144

$\begin{array}{ll}3.10 .1 \text {. Vegetales frescos y procesados } & 144\end{array}$

$\begin{array}{ll}3.10 .2 \text {. Aguas } & 145\end{array}$

3.10.2.1. Análisis de agua procedente de la Albufera 146 
3.11. DESARROLLO DE INMUNOSENSORES PARA 1-NAFTOL

3.11.1. Desarrollo de inmunosensores en formato directo

3.11.2. Desarrollo de inmunosensores en formato indirecto

3.11.3. Desarrollo de inmunosensores en formato de captura

3.11.4. Recapitulación

3.12. ESTUDIO DE REACTIVIDAD CRUZADA

3.13. ANÁLISIS DE MUESTRAS DE AGUAS NATURALES. ESTUDIOS DE PRECONCENTRACIÓN

3.14. DESARROLLO DE INMUNOSENSORES PARA IRGAROL 1051

3.14.1. Desarrollo de inmunosensores en formato de captura

3.14.2. Desarrollo de inmunosensores en formato directo

3.14.3. Desarrollo de inmunosensores en formato indirecto

3.14.4. Recapitulación

3.15. ESTUDIO DE REACTIVIDAD CRUZADA

3.16. ANÁLISIS DE IRGAROL 1051 EN MUESTRAS DE AGUA

\subsection{SISTEMAS DE DETECCIÓN ALTERNATIVOS}

3.18.1. Detección basada en fluorescencia con resolución temporal

3.18.1.1.Inmunosensores para la determinación de carbaril

3.18.1.2. Inmunosensores para la determinación de 1-naftol

3.18.1.3. Inmunosensores para la determinación de Irgarol 1051

3.18.1.4. Estudio de estabilidad del conjugado Ab ${ }_{2}$-complejo $\mathrm{Tb}$

3.18.2. Inmunosensores basados en detección luminiscente

3.18.2.1. Estudio de sustancias potenciadoras de la reacción de detección quimioluminiscente

3.18.2.2. Estudio de la estabilidad del substrato enzimático

3.18.2.3. Efecto de los medios orgánicos sobre la actividad de la 


\section{Fireruras}

Figura 1.1. Etapas de tratamiento de muestra previas al análisis cromatográfico

Figura 1.2. Estructura básica de un anticuerpo

Figura 1.3. Esquema de la obtención de anticuerpos para haptenos

Figura 1.4. Representación de la curva de calibrado

Figura 1.5. Esquema genérico de un biosensor

Figura 1.6. Esquema básico de un inmunosensor

Figura 1.7. Estructura de Carbaril

Figura 1.8. Estructura de 1-Naftol

Figura 1.9. Estructura de Irgarol 1051

Figura 2.1. Estructura de los haptenos para carbaril. Anticuerpos Monoclonales

Figura 2.2. Estructura de los haptenos para carbaril. Anticuerpo policlonal

Figura 2.3. Estructura de los haptenos utilizados en el sistema 1-naftol

Figura 2.4. Estructura de los haptenos utilizados en el sistema Irgarol 1051

Figura 2.5. Método del anhídrido mixto para el acoplamiento de haptenos a proteínas

Figura 2.6. Método del éster activo para el acoplamiento de haptenos a proteínas

Figura 2.7. Etapas del proceso de inmovilización de anticuerpos sobre CPG

Figura 2.8. Etapas del proceso de inmovilización de anticuerpos sobre gel de agarosa derivatizado con grupos hidrazina

Figura 2.9. Inmovilización de conjugados hapteno-proteína sobre gel de agarosa derivatizado con grupos $N$-hidroxisuccinimida

Figura 2.10. Esquema del sistema de inmunofiltración

Figura 2.11. Esquema del inmunosensor

Figura 2.12. Representación de las etapas seguidas en los ensayos en formato directo 
Figura 2.13. Formato directo. Conexión módulos-disoluciones

Figura 2.14. Representación de las etapas seguidas en los ensayos en formato indirecto

Figura 2.15. Formato indirecto. Conexión módulos-disoluciones

Figura 2.16. Representación de las etapas seguidas en los ensayos en formato de captura. Protocolos de ensayo simultáneo y secuencial

Figura 2.17. Formato de captura. Conexión módulos-disoluciones

Figura 2.18. Estructura del complejo de $\mathrm{Tb}$

Figura 2.19. Espectro de emisión del complejo de $\mathrm{Tb}$

Figura 2.20. Espectro de excitación del complejo de $\mathrm{Tb}$

Figura 2.21. Descripción de las etapas seguidas para la funcionalización de haptenos con cadaverina

Figura 2.22. Espectro de emisión del conjugado complejo de Tb-anticuerpo secundario

Figura 2.23. Espectro de excitación del conjugado complejo de Tb-anticuerpo secundario

Figura 2.24. Inmunosensores con detección fluorescente con resolución temporal. Conexión módulos-disoluciones

Figura 3.1. Porcentajes de señal obtenidos mediante inmunofiltración utilizando los anticuerpos monoclonales anti-carbaril inmovilizados en GAHz. Trazador CNH-HRP y todos los medios orgánicos estudiados

Figura 3.2.1 Señales de fluorescencia obtenidas en los ensayos de regeneración con el anticuerpo CNH 36 inmovilizado en GAHz (a) y CPG (b)

Figura 3.2.2 Señales de fluorescencia obtenidas en los ensayos de regeneración con el anticuerpo CNH 45 inmovilizado en GAHz (a) y CPG (b)

Figura 3.2.3 Señales de fluorescencia obtenidas en los ensayos de regeneración con el anticuerpo CNA 36 inmovilizado en GAHz (a) y CPG (b)

Figura 3.3. Curvas de competición obtenidas para todas las combinaciones inmunosoporte-trazador: a) anticuerpo CNA 36 inmovilizado en $\mathrm{GAHz}$ y CNH-HRP como trazador; b) idénticas condiciones, excepto trazador CPNU-HRP; c) CNA 36 inmovilizado en CPG y CNH-HRP como trazador; d) idénticas condiciones, excepto trazador CPNU-HRP. Medios

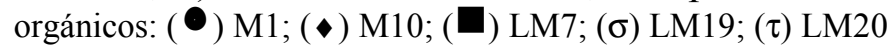


Figura 3.4. Influencia de la concentración de metanol en la sensibilidad del método ELISA empleado en la determinación de carbaril

Figura 3.5. Curvas de competición normalizadas obtenidas mediante los dos métodos inmunológicos: $(\sigma)$ Sensor utilizando 50\% MeOH-50 PBT como medio orgánico. ( $\lambda$ ) ELISA utilizando PBS-T con $5 \% \mathrm{MeOH}(\mathrm{v} / \mathrm{v})$

Figura 3.6. Correlación entre los resultados obtenidos en los análisis de carbaril mediante el inmunosensor, ELISA y HPLC en muestras vegetales

Figura 3.7. Curvas de calibrado obtenidas con el anticuerpo policlonal R2114: a) inmovilizado en GAHz con los trazadores CNH-HRP y CPNU-HRP en el medio 50\%MeOH-50\% PBST; b) inmovilizado en $\mathrm{CPG}$ con el trazador H4-HRP y los medios orgánicos seleccionados

Figura 3.8. Curvas de calibrado obtenidas con el anticuerpo policlonal R2114 inmovilizado en CPG con los trazadores CPNU-HRP (a); CNH-HRP (b); H4-HRP (c) y los medios orgánicos seleccionados

Figura 3.9. Comparación de las curvas de calibrado obtenidas en el medio M1 utilizando las condiciones más sensibles

Figura 3.10. Curvas de calibrado obtenidas con el anticuerpo R2114 en formato indirecto. Soporte: GASc

Figura 3.11. Curvas de competición obtenidas con el anticuerpo 3907 en formato de captura en los medios de ensayo estudiados: a) acuosos; b) orgánicos

Figura 3.12. Comparación de las curvas de calibrado obtenidas en medio acuoso y orgánico en las condiciones de máxima sensibilidad

Figura 3.13. Curva de preconcentración para 1-naftol

Figura 3.14. Curvas de competición normalizadas para Irgarol 1051 obtenidas en formato de captura (R-15/4d-HRP)

Figura 3.15. Evolución de la señal obtenida con el conjugado $\mathrm{Ab}_{2}-\mathrm{Tb}$ en función del tiempo (sin estabilizante)

Figura 3.16. Evolución de la señal obtenida con el conjugado $A b_{2}-\mathrm{Tb}$ en presencia de proteínas inertes; a) BSA (1\%); b) OVA $(0,5 \%)$

Figura 3.17. Evolución temporal de la señal obtenida con el substrato CDP Star

Figura 3.18. Valores de señal obtenidos con el substrato CDP Star en presencia de potenciadores

Figura 3.19. Señales blanco debidas a los potenciadores 
Figura 3.20. Estabilidad del substrato enzimático con el tiempo. Influencia de la adición de estabilizante

Figura 3.21. Efecto del medio orgánico ensayado en la actividad de la fosfatasa alcalina 


\section{Tablas}

Tabla 1.1. Valores de solubilidad $(\mathrm{mg} / \mathrm{l})$ de algunos productos fitosanitarios en disolventes orgánicos

Tabla 1.2. Etapas previas y técnica empleada para la determinación de algunos productos fitosanitarios utilizando los métodos de la AOAC

Tabla 1.3. Comparación de las principales características de los anticuerpos policlonales y monoclonales

Tabla 1.4. Aplicación de técnicas inmunoquímicas al análisis de residuos de productos fitosanitarios

Tabla 1.5. Métodos inmunoquímicos validados por la EPA para el análisis de residuos en aguas y suelos

Tabla 1.6. Valores de $I_{50}(\mu \mathrm{g} / \mathrm{l})$ para triazinas obtenidos en distintos disolventes orgánicos

Tabla 1.7. Parámetros solvatocrómicos de algunos disolventes orgánicos

Tabla 1.8. Efectos de los disolventes orgánicos sobre la actividad enzimática en función de $\log \mathrm{P}$

Tabla 1.9. Valores de log $\mathrm{P}$ para algunos disolventes orgánicos

Tabla 1.10. Clasificación de inmunosensores en función del transductor

Tabla 1.11. Comparación de los sistemas de transducción

Tabla 1.12. Principales sistemas de detección empleados en inmunosensores

Tabla 1.13. Modos de inmovilización de anticuerpos y haptenos

Tabla 2.1. Protocolo de ensayo correspondiente al formato directo

Tabla 2.2. Protocolo de ensayo correspondiente al formato indirecto

Tabla 2.3. Protocolos de ensayo correspondientes al formato de captura

Tabla 2.4. Protocolo de ensayo correspondiente al sistema con detección fluorescente con resolución temporal

Tabla 2.5. Relación de las sustancias empleadas como potenciadores

Tabla 2.6. Propiedades físico-químicas de los disolventes orgánicos empleados 
Tabla 3.1. Mezclas binarias y ternarias compatibles. Resultados expresados como porcentajes de disolvente orgánico en PBST (v/v)

Tabla 3.2. Señales obtenidas en los ensayos de competición mediante inmunofiltración (\%)

Tabla 3.3. Señales obtenidas tras varios ciclos de desorción

Tabla 3.4. Número mínimo de ciclos de regeneración efectuados con cada inmunosoporte y mezcla orgánica ensayada

Tabla 3.5. Valores de $I_{50}(\mu \mathrm{g} / \mathrm{l})$ obtenidos en formato directo con el anticuerpo monoclonal CNA 36 inmovilizado en los dos soportes. Ensayos realizados con los trazadores y medios orgánicos seleccionados

Tabla 3.6. Valores de $I_{50}(\mu \mathrm{g} / \mathrm{l})$ obtenidos en formato indirecto con los dos conjugados hapteno-proteína inmovilizados en GASc. Ensayos realizados con los anticuerpos y medios orgánicos seleccionados

Tabla 3.7. Valores de $I_{50}(\mu \mathrm{g} / 1)$ obtenidos en formato de captura con los anticuerpos monoclonales estudiados. Ensayos realizados con los trazadores y medios orgánicos seleccionados

Tabla 3.8. Resumen de las características de los inmunosensores para carbaril con anticuerpos monoclonales

Tabla 3.9. Valores de reactividad cruzada (\%RC) obtenidos utilizando formato directo en las condiciones seleccionadas

Tabla 3.10. Valores de reactividad cruzada $(\% \mathrm{RC})$ obtenidos utilizando formato indirecto en las condiciones seleccionadas

Tabla 3.11. Valores de reactividad cruzada ( $\% \mathrm{RC})$ obtenidos utilizando formato de captura en las condiciones seleccionadas

Tabla 3.12. Valores de $I_{50}(\mu \mathrm{g} / 1)$ de los inmunosensores en medio acuoso y medio orgánico para todos los formatos y soportes

Tabla 3.13. Valores comparados de reactividad cruzada (\%RC) obtenidos con los inmunosensores en medio orgánico y acuoso (condiciones de máxima sensibilidad)

Tabla 3.14. Determinación de carbaril en muestras vegetales mediante el inmunosensor con formato de captura. Comparación entre el método de extracción multirresiduo (MRS) y la extracción directa con metanol $(\mathrm{EDM})$

Tabla 3.15. Determinación de carbaril en muestras vegetales reforzadas utilizando el inmunosensor en formato de captura. Comparación con los resultados obtenidos en ELISA y HPLC 
Tabla 3.16. Análisis de carbaril en muestras de zumo de manzana reforzado

Tabla 3.17. Análisis de carbaril en muestras vegetales utilizando el inmunosensor en formato directo

Tabla 3.18. Análisis de carbaril en agua mineral utilizando el inmunosensor en formato directo

Tabla 3.19. Análisis de carbaril en agua mineral utilizando el inmunosensor en formato indirecto

Tabla 3.20. Análisis de carbaril en muestras de tomate utilizando el inmunosensor en formato indirecto

Tabla 3.21. Valores óptimos de concentración de trazador H4-HRP (mg/l) obtenidos en los ensayos de actividad realizados en el medio 50\%MeOH-50\% PBST

Tabla 3.22. Valores de $I_{50}(\mu \mathrm{g} / \mathrm{l})$ obtenidos con el anticuerpo policlonal R2114 inmovilizado en $\mathrm{GAHz}$ y $\mathrm{CPG}$, trazadores y medios orgánicos seleccionados

Tabla 3.23. Valores de $I_{50}(\mu \mathrm{g} / 1)$ obtenidos con el anticuerpo policlonal R2114 en formato de captura

Tabla 3.24. Resumen de las características de los inmunosensores desarrollados para carbaril con el anticuerpo policlonal R2114

Tabla 3.25. Valores de reactividad cruzada (\%RC) obtenidos con el anticuerpo R 2114 inmovilizando en GAHz y CPG. Comparación con ELISA

Tabla 3.26. Valores de reactividad cruzada ( $\% \mathrm{RC})$ obtenidos en formato de captura

Tabla 3.27. Determinación de carbaril en muestras vegetales utilizando el inmunosensor en formato de captura

Tabla 3.28. Análisis de carbaril en muestras de agua de la albufera

Tabla 3.29. Análisis de carbaril en muestras de agua del Río Llobregat reforzadas a $100 \mathrm{ng} / 1$

Tabla 3.30. Porcentaje de señal normalizada obtenida tras cada ciclo de regeneración

Tabla 3.31. Valores de $I_{50}(\mu \mathrm{g} / \mathrm{l})$ obtenidos en medio acuoso con el inmunosensor para 1-Naftol en formato de captura

Tabla 3.32. Valores de $\mathrm{I}_{50}(\mu \mathrm{g} / \mathrm{l})$ obtenidos en medio orgánico con el inmunosensor para 1-Naftol en formato de captura 
Tabla 3.33. Resumen de las características de los inmunosensores desarrollados para 1-naftol

Tabla 3.34. Valores de reactividad cruzada (\%RC) obtenidos en medio acuoso y orgánico con el inmunosensor en formato de captura

Tabla 3.35. Análisis de 1-naftol en muestras de agua reforzadas ( $40 \mu \mathrm{g} / \mathrm{l})$

Tabla 3.36. Rango óptimo de concentración de los trazadores en formato de captura

Tabla 3.37. Valores de $I_{50}(\mu \mathrm{g} / \mathrm{l})$ obtenidos con el inmunosensor para Irgarol 1051 en formato de captura

Tabla 3.38. Rango óptimo de concentración de los trazadores en formato directo

Tabla 3.39. Valores de $I_{50}(\mu \mathrm{g} / \mathrm{l})$ obtenidos con el inmunosensor para Irgarol 1051 en formato directo. Anticuerpos inmovilizados en $\mathrm{CPG}$

Tabla 3.40. Valores de $I_{50}(\mu \mathrm{g} / 1)$ obtenidos con el inmunosensor para Irgarol 1051 en formato indirecto

Tabla 3.41. Resumen de las características de los inmunosensores desarrollados para Irgarol 1051

Tabla 3.42. Valores de reactividad cruzada ( $\% \mathrm{RC})$ obtenidos con los inmunosensores para Irgarol 1051

Tabla 3.43. Análisis de Irgarol 1051 en muestras de agua dulce

Tabla 3.44. Análisis de Irgarol 1051 en muestras de agua marina

Tabla 3.45. Valores de $I_{50}(\mu \mathrm{g} / 1)$ obtenidos en formato indirecto con el conjugado $\mathrm{Ab}_{2}$ $\mathrm{Tb}$ y con el conjugado enzimático $\mathrm{Ab}_{2}$-HRP. Sistema Carbaril

Tabla 3.46. Valores de $I_{50}(\mu \mathrm{g} / \mathrm{l})$ obtenidos en formato indirecto con el conjugado $\mathrm{Ab}_{2}$ $\mathrm{Tb}$ y con el conjugado enzimático $\mathrm{Ab}_{2}-\mathrm{HRP}$. Sistema 1-Naftol

Tabla 3.47. Valores de $I_{50}(\mu \mathrm{g} / \mathrm{l})$ obtenidos en formato indirecto con el conjugado $\mathrm{Ab}_{2-}$ $\mathrm{Tb}$ y con el conjugado enzimático $\mathrm{Ab}_{2}$-HRP. Sistema Irgarol 1051

Tabla 3.48. Valores de $I_{50}(\mu \mathrm{g} / 1)$ obtenidos en formato de captura con detección luminiscente

Tabla 3.49. Intensidad de luminiscencia para distintas concentraciones del potenciador Emerald II

Tabla 3.50. Valores de $\mathrm{I}_{50}(\mu \mathrm{g} / \mathrm{l})$ obtenidos con el anticuerpo monoclonal CNH-45. Detección luminiscente 
Tabla 3.51. Análisis de muestras de agua reforzadas con carbaril (100 ng/l) con el sistema de detección luminiscente 


\section{Introducción}

\subsection{PRODUCTOS FITOSANITARIOS. PERSPECTIVA HISTÓRICA Y PROBLEMÁTICA}

Los productos fitosanitarios son sustancias orgánicas -de origen natural o sintético- empleadas como biocidas para combatir los parásitos de los cultivos, ganado y animales domésticos, y del hombre y su ambiente. En general, estas sustancias se pueden clasificar en: insecticidas, herbicidas, fungicidas, antibióticos, rodenticidas, acaricidas, etc., en función del organismo sobre el que actúan. También se suelen considerar como tales los atrayentes, repelentes y esterilizantes de insectos (1).

Por otro lado, los productos fitosanitarios pueden clasificarse por familias en función de su estructura química (2). Ejemplo de ello son los plaguicidas organofosforados, organoclorados, carbamatos, fenoxiácidos, piretroides, etc. Según esta clasificación, los compuestos de cada grupo tienen propiedades similares entre sí y básicamente distintas a las de otras familias. Sin embargo, una característica común a todos ellos es su solubilidad en disolventes orgánicos, aunque ésta depende del disolvente utilizado. La Tabla 1.1 recoge los valores de solubilidad de algunos de estos compuestos en los disolventes orgánicos más comunes (3).

El uso de los productos fitosanitarios es relativamente reciente. Las primeras sustancias empleadas para tal fin eran de origen inorgánico como el azufre, arseniatos o sulfato de cobre. A principio del siglo XX, se introducen en Holanda los aceites insecticidas, que incluían el pelitre y la rotenona. Sin embargo, el gran avance en este campo se produce en 1940 con el descubrimiento de las propiedades insecticidas del DDT; a partir de ese momento, la gran mayoría de los productos fitosanitarios utilizados son producidos mediante síntesis. Actualmente, se siguen sintetizando y probando nuevas sustancias que presenten efectos más específicos y baja persistencia en el medio. Todo ello ha provocado que el número de productos fitosanitarios así como su 
utilización, se haya incrementado durante las pasadas cuatro décadas, modificando las prácticas agrícolas y aumentando los rendimientos de la producción.

Tabla 1.1. Valores de solubilidad (mg/l) de algunos productos fitosanitarios en disolventes orgánicos

\begin{tabular}{|c|c|c|c|c|c|c|c|c|c|c|c|c|c|}
\hline Compuesto & Agua & $\mathbf{A C}$ & $\mathbf{B N}$ & ET & HX & MT & TL & $\mathbf{X L}$ & DC & $\overline{\mathbf{A E}}$ & TC & $\mathbf{C L}$ & DE \\
\hline Acetocloro & 223 & $\mathrm{~S}$ & $\mathrm{~S}$ & $\mathrm{~S}$ & & & $\mathrm{~S}$ & & & $\mathrm{~S}$ & $\mathrm{~S}$ & & $\mathrm{~S}$ \\
\hline Alacloro & 242 & $\mathrm{~S}$ & S & $\mathrm{S}$ & & & & & & $\mathrm{S}$ & & $\mathrm{S}$ & $\mathrm{S}$ \\
\hline Aldicarb & 4930 & 350 & 150 & & & & & 50 & 300 & & & & \\
\hline Ametrin & 200 & $5.10^{5}$ & & & $10^{3}$ & 4. $10^{4}$ & 4. $10^{5}$ & & & & & & \\
\hline Amitraz & 0.1 & $>10^{5}$ & & & & & $>10^{5}$ & $>10^{5}$ & & & & & \\
\hline Atrazina & 33 & 3. $10^{4}$ & & & $10^{2}$ & 1. $10^{4}$ & 6. $10^{3}$ & & 3. $10^{4}$ & 2. $10^{4}$ & & & \\
\hline Benomilo & 4 & 18 & & 4 & & & & 10 & & & & 94 & \\
\hline Captan & 3,3 & 21 & 21 & 2.9 & & & 6.9 & 20 & & & & 70 & 2,5 \\
\hline Carbaril & 120 & $\mathrm{~S}$ & S & $\mathrm{S}$ & & & & $\mathrm{S}$ & & & & & \\
\hline Carbendazima & 6 & 300 & & 300 & 0,5 & & & & 70 & & & 100 & 10 \\
\hline Carbofurano & 320 & & & & & & $10^{4}$ & & $>10^{5}$ & & & & \\
\hline Clorotalonil & 0,9 & 20 & & & & & & 80 & & & & & \\
\hline Clorpirifos & 1,4 & & & & & 450 & & 5000 & & & & & 5100 \\
\hline Cianazina & 171 & 2. $10^{5}$ & $10^{4}$ & 4. $10^{4}$ & $10^{4}$ & & & & & & & 2. $10^{5}$ & \\
\hline 2,4-D & 311 & 850 & & 1250 & & & & & & & & & 243 \\
\hline Diazinon & 60 & M & M & & M & M & M & & M & & M & & M \\
\hline Dicamba & 6500 & $8.10^{5}$ & & $9.10^{5}$ & & & $10^{5}$ & & & & & & \\
\hline Dimepiperato & 20 & $6.10^{6}$ & & 4. $10^{6}$ & 2. $10^{6}$ & & & & & & & $6.10^{6}$ & \\
\hline Endosulfan & 0.32 & & & $6.10^{4}$ & 2. $10^{4}$ & & 2. $10^{5}$ & & & 2. $10^{5}$ & & & \\
\hline Etion & 2 & $\mathrm{M}$ & & $\mathrm{M}$ & & M & & M & & & & & \\
\hline Folpet & 1 & & 2. $10^{4}$ & & & & & & & & & $9.10^{4}$ & \\
\hline Heptacloro & 0,056 & 7. $10^{5}$ & $10^{6}$ & 4. $10^{4}$ & & & & $10^{6}$ & & & & $10^{6}$ & \\
\hline Linuron & 81 & $5.10^{5}$ & $10^{5}$ & $10^{5}$ & & & & 1. $10^{5}$ & & & & $\mathrm{~S}$ & $\mathrm{~S}$ \\
\hline Metiocarb & 27 & & & & $10^{4}$ & & $3.10^{5}$ & & & & & & \\
\hline Metomilo & 6. $10^{4}$ & 7. $10^{5}$ & & 4. $10^{4}$ & $10^{6}$ & & & & & & & & \\
\hline Paration & 11 & & & & 7. $10^{5}$ & & 7. $10^{5}$ & & $>10^{5}$ & & & & \\
\hline PCP & 80 & $210^{5}$ & & $\mathrm{~S}$ & & & $\mathrm{~S}$ & & & $\mathrm{~S}$ & $\mathrm{~S}$ & & \\
\hline Procimidona & 4.5 & 2. $10^{5}$ & & & & 2. $10^{3}$ & & 4. $10^{4}$ & & & & 2. $10^{5}$ & \\
\hline Propazina & 5 & & 6. $10^{3}$ & & & & $6.10^{3}$ & & & & & 2. $10^{3}$ & 5. $10^{3}$ \\
\hline Quintoceno & 0,1 & & & & & 2. $10^{4}$ & $10^{6}$ & & & & & & \\
\hline Simazina & 6,2 & 1500 & & 570 & 3,1 & & 130 & & & & & & \\
\hline Terbumetón & 130 & 1. $10^{5}$ & & & & 2. $10^{5}$ & $10^{5}$ & & 4. $10^{5}$ & & & & \\
\hline Tiram & 18 & $8.10^{4}$ & & & & & & & & & & 2. $10^{5}$ & \\
\hline
\end{tabular}

A pesar de los beneficios reportados por los productos fitosanitarios -por ejemplo en los cultivos, asegurando la productividad agrícola- su uso presenta una serie de problemas, ya que tanto los residuos de estas sustancias como sus metabolitos presentan riesgos para la salud y el medio ambiente (4-6). La valoración del impacto medioambiental de estos productos se lleva a cabo tradicionalmente mediante tres 
parámetros generales: toxicidad, persistencia e impacto (7). Tomando en consideración estos parámetros, se elaboran las denominadas listas prioritarias, también llamadas listas "rojas" o "negras".

Los límites máximos de residuos (LMRs) son establecidos por cada país y marcan los niveles de residuos de productos fitosanitarios permitidos, tanto en el medio como en alimentos. Estos niveles pueden ser motivo de discrepancias entre los estados, por las diferencias de criterio establecidas, el tipo de producto recogido y los intereses respaldados. En un intento armonizador, diferentes organismos internacionales están involucrados en el establecimiento de LMRs de aceptación general $(8,9)$.

En el mismo sentido, el primer intento a escala europea lo constituyó una Directiva del Consejo de Europa (Directiva 76/895/ECC) (10) para el control de residuos en frutas y vegetales. En 1990, la Directiva 90/642/ECC (11), modificada mas tarde por la 93/58/ECC (12) y 94/30/ECC (13), establecieron el marco legal en el que se fijaron los LMRs de residuos de productos fitosanitarios en productos vegetales para toda la UE.

Así, cada estado miembro debe adaptar su normativa a la marcada por las anteriores directivas, fijando los valores para cada combinación producto/plaguicida. Además, debe establecer programas de vigilancia y control que garanticen que los niveles de residuos de productos fitosanitarios no superen en ningún caso los establecidos. Las regulaciones correspondientes al Estado Español han sido resumidas en una monografía realizada por Brotons (14).

A continuación se comentan algunos de los resultados obtenidos en diferentes países dentro de los programas de vigilancia y control de residuos de productos fitosanitarios.

En Canadá se analizaron residuos de productos fitosanitarios en frutas y vegetales durante un periodo de 27 meses, encontrando que un 2,86\% de las muestras importadas superaban los LMRs (15). En EEUU, la Food and Drug Administration (FDA), tras un estudio estadístico realizado entre 1993-1994, indicó que los niveles de productos fitosanitarios se situaron, en todos los casos, por debajo del máximo tolerable en dicho país (16).

En España, y sólo durante el año 1996, se analizaron 3022 muestras, de las cuales 1603 correspondían a frutas, 1231 a hortalizas, 5 a almendras y 183 a otros productos vegetales. Los resultados obtenidos mostraron que el 36,20\% de las muestras contenían residuos por debajo de los LMRs establecidos, el 2,64\% presentaban niveles 
de residuos comprendidos entre el 50-100\% de dichos límites y únicamente el 1,38\% los superaron (17).

En Noruega, de las 5940 muestras analizadas en el estudio correspondiente a los años 1996 y 1997, sólo el 1,90\% contenían residuos a niveles superiores a los LMRs (18). En Dinamarca, se analizaron un total de 1606 muestras en 1997, de las cuales el $34 \%$ contuvieron residuos de productos fitosanitarios, aunque sólo el $2 \%$ superó los LMRs (19).

En general, los LMRs en la Unión Europea están comprendidos entre 0,01 y 10 $\mu \mathrm{g} / \mathrm{ml}$ (o $\mu \mathrm{g} / \mathrm{mg}$ ) dependiendo del tipo de producto y campo de aplicación (vegetales, frutas, frutos secos y derivados, etc.). Para compuestos de alta toxicidad se aplica el denominado límite de tolerancia cero, por el cual no debe existir residuo alguno de estos productos.

Por otro lado, la Comisión de la UE ha fijado $0,1 \mu \mathrm{g} / 1$ como límite máximo para un producto fitosanitario individual o producto de su transformación y $0,5 \mu \mathrm{g} / \mathrm{l}$ para el total de productos fitosanitarios en aguas destinadas a consumo humano (20).

Por todo ello, el control de productos fitosanitarios es necesario y debe ser llevado a cabo con el fin de garantizar la salud del consumidor así como la correcta protección del medio ambiente. Para conseguir dicho objetivo es necesario armonizar los criterios de evaluación, definir los metabolitos a determinar y establecer los procedimientos de análisis. En este sentido, la disminución en los límites permitidos de residuos requiere una metodología sensible y selectiva, capaz de procesar gran cantidad de muestras de forma efectiva, con el fin de garantizar los valores dados por la legislación para este tipo de productos.

Para ello, se hace necesario disponer de métodos de análisis sensibles, que permitan procesar de modo rápido y descentralizado un gran número de muestras con residuos de productos fitosanitarios, y a bajo coste.

\subsection{ANÁLISIS DE PRODUCTOS FITOSANITARIOS}

\subsubsection{Métodos oficiales de análisis de productos fitosanitarios}

La presencia de residuos de productos fitosanitarios y los programas de vigilancia vigentes en cada país hacen necesario el análisis rutinario de estas sustancias con fines de evaluación y control.

Las técnicas mas comúnmente empleadas para el análisis de estos compuestos son las cromatográficas -Cromatografía de Gases (GC) y Cromatografía líquida de alta 
resolución (HPLC)-. El desarrollo de estas técnicas, su robustez y la posibilidad de analizar varias sustancias simultáneamente hace de ellas el instrumento básico utilizado en los métodos oficiales de análisis.

Sin embargo, estas técnicas presentan ciertos inconvenientes, como el derivado de la preparación y tratamiento de las muestras. Las muestras deben ser sometidas a procesos de extracción, limpieza y preconcentración antes de su determinación cromatográfica. Además, dependiendo del tipo de analito, se hacen necesarias etapas de derivatización con el fin de obtener especies más fácilmente detectables, lo que supone una complicación añadida.

En general, los procesos de extracción, purificación, preconcentración y derivatización son realizados -todos o en parte-, siguiendo un orden determinado en función del analito, la matriz en que se encuentre y la técnica cromatográfica a emplear. Estas etapas previas suponen una ralentización importante en el proceso de generación de datos. Además, el alto coste de los equipos, su mantenimiento y el requerir personal cualificado, hacen necesario disponer de laboratorios muy especializados.

Los laboratorios que analizan muestras medioambientales, aguas y suelos especialmente, siguen lo que se conoce como métodos "cookbook", es decir, protocolos muy detallados prescritos por la EPA a finales de los años 70 y principios de los 80 . Esta metodología es de uso generalizado, sin embargo, y en aras de una mayor calidad, versatilidad y agilidad, deben introducirse metodologías alternativas a las famosas "recetas".

En el fondo, lo que ocurre es que la metodología oficial, tanto americana como europea, se mueve entre dos posiciones divergentes: aplicar los métodos oficiales con sus ventajas e inconvenientes o permitir que se apliquen otros métodos alternativos que resuelvan mejor que los oficiales ciertas situaciones, aunque no son métodos de referencia, con los inconvenientes legales que ello puede conllevar.

De acuerdo a esta nueva filosofía, la EPA está trabajando en lo que denomina "Performance-based measurement systems" (PBMS), que permitirá a los laboratorios utilizar cualquier técnica de medida si se demuestra que reúne ciertos estándares de calidad. Con ello, la EPA pretende mejorar la calidad de los resultados, abaratar el precio de los análisis y estimular la innovación hacia la creación de una metodología alternativa y más apropiada.

Por otro lado, la casi totalidad de los procedimientos oficiales de análisis requiere el uso de disolventes orgánicos, lo que supone un riesgo añadido a las 
determinaciones, una mayor contaminación y costes, además de una laboriosa manipulación. Estos disolventes son escogidos teniendo en cuenta el tipo de extracción a emplear, los rendimientos a conseguir, la necesidad de utilizar uno o más disolventes, su miscibilidad, así como su compatibilidad con la técnica cromatográfica a emplear.

La Tabla 1.2 resume las condiciones utilizadas para el análisis de algunos productos fitosanitarios en distintas matrices, según los métodos de la AOAC (21). En ella se muestran las etapas seguidas en el proceso analítico, así como el método de detección empleado, haciendo especial hincapié en los disolventes orgánicos utilizados en cada caso. Como puede apreciarse, los disolventes más utilizados como extractantes son:

(i) Disolventes inmiscibles en agua: éter de petróleo, hexano, diclorometano, acetato de etilo y cloroformo.

(ii) Disolventes miscibles en agua: acetonitrilo, acetona, isopropanol y metanol. 
Tabla 1.2. Etapas previas y técnica empleada para la determinación de algunos productos fitosanitarios utilizando los métodos de la AOAC (21)

\begin{tabular}{|c|c|c|c|c|c|}
\hline ANALITO & MATRIZ & EXTRACCIÓN & LIMPIEZA & $\begin{array}{l}\text { TÉCNICA- } \\
\text { DETECCIÓN }\end{array}$ & $\begin{array}{l}\text { DISOLVENTES } \\
\text { EMPLEADOS }^{*}\end{array}$ \\
\hline Organoclorados & Pescado & Mezcla éter y $\mathrm{Na}_{2} \mathrm{SO}_{4}$ & $\mathrm{FC}$ & GC-EC & $\begin{array}{l}\text { Éter, hexano, } \\
\text { metanol }\end{array}$ \\
\hline Organoclorados & Grasa animal & $\begin{array}{l}\text { Disolución en } \\
\text { diclorometano-ciclohexano }\end{array}$ & GPC & GPC-EC & $\begin{array}{l}\text { Diclorometano, } \\
\text { ciclohexano, } \\
\text { isooctano }\end{array}$ \\
\hline $\begin{array}{l}\text { Endosulfan } \\
\text { Tetradifon }\end{array}$ & Manzana, pepino & $\begin{array}{l}\text { Extracción con acetonitrilo, } \\
\text { partición con éter }\end{array}$ & $\mathrm{FC}$ & GC-EC & $\begin{array}{l}\text { Acetonitrilo, éter, } \\
\text { hexano, } \\
\text { diclorometano }\end{array}$ \\
\hline $\begin{array}{l}\text { Bifenilos } \\
\text { policlorados }\end{array}$ & Papel & $\begin{array}{l}\text { Reflujo en disolución } \\
\text { hidroalcohólica } 2 \% \mathrm{KOH} \text {, } \\
\text { lavado con éter }\end{array}$ & $\mathrm{FC}$ & GC-EC & Éter, acetonitrilo \\
\hline Organofosforados & Manzana, guisante & $\begin{array}{l}\text { Extracción con acetonitrilo y } \\
\text { agitación con } \mathrm{CH}_{2} \mathrm{Cl}_{2}\end{array}$ & $\mathrm{CHC}$ & GC-LD-TD & $\begin{array}{l}\text { Acetato de etilo, } \\
\text { benceno, hexano, } \\
\text { diclorometano, } \\
\text { acetonitrilo, } \\
\text { isopropanol }\end{array}$ \\
\hline $\begin{array}{l}\text { Diazinom, } \\
\text { malation, } \\
\text { paration, } \\
\text { Me-paration } \\
\end{array}$ & $\begin{array}{l}\text { Endibia, zanahoria, } \\
\text { lechuga, manzana, } \\
\text { patata, fresa }\end{array}$ & $\begin{array}{l}\text { Extracción con acetato de } \\
\text { etilo }\end{array}$ & $\mathrm{FC}, \mathrm{cKD}$ & Polarografía & $\begin{array}{l}\text { Acetonitrilo, } \\
\text { acetona, acetato } \\
\text { etilo, éter }\end{array}$ \\
\hline Organofosforados & $\begin{array}{l}\text { Endibia, zanahoria, } \\
\text { lechuga, manzana, } \\
\text { patata, fresa }\end{array}$ & $\begin{array}{l}\text { Extracción con acetato de } \\
\text { etilo }\end{array}$ & $\mathrm{SCC}$ & GC-TD & Acetato etilo \\
\hline $\begin{array}{l}\text { Fumigantes } \\
\text { volátiles }\end{array}$ & Grano & $\begin{array}{l}\text { Inmersión en acetona/agua } \\
48 \text { horas }\end{array}$ & $\begin{array}{ll}-- \\
\end{array}$ & GC-EC & Acetona \\
\hline Carbamatos & $\begin{array}{l}\text { Manzana, } \\
\text { calabacín, maíz, } \\
\text { guisante }\end{array}$ & Extracción acetonitrilo & $\begin{array}{l}\text { Partición } \\
\text { éter/ } \mathrm{CH}_{2} \mathrm{Cl}_{2}\end{array}$ & GC-EC & $\begin{array}{l}\text { Acetonitrilo, éter, } \\
\text { diclorometano }\end{array}$ \\
\hline $\begin{array}{l}\text { Carbamatos y } \\
\text { metabolitos }\end{array}$ & Uva, patata & Extracción con metanol & $\begin{array}{l}\text { Partición, } \\
\text { columna } \\
\text { Celite } \\
\end{array}$ & HPLC-FD & $\begin{array}{l}\text { Metanol, tolueno } \\
\text { acetonitrilo, } \\
\text { diclorometano, éter, }\end{array}$ \\
\hline Bifenilos & Cítricos & Extracción con n-pentano & Partición & $\begin{array}{l}\text { TLC- } \\
\text { Espectrofotomet. }\end{array}$ & n-pentano, metanol \\
\hline Tiram & $\begin{array}{l}\text { Maíz, manzana, } \\
\text { tomate, fresa y } \\
\text { similares }\end{array}$ & Extracción con cloroformo & $\begin{array}{ll}-- \\
\end{array}$ & $\begin{array}{l}\text { Espectrofotomet. } \\
440 \mathrm{~nm}\end{array}$ & Cloroformo \\
\hline Carbaril & & Extracción $\mathrm{CH}_{2} \mathrm{Cl}_{2} / \mathrm{Na}_{2} \mathrm{SO}_{4}$ & Evaporación & $\begin{array}{l}\text { Espectrofotomet. } \\
425 \mathrm{~nm}\end{array}$ & $\begin{array}{l}\text { Acetona, } \\
\text { diclorometano }\end{array}$ \\
\hline Carbaril & Manzana, espinaca & Extracción $\mathrm{CH}_{2} \mathrm{Cl}_{2} / \mathrm{Na}_{2} \mathrm{SO}_{4}$ & Evaporación & TLC & Diclorometano \\
\hline Etilan & & Extracción hexano & --- & GC-EC & Hexano \\
\hline Diclone & $\begin{array}{l}\text { Frutas frescas y } \\
\text { vegetales }\end{array}$ & Extracción benceno & --- & $\begin{array}{l}\text { Espectrofotomet. } \\
495 \mathrm{~nm}\end{array}$ & Benceno \\
\hline Dodine & $\begin{array}{l}\text { Manzana, fresa } \\
\text { melocotón, pera, }\end{array}$ & Extracción $\mathrm{CCl}_{4}$ & $\begin{array}{l}-- \\
\end{array}$ & $\begin{array}{l}\text { Espectrofotomet. } \\
590 \mathrm{~nm}\end{array}$ & $\begin{array}{l}\text { Metanol, } \\
\text { diclorometano }\end{array}$ \\
\hline $\begin{array}{l}\text { Dibromuro de } \\
\text { etileno }\end{array}$ & Grano y derivados & $\begin{array}{l}\text { Agitación con acetona y } \\
\text { destilación con hexano }\end{array}$ & $\begin{array}{ll}-- \\
\end{array}$ & GC-EC & Acetona, hexano \\
\hline $\begin{array}{l}\text { Acido } \\
\text { monofluoracético }\end{array}$ & Diversas matrices & Extracción con éter & Partición & $\mathrm{GC}$ & Éter \\
\hline
\end{tabular}


Tabla 1.2. (Continuación)

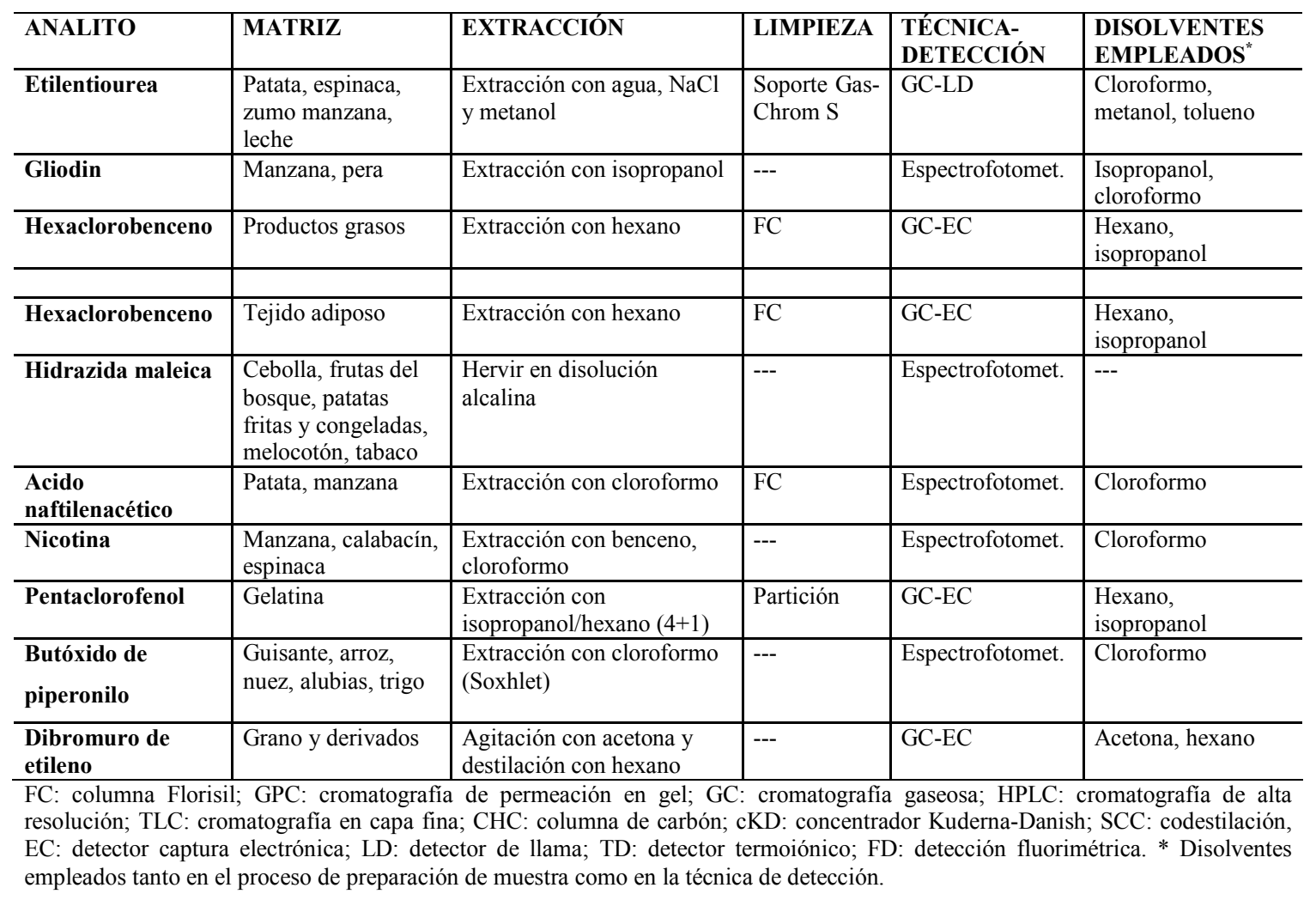

En la mayoría de los métodos expuestos es necesaria una etapa de limpieza de los extractos obtenidos antes su análisis.

A continuación se describen brevemente los protocolos de tratamiento de muestra utilizados en los programas de vigilancia de residuos establecidos en España, muy similares a los de otros países de la UE y en su mayoría basados en los de la AOAC.

En el "Programa Nacional de Vigilancia de Residuos de Productos Fitosanitarios en Origen" del Ministerio de Agricultura, Pesca y Alimentación, Subdirección General de Sanidad Vegetal (17), en el que se fijan los límites máximos de residuos de productos fitosanitarios y su control en determinados productos de origen vegetal, se distinguen distintos procedimientos de preparación de muestras, a saber:

(1) Método IA, método del acetato de etilo: Las muestras se extraen con acetato de etilo anhidro. Los extractos se purifican utilizando cartuchos de Florisil (Sep-pack) o mediante cromatografía de permeación en gel (GPC). Finalmente, las fracciones purificadas se cromatografían en GC utilizando detector de captura electrónica (ECD), de llama (FPD) o selectivo de N-P (NPD). Los ensayos confirmatorios se realizan mediante GC-MS. 
(2) Método IB, método de la acetona: Las muestran se homogeneizan con acetona y se filtran. El proceso de limpieza consiste en una partición con éter de petróleo y diclorometano. La fase orgánica se concentra y se vuelve a extraer con los mismos disolventes. El concentrado se purifica del modo descrito en el método IA y el extracto se cromatografía utilizando un GC con detector ECD, FPD o NPD. La técnica confirmatoria utilizada es GC-MS.

(3) Método IIA, método espectrofotométrico para ditiocarbamatos: Las muestras se hidrolizan en medio ácido y el $\mathrm{CS}_{2}$ formado se separa de otros compuestos gaseosos haciéndolo pasar por dos trampas. En la primera se retiene el ácido sulfúrico y otros compuestos volátiles, y en la segunda el $\mathrm{CS}_{2}$ se hace reaccionar con una disolución etanólica de $\mathrm{CuSO}_{4} /$ etanolamina formando un complejo de color pardo, que se cuantifica fotométricamente a $435 \mathrm{~nm}$.

(4) Método IIB, método cromatográfico para ditiocarbamatos: Estos productos fitosanitarios se descomponen en medio ácido produciendo $\mathrm{CS}_{2}$ que se recoge en tolueno. Esta disolución se cromatografía (GC) utilizando un detector electroquímico o de llama con filtro de azufre.

(5) Método III, método para bencimidazoles: Estos fungicidas se extraen con acetato de etilo anhidro. Una vez purificado el extracto mediante separación ácido/base, la determinación se realiza mediante cromatografía líquida de alta resolución (HPLC) con detección UV a $283 \mathrm{~nm}$.

(6) Método IV, método para N-metilcarbamatos: Las muestras se trituran y extraen con acetato de etilo anhidro. El extracto se purifica mediante cromatografía de permeación en gel (GPC) y se analiza mediante HPLC en fase reversa. El método incluye derivatización postcolumna mediante hidrólisis alcalina de los productos fitosanitarios en presencia de $o$-phtaldehido y mercaptoetanol. El producto formado se detecta fluorimétricamente.

(7) Método $V$, método de determinación de fumigantes en cereales: Las muestras, una vez homogeneizadas, se extraen con una mezcla acetona/agua, se filtran y se secan con $\mathrm{Na}_{2} \mathrm{SO}_{4}$. El extracto así obtenido se cromatografía (GC) utilizando detector FPD o ECD.

(8) Método VI, métodos específicos: incluyen una serie de procedimientos individuales para cada uno de los siguientes productos fitosanitarios: metalaxil, benalaxil, daminozida, glifosato y hidracida maleica. 
Los métodos IA y IB pueden considerarse multirresiduo y los restantes son métodos específicos para diferentes productos fitosanitarios. Todos estos métodos utilizan las recomendaciones aceptadas internacionalmente sobre tratamiento de muestra (16). La Figura 1.1 representa las etapas básicas de un método multirresiduo previas al análisis cromatográfico.

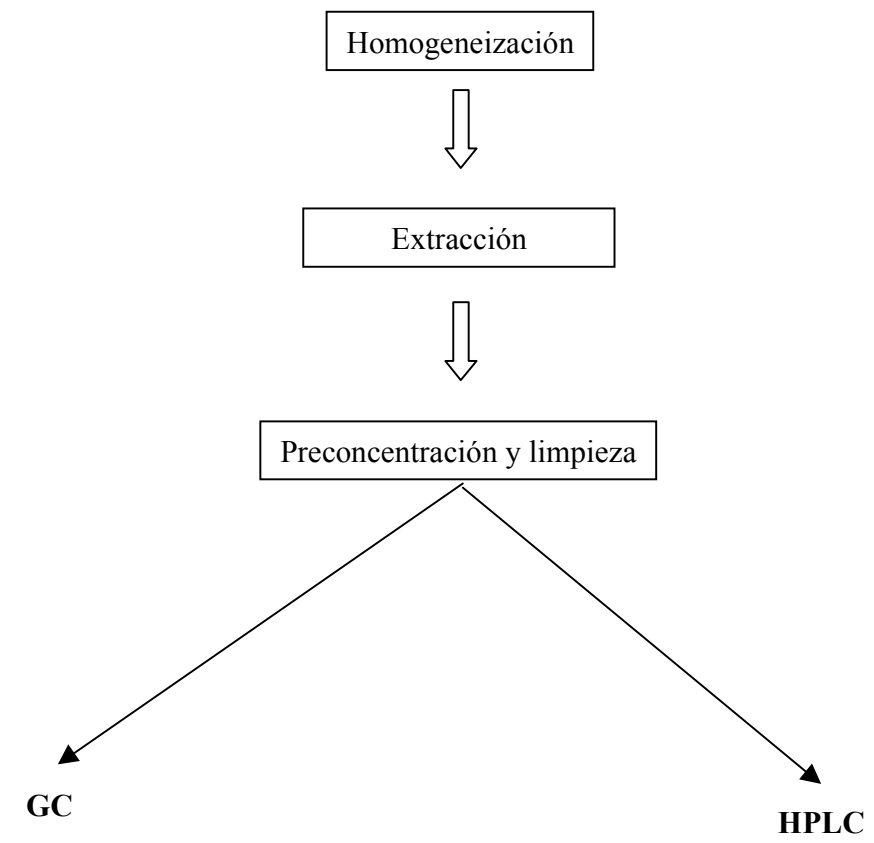

Figura 1.1. Etapas de tratamiento de muestra previas al análisis cromatográfico

Un factor común a todos los métodos descritos es que requieren un consumo elevado de disolventes orgánicos, además de exhaustivas etapas de purificación y limpieza antes de proceder al análisis cromatográfico.

Un ejemplo práctico lo constituye el análisis de productos fitosanitarios en agua, utilizando el método USEPA 625 (22). Este método emplea $150 \mathrm{ml}$ de diclorometano por muestra analizada, por lo que se estima que la cantidad de disolvente liberado a la atmósfera en los ensayos realizados por el US Superfund Contract Laboratory Program (23), es de 5 a 10 millones de litros por año.

\subsubsection{Métodos inmunoquímicos de análisis}

Las técnicas inmunoquímicas están basadas en la interacción antígenoanticuerpo (Ag-Ab). Los anticuerpos son proteínas globulares (inmunoglobulinas) (Figura 1.2) que contienen cientos de aminoácidos dispuestos en una secuencia dada. 


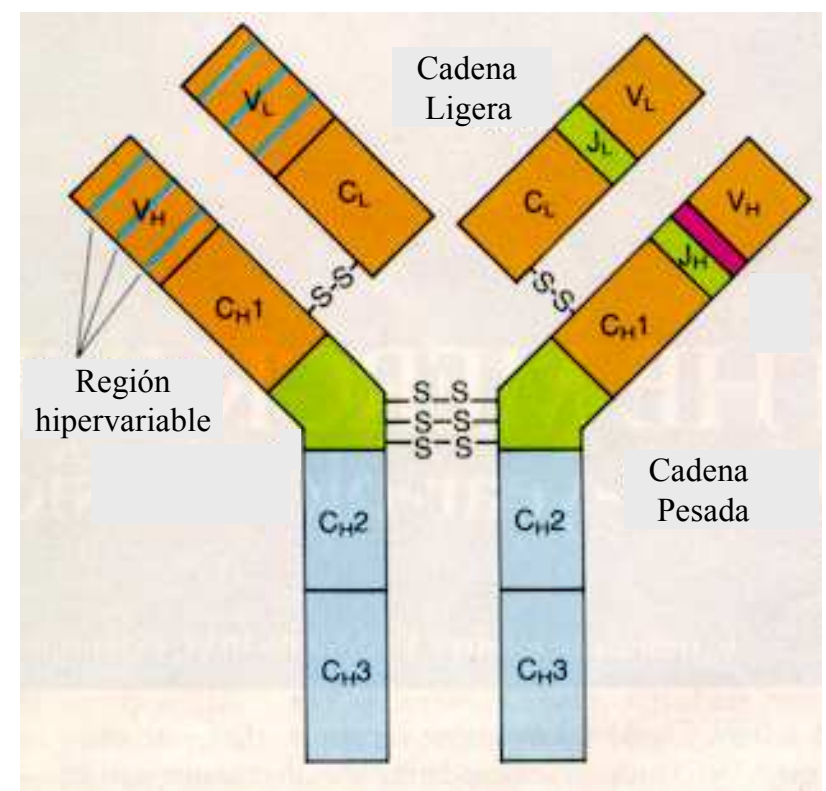

Figura 1.2. Estructura básica de un anticuerpo

Básicamente, un anticuerpo está formado por dos cadenas polipeptídicas ligeras e idénticas y por otras dos cadenas pesadas también iguales. Las cadenas pesadas están unidas entre sí mediante dos puentes disulfuro, y cada una de ellas unida a su vez a una cadena ligera mediante otro puente disulfuro. Por otro lado, las cadenas pesadas poseen en su extremo C-terminal un hidrato de carbono como grupo prostético (supone un contenido entre el 2-14\%). En función de la cadena pesada, las inmunoglobulinas se clasifican en distintas clases y subclases, siendo las denominadas de tipo G (70-75\% del total) las más abundantes entre los mamíferos, con una masa molecular entre 150.000900.000 daltons. Estos polipéptidos son producidos por las células del sistema inmune (linfocitos B) cuando son expuestas a sustancias o moléculas antigénicas, es decir, ajenas al organismo receptor (24). Los anticuerpos contienen en su estructura los denominados "sitios de reconocimiento/unión" frente a las estructuras moleculares específicas de los antígenos. De acuerdo a este modelo, un anticuerpo interacciona -en la mayoría de los casos- específica y reversiblemente con el antígeno que indujo su producción. Esta interacción obedece a la ley de acción de masas e incluye fuerzas electrostáticas, puentes de hidrógeno e interacciones hidrófobas y de Van der Waals.

La tecnología inmunoquímica se originó alrededor de 1950, cuando Yalow y Berson desarrollaron un ensayo inmunológico cuantitativo que permitía detectar insulina humana a nivel de picogramos. A partir de ese momento, esta metodología encontró aplicación en biología, endocrinología y química clínica. Pero no fue hasta finales de los '70, en que Hammock y Mumma (25), entre otros, resaltaron el potencial 
de esta tecnología para la determinación de productos fitosanitarios y contaminantes, impulsando su aceptación como metodología analítica.

El impacto de las técnicas inmunoquímicas en el campo medioambiental y alimentario ha crecido enormemente en los últimos años. Actualmente se dispone ya de una gran variedad de protocolos de inmunoensayo para la detección de trazas de compuestos orgánicos de bajo peso molecular, incluyendo los fitosanitarios, residuos industriales y sus productos de degradación (26-28). La selectividad y sensibilidad exhibida por los anticuerpos, junto con la simplicidad operativa, son las razones básicas de este desarrollo.

\subsubsection{Producción de anticuerpos}

Cuando se pretende desarrollar un inmunoensayo para moléculas de bajo peso molecular como los plaguicidas surgen ciertos inconvenientes, ya que estas sustancias no son capaces de provocar "per se" respuesta inmune en el organismo receptor. Por ello, el desarrollo de un ensayo se convierte en un proceso largo y complejo que requiere personal altamente cualificado, que combine su experiencia en síntesis orgánica, bioquímica, inmunología y química analítica.

Para inducir respuesta inmune y en consecuencia la producción de anticuerpos, estas "pequeñas moléculas" deben ser acopladas a sustancias denominadas "carrier", usualmente proteínas inertes como KLH, BSA, CONA, OVA, etc. Generalmente, en este proceso es necesaria una etapa de síntesis para obtener moléculas estructuralmente similares al analito de interés (haptenos). Los haptenos son moléculas derivatizadas de modo que pueden unirse covalentemente a la proteína carrier formando el inmunógeno.

La Figura 1.3 muestra el proceso a seguir en el desarrollo de anticuerpos para haptenos (29). 


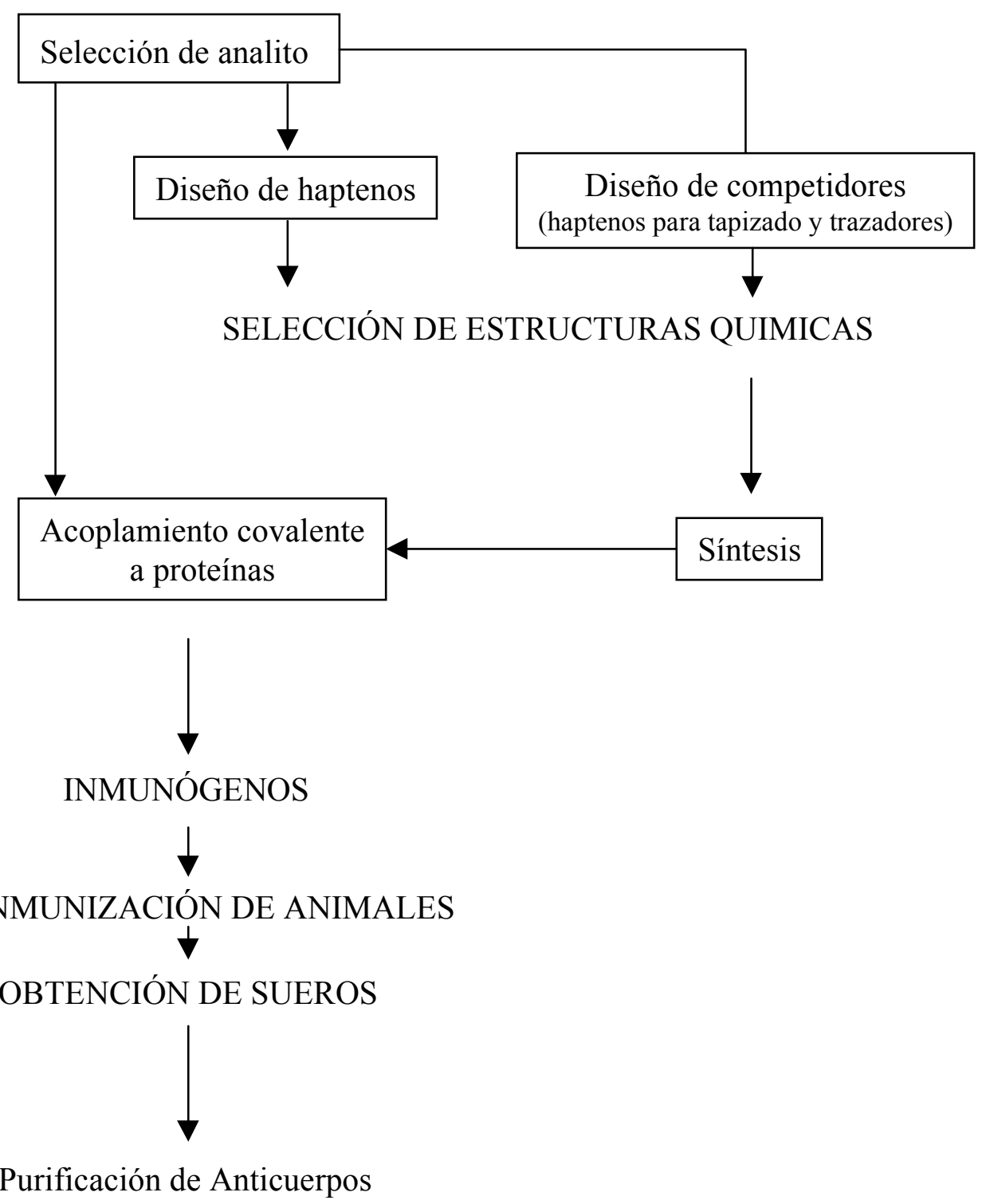

Figura 1.3. Esquema de la obtención de anticuerpos para haptenos

En general, en los inmunoensayos se utilizan tanto anticuerpos monoclonales como policlonales, siendo éstos los más empleados en el análisis de plaguicidas. Los anticuerpos policlonales (PAb) son obtenidos a partir del suero de animales inmunizados y comprenden una mezcla heterogénea de anticuerpos con diferentes especificidades. Los anticuerpos monoclonales (MAb) están compuestos de una población homogénea de anticuerpos teóricamente idénticos y son producidos mediante cultivos celulares de una única célula (clon) de hibridoma surgida de la fusión de linfocitos B con células de mieloma (30).

La tecnología del hibridoma garantiza la producción ilimitada de anticuerpos con propiedades constantes. El cultivo industrial de líneas celulares permite la obtención 
de cantidades elevadas de anticuerpo. Sin embargo, la producción de MAbs necesita de un equipamiento especial, material y medios de cultivo celulares bastante caros, además de personal altamente cualificado y un tiempo relativamente largo (1 año aproximadamente). Por otro lado, la producción de anticuerpos policlonales es más rápida y sencilla; además, requiere pocos medios materiales, por lo que su obtención es económicamente ventajosa. En la Tabla 1.3. se comparan las propiedades de ambos tipos de anticuerpos.

Tabla 1.3. Comparación de las principales características de los anticuerpos policlonales y monoclonales

\begin{tabular}{lll}
\hline Propiedades & Anticuerpos policlonales & Anticuerpos monoclonales \\
\hline Suministro & Limitado & Ilimitado \\
Uniformidad & $\begin{array}{l}\text { Cambio de propiedades con } \\
\text { diferentes sueros y sangrías }\end{array}$ & $\begin{array}{l}\text { Propiedades constantes. Variable } \\
\text { según clon }\end{array}$ \\
Afinidad & $\begin{array}{l}\text { Mezcla de Abs con } \\
\text { diferentes afinidades. Puede } \\
\text { seleccionarse a posteriori }\end{array}$ & Puede seleccionarse a priori \\
Reactividad cruzada & $\begin{array}{l}\text { Variable en función de } \\
\text { diferentes selectividades }\end{array}$ & $\begin{array}{l}\text { Diferente, depende de cada Ab } \\
\text { individual }\end{array}$ \\
Clases y subclases & Muchos isotipos & Un isotipo definido \\
Demanda en antígeno & $\begin{array}{l}\text { Se requiere alta pureza para } \\
\text { un antisuero específico }\end{array}$ & $\begin{array}{l}\text { Pueden ser antígenos impuros, o } \\
\text { mezcla de antígenos para }\end{array}$ \\
& & $\begin{array}{l}\text { inmunización. Antígenos puros } \\
\text { para screening }\end{array}$ \\
& & Largo (12 meses) \\
Tiempo de desarrollo & Corto (2-3 meses) & Alto \\
\hline Coste & Bajo &
\end{tabular}

\subsubsection{Clasificación de los inmunoensayos}

En general, existen varios criterios de clasificación de los inmunoensayos: (i) en función del modo de operación, inmunoensayos competitivos y no competitivos; (ii) según las fases en que se realiza la interacción $\mathrm{Ag}-\mathrm{Ab}$, inmunoensayos homogéneos y heterogéneos; (iii) en función del marcador y método de detección, inmunoensayos enzimáticos, radioinmunoensayos, fluoroinmunoensayos, etc. A continuación se 
describen los principales formatos de inmunoensayo utilizados en diferentes campos de aplicación: clínico, agroalimentario y medioambiental.

\section{(i) Inmunoensayos competitivos y no-competitivos}

Un ensayo competitivo puede ser descrito por la siguiente reacción inmunoquímica:

$$
2 \mathrm{Ab}+\mathrm{Ag}+\mathrm{Ag}^{*} \rightleftarrows \mathrm{Ab}-\mathrm{Ag}+\mathrm{Ab}-\mathrm{Ag}^{*}
$$

Un antígeno libre $(\mathrm{Ag})$ compite con un antígeno marcado $\left(\mathrm{Ag}^{*}\right)$ por un número fijo y limitado de sitios de unión del anticuerpo. La extensión de la unión $\mathrm{Ab}-\mathrm{Ag}^{*}$ depende de la concentración de Ag libre. A mayor concentración de analito (Ag libre), menos $\mathrm{Ag}^{*}$ se une al $\mathrm{Ab}$, permitiendo la cuantificación de la concentración del analito (Ag libre). Basados en este concepto general, existen dos modos de operar:

Ensayo directo: el anticuerpo compite con el analito y un hapteno marcado con una especie fácilmente detectable.

Ensayo indirecto: la extensión de la unión $\mathrm{Ag}-\mathrm{Ab}$ se mide habitualmente utilizando un segundo anticuerpo específico (anticuerpo secundario), marcado con una especie fácilmente detectable.

Los formatos de ensayo no-competitivos, son normalmente utilizados en las determinaciones de moléculas de gran tamaño que poseen más de un epitopo o determinante antigénico. En estos ensayos se emplea un sistema de dos anticuerpos específicos, de modo que uno de ellos sirve para "fijar" el antígeno. Tras un proceso de lavado y eliminación de las fracciones no unidas, se adiciona el segundo anticuerpo específico que sirve para cuantificar la extensión de la reacción. Los ensayos nocompetitivos son generalmente más sensibles que los correspondientes ensayos competitivos. Sin embargo, este tipo de ensayo no es adecuado para moléculas de bajo peso molecular, como es el caso de los productos fitosanitarios.

\section{(ii) Inmunoensayos homogéneos y heterogéneos}

Los inmunoensayos homogéneos no requieren la separación entre las fracciones de inmunorreactivos libres y unidas. Utilizan el cambio de señal producido cuando el antígeno marcado se une al anticuerpo. Esa variación en la señal se debe a un cambio de la actividad del marcador y puede ser utilizada para cuantificar. Este tipo de ensayos presenta la ventaja de requerir tiempos de análisis más cortos, ya que no son necesarias 
etapas de lavado. En contrapartida hay que señalar que la sensibilidad es menor y el efecto matriz de las muestras más elevado.

En los ensayos heterogéneos, existe una separación física entre las fracciones unidas y libres. Aunque este formato de ensayo incluye un mayor número de etapas debido a los procesos secuenciales de lavado que deben realizarse para eliminar los componentes que no han reaccionado, el efecto matriz es menor. Por lo general, mejoran la sensibilidad y los límites de detección. Los ensayos inmunoenzimáticos, especialmente en formatos ELISA (enzyme-linked immunosorbent assay), son un ejemplo de este tipo de ensayos, cuyos fundamentos se comentan a continuación.

\section{Técnica ELISA}

La mayoría de los inmunoensayos para plaguicidas utilizan la técnica ELISA $(31,32)$. Este es un ensayo heterogéneo en fase sólida que utiliza un marcador enzimático, y donde uno de los inmunorreactivos está fijado (generalmente adsorbido) en la superficie de un tubo de ensayo o en los pocillos de una placa ELISA. Las configuraciones más usuales en este tipo de ensayos son:

\section{ELISA competitivo directo}

Formato de anticuerpo inmovilizado: en este caso se establece un equilibrio entre el anticuerpo unido a la fase sólida (por adsorción directa o mediante reactivos orientadores), el analito y un conjugado analito-enzima (trazador enzimático) que están en disolución. Tras una etapa de incubación, los reactivos no unidos son eliminados por lavado, midiendo por último la señal producida por el trazador enzimático unido al $\mathrm{Ab}$. La disminución de la actividad enzimática es directamente proporcional a la cantidad de analito presente en la muestra.

Formato de antígeno inmovilizado: este formato está basado en la competición entre el antígeno inmovilizado (usualmente derivatizado y unido a una proteína, denominado conjugado de tapizado) y el analito, por una cantidad fija de anticuerpo marcado.

\section{ELISA competitivo indirecto}

El fundamento es el mismo que el del formato de antígeno inmovilizado, pero en este caso la concentración del analito es medida indirectamente utilizando un segundo anticuerpo unido covalentemente a una enzima. 


\section{ELISA sandwich}

En este ensayo se utiliza un segundo anticuerpo marcado para detectar la interacción entre el analito y el anticuerpo unido a la fase sólida. Sin embargo, esta configuración es restrictiva para analitos con más de un sitio de unión de anticuerpo, por lo que no es utilizada en el caso de los productos fitosanitarios.

\section{(iii) Otros modos de detección}

Dentro de este apartado se describen otros métodos de inmunoensayo clasificados en función del tipo de marcador o de substrato. Estos incluyen el uso de marcadores fluorescentes (fluoroinmunoensayo), radiactivos (radioinmunoensayo), quimioluminiscentes o bioluminiscentes, así como otras técnicas como la cromatografía de inmunoafinidad.

Los inmunoensayos fluorescentes (FIA, fluoroimmunoassay) combinan la especificidad de los anticuerpos con la sensibilidad de los ensayos fluorimétricos, y han sido desarrollados en formatos tanto competitivos como no-competitivos. La primera aplicación de esta técnica al análisis de productos fitosanitarios fue desarrollada por Colbert y Coxon (33) para la determinación de paraquat en muestras de suero. Algunas aplicaciones recientes incluyen la determinación de los herbicidas 2,4-D y 2,4,5-T, así como simazina y atrazina (34). A pesar de su simplicidad, precisión y posible automatización, su uso es limitado dada la tendencia natural de los compuestos orgánicos a interferir con la detección.

En el desarrollo de inmunoensayos quimioluminiscentes es habitual emplear luminol; sin embargo, su uso es restringido dada la tendencia de los componentes de la muestra a causar errores en la detección y al precio e inestabilidad de los reactivos. Dentro de los ensayos bioluminiscentes cabe destacar el uso de la luciferina como substrato de peroxidasa. Estos sistemas son relativamente poco aplicados al análisis de productos fitosanitarios.

La cromatografía de inmunoafinidad es un método de separación basado en la interacción reversible y específica entre el antígeno y el anticuerpo. En esta técnica, la unión del anticuerpo al soporte es covalente y se recomienda, generalmente, para la separación selectiva de un analito o grupo de analitos sin la necesidad de emplear disolventes orgánicos $(35,36)$. 


\subsubsection{Características analiticas de los formatos de ensayo competitivos}

En los formatos de ensayo competitivos, tanto en fase homogénea como heterogénea, la relación entre la concentración de analito (en escala logarítmica) y la señal registrada no es lineal $(37,38)$, sino que presenta una pauta sigmoide (Figura 1.4) cuyo ajuste matemático corresponde a la siguiente ecuación logística:

$$
\text { Señal }=\frac{A_{\text {max }}-A_{\text {min }}}{1+\left(\frac{[\text { Analito }]}{I_{50}}\right)^{b}}+A_{\text {min }}
$$

Donde: $\mathrm{A}_{\max }$ es la asíntota máxima y se corresponde a la señal obtenida en ausencia de analito; $\mathrm{A}_{\min }$-asíntota mínima-, es la señal obtenida en un exceso de analito; $\mathrm{b}$ es la pendiente de la curva en el punto de inflexión e $\mathrm{I}_{50}$ la concentración correspondiente a dicho punto. De estos parámetros, los valores de $\mathrm{I}_{50}$ y b son los más importantes, ya que determinan la sensibilidad y rango dinámico de trabajo. Por otro lado, el valor de $\mathrm{I}_{50}$ ha sido relacionado con la afinidad del anticuerpo por un analito dado $(37,39)$. El valor de $I_{50}$ depende de las características de los anticuerpos y tipo de formato utilizados, de las condiciones de ensayo -como $\mathrm{pH}$, fuerza iónica del medio o presencia de tensoactivos- y de las especies utilizadas en los procesos de competición, principalmente conjugados de tapizado y trazadores.

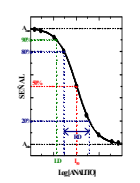

\section{Figura 1.4. Representación de la curva de calibrado}

A partir de la curva de calibrado descrita se pueden definir los siguientes parámetros analíticos de interés:

- Rango dinámico (RD): es el rango de concentraciones de analito que producen señales comprendidas entre el $80 \%$ y $20 \%$ del rango definido por ambas asíntotas.

- Límite de detección (LD): es la concentración de analito que produce una señal del 90\% del rango anteriormente mencionado. 
Estos dos parámetros -junto con la $\mathrm{I}_{50}$, que se utiliza para estimar la sensibilidad del ensayo- son los que caracterizan un método inmunoquímico y determinan su adecuación para el análisis del analito para el que fue desarrollado.

Respecto a la señal, una forma usual de trabajo consiste en utilizar la señal normalizada, cuyo cálculo viene dado por la ecuación:

$$
\text { Señal Normalizada }=\left(B-B_{\infty} / B_{0}-B_{\infty}\right) \times 100
$$

donde $\mathrm{B}$ es la señal obtenida con una muestra de concentración arbitraria, $\mathrm{B}_{0}$ es la señal obtenida en ausencia de analito y $\mathrm{B}_{\infty}$ es la señal correspondiente a una muestra con un gran exceso de analito o señal de fondo.

Esta forma de proceder no modifica los valores de $\mathrm{I}_{50} \mathrm{y}$ b respecto a las curvas de calibrado obtenidas con señales absolutas, pero tiene la ventaja de hacer posible la comparación de las respuestas obtenidas en diferentes días y condiciones experimentales. Por otro lado, una vez definida la curva de calibrado y comprobada su estabilidad, es posible recalibrar el método determinando los nuevos valores de unos pocos puntos, incluyendo $\mathrm{B}_{0} \mathrm{y} \mathrm{B}_{\infty}$.

Otra propiedad importante de un método inmunoquímico es la selectividad, que determina la capacidad de discriminación del anticuerpo entre el analito de interés y especies de estructura similar, y por tanto de los posibles interferentes. Este parámetro se cuantifica mediante la reactividad cruzada $(\mathrm{RC})$, que se define como la relación porcentual entre los valores de $\mathrm{I}_{50}$ (en molaridad) para el analito de interés y para el interferente. Matemáticamente se calcula según la expresión:

$$
\mathrm{RC}=\left(\mathrm{I}_{50} \text { analito/ } \mathrm{I}_{50} \text { interferente }\right) \times 100
$$

Se considera que un compuesto presenta interferencia apreciable cuando el valor de $\mathrm{RC}$ es superior al 10\%. Valores comprendidos entre 1-10\% indican interferencias poco importantes y si son inferiores al 1\% se consideran despreciables.

\subsubsection{Aplicación de las técnicas inmunoquímicas al análisis de residuos de productos}

fitosanitarios en aguas y alimentos

Cuando se analizan compuestos hidrófobos en matrices no acuosas, la preparación de muestra requiere procedimientos particulares, desde extraer con disolventes orgánicos y diluir, hasta etapas de purificación propiamente dichas, en función de la complejidad de la matriz y/o de la susceptibilidad del ensayo a los componentes coextraídos (40). En inmunoensayo, como en otras técnicas, el tratamiento 
de muestra previo al análisis es una etapa crítica. En general, las muestras acuosas son analizadas sin pretratamiento, excepto la eliminación de material particulado y el ajuste del pH y fuerza iónica, en caso necesario.

La preparación de muestras se requiere, por ejemplo, cuando la concentración esperada está por debajo o cerca del límite de cuantificación, cuando es necesario realizar un cambio de medio (orgánico/acuoso) o cuando existe efecto matriz debido, entre otros, a la presencia de sustancias húmicas. En estos casos deben llevarse a cabo etapas de preconcentración o extracción en fase sólida (SPE), utilizando columnas $\mathrm{C}_{18}$, columnas de inmunoafinidad $(41,42)$, etc.

En el caso de alimentos líquidos como por ejemplo zumos, generalmente no es necesaria una excesiva preparación de muestra, tan sólo ajustar el pH y diluir la muestra convenientemente. Algunos ejemplos los constituyen los trabajos de Wittmann y Hock (43) que determinan atrazina en leche y zumo de manzana, y González-Martínez y col. (44) que analizan muestras de zumos, aguas y miel reforzadas con carbaril.

Para muestras sólidas y matrices complejas como suelos, alimentos o aceites, es necesaria una mayor preparación de muestra antes de proceder a su análisis mediante inmunoensayo. Los métodos de extracción previos a la determinación han sido ampliamente discutidos (45) observándose que, en general, los disolventes orgánicos mas utilizados para la extracción de los productos fitosanitarios son: acetona, éter, éter de petróleo, acetato de etilo, metanol, acetonitrilo y hexano.

En la Tabla 1.4 se muestran algunos de los métodos inmunoquímicos aplicados al análisis de residuos en distintas matrices, indicando los disolventes empleados, así como los procedimientos de extracción y limpieza utilizados. 
Tabla 1.4. Aplicación de técnicas inmunoquímicas al análisis de residuos de productos fitosanitarios

\begin{tabular}{|c|c|c|c|c|c|}
\hline Plaguicida & Matriz & Disolventes & Procedimiento & Limpieza/preparación & Refs. \\
\hline \multirow[t]{3}{*}{ Carbaril } & Agua & --- & --- & Dilución PBST & \multirow[t]{3}{*}{46} \\
\hline & Leche,miel,orina & $\begin{array}{ll}-- \\
\end{array}$ & --- & Dilución PBST & \\
\hline & Suelo & $\begin{array}{l}\text { Clofoformo, } \\
\text { metanol }\end{array}$ & $\begin{array}{l}\text { Agitación, } \\
\text { evaporación }\end{array}$ & $\begin{array}{l}\text { Resuspensión en metanol, } \\
\text { dilución PBST }\end{array}$ & \\
\hline \multirow[t]{2}{*}{ Atrazina } & Aceite vegetal & Acetonitrilo & \multirow[t]{2}{*}{ Agitación } & \multirow[t]{2}{*}{ Dilución 1/50 tampón } & \multirow[t]{2}{*}{47} \\
\hline & Grano & Metanol & & & \\
\hline Piretroides & Carne & Acetonitrilo/agua & $\begin{array}{l}\text { Agitación, partición } \\
\text { con hexano }\end{array}$ & Columna alúmina & 48 \\
\hline Ciclodienos & $\begin{array}{l}\text { Manzana, } \\
\text { tomate, lechuga }\end{array}$ & Acetona & $\begin{array}{l}\text { Agitación, partición } \\
\text { hexano/dicloroetano }\end{array}$ & Dilución residuo & 49 \\
\hline \multirow[t]{2}{*}{ Pentaclorofenol } & Aguas residuales & \multirow[t]{2}{*}{ Metanol } & SPE & \multirow[t]{2}{*}{ SPE } & \multirow[t]{2}{*}{50} \\
\hline & Suelos & & Soxlet & & \\
\hline Carbofurano & Zumos & --- & $\begin{array}{ll}-- \\
\end{array}$ & Dilución $1 / 10,1 / 25$ & 51 \\
\hline Metilazinfos & Zumos & --- & --- & Dilución PBS & 52 \\
\hline $\begin{array}{l}\text { Fenitotrion } \\
\text { Metilclorpirifos } \\
\text { Metilpirimifos } \\
\end{array}$ & Trigo, harina & Metanol & $\begin{array}{l}\text { Agitación, } \\
\text { centrifugación }\end{array}$ & Dilución & 53 \\
\hline $\begin{array}{l}\text { Atrazina } \\
\text { Metolacloro } \\
\text { Alacloro } \\
\text { 2,4-D } \\
\end{array}$ & Maíz & $\begin{array}{l}\text { Metanol/agua } \\
(80 / 20)\end{array}$ & $\begin{array}{l}\text { Agitación, } \\
\text { centrifugación }\end{array}$ & Dilución & 54 \\
\hline Tiabendazol & Manzana, patata & Agua & $\begin{array}{l}\text { Mezcla, } \\
\text { centrifugación }\end{array}$ & --- & 55 \\
\hline $\begin{array}{l}\text { 2-Metil- } \\
\text { benzimidazol }\end{array}$ & Arándanos & Metanol & Mezcla & Alúmina & 56 \\
\hline Paracuat & $\begin{array}{l}\text { Patata, leche, } \\
\text { carne }\end{array}$ & $\mathrm{HCl}$ & Mezcla & --- & 57 \\
\hline $\begin{array}{l}\text { Ioprodion, } \\
\text { vinclozolina, } \\
\text { procimidona } \\
\end{array}$ & $\begin{array}{l}\text { Zanahoria, } \\
\text { patata }\end{array}$ & $\begin{array}{ll}-- \\
\end{array}$ & --- & Gel de sílice & 58 \\
\hline Clorotalonil & Apio, guisantes & Acetona, metanol & $\begin{array}{ll}-- \\
\end{array}$ & Dilución & 59 \\
\hline Procimidona & Pimiento & Acetato etilo & --- & Gel de sílice & 60 \\
\hline $\begin{array}{l}\text { Benomilo } \\
\text { Carbendazim } \\
\text { Tiabendazol } \\
\end{array}$ & $\begin{array}{l}\text { Frutas y } \\
\text { vegetales }\end{array}$ & Metanol & Agitación & Dilución & 61 \\
\hline $\begin{array}{l}2,4-D \\
\text { Simazina } \\
\text { Atrazina } \\
\text { Alacloro }\end{array}$ & Suelo & Acetonitrilo/agua & $\begin{array}{l}\text { Vortex, } \\
\text { centrifugación }\end{array}$ & Dilución & 62 \\
\hline 2,4-D & $\begin{array}{l}\text { Manzana, uva, } \\
\text { patata, naranja }\end{array}$ & Acetonitrilo & Mezcla, filtración & $\begin{array}{l}\text { Dilución, limpieza } \mathrm{C}_{18}, \\
\text { secado/resuspensión } \\
\text { acetona, dilución } 1 / 40\end{array}$ & 63 \\
\hline Atrazina & Agua & Metanol & $\mathrm{SPE}\left(\operatorname{discos} \mathrm{C}_{18}\right)$ & $\begin{array}{l}\text { Secado, resuspensión en } \\
\text { tampón }\end{array}$ & 64 \\
\hline TCP & Suelo, manzana & Acetona & Lixiviación & Resuspensión & 65 \\
\hline $\begin{array}{l}\text { Metilclorpirifos } \\
\text { Metilpirimifos } \\
\text { Fenitotrion }\end{array}$ & Grano & Metanol & $\begin{array}{l}\text { Agitación, } \\
\text { concentración }\end{array}$ & Dilución & 66 \\
\hline Benomilo & Frutas, verduras & Acetona & $\begin{array}{l}\text { Agitación, } \\
\text { concentración }\end{array}$ & Dilución & 67 \\
\hline Metopreno & Tabaco & $\begin{array}{l}\text { Acetonitrilo, } \\
\text { metanol }\end{array}$ & Extracción directa & Dilución & 68,69 \\
\hline Imazetapyr & Suelo, agua & Agua & $\begin{array}{l}\text { Extracción acuosa, } \\
\text { neutralización }\end{array}$ & Dilución & 70 \\
\hline Tiabendazol & Hígado & DMSO-agua & Extracción directa & Dilución & 55 \\
\hline
\end{tabular}




\begin{tabular}{l|l|l|l|l|l} 
Fumagillin & Miel & Etanol/agua & Extracción directa & Dilución & 71 \\
\hline Fenitotrion & Carne & Metanol & Extracción directa & Dilución & 72,53 \\
\hline Metolacloro & Suelo & Metanol & Extracción directa & Dilución & 73 \\
\hline
\end{tabular}

Tabla 1.4. (Continuación)

\begin{tabular}{l|l|l|l|l|l}
\hline Plaguicida & Matriz & Disolventes & Procedimiento & Limpieza/preparación & Refs. \\
\hline Atrazina & Agua & Metanol & SPE, $\mathrm{C}_{18}$ & Cambio de disolvente & 74,75 \\
\hline Tatraconazol & $\begin{array}{l}\text { Manzana, pera, } \\
\text { melocotón, } \\
\text { albaricoque }\end{array}$ & Metanol & $\begin{array}{l}\text { Reflujo, partición } \\
\text { éter/hexano }\end{array}$ & $\begin{array}{l}\text { Secado, resuspensión en } \\
\text { tampón acuoso }\end{array}$ & 76 \\
\hline $\begin{array}{l}\text { Bifenilos } \\
\text { policlorados } \\
\text { (PCBs) }\end{array}$ & Suelo & Metanol & Agitación & Dilución & 77 \\
\hline Atrazina & Agua & Acetato etilo & SPE, $\mathrm{C}_{18}$ & Cambio de disolvente & 78 \\
\hline $\begin{array}{l}\text { Alacloro y su } \\
\text { metabolito } \\
\text { ácido sulfónico }\end{array}$ & Agua & $\begin{array}{l}\text { Metanol, acetato } \\
\text { etilo }\end{array}$ & SPE, $\mathrm{C}_{18}$ & Dilución & 79 \\
\hline Glicoalcaloides & Patata & Metanol & Extracción directa & Dilución & 8 \\
\hline $\begin{array}{l}\text { Diazinon } \\
\text { Frutas, vegetales }\end{array}$ & Metanol & $\begin{array}{l}\text { Politrón, dilución con } \\
\text { agua }\end{array}$ & $\begin{array}{l}\text { SPE, elución acetonitrilo, } \\
\text { secado y resuspensión en } \\
\text { tampón acuoso }\end{array}$ & 81 \\
\hline
\end{tabular}

Formato de ensayo ELISA

En contraste con los métodos convencionales de análisis de productos fitosanitarios en matrices medioambientales y alimentos, los inmunoensayos aún no están suficientemente caracterizados y aceptados como métodos de rutina. En este sentido, muy pocos trabajos abordan la validación de métodos inmunoquímicos.

Dado que el desarrollo y aplicación de esta metodología al análisis de plaguicidas es una tecnología bastante reciente, los estudios de evaluación son una etapa importante para consolidar su aceptación e implantación, aunque, hoy por hoy, las normas para llevar a cabo dicha evaluación no están plenamente elaboradas y aceptadas a escala internacional. No obstante, ciertas instituciones de prestigio como la EPA, AOAC y USFDA en USA, la SCA (Standing Committe of Analysis) en el Reino Unido, o la GISG (German Immunoassay Study Group) en Alemania, han propuesto programas y directrices para evaluar los inmunoensayos de plaguicidas. En ellas se recomienda que la evaluación se lleve a cabo en muestras reales -en las cuales se sospeche de la presencia del analito- o en su defecto, emplear muestras reforzadas con cantidades determinadas del analito.

Así, en 1994 la EPA editó una primera guía de análisis inmunoquímico con el objetivo de ayudar a los usuarios de estas nuevas técnicas aplicadas a la determinación de plaguicidas (82). Además, la ISO/CD Nº 15089 (83) ofrece información, en forma de guías prácticas, para la determinación de residuos de productos fitosanitarios por 
inmunoensayo. El principal objetivo de este documento es suministrar una serie de protocolos analíticos estandarizados para la evaluación de la calidad del agua.

La Tabla 1.5 recoge los métodos inmunoquímicos de determinación de residuos en aguas y suelos, validados y recomendados por la EPA, e incluidos en su compendio de métodos. También se han incluido en el listado de métodos de la FDA y son utilizados por el NIOSH para el control de la exposición ocupacional a plaguicidas y sus metabolitos.

Por otro lado, Gabaldón y col. (84) resumen las principales aplicaciones de los inmunoensayos desarrollados en kits comerciales y su aplicación a la determinación de productos fitosanitarios en diferentes matrices.

Tabla 1.5. Métodos inmunoquímicos validados por la EPA para el análisis de residuos en aguas y suelos

\begin{tabular}{ll}
\hline Método No & Inmunoensayo \\
\hline $4010^{\text {a }}$ & Screening para pentaclorofenol \\
4015 & Screening para 2,4-D \\
$4020-4021$ & Screening para bifenilos policlorados (PCBs) \\
4030 & Screening para hidrocarburos del petróleo en suelos \\
4031 & Screening para BTEX (benceno, tolueno, etilbenceno y xilenos) en suelos \\
4035 & Screening para hidrocarburos aromáticos polinucleares (PAHs) en suelos \\
4040 & Screening para toxafeno en suelos \\
4041 & Screening para clordano en suelos \\
4042 & Screening para DDT en suelos \\
4050 & $\begin{array}{l}\text { Screening para TNT en aguas y suelos } \\
4051\end{array}$ \\
$\begin{array}{l}\text { Screening para hexahidro-1,3,5-trinitro-1,3,5-triazina (RDX) en aguas y } \\
\text { suelos } \\
4669\end{array}$ & Inmunoensayo cuantitativo para triazinas como atrazina en aguas \\
\hline
\end{tabular}

\subsection{INMUNOENSAYOS Y MEDIOS ORGÁNICOS}

Para poder aplicar un método inmunoquímico al análisis de residuos de plaguicidas, estos analitos deben presentar ciertas propiedades como: ser hidrofílicos, no volátiles y estables en agua (40). Aparecen, por tanto, ciertos inconvenientes derivados de la baja solubilidad de dichas sustancias. Cuando se analiza un compuesto de estas características, suele dar buenos resultados diluir la muestra problema en agua o tampón acuoso. A pesar de las altas diluciones aplicadas, es posible detectar el analito 
debido a la excepcional sensibilidad de la técnica. Sin embargo, por lo general, la determinación de concentraciones del orden de $\mu \mathrm{g} / \mathrm{l}$ de compuestos más lipofílicos o en matrices complejas requieren aplicar etapas de extracción, limpieza y preconcentración.

Por otro lado, en el desarrollo de un nuevo método inmunológico habría que tener en cuenta las recomendaciones dadas por los métodos de referencia respecto a los procedimientos de preparación de muestra, en cada matriz y para cada tipo de analito (85). En caso contrario, se tendría que realizar un trabajo ímprobo de validación de la nueva metodología propuesta, lo que únicamente estaría justificado para casos muy concretos. Ello implica, generalmente, trabajar con analitos extraídos con disolventes orgánicos como metanol, acetonitrilo, acetona o hexano, entre otros.

Surge pues el problema de ampliar los inmunoensayos a compuestos apolares en medios orgánicos, por lo que se deben tener en cuenta aspectos tales como:

(1) Problemática relacionada con el tratamiento de muestra (extracción, preconcentración, purificación, etc.).

(2) Efectos de los medios orgánicos en las interacciones inmunoquímicas.

Una primera aproximación al desarrollo de métodos inmunoquímicos en medios orgánicos exige evaluar los efectos de dichos medios sobre los reactivos implicados, que básicamente son anticuerpos y enzimas.

La capacidad de los disolventes orgánicos de interferir con las propiedades fisicoquímicas de las enzimas es bien conocida. Los efectos de estos disolventes son generalmente atribuidos a cambios de interacciones no covalentes en las proteínas, incluyendo la solvatación de grupos iónicos y dipolos, enlaces de $\mathrm{H}$ e interacciones hidrofóbicas. Estas alteraciones pueden modificar la estructura terciaria de las proteínas provocando su desnaturalización, en mayor o menor grado. Es ampliamente aceptado, sin embargo, que la eficiencia de las reacciones enzimáticas en medio orgánico es comparable, o incluso mayor en algunos casos, a la que tiene lugar en medio acuoso, siempre que las enzimas estén rodeadas de una capa de agua, la cual es necesaria para la retención de su actividad (86).

Diferentes sistemas bioanalíticos basados en enzimas han sido desarrollados para ser usados en medios orgánicos, generalmente electrodos enzimáticos $(87,88)$. La utilización de estos sistemas ofrece ventajas, tales como extender el rango de trabajo, prevenir reacciones colaterales indeseables, mejorar la estabilidad operacional y simplificar las técnicas de inmovilización. La cinética y aplicaciones analíticas de este tipo de electrodos han sido revisadas recientemente por Iwoha y col.(89). 
Diferentes investigadores han demostrado que la actividad catalítica de muchas enzimas cambia con el contenido en agua de los disolventes orgánicos. En una experiencia realizada con peroxidasa del rábano picante (HRP), Lu y col. (90) observan que la actividad catalítica aumenta más de dos órdenes de magnitud cuando el contenido en agua pasa del 1 al 20\% (v/v) en disoluciones conteniendo $\mathrm{MeCN}$, seguido por un drástico descenso de la actividad. Los autores sugieren que el aumento en la actividad de las enzimas es consecuencia directa de un aumento en su flexibilidad conformacional, la cual puede ser debida a la reducida interacción de los residuos de aminoácidos cargados o polares dentro de la molécula de enzima, propiciada por la capacidad del agua para modificar el apantallamiento dieléctrico. Cuando el contenido en agua aumenta por encima de un valor, el incremento en la hidratación es acompañado por un incremento en la flexibilidad de la enzima y este menor cambio conformacional reduce su actividad catalítica.

En general, una enzima en medio acuoso pierde actividad y llega a desnaturalizarse a medida que se incrementa la concentración de disolvente orgánico miscible. Sin embargo, en el caso de una enzima liofilizada suspendida en un medio predominantemente anhidro (preferentemente no polar), la proteína es cinéticamente atrapada en una conformación más activa que la que tiene en disolución. Es decir, la enzima debe desnaturalizarse en disolventes orgánicos (desde el punto de vista termodinámico) pero no puede (desde el punto de vista cinético) debido a la restricción de agua, y de ahí la falta de flexibilidad conformacional necesaria para desplegarse (91).

Recientemente, Klibanov y col. (92) han estudiado los modos de incrementar la actividad de ciertas enzimas en medios no acuosos. Encuentran que varias oxidasas (HRP, por ejemplo) liofilizadas funcionan mejor en medios no acuosos si son primero disueltas en agua y luego introducidas en el disolvente anhidro. Así pues, indican que las enzimas que son desnaturalizadas durante la liofilización, exhiben poca actividad cuando son suspendidas directamente en medio orgánico, pero se reactivan si primero son disueltas en agua.

La idea de que las enzimas pueden retener su actividad en una amplia variedad de medios orgánicos está actualmente aceptada (93-95). Sin embargo, en todos los casos mencionados, las enzimas permanecen activas en función de la fina capa de agua que las rodea y estabiliza. Esta agua parece necesaria para la retención de su actividad catalítica y su eliminación supone el cese de dicha actividad. 
En referencia a las anteriores premisas, se pueden formular unos principios básicos de comportamiento de las enzimas en medios orgánicos. Respecto a la forma de trabajar, se recurre en todos los casos a "aislar" la enzima de dichos medios $(94,95)$. En este caso hay que tener en cuenta varios aspectos:

(1) Selección del disolvente: los disolventes miscibles con agua no distorsionan fuertemente las interacciones en la capa de hidratación de la enzima que es necesaria para el mantenimiento de su conformación nativa.

(2) Selección de la enzima: en principio, pueden ser usadas enzimas con propiedades intrínsecas para mantener su conformación activa en medios no acuosos.

(3) Separación espacial: las propiedades catalíticas de una enzima pueden ser mantenidas si la enzima hidratada y el medio orgánico tienen localizaciones separadas en el sistema de reacción, i.e. se previene el contacto directo entre ellos.

(4) Inmovilización de la enzima: si el disolvente orgánico es capaz de afectar a la capa de hidratación, la conformación de la enzima puede fijarse artificialmente por inmovilización en un soporte inerte. De este modo, la enzima mantiene su conformación incluso en un estado (parcialmente) deshidratado.

Finalmente, cabe destacar algunas ventajas de las transformaciones enzimáticas en medios orgánicos (96):

- Los rendimientos medios del proceso en medio orgánico son mayores debido a la omisión de pasos de extracción. Se evita la formación de emulsiones y la recuperación del producto(s) está facilitada por el uso de disolventes orgánicos de bajo punto de ebullición.

- Los substratos no polares se transforman mejor debido a su alta solubilidad.

- La contaminación microbiana es despreciable ya que el medio orgánico es hostil para células vivas.

- La desactivación o inhibición de la enzima por un substrato lipofílico es despreciable ya que su concentración en la superficie de la enzima es mínima.

- Muchas reacciones como hidrólisis de grupos lábiles, polimerización de quinonas, racemización, etc. son dependientes del agua por lo que están suprimidas en medio orgánico.

- La principal ventaja consiste en la posibilidad de llegar al equilibrio termodinámico en favor de la síntesis sobre la hidrólisis. 
Por analogía con las enzimas, es presumible que la hidrofobicidad de los disolventes no cause un desplazamiento de la película de agua que rodea a las moléculas de anticuerpo, manteniendo su inmunorreactividad.

Sin embargo, y en contraste con las enzimas, no son muchas las investigaciones realizadas sobre el comportamiento de los anticuerpos en medios orgánicos. Russell y col. (97) describen por primera vez el comportamiento de un Ab inmovilizado en presencia de varios disolventes inmiscibles en agua, observando que la intensidad de unión del hapteno (4-aminobifenilo) al $\mathrm{Ab}$ disminuye a medida que aumenta la hidrofobicidad del disolvente.

Weetall (98) examina la velocidad de reacción de un $\mathrm{Ab}$ y su hapteno en disolventes inmiscibles en agua, demostrando que la velocidad de reacción depende de la transferencia del hapteno entre la fase orgánica y la capa de agua residual que rodea al $\mathrm{Ab}$. En este estudio, se utilizaron anticuerpos inmovilizados covalentemente en partículas paramagnéticas para la determinación de progesterona disuelta en hexano, observándose que la velocidad de reacción se ralentiza en medio orgánico, pero que no existe pérdida en la actividad de los anticuerpos. En estos ensayos de transferencia de fase, los anticuerpos permanecen en el medio acuoso mientras que el antígeno se encuentra en la fase orgánica, siendo la interfase el lugar donde transcurren las reacciones inmunoquímicas.

Los cambios en la hidrofobicidad del disolvente, constante dieléctrica y contenido en agua del medio de reacción pueden afectar la capacidad de enlace del Ab, lo cual altera invariablemente la especificidad y reactividad (89). Sin embargo, en un estudio sobre el efecto del tipo de disolvente en la interacción Ab-Ag utilizando antitestosterona $\operatorname{IgG}$ (99), no se encontró correlación entre la afinidad aparente y algunas propiedades de los disolventes tales como constante dieléctrica, índice de polaridad y momento dipolar, pero fue inversamente correlacionada con la masa molecular del disolvente. Esto sugiere que la inhibición del enlace puede relacionarse con la capacidad del disolvente de desplazar la capa de agua que rodea al hapteno. En dicho estudio se observó un aumento en la capacidad de reconocimiento del Ab a medida que se reducía la concentración de algunos disolventes.

Utilizando un kit comercial RIA para digoxina y diferentes disolventes orgánicos, Hedenfalk y col. (100) observaron que la sensibilidad aumentaba hasta cuatro órdenes de magnitud y que las diferencias observadas eran debidas, principalmente, al cambio del coeficiente de partición del analito. 
Los efectos de los disolventes orgánicos descritos para sistemas inmunoanalíticos incluyen cambios en la especificidad y algunos ejemplos de incremento en la afinidad (101). La afinidad del anticuerpo está relacionada con la polaridad del disolvente y la solubilidad del hapteno en el mismo (102).

La mayor parte de los estudios de compatibilidad de los anticuerpos frente a los medios orgánicos han sido desarrollados utilizando la técnica ELISA, donde el análisis directo de extractos exige usar disolventes miscibles en agua, generalmente a bajas concentraciones.

A continuación se comentan algunas de las investigaciones realizadas sobre el comportamiento de los $\mathrm{Ab}$ en medios orgánicos. Así, utilizando la técnica ELISA, Stocklein $y$ col. (103) determinan dos herbicidas de la familia de las s-triazinas basándose en los cambios de especificidad de los trazadores enzimáticos y cambios en la selectividad mostrada por los anticuerpos, al adicionar disolventes orgánicos al tampón acuoso de trabajo (10-20\% v/v). Además, observan una variación en la afinidad del anticuerpo utilizado frente a los dos analitos en función del medio de análisis (DMF, metanol, acetonitrilo, etanol, acetona, etc.). En otro trabajo, Nugent (104) desarrolla un inmunoensayo para el análisis de clorpirifos empleando tampón acuoso con un $10 \%$ de propanol. Schneider y col. (105) desarrollan un inmunoensayo para s-triazinas utilizando anticuerpos monoclonales que toleran hasta un $10 \%$ de metanol. Hill y col. (106) en un estudio sobre la presencia de metopreno en grano, obtienen los mejores resultados utilizando en el análisis un 5\% de metanol y un 2,5\% de acetonitrilo. Ambos medios causaron menos de un $10 \%$ de inhibición en el desarrollo de color respecto a los controles acuosos. Sin embargo, el inmunoensayo fue unas 3 veces más sensible en metanol que en acetonitrilo. Fan y Bushway (81) analizan diazinón en frutas y vegetales mediante ELISA utilizando hasta un 10\% de metanol. En el ELISA desarrollado por Beckeit y col. (107) para el herbicida bromacilo, los disolventes orgánicos empleados afectaron a la sensibilidad de los ensayos. A concentraciones de hasta un $12,5 \%$, la $\mathrm{I}_{50}$ se mantuvo por debajo de $10 \mu \mathrm{g} / \mathrm{l}$, pero para porcentajes superiores, dicho valor se incrementó entre 2 y 110 veces en función del disolvente empleado. Por otro lado, Wittmann y Hock (108) en un ensayo desarrollados en placa ELISA para hidroxiatrazina, indican que porcentajes de metanol superiores al 5\% (v/v) afectan sensiblemente las prestaciones del ensayo. Schmidt y col. desarrollaron un ensayo (109) para avermectinas con anticuerpos monoclonales, uno de los cuales era capaz de unir el analito en tampones acuosos con contenidos en disolventes orgánicos (metanol, etanol, 
acetona, etc) de hasta un 30\% (v/v). Los límites de detección encontrados se situaron entre 0,5 y $1 \mu \mathrm{g} / 1$.

Sasaki y col. (110) indican que la afinidad de los anticuerpos policlonales antiatrazina no se ve alterada al modificarlos químicamente con el reactivo 2,4-bis(ometoxi-polietilenglicol)-6-cloro-s-triazina. Observaron que el anticuerpo modificado era más soluble en tolueno $(270 \mu \mathrm{g} / \mathrm{ml})$ que en cloroformo $(26 \mu \mathrm{g} / \mathrm{ml})$ y que dicha modificación no influyó en su capacidad de enlace en fase acuosa. Estos anticuerpos fueron inmovilizados en un soporte silíceo y tras su incubación con una disolución de atrazina en tolueno y la adición del trazador enzimático atrazina-HRP, obtuvieron un límite de detección de $0,5 \mathrm{mg} / \mathrm{l}$.

Stocklein y col. (85) analizan derivados de la cumarina mediante un sistema en flujo utilizando anticuerpos policlonales inmovilizados en un soporte poroso y trazadores enzimáticos con HRP, como enzima marcadora, en disoluciones con un contenido en medio orgánico de hasta un $20 \%(\mathrm{v} / \mathrm{v})$. Con los disolventes orgánicos empleados observaron que la actividad enzimática se veía afectada en el siguiente orden: THF $>$ acetonitrilo $>$ etanol $>$ metanol.

En el análisis de aflatoxina $\mathrm{B}_{1}$ en alimentos mediante radioinmunoensayo (RIA), Fukal y col. (111) demostraron que la presencia de disolventes orgánicos (hasta un 60\%) disminuye el título del antisuero, así como la precisión del ensayo en el análisis de esta aflatoxina -a bajos niveles- en extractos de alimentos. Matsura y col. $(112,113)$ desarrollan anticuerpos monoclonales frente a ácido okadaico, compuesto altamente hidrofóbico. Siete de los veinte anticuerpos obtenidos fueron evaluados en función de su actividad frente a esta toxina, aislada de esponjas marinas en diferentes medios orgánicos. Dos de ellos mantuvieron su actividad en dichos medios conteniendo entre $90-100 \%$ de metanol, mientras que el resto no toleraron concentraciones superiores al 50-60\%. Los resultados obtenidos demostraron que el reconocimiento de los anticuerpos inmovilizados decrecía al aumentar la concentración del alcohol. Los valores de $\mathrm{I}_{50}$ oscilaron entre $0,18 \mathrm{ng} / \mathrm{ml}$ con $0 \%$ metanol y $570 \mathrm{ng} / \mathrm{ml}$ con $100 \%$ metanol. Disoluciones entre $0-50 \%$ de acetona, éter dietílico y benceno en metanol, produjeron señales similares a las obtenidas en metanol puro.

En otro trabajo, Stocklein y col. (102) describen un sistema inmunoquímico basado en anticuerpos policlonales inmovilizados en una membrana de nylon (Inmunodyne), que es capaz de detectar triazinas disueltas en disolventes orgánicos 
anhidros (cloroformo, diclorometano, tolueno y hexano). Los valores de $I_{50}(\mu \mathrm{g} / \mathrm{l})$ obtenidos se muestran en la Tabla 1.6.

Tabla 1.6. Valores de $I_{50}(\mu \mathrm{g} / \mathrm{l})$ para triazinas obtenidos en distintos disolventes orgánicos (102)

\begin{tabular}{lcc}
\hline & \multicolumn{2}{c}{ Anticuerpo policlonal } \\
\cline { 2 - 3 } Disolvente & $\mathrm{C} 14$ & $\mathrm{C} 193$ \\
\hline Tampón acuoso & 6 & 1 \\
Diclorometano & 12 & 10 \\
Cloroformo & 22 & 8 \\
Tolueno & 22 & 10 \\
Hexano & 43 & 3 \\
\hline
\end{tabular}

Generalmente, la capacidad de los Ab para mantener su función en disolventes no acuosos ha sido investigada en mezclas binarias disolvente-agua. Sin embargo, para disolventes hidrofóbicos, los cuales difícilmente disuelven proteínas, pueden utilizarse otras alternativas como la inmovilización o encapsulación del Ab en micelas reversas $(114,115)$.

Los sistemas micelares reversos permiten solubilizar simultáneamente tanto los compuestos insolubles en agua como al Ab. Durante la solubilización, las moléculas de $\mathrm{Ab}$ se incorporan espontáneamente en la cavidad acuosa de la micela reversa, permaneciendo "oculto" para el disolvente orgánico debido a la monocapa de hidratación del surfactante $(114,115)$. El compuesto insoluble en agua se distribuye entre el disolvente orgánico y la película hidratada de la micela reversa, entrando en contacto con el Ab solubilizado.

Utilizando micelas reversas del aerosol OT (AOT) en n-octano como medio de ensayo, Matveeva y col. (118), presentan un método nuevo para llevar a cabo fluoroinmunoensayos homogéneos para atrazina en medios orgánicos apolares basados en la desactivación de la fluorescencia (QFIA). La unión del trazador atrazinafluoresceina al Ab solubilizado en las micelas reversas da lugar a una extinción de la fluorescencia, cuya eficiencia depende de las propiedades del sistema micelar (Wo). Las condiciones óptimas para la desactivación son: baja concentración de surfactante y un grado de hidratación adecuado para permitir la formación de grandes micelas reversas $\left(\mathrm{Wo}_{\mathrm{O}}=15-20\right)$. La adición de atrazina libre produce un desplazamiento del conjugado y la 
restauración de su fluorescencia. La sensibilidad de este tipo de ensayo es sólo 10 veces menor $(30 \mu \mathrm{g} / \mathrm{l})$ que la del fluoroinmunoensayo de polarización realizado en medio acuoso $(3 \mu \mathrm{g} / 1)$.

Francis y Craston (117) desarrollan un ELISA para la determinación de paratión en medio acuoso y lo adaptan a la medida de este analito extraído en hexano utilizando el Ab encapsulado en micelas reversas AOT. Aunque en este trabajo se muestra que el paratión puede ser determinado cuantitativamente en ELISA, la curva de calibrado en hexano está desplazada respecto a la acuosa $\left(10^{4}\right.$ veces más sensible), en correspondencia con el coeficiente de reparto del paratión entre el hexano y el agua. Esta pérdida de sensibilidad puede deberse, probablemente, a que la barrera termodinámica para la transferencia del paratión desde la mayor parte de la fase orgánica a la acuosa de una micela reversa balancea la fuerza de unión Ag-Ab, reduciendo la potencia del paratión como competidor antigénico.

Finalmente, Aston y col. (93) han desarrollado un inmunoensayo competitivo utilizando Ab monoclonales, para la cuantificación de un derivado hidrofóbico del 2,4D en hexano, tolueno y xileno, obteniendo una respuesta lineal en el rango 1-20 $\mu \mathrm{g} / \mathrm{ml}$ en los tres disolventes. Estos investigadores observan que la mezcla del $\mathrm{Ab}$ con hexano durante 20 minutos tiene poco efecto en la inmunorreactividad $(\approx 7 \%)$, y que la relación 4:1 (disolvente:Ab acuoso, v/v) es la óptima.

A modo de resumen podemos decir que, en los formatos habituales (placa, EIA), en raras ocasiones se pueden sobrepasar concentraciones de disolventes miscibles con los reactivos acuosos de trabajo superiores al 10\% (v/v). En general, la sensibilidad alcanzada en medio orgánico es menor, pero se ha demostrado que la unión Ag-Ab es posible en estos medios e incluso que la selectividad aumenta. Por otro lado, no es práctico el uso de disolventes inmiscibles en agua debido a la separación de fases producida y a la partición del analito, si bien es posible realizar la reacción inmunoquímica en la interfase acuosa-orgánica, aunque el tiempo de incubación es mucho mayor (10-20 horas) comparado con el requerido en medio acuoso. Por otro lado, la mayoría de los ensayos han sido desarrollados en batch, lo que supone serios inconvenientes al trabajar con disolventes orgánicos como: toxicidad, compatibilidad con los soportes (placas, tubos, etc), manipulación (pipeteo, etc), contaminación y costes, así como la falta de prestaciones conseguidas, en general, en estos formatos. En 
este sentido, han sido revisadas recientemente algunas aproximaciones sobre inmunoensayos en medios orgánicos incluyendo mezclas disolvente/agua (118).

Todos estos inconvenientes, especialmente los relacionados con la utilización de disolventes volátiles, materiales compatibles, etc., pueden ser resueltos parcialmente con el desarrollo de sensores y sistemas en flujo. Sin embargo, los estudios de la interacción $\mathrm{Ab}-\mathrm{Ag}$ en presencia de altas concentraciones de disolventes orgánicos utilizando inmunosensores, son escasos, especialmente para plaguicidas.

El hecho de que los Abs puedan retener su actividad en disolventes orgánicos, hace posible realizar el análisis directo de muestras extraídas en dichos medios. Además, la posibilidad de utilizar Ab en un sistema acuoso-orgánico evitaría la etapa de evaporación del disolvente, problemas de contaminación, degradación, etc., haciendo más versátiles este tipo de ensayos. Así pues, la posibilidad de desarrollar métodos inmunológicos en medios orgánicos parece una elección atractiva y suscita gran interés.

Por ello, deben estudiarse y resolverse muchos aspectos críticos poco investigados, tales como: la compatibilidad de los disolventes entre sí y con cada sistema $\mathrm{Ab}-\mathrm{Ag}$, así como la tolerancia de los Abs a los medios orgánicos debido a la naturaleza única de cada sistema, entre otros.

\subsection{DISOLVENTES ORGÁNICOS}

Los disolventes orgánicos se clasifican, generalmente, por una serie de propiedades físico-químicas como puntos de ebullición, presión de vapor, calor de vaporización, índice de refracción, viscosidad, densidad, tensión superficial, constante dieléctridca, polarizabilidad, conductividad específica, etc. Estas propiedades pueden utilizarse para caracterizar el comportamiento de los disolventes, pero desafortunadamente muchas de las clasificaciones sólo tienen en cuenta algunas de ellas, lo que las hace muy pobres. Una de las escalas más utilizadas es la serie eluótropa, de uso frecuente en cromatografía y otros procesos de separación.

Gramática y col. (119) proponen un modo general de clasificación de los disolventes orgánicos basado en descriptores moleculares teóricos en lugar de en propiedades físico-químicas. Utilizando herramientas quimiométricas elaboran una clasificación general aplicada a 152 disolventes, obteniendo modelos de regresión 
capaces de predecir sus propiedades físico-químicas. Utilizando el método molecular de Allinger obtienen las conformaciones de mínima energía para dichos disolventes y calculan los descriptores moleculares (estructurales, empírico, topológicos y holísticos). Como ejemplo, según la clasificación multivariante de los disolventes orgánicos obtenida por estos autores, el tetrahidrofurano que era clasificado como un disolvente aromático apolar (Clase 4 de Chastrete) pasa a considerarse Clase 3 (disolvente aprótico, altamente dipolar y polarizable) y el hexano pasa de la Clase 3 a la 5 (disolvente aromático, relativamente polar).

Por otro lado, hay que indicar que el comportamiento de los disolventes está íntimamente relacionado con la naturaleza y extensión de la interacción solutodisolvente. La inconsistencia en el comportamiento de los solutos en base a las propiedades físicas de los disolventes, indica que éstos no pueden considerarse como medios continuos macroscópicos, si no como moléculas con estructuras dinámicas que interaccionan de forma diferente con los solutos. Así pues, dado que los parámetros macroscópicos (puntos de ebullición, constante dieléctrica, etc.) no bastan para explicar la estructura de los disolventes en la esfera de solvatación de los solutos, ha sido necesario considerar nuevos parámetros que definan el comportamiento de los disolventes en ambientes microscópicos (120).

En este sentido, las escalas uniparamétricas intentan incorporar en un solo parámetro, que generalmente es la polaridad, todas las interacciones soluto-disolvente. En contraste, las aproximaciones multiparamétricas asocian cada clase de interacción soluto-disolvente con un parámetro independiente. Los valores de $\mathrm{E}_{\mathrm{T}}$ (parámetro de Reichardt) (121) y el grupo formado por los parámetros solvatocrómicos de Kamlet y Taft $\alpha, \beta$ y $\pi^{*}$ (122) son los más utilizados. $\mathrm{E}_{\mathrm{T}}$ ha sido definido como un parámetro de polaridad. Los otros parámetros dependen de la acidez del enlace de hidrógeno $(\alpha)$, la basicidad del enlace de hidrógeno $(\beta)$ y la polaridad-polarizabilidad $\left(\pi^{*}\right)$. Muchos estudios han mostrado una relación entre los dos grupos de parámetros en disolventes puros y mezclas $(120,123,124)$, siendo $\mathrm{E}_{\mathrm{T}}$ una combinación lineal de $\pi^{*} \mathrm{y} \alpha$. En la tabla 1.7 se indican los parámetros solvatocrómicos para algunos disolventes orgánicos.

Tabla 1.7. Parámetros solvatocrómicos de algunos disolventes orgánicos

\begin{tabular}{llll}
\hline Disolvente & $\boldsymbol{\alpha}$ & $\boldsymbol{\beta}$ & $\boldsymbol{\pi}^{*}$ \\
\hline Eter dietílico & 0,00 & 0,55 & 0,58
\end{tabular}




\begin{tabular}{llll} 
Tetrahidrofurano & 0,00 & 0,55 & 0,58 \\
Acetona & 0,08 & 0,48 & 0,71 \\
Acetato de etilo & 0,00 & 0,45 & 0,55 \\
Dimetilformamida & 0,00 & 0,69 & 0,88 \\
Nitrobenceno & 0,00 & 0,39 & 1,01 \\
Acetonitrilo & 0,19 & 0,31 & 0,75 \\
Tolueno & 0,00 & 0,11 & 0,54 \\
Tetracloruro de carbono & 0,00 & 0,00 & 0,28 \\
Cloroformo & 0,44 & 0,00 & 0,58 \\
Isopropanol & 0,76 & 0,95 & 0,48 \\
Metanol & 0,93 & 0,62 & 0,60 \\
Agua & 1,17 & 0,18 & 1,09 \\
\hline
\end{tabular}

En base a estos parámetros solvatocrómicos, disolventes como el tetrahidrofurano, acetona, acetato de etilo y acetonitrilo se incluyen en el grupo de disolventes polares apróticos, todos relativamente básicos y moderada o altamente polares, que incluyen éteres cíclicos alifáticos, disolventes conteniendo grupos funcionales carbonilo y nitrilo. La dimetilformamida se encuentra entre los disolventes fuertemente polares y básicos, y el diclorometano en el grupo de los disolventes relativamente polares formados por hidrocarburos alifáticos polihalogenados, cuyos heteroátomos causan un efecto inductivo responsable del enlace de hidrógeno. Finalmente, el isopropanol y el metanol pertenecen al grupo formado por disolventes anfipróticos (alcoholes y agua) con marcadas propiedades para formar puentes de hidrógeno.

Finalmente, cabe preguntarse en base a que criterios se han obtenido estas clasificaciones y su ámbito de aplicación, ya que no es lo mismo desarrollar un modelo que prediga el comportamiento de una proteína en un medio orgánico, que el de un compuesto apolar volátil. Por ello debemos concluir que -en la actualidad- aún no se tiene un modelo universal que prediga teóricamente el comportamiento de compuestos químicos tan complejos y heterogéneos como las IgGs en medios orgánicos, y que la complejidad del problema hace difícil desarrollar este tipo de aproximaciones. 


\subsubsection{Elección de disolventes para bioensayos en medios orgánicos}

En este apartado, el término bioensayo hace referencia únicamente a los sistemas enzimáticos, ya que las investigaciones efectuadas con otro tipo de proteínas, especialmente las que presentan reconocimiento molecular, son muy escasas.

Los disolventes utilizados en biosensayos pueden clasificarse en dos grupos principales: anhidros y no anhidros. Los primeros incluyen ensayos en disolventes puros o mezclas de los mismos que pueden ser polares o apolares. Los segundos comprenden sistemas microacuosos, mezclas de disolventes miscibles en agua, agua y disolventes inmiscibles en sistemas bifásicos y disoluciones micelares reversas. A su vez, los medios de reacción microacuosos son asociados con disolventes no polares los cuales son inmiscibles en agua.

Aunque durante mucho tiempo se ha creído que la biocatalisis estaba limitada a medios acuosos, actualmente se conoce que muchos disolventes no acuosos mantienen la actividad enzimática. En consecuencia, se han realizado intentos para correlacionar la actividad enzimática en un disolvente orgánico con algunas de las propiedades de éste como: momento dipolar $(\mu)$, constante dieléctrica $(\varepsilon)$ y viscosidad $(\eta)$.

Así, $\mu$ es una propiedad física del disolvente que depende de su estructura molecular y $\varepsilon$ de la carga del mismo. Ambas propiedades muestran relación con la polaridad del disolvente, aunque $\varepsilon$ y $\mu$ no se correlacionen bien.

Los enzimólogos han intentado durante años relacionar la actividad enzimática en medio orgánico con algún índice de polaridad del disolvente. Los primeros fueron Brink y Tramper (125) quienes usaron el parámetro de solubilidad de Hildrebrand $(\delta)$ como medida de la polaridad de los disolventes orgánicos, que mide la cohesión molecular total por unidad de volumen y representa la suma total de contribuciones debidas a fuerzas de dispersión moleculares y de hidrógeno.

Según Connors (126), para un disolvente dado:

$$
\delta=\left[\left(\Delta \mathrm{E}_{\mathrm{vap}} / \mathrm{V}\right)\right]^{1 / 2}=\left[\left(\Delta \mathrm{H}_{\mathrm{vap}}-\mathrm{RT} / \mathrm{V}\right)\right]^{1 / 2}
$$

Así, las enzimas estudiadas en disolventes con baja polaridad $(\delta<8)$ y con $\mathrm{Mr}>$ 150, exhiben una actividad apreciable. Sin embargo, debido a que $\delta$ es la suma total de contribuciones debidas a las fuerzas de dispersión polares y de hidrógeno, esta es una pobre medida de la polaridad, especialmente para disolventes no polares. 
El parámetro de mayor aceptación para predecir la actividad biocatalítica en un disolvente es el de Laane (log P). Log P, es el logaritmo del coeficiente de partición del disolvente investigado en el sistema bifásico octanol:agua. Es un indicador de la hidrofobicidad del disolvente: a mayor $\log$ P, mayor hidrofobicidad.

Las enzimas muestran mayor reactividad en disolventes más hidrofóbicos $(\log \mathrm{P}$ $>4)$ y menor en hidrofílicos $(\log \mathrm{P}<2)$. Los disolventes con valores de $\log \mathrm{P}$ entre 2 y 4, dan lugar a medios de reacción con actividad enzimática intermedia. Los disolventes hidrofóbicos no eliminan el agua de hidratación necesaria para mantener la actividad enzimática, mientras que los hidrofílicos deshidratan la enzima, distorsionando en gran medida la estructura de los centros activos.

En la Tabla 1.8. se muestran los efectos más significativos sobre la actividad enzimática en función del $\log \mathrm{P}$ de un disolvente dado (96). 
Tabla 1.8. Efectos de los disolventes orgánicos sobre la actividad enzimática en función de $\log P$

\begin{tabular}{|l|l|l|}
\hline Log P & Miscibilidad en agua & Efectos en actividad enzimática \\
\hline$-2,5$ a 0 & Completamente miscible & $\begin{array}{l}\text { Puede ser usado solamente para solubilizar substratos } \\
\text { lipofilicos a concentraciones en un rango de 10-50\% v/v sin } \\
\text { desactivar la enzima }\end{array}$ \\
\hline 0 a 1,5 & Parcialmente miscible & $\begin{array}{l}\text { Causa una seria distorsión enzimática, sólo puede ser usado } \\
\text { con proteínas estables* pero desactiva la mayor parte de las } \\
\text { enzimas }\end{array}$ \\
\hline 1,5 a 2 & Baja miscibilidad & $\begin{array}{l}\text { Causa alguna distorsión en la enzima. Puede ser usada con } \\
\text { precaución con muchas enzimas pero su actividad es a } \\
\text { menudo impredecible }\end{array}$ \\
\hline$>2$ & Immiscible & $\begin{array}{l}\text { Causa una despreciable distorsión enzimática y asegura una } \\
\text { alta retención de la actividad }\end{array}$ \\
\hline
\end{tabular}

Se ha comprobado que a mayor log $\mathrm{P}$ aumenta la actividad enzimática hasta un cierto porcentaje de disolvente orgánico. Además, hay que tener en cuenta los valores de este parámetro para cada compuesto y medio estudiado.

En la Tabla 1.9 se dan los valores de log P para algunos disolventes orgánicos (103).

Tabla 1.9. Valores de log $P$ para algunos disolventes orgánicos

\begin{tabular}{lc}
\hline Disolvente & Log P \\
\hline Tampón fosfato salino (PBS) & $-2,7$ \\
Dimetilsulfóxido (DMSO) & $-1,3$ \\
Dimetilformamida & $-1,0$ \\
Metanol & $-0,76$ \\
Acetonitrilo & $-0,33$ \\
Etanol & $-0,23$ \\
Acetona & $-0,23$ \\
n-propanol & 0,28 \\
\hline
\end{tabular}

Sin embargo, en muchas ocasiones, las predicciones teóricas obtenidas a partir de los valores del parámetro P se desvían de los resultados experimentales. El valor de log $\mathrm{P}$ no es una fórmula absoluta de selección del disolvente (por ejemplo, enzimas disueltas en algunos disolventes con $\log \mathrm{P}<2$ exhiben una elevada actividad catalítica, como se ha demostrado para el caso del acetonitrilo (90)), aunque la hidrofobicidad juega un papel importante en las interacciones que implican substratos hidrofóbicos en disolventes orgánicos. 


\subsection{INMUNOSENSORES. TIPOS}

A la hora de realizar un análisis de forma automática, una alternativa muy atractiva es el uso de reactivos bioespecíficos para el desarrollo de los denominados biosensores, dispositivos capaces de realizar un control continuo y en tiempo real. Estos sistemas surgen para ofrecer una solución al problema planteado cuando es necesario analizar un gran número de muestras de forma rápida y fiable.

Un biosensor está definido genéricamente como un instrumento analítico formado por un componente bioespecífico inmovilizado y en íntimo contacto con un dispositivo de transducción, que convierte la interacción del elemento biológico en una señal cuantificable. El esquema básico de un biosensor esta representado en la Figura 1.5 .

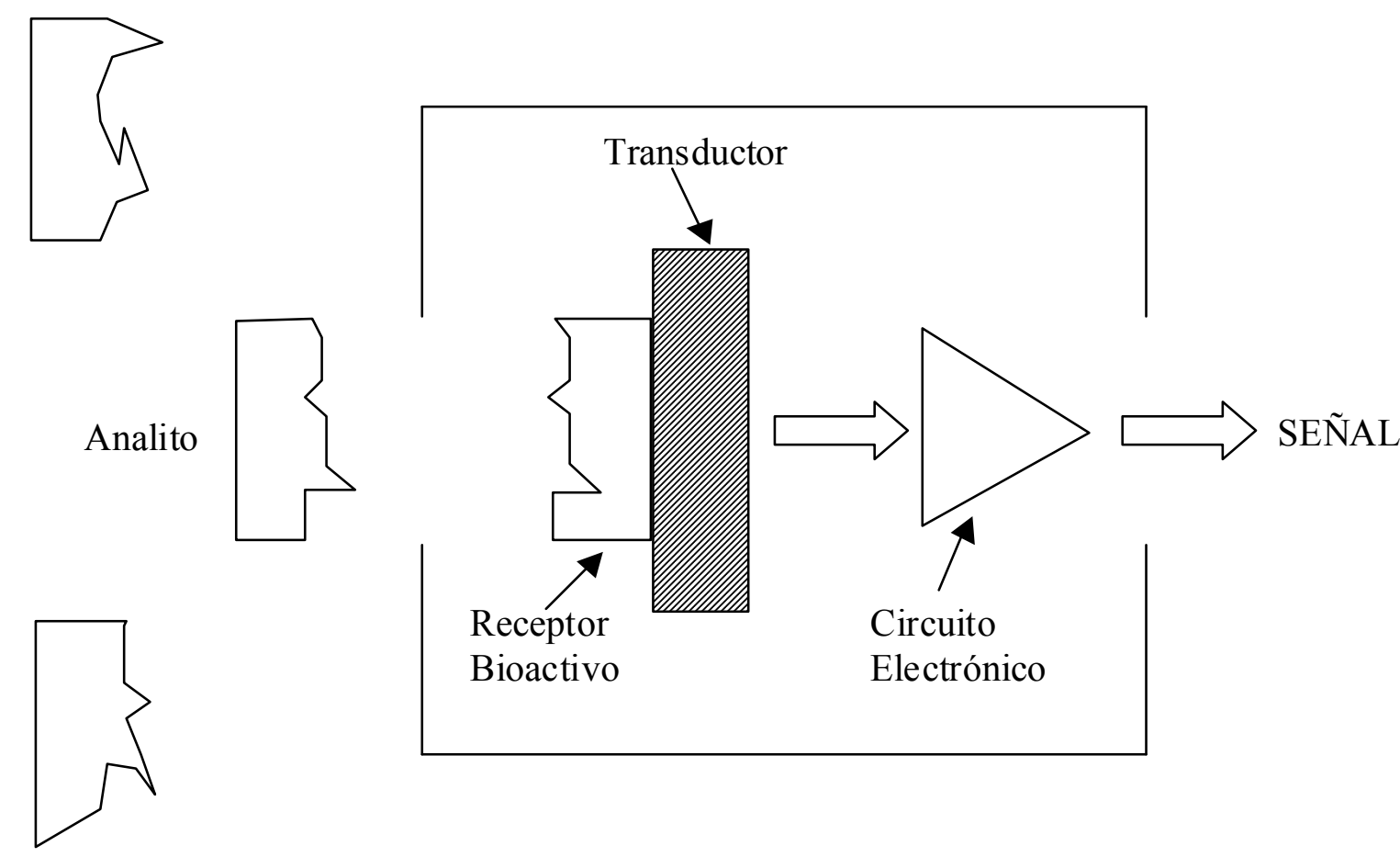

Interferente

Figura 1.5 Esquema genérico de un biosensor

Un caso particular lo constituyen los inmunosensores, donde la medida directa de la interacción inmunoquímica permite el diseño de sistemas analíticos sin la necesidad de reactivos adicionales, excepto el inmunorreactivo inmovilizado. Estos sistemas son dispositivos analíticos que utilizan la interacción Ag-Ab para medir de un modo rápido, selectivo y automático, la concentración de problema a niveles muy bajos. Básicamente, están compuestos por una superficie bioactiva (anticuerpo inmovilizado) en íntimo contacto con un sistema transductor capaz de transformar el efecto de la 
interacción inmunoquímica en una señal cuantificable (128). En la Figura 1.6 se muestra el esquema genérico de un inmunosensor. Existen varias clasificaciones de inmunosensores en función del criterio escogido. Así, se pueden clasificar (39) en: (a) inmunosensores directos, cuando no se requieren especies auxiliares para evaluar la extensión de la reacción inmunoquímica y (b) inmunosensores indirectos, cuando se utiliza un sistema de marcaje capaz de proporcionar una señal relacionada con la concentración de analito.

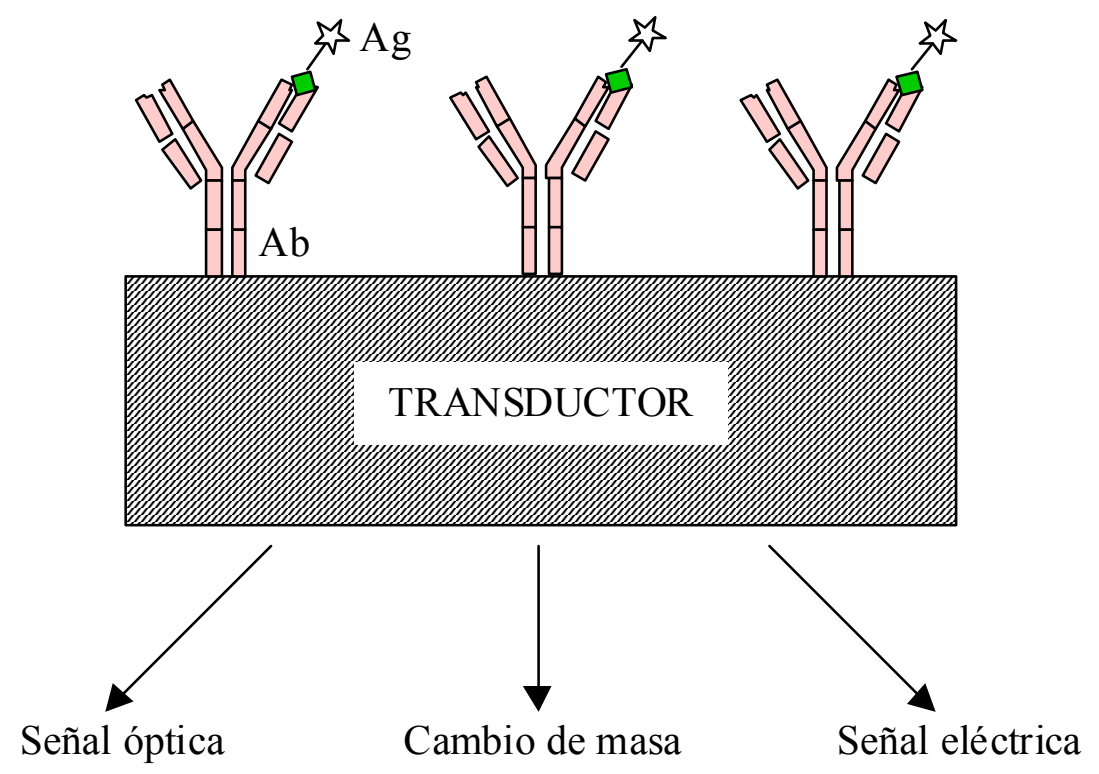

Figura 1.6 Esquema básico de un inmunosensor

Otra clasificación es la realizada según la disposición espacial entre la superficie inmunoactiva y el analito objeto de estudio. En los inmunosensores hidroestáticos, el elemento inmunoactivo es portátil y se pone en contacto con la disolución a medir por simple inmersión en la muestra problema. En los inmunosensores hidrodinámicos la superficie bioactiva es fija y un sistema de distribución de fluidos permite poner en contacto la muestra problema con dicho elemento bioactivo.

Por otro lado, los inmunosensores se pueden clasificar en función del sistema transductor utilizado, en ópticos, electroquímicos, piezoeléctricos, magnéticos, termoeléctricos, másicos o gravimétricos, radiactivos, etc. En la Tabla 1.10 se enumeran los sistemas básicos empleados en función del tipo de señal manejada. 


\section{Tabla 1.10. Clasificación de inmunosensores en función del transductor}

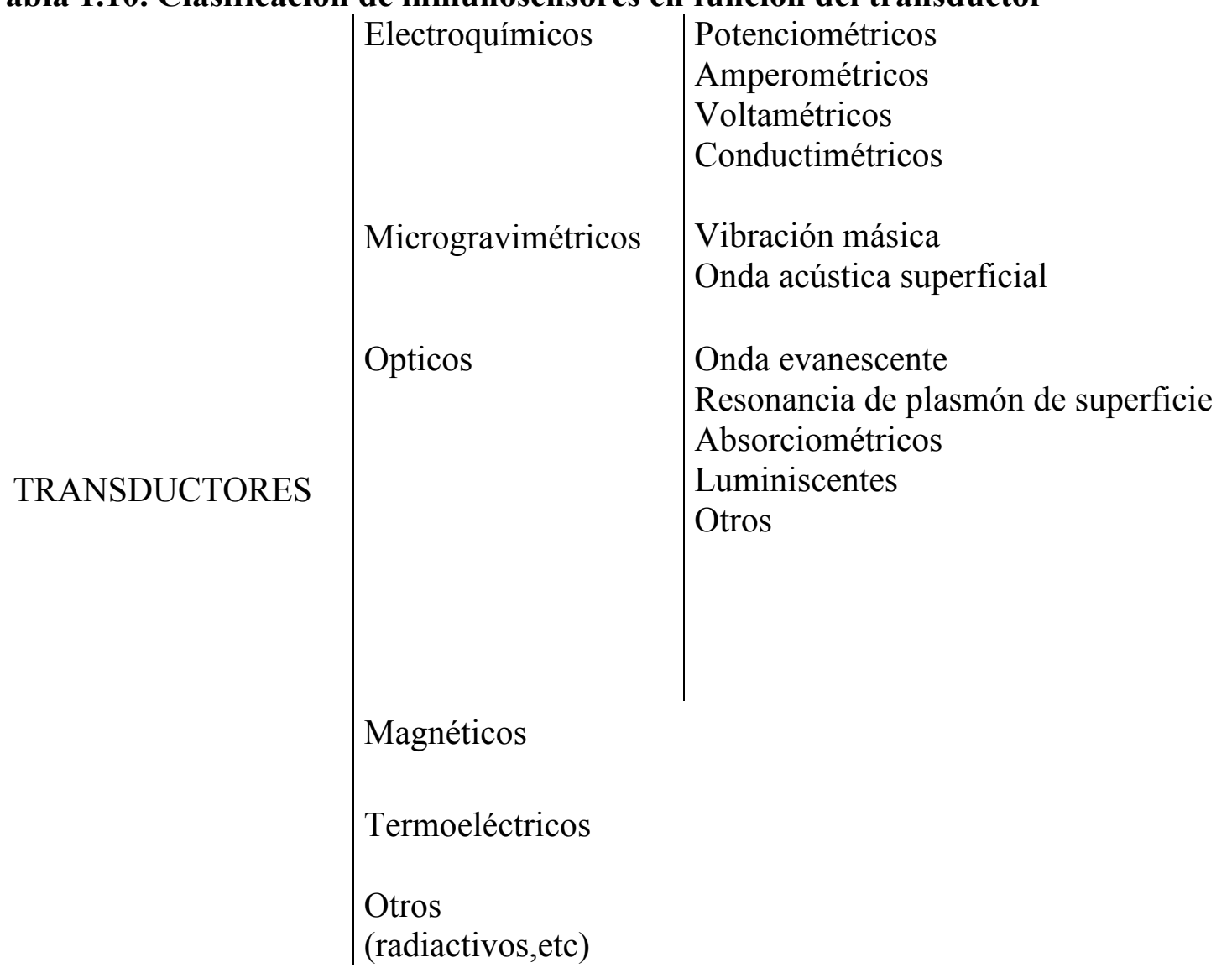

La detección mediante sensores electroquímicos suele ser barata y además existe la posibilidad de acoplar sistemas químicos de amplificación para mejorar los límites de detección. Un verdadero inmunoelectrodo es capaz de detectar directamente una inmunoreacción, por ejemplo mediante cambios de potencial de superficie. Sin embargo, este modo de operar no permite alcanzar buena sensibilidad, por lo que -en general- los inmunoensayos electroquímicos emplean marcaje enzimático. Dentro de este modo de detección, los más frecuentes son los poténciométricos, amperométricos, capacitivos y conductimétricos (129-132).

Los sistemas piezoeléctricos están basados en materiales, usualmente cristales de cuarzo, que pueden entrar en resonancia mediante la aplicación externa de un campo eléctrico alterno. La frecuencia de la oscilación resultante está determinada por la masa del cristal. Varios autores han revisado estos principios $(133,134)$. Los inmunosensores piezoeléctricos pueden ser empleados para la detección directa de interacciones $\mathrm{Ab}-\mathrm{Ag}$ y se pueden dividir en dos tipos: vibración másica e inmunosensores de onda acústica superficial (134-136). Este tipo de sensores que teóricamente deberían dar resultados satisfactorios, en la práctica no muestran suficiente precisión y son poco utilizados. 
Los sensores ópticos están basados en la medida de la absorción o emisión a una longitud de onda que depende de los inmunorreactivos utilizados. Estos sistemas tienen la ventaja de poder utilizar fibra óptica. En estos materiales la luz se transmite por reflexión total interna, de modo que interacciona con el analito en la zona activa, obteniéndose una señal que se corresponde con la concentración del mismo. Como mecanismos de transducción pueden ser utilizados los cambios de absorbancia, luminiscencia, polarización o índice de refracción. Las principales ventajas de estos sistemas radican en la posibilidad de realizar análisis remotos, ya que la luz transmitida es bidireccional, las reacciones para derivatizar los materiales están muy establecidas y además, son bastante económicos. Estos sistemas suelen estar basados en formatos de ensayo competitivos y sandwich.

Los inmunosensores ópticos fueron declarados en 1995 por la Comisión V-4 (división Quimico-Analítica) de la IUPAC como "un tema nuevo de interés", indicando que estos inmunosensores "combinan la exquisita selectividad del reconocimiento molecular de los Abs y la excepcional sensibilidad de la detección espectroquímica" para "aplicaciones medioambientales".

Un tipo de sensores ópticos muy interesantes son los de onda evanescente (137), con dos variantes reflexión total atenuada y reflexión de fluorescencia total interna $(138,139)$ y los inmunosensores de resonancia de plasmón de superficie $(140)$.

En estos dispositivos los cambios fisico-químicos producidos como resultado de la interacción inmunoquímica son a menudo insuficientes para alcanzar los límites de detección deseados -comparables a los protocolos convencionales de inmunoensayo-, por lo que se suelen acoplar sistemas indirectos de detección con el fin de amplificar estos cambios.

Finalmente, y a modo de resumen, en la Tabla 1.11 se comparan los sistemas de transducción más empleados en los sensores y se valoran sus principales características (Tabla 1.12). 
Tabla 1.11. Comparación de los sistemas de transducción

\begin{tabular}{|c|c|c|}
\hline Transductor & Ventajas & Desventajas \\
\hline Electrodos potenciométricos & $\begin{array}{l}\text { Simples } \\
\text { Sensibles } \\
\text { Adecuado para muestras turbias }\end{array}$ & $\begin{array}{l}\text { Las lecturas de potencial } \\
\text { dependen de factores no } \\
\text { relacionados con la concentración } \\
\text { de analito (tampón, pH y fuerza } \\
\text { iónica) } \\
\text { Requiere el uso de marcadores }\end{array}$ \\
\hline Electrodos selectivos & $\begin{array}{l}\text { Simples } \\
\text { Fiables }\end{array}$ & $\begin{array}{l}\text { Respuesta lenta } \\
\text { Necesidad de un electrodo de } \\
\text { referencia estable } \\
\text { Susceptibles al ruido electrónico } \\
\text { y no suficientemente cuantitativos }\end{array}$ \\
\hline Amperométrico & $\begin{array}{l}\text { Sensibles } \\
\text { Respuesta rápida } \\
\text { Amplio rango dinámico }\end{array}$ & $\begin{array}{l}\text { La detección indirecta requiere el } \\
\text { uso de marcadores } \\
\text { Poco selectivos }\end{array}$ \\
\hline $\begin{array}{l}\text { Fibra óptica/detector } \\
\text { absorcimétrico o luminométrico }\end{array}$ & $\begin{array}{l}\text { Posibilidad de detección remota } \\
\text { Libres de interferencias eléctricas }\end{array}$ & $\begin{array}{l}\text { Posible interferencia de la luz } \\
\text { ambiental } \\
\text { Baja sensibilidad } \\
\text { Requiere una fuente de alta } \\
\text { energía } \\
\text { La detección directa no es muy } \\
\text { utilizada }\end{array}$ \\
\hline Onda evanescente & Libres de interferencias eléctricas & $\begin{array}{l}\text { Baja sensibilidad, absorción y } \\
\text { configuración lo limitan a pocos } \\
\text { analitos } \\
\text { Sometidos a alta unión } \\
\text { inespecífica }\end{array}$ \\
\hline $\begin{array}{l}\text { Resonancia de plasmón de } \\
\text { superficie (SPR) }\end{array}$ & $\begin{array}{l}\text { Detección directa } \\
\text { Adecuado para medidas con } \\
\text { sensores de grosor da hasta } 20 \AA\end{array}$ & $\begin{array}{l}\text { Afectados por la constante } \\
\text { dieléctrica del medio } \\
\text { Dificil de aplicar para haptenos }\end{array}$ \\
\hline Acústico & $\begin{array}{l}\text { Repuesta rápida } \\
\text { Simples } \\
\text { Estabilidad de la señal } \\
\text { Bajo coste } \\
\text { No es necesario un manejo } \\
\text { especial de muestra }\end{array}$ & $\begin{array}{l}\text { Baja sensibilidad al aplicarlo en } \\
\text { líquidos } \\
\text { Interferencias inespecíficas } \\
\text { Sensibles a cambios de } \\
\text { viscosidad en la interfase }\end{array}$ \\
\hline
\end{tabular}


Tabla 1.12. Principales sistemas de detección empleados en inmunosensores

\begin{tabular}{ccc}
\hline \multirow{2}{*}{ Esquema } & \multicolumn{2}{c}{ Propiedades } \\
\cline { 2 - 3 } & \multicolumn{2}{c}{ Formatos } \\
& Reusabilidad Selectividad Rapidez & Ensayo $\quad$ Coste \\
\hline
\end{tabular}
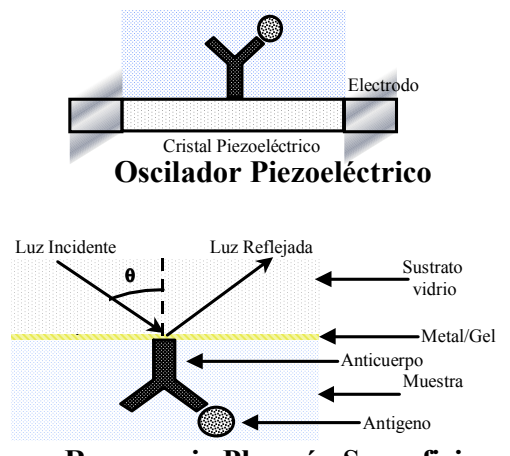

Resonancia Plasmón Superficie
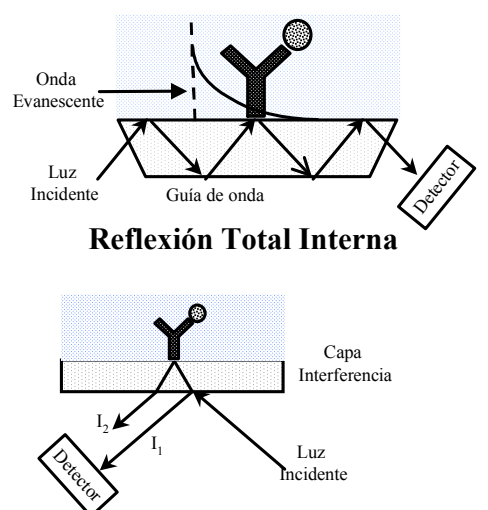

Espectroscopía Interferencia Reflectometrica

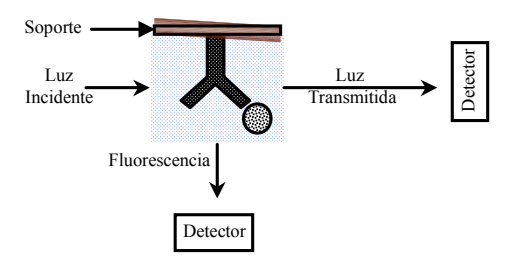

Fotometría y fluorimetría

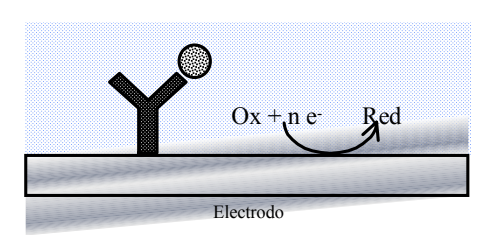

Electroquímica

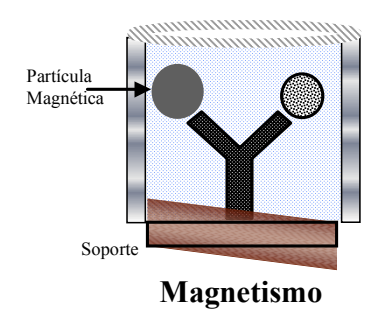




\subsubsection{Inmunosensores en flujo}

Los inmunosensores en flujo se enmarcan dentro del grupo de sensores hidrodinámicos, donde en general el sistema de detección está desplazado del lugar donde se produce la interacción Ab-Ag. El producto a detectar es impulsado hasta el detector con ayuda de un fluido.

Este grupo de sistemas está basado principalmente en la técnica de Análisis por Inyección en Flujo (FIA, Flow Injection Analysis), dando lugar al desarrollo de Inmunoensayos en flujo (FIIA, Flow Injection Immunoassay). Dichos ensayos surgen en 1980 a partir del trabajo publicado por Lim y Miller (141).

Los inmunoensayos por inyección en flujo permiten el análisis automático de un gran número de muestras y/o medidas continuas. Este método ha demostrado ser muy eficaz en una amplia variedad de problemas analíticos. Las ventajas de la especificidad inherente de las reacciones inmunoquímicas han sido incorporadas a las técnicas en flujo, mostrándose como un poderoso instrumento para el desarrollo de protocolos analíticos, mejorando la velocidad y calidad del inmunoensayo convencional. Este tipo de sistemas de análisis tienen una sensibilidad y selectividad similares a las de otros inmunoensayos, pero presentan la ventaja de una mayor rapidez de respuesta, precisión en las medidas y una completa automatización del procedimiento analítico (142), facilitando su incorporación en línea. Este último aspecto confiere a los biosensores una gran ventaja frente a los sistemas discontinuos.

Otra modalidad de operación la constituye la Inyección Secuencial (143) (SIA, Sequential Inyection Analysis), cada vez más utilizada, donde los reactivos se ponen en contacto con el inmunosoporte de una forma secuencial ordenada, sin existir una corriente portadora continua.

Este campo es un área activa de investigación que ha permitido desarrollar diferentes inmunosensores en flujo $(144,145)$, lo que ha supuesto un avance espectacular -especialmente en el campo medioambiental- en los últimos años (146).

Estos sistemas generalmente están basados en protocolos de inmunoensayo heterogéneo con formato competitivo directo, por lo que los procesos básicos suelen coincidir en mayor o menor medida con el desarrollo de un ensayo ELISA (147). Así es usual utilizar marcadores enzimáticos (148). Otros formatos, como el competitivo indirecto, donde es el antígeno la especie inmovilizada, son menos usuales (149).

En el desarrollo de un inmunosensor en flujo basado en formato competitivo, se deben considerar las siguientes etapas: a) inmovilización de la especie activa sobre un 
material inerte e insoluble (soporte), b) preparación e inyección de la disolución de muestra y de las especies capaces de reaccionar con la especie inmovilizada, c) lavado de las sustancias no adsorbidas selectivamente sobre el soporte, d) medida de la actividad del marcador, indicativa de la extensión de la inmunorreacción y e) regeneración o sustitución parcial o total del inmunosoporte, para que pueda ser utilizado en sucesivos análisis.

En lo expuesto anteriormente quedan implícitos los problemas que tendrán que abordarse en el desarrollo de los inmunosensores en flujo. Es necesario conocer los soportes potencialmente útiles de inmovilización de inmunorreactivos, los procedimientos de inmovilización y las condiciones de regeneración del inmunosoporte, entre otros.

\subsubsection{Soportes de inmovilización de inmunorreactivos}

A la hora de desarrollar los inmunosensores heterogéneos en flujo, el principal aspecto a tener en cuenta es la separación de los inmunorreactivos libres de los inmunocomplejos formados. Para tal fin, una de las especies debe estar inmovilizada en un soporte sólido. Generalmente, las propiedades requeridas en dichas fases sólidas son: (i) alta capacidad de inmovilización de inmunorreactivos (alta relación superficie/volumen), (ii) posibilidad de inmovilización de diferentes tipos de inmunorreactivos, (iii) mínima disociación, (iv) desnaturalización despreciable de la especie inmovilizada, y (v) posibilidad de inmovilización orientada.

En el caso concreto de trabajar con medios orgánicos, la compatibilidad del soporte y de cualquier reactivo o material utilizado es también una característica indispensable. Así pues, en el desarrollo de sistemas en medios orgánicos, será necesario realizar -entre otros aspectos- una evaluación exhaustiva de los materiales a utilizar como inmunosoportes

Los soportes particulados son los mas ampliamente empleados en el desarrollo de inmunosensores. De ellos destacan los soportes silíceos, ya que permiten varios modos de inmovilización de antígenos o anticuerpos, bien químicamente o por simple adsorción. Además, estos soportes son muy estables mecánicamente, compatibles con la mayoría de los sistemas de detección empleados y resistentes a los disolventes orgánicos. Otro gran grupo lo constituyen los geles. Estas sustancias derivadas principalmente de la agarosa, son ampliamente utilizadas en diversas aplicaciones 
debido a la posibilidad de su funcionalización, lo que permite la inmovilización covalente y orientada de los inmunorreactivos.

Otro grupo de soportes de inmovilización lo forman las membranas, generalmente derivatizadas para la inmovilización de los inmunorreactivos (preferentemente anticuerpos). En sistemas en flujo, estos soportes se utilizan para la preparación de reactores de membrana, con la ventaja inherente de la ausencia de compactación del soporte -como ocurre en los reactores de lecho empaquetado-, si bien estos sistemas han sido poco aplicados y sin demasiado éxito (148).

\subsubsection{Modos de inmovilización}

El modo de inmovilización es una variable de considerable importancia, puesto que puede influir en las prestaciones analíticas del inmunosensor, es decir en la sensibilidad y especificidad (150). En muchas ocasiones, el proceso de inmovilización redunda en un incremento de la estabilidad de la molécula, como se mencionó anteriormente para el caso de enzimas. En este sentido, existen una serie de factores relacionados directamente con el modo de inmovilización, que afectan en particular al buen funcionamiento del inmunosensor. De ellos cabe destacar: (i) estabilidad del inmunosoporte -en moléculas bioactivas la inmovilización produce una estabilización; (ii) orientación de la biomolécula- en el caso de anticuerpos la inmovilización orientada facilita la interacción Ab-Ag de modo que la actividad y la sensibilidad aumenta; (iii) actividad del inmunosoporte -relacionado con la regeneración de la superficie activa; (iv) reacciones inespecíficas- inmovilizar una especie $\mathrm{u}$ otra puede influir en la magnitud de las señales inespecíficas, ya que las especies auxiliares utilizadas en la detección de la interacción son distintas; (v) rapidez del ensayo -la duración del ensayo está condicionada por el formato de ensayo, que depende a su vez de la especie inmovilizada; (vi) viabilidad de inmovilización- dependiente de los grupos funcionales presentes, tanto en la especie a inmovilizar como en el soporte.

En la práctica, todos estos factores -esenciales para un correcto desarrollo de inmunosensores- han sido poco estudiados, por lo que la información sobre estos aspectos que garantice resultados inmediatos es escasa. En definitiva, son muchas las variables y aspectos a tener en cuenta antes de decidir el formato de ensayo a utilizar (anticuerpo o antígeno inmovilizado). En la Tabla 1.13, se muestran los modos de inmovilización más empleados. 
Tabla 1.13. Modos de inmovilización de anticuerpos y haptenos

\begin{tabular}{|c|c|c|c|c|}
\hline & & Indirecta & Proteínas de $\mathrm{c}$ & ura, IgGs, lectinas \\
\hline & Anticuerpo & Directa & No-covalente & $\begin{array}{l}\text { Adsorción: } \\
\text { membranas } \\
\text { Encapsulamiento: } \\
\text { soportes Sol-Gel }\end{array}$ \\
\hline $\begin{array}{l}\text { Modos de } \\
\text { Inmovilización }\end{array}$ & & & Covalente & $\begin{array}{l}\text { Activación } \\
\text { química del } \\
\text { soporte }\end{array}$ \\
\hline & & Indirecta & & $\begin{array}{l}\text { Vía conjugado } \\
\text { proteico }\end{array}$ \\
\hline & & Directa co & ente & $\begin{array}{l}\text { Enzimáticamente } \\
\text { Fotoquímicamente }\end{array}$ \\
\hline
\end{tabular}

\subsubsection{Reversibilidad y reusabilidad}

Los inmunosensores deben ser capaces de detectar el analito de forma continua, reversible y selectiva. De dichos términos cabe destacar el término reversibilidad, lo que supone revertir la unión inmunoquímica, proceso posible gracias a la naturaleza no covalente de los enlaces entre los anticuerpos y antígenos (151). La regeneración de los inmunosoportes es una opción descartable para algunos autores (152), debido a que este proceso supone exponer al inmunocomplejo a condiciones de desnaturalización proteica, con la consiguiente posibilidad de pérdida de actividad del reactivo inmovilizado. Sin embargo, en la mayoría de los casos se reutilizan los inmunosoportes mas de una vez, llegando incluso en casos excepcionales hasta varios cientos de veces (153). Hay que señalar que, en todos los casos, el inmunosoporte posee una vida útil limitada debido a la desnaturalización del reactivo inmovilizado o a la pérdida de las propiedades del soporte.

El agente desorbente escogido para regenerar un inmunosoporte debe romper la interacción $\mathrm{Ab}-\mathrm{Ag}$, manteniendo mas o menos intacta la actividad del inmunorreactivo inmovilizado. Las sustancias empleadas para ello son disoluciones de alta concentración salina o pH ácido y disolventes orgánicos $(154,155)$. Así, por ejemplo, en los sistemas basados en anticuerpo inmovilizado (formato competitivo directo), la vida útil del inmunosoporte dependerá de la afinidad del anticuerpo por su antígeno. Por ello, si los anticuerpos son de muy alta afinidad, la reversión de la interacción inmunoquímica será 
extremadamente difícil (35), lo que supondrá un sistema de un solo uso y los inmunosensores resultantes serán poco prácticos. Por el contrario, anticuerpos de baja afinidad darán sistemas altamente reusables, pero de baja sensibilidad frente al analito para el que se diseñó. Así pues, es necesario establecer un compromiso entre sensibilidad y reusabilidad (156). En general, la elección de un agente desorbente adecuado es un factor clave ya que debe producir una desorción efectiva minimizando su influencia.

\subsection{PRODUCTOS FITOSANITARIOS OBJETO DE ESTUDIO}

Para el presente estudio se han escogido como sistemas modelo una serie de productos fitosanitarios de gran interés, con el fin de desarrollar inmunosensores en medios orgánicos y estudiar su aplicación a la determinación de otros tipos de compuestos.

\subsubsection{Carbaril}

El carbaril, utilizado en este estudio como analito modelo, es el principal insecticida de la familia de los N-metilcarbamatos. Comercialmente se denomina $\mathrm{SEVIN}^{\circledR}$ y su aplicación data de 1957 , cuando se dio a conocer como un producto de gran actividad insecticida y amplio espectro de acción. La estructura molecular se muestra en la Figura 1.7.

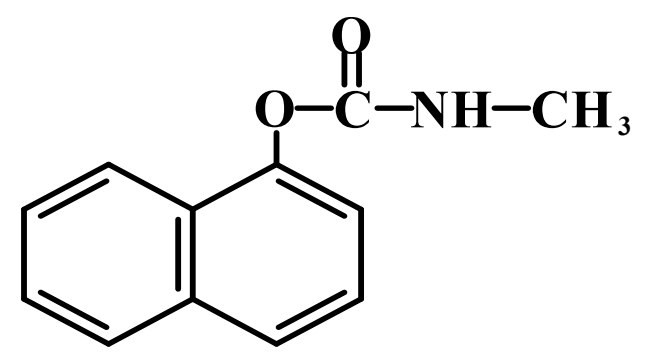

Figura 1.7. Estructura de Carbaril

Su poder insecticida radica en la inhibición de la actividad de la colinesterasa debido a que este compuesto posee una estructura molecular y una distribución de polaridades análogas a las de la acetilcolina. Este hecho provoca una inhibición competitiva, fijándose reversiblemente a la enzima y ocupando el sitio de la acetilcolina, debido a que la carbamilación da compuestos más estables que la fosforilación. En 
general, los insecticidas carbamatos tienen una estructura semejante a la fisostigmina, potente inhibidor de la colinesterasa. Estos compuestos presentan propiedades colinérgicas y son antagónicos de la atropina.

El grado de toxicidad de los carbamatos depende, en gran parte, de su carácter mas o menos iónico o covalente, pues los compuestos iónicos o muy polares atraviesan con dificultad la cubierta nerviosa. En cambio, los compuestos no iónicos, como el carbaril, tienen un marcado poder insecticida.

El carbaril es un sólido blanco, poco soluble en agua y soluble en disolventes orgánicos (ver Tabla 1.1). Es estable en las condiciones de almacenaje, resiste el calor y la luz. Sólo en medio básico se hidroliza a 1-naftol, su principal metabolito.

$\mathrm{Su}$ toxicidad es pequeña, teniendo una $\mathrm{DL}_{50}$ aguda oral para ratas de $560 \mathrm{mg} / \mathrm{Kg}$. En el hombre, el carbaril se hidroliza a 1-naftol, el cual se elimina por la orina en forma de glucósido con el ácido glucurónico.

Los N-metilcarbamatos son analizados habitualmente mediante técnicas cromatográficas incluyendo HPLC, GC, cromatografía de fluidos supercríticos (SFC), cromatografía en capa fina (TLC) y electroforesis capilar. En particular, el carbaril es analizado mediante HPLC con hidrólisis y derivatización postcolumna, y detección fluorescente. La reacción postcolumna inicialmente aplicada por Moye y col. (157), se basa en la hidrólisis de los $\mathrm{N}$-metilcarbamatos con $\mathrm{NaOH}$ para formar metilamina, que se derivatiza con o-phtaldehido en presencia de 2-mercaptoetanol. Existen algunas modificaciones a este procedimiento como la descrita por Simon y col. (158). En este caso se realiza una derivatización postcolumna en una única etapa, utilizando un reactivo formado por $\mathrm{NaOH}$, o-phtaldehido y N,N-dimetil-2-mercaptoetilendiamina hidrocloruro (thiofluor). Esta metodología constituye el método oficial de análisis de rutina de los $\mathrm{N}$-metilcarbamatos (método EPA 531.1).

Existen además otros métodos no cromatográficos, como los espectrofotométricos $(159,160)$, espectrofluorimétricos (161), espectroscopia infrarroja (162) y enzimáticos basados en la inhibición de la acetilcolinesterasa $(163,164)$.

Se han descrito también métodos basados en la técnica ELISA e inmunosensores en flujo para la determinación de carbaril, utilizando tanto anticuerpos policlonales $(46,165)$ como monoclonales (166-169). Todos estos formatos de ensayo se caracterizan por su alta sensibilidad $\left(\mathrm{I}_{50}<0,1 \mu \mathrm{g} / \mathrm{l}\right)$ y baja reactividad cruzada con otros productos fitosanitarios de la misma familia. Estos métodos se han utilizado para el análisis de carbaril en distintas matrices como aguas, suelos, miel y alimentos. Abad y col. (168) 
estudiaron la influencia de los medios orgánicos en las prestaciones de los sistemas ELISA para carbaril. En todos los casos estudiados, solo fueron tolerados los disolventes miscibles en agua a bajos porcentajes $(<10 \%)$.

\subsubsection{1-Naftol}

El 1-naftol es el principal metabolito del carbaril. Es un sólido que cristaliza en prismas, sublimable y volátil bajo corriente de vapor. Se oscurece por acción de la luz. Es ligeramente soluble en agua y totalmente soluble en alcohol, benceno, cloroformo y disoluciones básicas. La estructura molecular se muestra en la Figura 1.8.

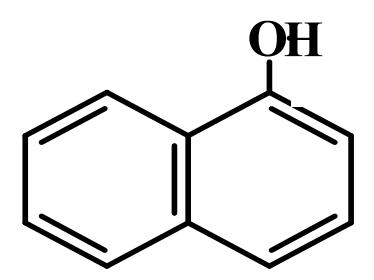

Figura 1.8. Estructura de 1-Naftol

La ingestión de gran cantidad en humanos puede causar nefritis, opacidad ocular, vómitos, diarreas, dolores abdominales, colapso circulatorio, convulsiones, anemia hemolítica y la muerte. Por otro lado, existen evidencias (170) que demuestran que su conjunción con el carbaril muestra alta toxicidad frente a algas verdes $\mathrm{y}$ cianobacterias.

Los métodos de análisis de 1-naftol están basados en HPLC, GC, métodos espectrofotométricos y espectrofluorimétricos (171-173).

Al igual que su precursor, el 1-naftol también ha sido analizado mediante la técnica ELISA utilizando anticuerpos policlonales $(165,174)$. Este ensayo mostró una sensibilidad $\left(\mathrm{I}_{50} \cong 60 \mu \mathrm{g} / \mathrm{l}\right)$, relativamente pobre si se compara con la de otros anticuerpos, y baja reactividad cruzada con el carbaril (RC, 0,5\%), aplicándose a la determinación selectiva de 1-naftol en orina y extractos de suelo.

Respecto a la aplicación de medios orgánicos, se ha desarrollado un ELISA selectivo para 1-naftol (165) que toleró al menos un 10\% de acetona, acetonitrilo y metanol. 


\subsubsection{Irgarol 1051}

El Irgarol 1051 (2-metiltio-4-tert-butilamino-6-ciclopropilamino-s-triazina) es un alguicida perteneciente a la familia de las triazinas (Figura 1.9) usado como ingrediente en pinturas marinas para evitar el crecimiento de algas, generalmente aplicado con compuestos de cobre. Este producto viene sustituyendo a otros compuestos, especialmente organoestannicos, que presentan efectos perniciosos sobre diferentes organismos (175), estando estrictamente regulado y en ocasiones prohibido por la legislación europea (176).

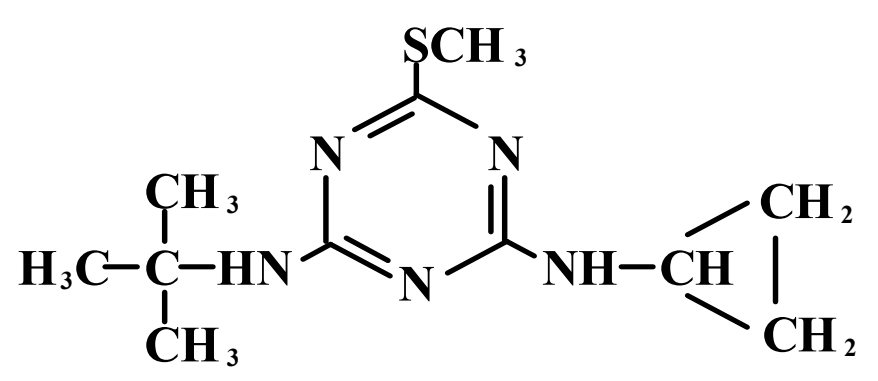

Figura 1.9. Estructura de Irgarol 1051

La actividad biológica del Irgarol 1051 se manifiesta por la inhibición del transporte electrónico en la fotosíntesis en los cloroplastos (177). Debido a su efecto específico muestra baja toxicidad frente a animales, pero ha demostrado ser muy tóxico frente a todas las microalgas (178).

La solubilidad del Irgarol 1051 en agua es muy baja $(7 \mathrm{mg} / \mathrm{l})$, pero es bastante soluble en disolventes orgánicos como metanol (18 g/l) y cloroformo (52 g/l) (179).

El análisis de Irgarol 1051 se realiza normalmente por GC con detector selectivo N-P (180) o detector de masas (181). También se ha aplicado la cromatografía líquida con detección UV/V y espectrometría de masas (182). Dada su alta persistencia ha sido detectado en aguas marinas, tales como las costas del sur del Reino Unido (180), Costa Azul francesa $(183,184)$ y en la costa oeste de Suecia (182). Además, ha sido encontrado en el Lago Ginebra (Suiza) (185) y en la Albufera de Valencia $(186,187)$.

Por otro lado, han sido desarrollados ensayos tipo ELISA $(188,189)$ altamente sensibles -límite de detección de 0,02 $\mu \mathrm{g} / \mathrm{l}$ - que han demostrado ser muy eficaces en el análisis de esta sustancia en agua marina. No se han encontrado referencias bibliográficas sobre el comportamiento de los sistemas inmunoquímicos frente a este analito en medios orgánicos. 


\subsection{OBJETIVOS}

El objetivo general es desarrollar inmunoensayos para productos fitosanitarios en medios orgánicos compatibles con los métodos oficiales de tratamiento de muestra. Los objetivos particulares son los siguientes:

- Estudiar la compatibilidad de las inmunointeracciones con distintos medios orgánicos.

- Seleccionar disolventes y mezclas útiles para el desarrollo de inmunosensores en flujo.

- Estudiar la posibilidad de desarrollar inmunosensores capaces de trabajar en estos medios.

- Desarrollar protocolos de inmunoensayo para el análisis de productos fitosanitarios en distintas matrices (aguas, muestras vegetales).

- Estudiar alternativas al marcaje enzimático.

- Estudiar los efectos que sobre la sensibilidad y selectividad de los ensayos tienen los medios orgánicos de trabajo.

- Obtener conocimientos sobre las propiedades de regeneración de los sistemas en medios orgánicos.

- Establecer una serie de reglas básicas para el desarrollo de este tipo de sistemas en medios orgánicos. Determinar cual es el soporte, marcaje, sistema de detección, etc., óptimos.

- Conocer el comportamiento de los sistemas inmunoquímicos frente a los disolventes o sus mezclas y poder relacionar las prestaciones con sus características.

La consecución con éxito de todos estos objetivos supondría las siguientes ventajas:

- Aportar datos y metodología para un mejor conocimiento de la Inmunoquímica.

- Ampliar las aplicaciones de los métodos inmunoquímicos en el campo del análisis de residuos de plaguicidas.

- Determinar residuos de productos fitosanitarios extraídos según los métodos oficiales de análisis.

- Aumentar la sensibilidad debido a la posibilidad de conseguir altos factores de preconcentración.

- Facilitar la manipulación de los medios orgánicos, haciéndola más segura. 
- Analizar compuestos inestables o de baja solubilidad en agua.

- Ampliar el campo de aplicación de las técnicas inmunoanalíticas. 


\section{Materiales Y métodos}

\subsection{REACTIVOS}

Todos los plaguicidas puros utilizados en la realización de esta tesis doctoral fueron adquiridos a las siguientes firmas comerciales: Dr. Ehrenstorfer (Augsburg, Alemania), DowElanco (Midland, MI), Riedel de Häen (Seelze-Hannover, Alemania) y Ciba- Geigy (Barcelona). Las disoluciones stock de estos compuestos fueron preparadas a concentraciones entre $10-20 \mathrm{mg} / \mathrm{ml}$ en $N, N^{\prime}$ dimetilformamida, excepto carbaril que fue preparado en metanol a $100 \mathrm{mg} / \mathrm{l}$.

Los reactivos Tween 20, ácido 3-(p-hidroxifenil)-propanoico (HPPA), ofenilendiamina (OPD), dietanolamina, Trizma ${ }^{\circledR}$ base, ovoalbúmina (OVA), seroalbúmina bovina (BSA, fracción V) y 1,5 pentanodiamina (cadaverina) fueron suministrados por Sigma Chemical Co. (St. Louis, MO).

Así mismo, los disolventes empleados (metanol, acetonitrilo, acetato de etilo, hexano, isopropanol, acetona, cloroformo, diclorometano, tetrahidrofurano $\mathrm{y}$ $N, N^{\prime}$ dimetilformamida) fueron adquiridos a las firmas comerciales Panreac (Barcelona), Scharlau (Barcelona) y Prolabo (Barcelona), en diferentes calidades (pureza para análisis, calidad HPLC o para análisis de residuos).

Por otro lado se emplearon las siguientes disoluciones tampón:

- Fosfato 0,01M, $\mathrm{NaCl}$ 0,137 M, $\mathrm{KCl}$ 0,027 M, pH 7,4 (PBS)

- $\mathrm{PBS}+0,05 \% \mathrm{v} / \mathrm{v}$ Tween $20(\mathrm{PBST})$

- Tampón fosfato sódico 0,02 M, pH 8,0 (PB)

- $\mathrm{PB}+$ Tween 20 (generalmente con $0,05 \% \mathrm{v} / \mathrm{v})(\mathrm{PBT})$

- Tampón acetato sódico 0,05 M, pH 5,5

- Tampón Trizma base 0,05 M, NaCl 0,138 M, KCl 0,027 M, pH 8,0 (TBS)

- $\mathrm{TBS}+0,05 \% \mathrm{v} / \mathrm{v}$ de Tween 20 (TBST)

- Tampón dietanolamina $10 \%, \mathrm{MgCl}_{2} 0,01 \%, \mathrm{pH} 9,8$ (TS) 
Las enzimas peroxidasa del rábano picante (HRP) y fosfatasa alcalina (AP) fueron suministradas por Boehringer (Mannheim, Alemania) y Sigma Chemical Co. (St. Louis, MO), respectivamente.

Para los sistemas quimioluminiscentes se utilizó el reactivo comercial CDP-Star y las sustancias potenciadores luminiscentes Emerald, Emerald II, Sapphire y Sapphire II (Tropix, PE Applied Biosystems, MA).

\subsection{INMUNORREACTIVOS}

En el desarrollo de inmunosensores para los distintos productos fitosanitarios estudiados, se utilizaron los siguientes inmunorreactivos:

\section{SISTEMA CARBARIL}

Se emplearon anticuerpos monoclonales y policlonales. Respecto a los anticuerpos monoclonales, se utilizó un conjunto de 8 anticuerpos -denominados CNA 36, CNH 36, CNH 45, CNH 32, CNH 37, CNH 89, CNH 101 y CNH 103-producidos y cedidos por el Laboratorio Integrado de Bioingeniería de la Universidad Politécnica de Valencia.

Estos anticuerpos fueron obtenidos a partir de la inmunización de ratones con los haptenos CNH (ácido 6-[[(1-naftiloxi)carbonil]amino] hexanoico) y CNA (ácido 3-[[1naftiloxi)carbonil]amino] propanoico). Para la preparación de trazadores enzimáticos se utilizó además el hapteno CPNU (1-(5-carboxipentil)-3-((1-naftil) urea). La estructura de los tres haptenos se muestra en la Figura 2.1. Este sistema inmunoanalítico ha sido previamente descrito y caracterizado mediante ELISA $(166,168)$.

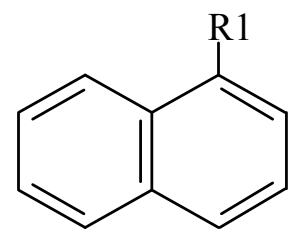

\begin{tabular}{c|c}
\hline Hapteno & $R l$ \\
\hline $\mathrm{CNA}$ & $-\mathrm{O}-\mathrm{CO}-\mathrm{NH}-\left(\mathrm{CH}_{2}\right)_{2}-\mathrm{COOH}$ \\
$\mathrm{CPNU}$ & $-\mathrm{HN}-\mathrm{CO}-\mathrm{NH}-\left(\mathrm{CH}_{2}\right)_{5}-\mathrm{COOH}$ \\
$\mathrm{CNH}$ & $-\mathrm{O}-\mathrm{CO}-\mathrm{NH}-\left(\mathrm{CH}_{2}\right)_{5}-\mathrm{COOH}$ \\
\hline
\end{tabular}

Figura 2.1. Estructura de los haptenos para carbaril. Anticuerpos Monoclonales

Así mismo se utilizó el anticuerpo policlonal R2114, obtenido mediante inmunización de conejos con el hapteno CPNU. Este anticuerpo, así como los inmunorreactivos utilizados fueron cedidos por el Profesor B.D. Hammock del 
Departamento de Entomología de la Universidad de California en Davis (EE.UU.). Para completar el estudio se emplearon también los haptenos H4 (ácido N-(1-naftoil)-6aminohexanoico) y H5 (ácido N-(2-naftoil)-6-aminohexanoico) cuyas estructuras se muestran en la Figura 2.2. La utilización de estos inmunorreactivos en los trabajos de caracterización mediante ELISA previamente descritos (46), dio lugar a los ensayos más sensibles.<smiles>[R2]c1ccc2ccccc2c1[R]</smiles>

\begin{tabular}{c|cc}
\hline Hapteno & $\mathrm{Rl}$ & $\mathrm{R} 2$ \\
\hline $\mathrm{H} 4$ & $-\mathrm{CO}-\mathrm{NH}-\left(\mathrm{CH}_{2}\right)_{5}-\mathrm{COOH}$ & $\mathrm{H}$ \\
$\mathrm{H} 5$ & $\mathrm{H}$ & $-\mathrm{CO}-\mathrm{NH}-\left(\mathrm{CH}_{2}\right)_{5}-\mathrm{COOH}$ \\
\hline
\end{tabular}

Figura 2.2. Estructura de los haptenos para carbaril. Anticuerpo Policlonal

\section{SISTEMA 1-NAFTOL}

Para este analito se utilizaron los anticuerpos policlonales 3898, 3905 y 3907 obtenidos mediante la inmunización de conejos con los haptenos sintéticos $2 \mathrm{~b}$ (ácido [(5-hidroxi-2-naftilenil)oxi] acético), 4N (ácido [(5-hidroxi-1-naftilenil) acético) y 7N (ácido 5-hidroxi-2-naftoico). Las estructuras de dichos haptenos se muestran en la Figura 2.3. Todos los inmunorreactivos fueron cedidos por el profesor Hammock, cuyo equipo de colaboradores realizó la caracterización del sistema inmunoanalítico (175).<smiles>[R2]c1ccc2c([R1])cccc2c1[R3]</smiles>

\begin{tabular}{l|ccc}
\hline Hapteno & $R 1$ & $R 2$ & $R 3$ \\
\hline $2 \mathrm{~b}$ & $-\mathrm{OH}$ & $-\mathrm{O}-\mathrm{CH}_{2}-\mathrm{COOH}$ & $-\mathrm{H}$ \\
$4 \mathrm{~N}$ & $-\mathrm{OH}$ & $-\mathrm{COOH}$ & $-\mathrm{H}$ \\
$7 \mathrm{~N}$ & $-\mathrm{OH}$ & $\mathrm{H}$ & $-\mathrm{O}-\mathrm{CH}_{2}-\mathrm{COOH}$ \\
\hline
\end{tabular}

Figura 2.3. Estructura de los haptenos utilizados en el sistema 1-naftol 
Se utilizaron anticuerpos policlonales (R15 y R16) obtenidos y caracterizados previamente mediante ELISA por Marco y col. (188-190). Todos los inmunorreactivos fueron cedidos por los Departamentos de Química Orgánica Biológica y Química Ambiental del Centro de Investigación y Desarrollo del Consejo Superior de Investigaciones Científicas (CID-CSIC) de Barcelona. Las estructuras de los haptenos $4 a \quad$ ácido $S$-(4-etilamino-6-isopropilamino-[1,3,5]-triazin-2-il)-3-tiopropanoico), 4b (ácido $S$-(4,6-bis-etilamino-[1,3,5]-triazin-2-il)-3-tiopropanoico), $4 c \quad$ (ácido $S$-(4terbutilamino-6-ciclopropilamino-[1,3,5]-triazin-2-il)-3-tiopropanoico), 4d (ácido $N$-(4terbutilamino-6-metiltio-[1,3,5]-triazin-2-il)-4-aminobutanoico) y $4 \mathrm{e}$ (ácido $\mathrm{N}$-(4ciclopropilamino-6-metiltio-[1,3,5]-triazin-2-il)-4-aminobutanoico), utilizados en este estudio, se muestran en Figura 2.4.<smiles>[R]c1nc([R])nc([R])n1</smiles>

\begin{tabular}{c|ccc}
\hline Hapteno & $R 1$ & $R 2$ & $R 3$ \\
\hline $4 \mathrm{a}$ & $-\mathrm{NH}-\mathrm{CH}_{2}-\mathrm{CH}_{3}$ & $-\mathrm{NH}-\mathrm{CH}-\left(\mathrm{CH}_{3}\right)_{2}$ & $-\mathrm{S}-\left(\mathrm{CH}_{2}\right)_{2}-\mathrm{COOH}$ \\
$4 \mathrm{~b}$ & $-\mathrm{NH}-\mathrm{CH}_{2}-\mathrm{CH}_{3}$ & $-\mathrm{NH}-\mathrm{CH}_{2}-\mathrm{CH}_{3}$ & $-\mathrm{S}-\left(\mathrm{CH}_{2}\right)_{2}-\mathrm{COOH}$ \\
$4 \mathrm{c}$ & $-\mathrm{NH}-\mathrm{C}-\left(\mathrm{CH}_{3}\right)_{3}$ & $-\mathrm{NH}-\mathrm{CH}-\left(\mathrm{CH}_{2}\right)_{2}{ }^{\mathrm{a}}$ & $-\mathrm{S}-\left(\mathrm{CH}_{2}\right)_{2}-\mathrm{COOH}$ \\
$4 \mathrm{~d}$ & $-\mathrm{NH}-\mathrm{C}-\left(\mathrm{CH}_{3}\right)_{3}$ & $-\mathrm{NH}-\left(\mathrm{CH}_{2}\right)_{3}-\mathrm{COOH}$ & $-\mathrm{S}-\mathrm{CH}_{3}$ \\
$4 \mathrm{e}$ & $-\mathrm{NH}-\mathrm{CH}-\left(\mathrm{CH}_{2}\right)_{2}{ }^{\mathrm{a}}$ & $-\mathrm{NH}-\left(\mathrm{CH}_{2}\right)_{3}-\mathrm{COOH}$ & $-\mathrm{S}_{-} \mathrm{CH}_{3}$ \\
\hline
\end{tabular}

${ }^{a}$ Radical ciclopropilamino

Figura 2.4. Estructura de los haptenos utilizados en el sistema Irgarol 1051

\subsection{INSTRUMENTACIÓN}

En el desarrollo de las investigaciones se utilizaron los siguientes equipos:

- Sistema básico de manipulación y distribución de fluidos. Dicho equipo fue adquirido a Kloehn Co. LTD. (Las Vegas, NV) y está compuesto por dos módulos diferenciados. El primero consta de una bomba de pistón y una válvula de distribución de 8 vías (módulo 50300), y el otro es una válvula de distribución de 8 vías (módulo 50120). Ambos están provistos de los dispositivos electromecánicos necesarios para su funcionamiento y programación, e interconectados mediante una conducción. Todas las operaciones realizadas por el sistema están totalmente automatizadas y manejadas mediante un programa informático específico. 
- Dispositivo de inmunofiltración: los ensayos preliminares de selección de condiciones para el posterior desarrollo de los inmunosensores fueron llevados a cabo utilizando el dispositivo comercial ELIFA ${ }^{\circledR}$ (Pierce Chemical Co, Rockford, IL), que fue modificado para imitar las operaciones que tienen lugar en los posteriores inmunosensores (191).

- Detectores:

- Fluorímetro TURNER DESINGS modelo 450 (Sunnyvale, CA)

- Espectrofluorímetro Perkin-Elmer modelo LS50 (Sussex, UK.)

- Luminómetro TURNER TD-20e (Sunnyvale, CA)

- Espectrofotómetro UV/V de diodos en fila Hewlett-Packard, modelo 845A2.

- Lector de placas MR700 de Dynatech (Sussex, UK) y Victor Multilabel Counter 1420 de Wallac (Turku, Finlandia)

- $\quad$ Bomba peristáltica Gilson Minipuls 2, Villiers le Bel (Francia), utilizada para la preparación de los inmunorreactores.

\subsection{MÉTODOS DE CONJUGACIÓN}

Los haptenos fueron conjugados a enzimas para formar los "trazadores enzimáticos” y a proteínas sin actividad biológica específica como la BSA, para los "conjugados de tapizado".

El acoplamiento se llevó a cabo a través de los grupos carboxílicos presentes en todos los haptenos empleados. La extensión de la reacción viene dada por la relación molar de marcaje o número de moléculas de hapteno unidas a una molécula de proteína. Su cuantificación se realizó espectrofotométricamente a dos longitudes de onda distintas y características de cada una de las especies (hapteno y proteína), suponiendo la aditividad de las absorbancias de los conjugados. A continuación se describen los métodos empleados para tal fin.

\subsubsection{Método del anhídrido mixto}

Su fundamento está ampliamente recogido en la bibliografía $(192,193)$ y ha sido el método empleado para la obtención de trazadores enzimáticos.

Básicamente, se mezclan 12,3 $\mu$ moles de hapteno disuelto en DMF con 2,9 $\mu 1$ de tributilamina, 1,6 $\mu 1$ de cloroformato de isobutilo y $63 \mu 1$ de DMF. El volumen final de reacción es de $200 \mu \mathrm{l}$, siendo $66 \mathrm{mM}$ la concentración final de todos los reactivos. La 
mezcla de reacción se incuba 1 hora en la oscuridad a temperatura ambiente con ligera agitación. Transcurrido este tiempo, se añaden a la mezcla 1,8 $\mathrm{ml}$ de disolvente (DMF), de los cuales $135 \mu 1$ se adicionan lentamente a una disolución de proteína en tampón carbonato $50 \mathrm{mM}, \mathrm{pH}$ 9,6 (3 mg proteína/ml disolución tampón). La reacción de conjugación tiene lugar a temperatura ambiente durante 5 horas en oscuridad. El conjugado obtenido es cromatografiado por exclusión molecular utilizando una columna de gel Sephadex G-25 (20 cm de longitud y 0,6 cm de diámetro). El rendimiento del método en estas condiciones es aproximadamente del 30-35\%, en función de las relaciones molares inicial y final. En la Figura 2.5 se muestran esquemáticamente las etapas involucradas en el método de conjugación. 


\section{Cloroformiato de isobutilo}
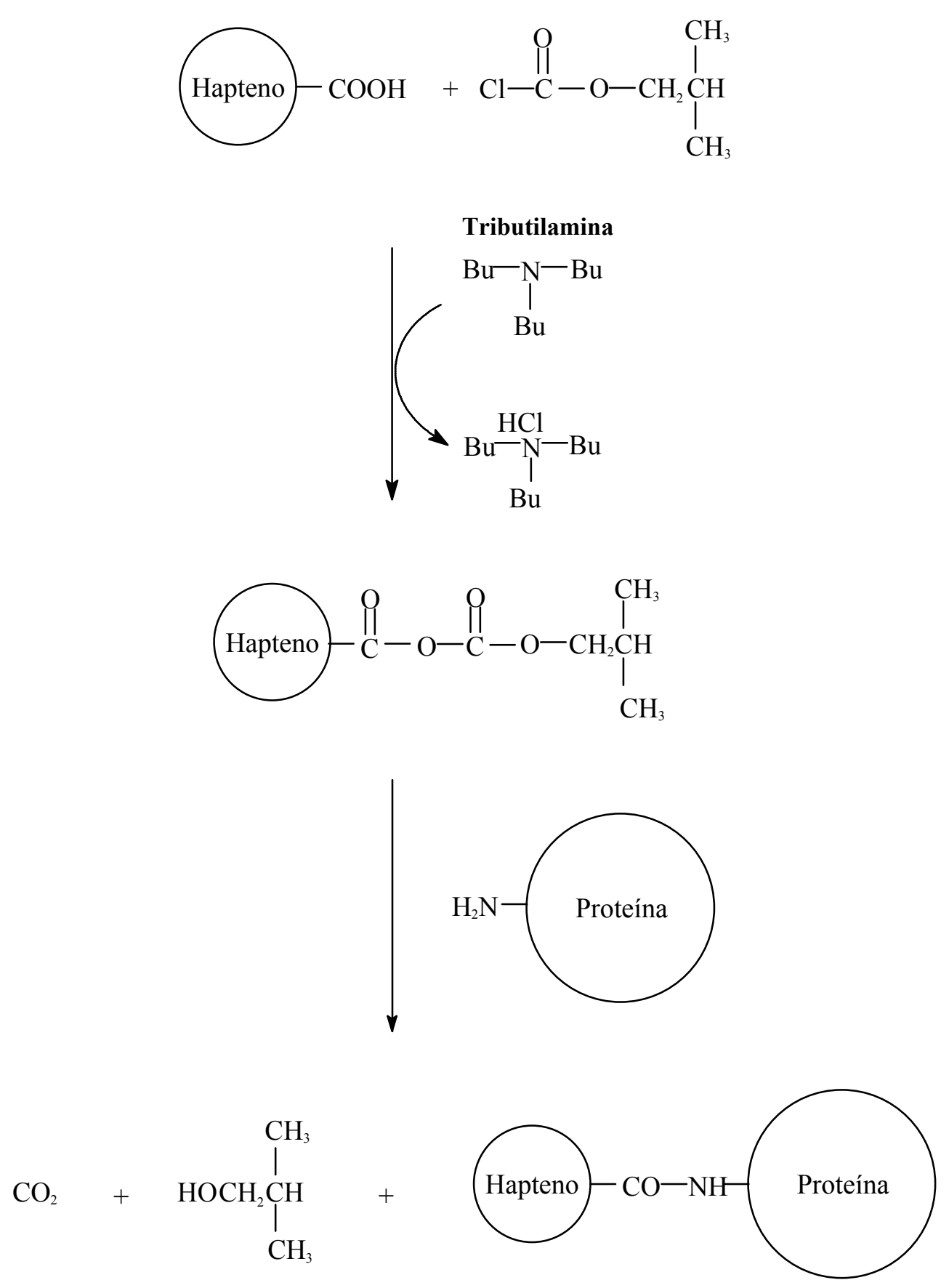

Figura 2.5. Método del anhídrido mixto para el acoplamiento de haptenos a proteínas

\subsubsection{Método del éster activo}

En este método (194,195), se mezclan 48,77 $\mu \mathrm{mol}$ de hapteno disueltos en DMF con $168 \mu 1$ de una disolución $(60 \mathrm{mg} / \mathrm{ml})$ de $N-N$ ' diciclohexilcarbodiimida en DMF y con $94 \mu 1$ de una disolución de $N$-hidroxisuccinimida $(60 \mathrm{mg} / \mathrm{ml})$ en DMF. El volumen total de activación es de $325 \mu \mathrm{l}$ y la concentración de los reactivos $150 \mathrm{mM}$. 
Esta mezcla se deja reaccionar durante 1-2 horas con agitación a temperatura ambiente, hasta que aparezca cierta cantidad de precipitado de diclicohexilurea,. La aparición del precipitado es indicativa de la activación del hapteno (Figura 2.6). Tras centrifugar la mezcla de reacción durante 15 minutos a 12.000 g, se añaden $56 \mu 1$ de DMF a $144 \mu 1$ de sobrenadante y la mezcla se añade lentamente a una disolución de proteína en tampón carbonato $50 \mathrm{mM} \mathrm{pH}$ 9,6 (20 mg proteína/0,8 $\mathrm{ml}$ tampón). La relación molar inicial fue de 68 . La mezcla resultante se va enturbiando a medida que se añade el hapteno activado. La reacción de conjugación transcurre en la oscuridad durante 4 horas con ligera agitación. La mezcla de reacción se centrifuga en las condiciones anteriormente mencionadas y el sobrenadante es cromatografiado por exclusión molecular en gel Sephadex G-25, utilizando tampón fosfato sódico $100 \mathrm{mM}$, $\mathrm{pH} 7,4$.

Los conjugados obtenidos por ambos métodos se mantienen congelados a $-20{ }^{\circ} \mathrm{C}$. Las disoluciones de trabajo se preparan a la concentración deseada en glicerol al $50 \%(\mathrm{v} / \mathrm{v})$; en estas condiciones, las especies son estables al menos dos semanas a $4{ }^{\circ} \mathrm{C}$. 

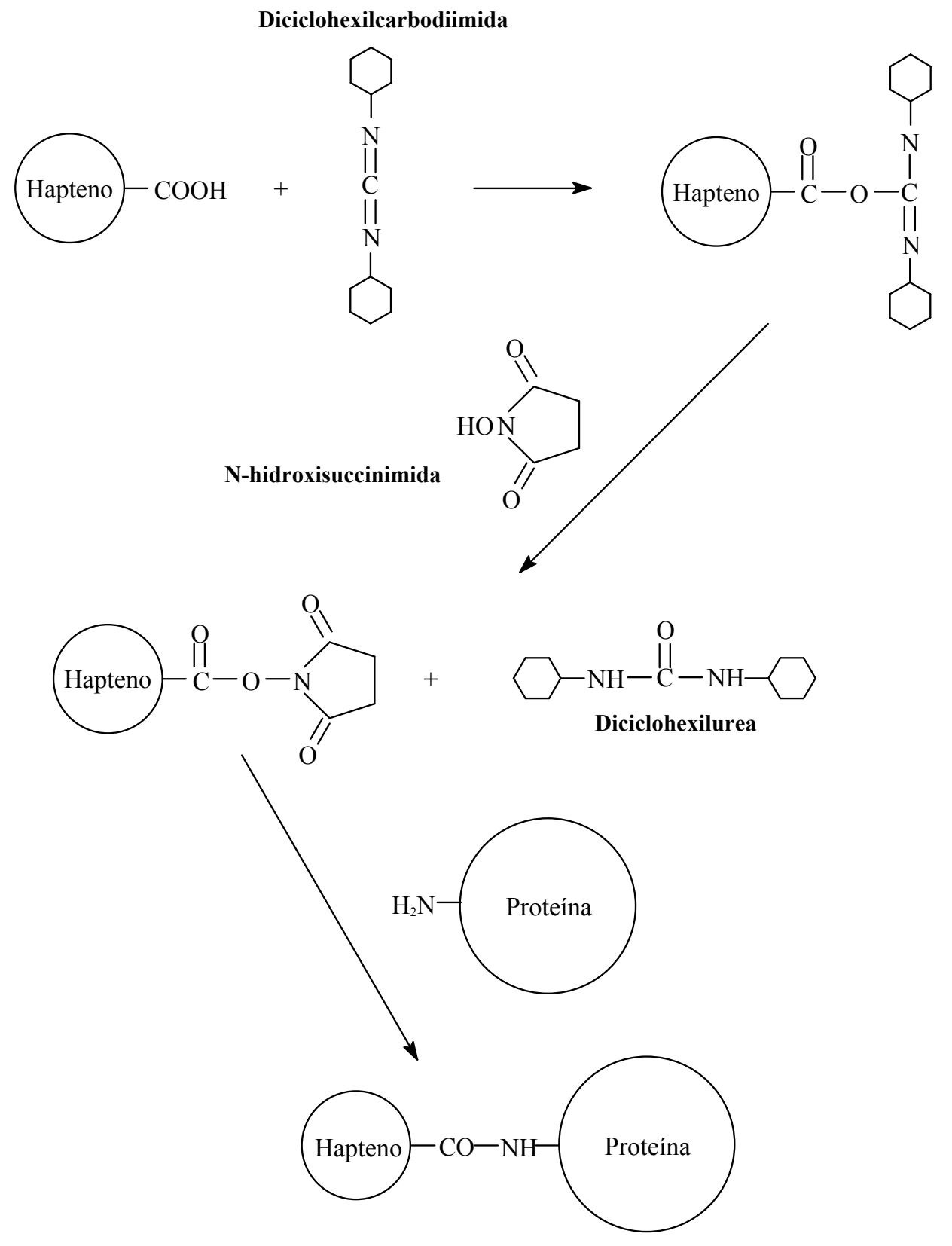

Figura 2.6. Método del éster activo para el acoplamiento de haptenos a proteínas

\subsection{SOPORTES DE INMOVILIZACIÓN DE INMUNORREACTIVOS}

Los soportes utilizados en la preparación de los inmunorreactores incluyeron materiales de naturaleza silícea y geles de agarosa. Como soporte silíceo se utilizó vidrio de poro controlado PG-240-200 (CPG, Sigma). Este soporte, una vez activado, fue empleado para la inmovilización tanto de haptenos como de anticuerpos.

Además, se utilizaron distintos geles en función de la especie a inmovilizar. Así, para la inmovilización de anticuerpos fue utilizado Affi-Gel Hz (GAHz) -gel de agarosa derivatizado con grupos hidrazina que permite la inmovilización covalente y orientada 
de los anticuerpos-. Para la inmovilización de haptenos se utilizó el soporte Affi-Gel 15 (GASc) -gel de agarosa derivatizado con grupos N-hidroxisuccinimida que permite la inmovilización covalente de proteínas vía enlace amida-, ambos suministrados por BioRad Laboratorios, Richmond, CA

Finalmente, se utilizó un gel polimérico activado con grupos azlactona con la proteína A/G inmovilizada (Ultralink Immobilized Protein A/G, Pierce, Rockford, IL). Este inmunosoporte es capaz de unir de forma orientada y covalente inmunoglobulinas de varias especies (196).

\subsection{MÉTODOS DE INMOVILIZACIÓN}

La inmovilización covalente y orientada de inmunorreactivos se llevó a cabo según las recomendaciones descritas por los fabricantes de los distintos soportes utilizados. La cuantificación de los rendimientos de inmovilización se llevó a cabo mediante la medida de absorbancia a $280 \mathrm{~nm}$ de las disoluciones de inmunorreactivos, antes y después del proceso de inmovilización. Estas medidas son orientativas, y las prestaciones de los inmunosoportes son estimadas mediante ensayos previos de inmunofiltración y posteriormente en flujo con el propio sistema sensor.

\subsubsection{Inmovilización de anticuerpos sobre CPG alquilaminado}

La inmovilización está basada en la oxidación (grupos - $\mathrm{OH}$ ) de las moléculas de carbohidratos presentes en la región constante $(\mathrm{Fc})$ de los anticuerpos. De este modo, la inmovilización permite además orientar los anticuerpos, así como alejar las zonas activas del soporte, minimizando los posibles efectos estéricos. El método seguido fue el descrito por Wilson y Nakane (197) que básicamente consiste en oxidar los anticuerpos con peryodato sódico en tampón acetato sódico 0,05M, pH 5,5. Este procedimiento genera grupos aldehído que se unen directamente al soporte (CPG alquilaminado) formando bases de Schiff. Este enlace es estabilizado mediante la reducción con una disolución de borohidruro sódico (40 mg/100 mg de soporte, durante 45 minutos a $4{ }^{\circ} \mathrm{C}$ ). El resto de los grupos amino del soporte -una vez inmovilizados los anticuerpos- son inertes, no siendo necesaria una etapa posterior de bloqueo. El inmunosoporte es conservado en PBS con $0,02 \%$ de azida sódica.

Alquilaminación del CPG (198). 0,2 mg de soporte se hierven en $20 \mathrm{ml}$ de ácido nítrico al 5\% (v/v) durante 30 minutos, tras lo cual el CPG se lava con abundante agua destilada y se filtra con una placa porosa G3. A continuación, se seca en estufa a $110{ }^{\circ} \mathrm{C}$ 
durante 15 minutos y se procede a su alquilaminación mediante tratamiento con una disolución acuosa de 3-aminopropiltrietoxisilano al 10\% (la disolución de alquilaminación se ajusta a pH 3,5 con ácido clorhídrico concentrado). La mezcla es calentada a $75^{\circ} \mathrm{C}$ en baño de agua durante 5 horas y el CPG activado se lava y filtra del modo descrito anteriormente. Finalmente, el CPG alquilaminado se seca durante toda la noche en estufa a $110^{\circ} \mathrm{C}$.

La Figura 2.7 esquematiza el procedimiento general de inmovilización.
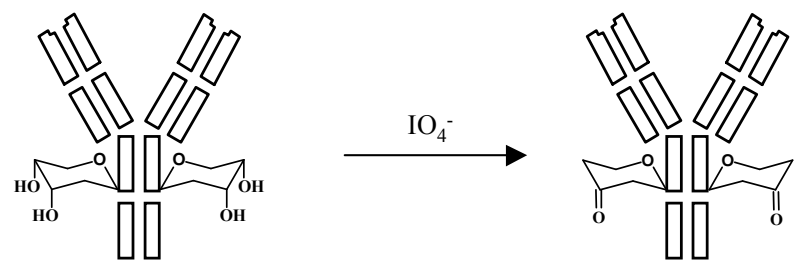

OXIDACION DE

ANTICUERPOS
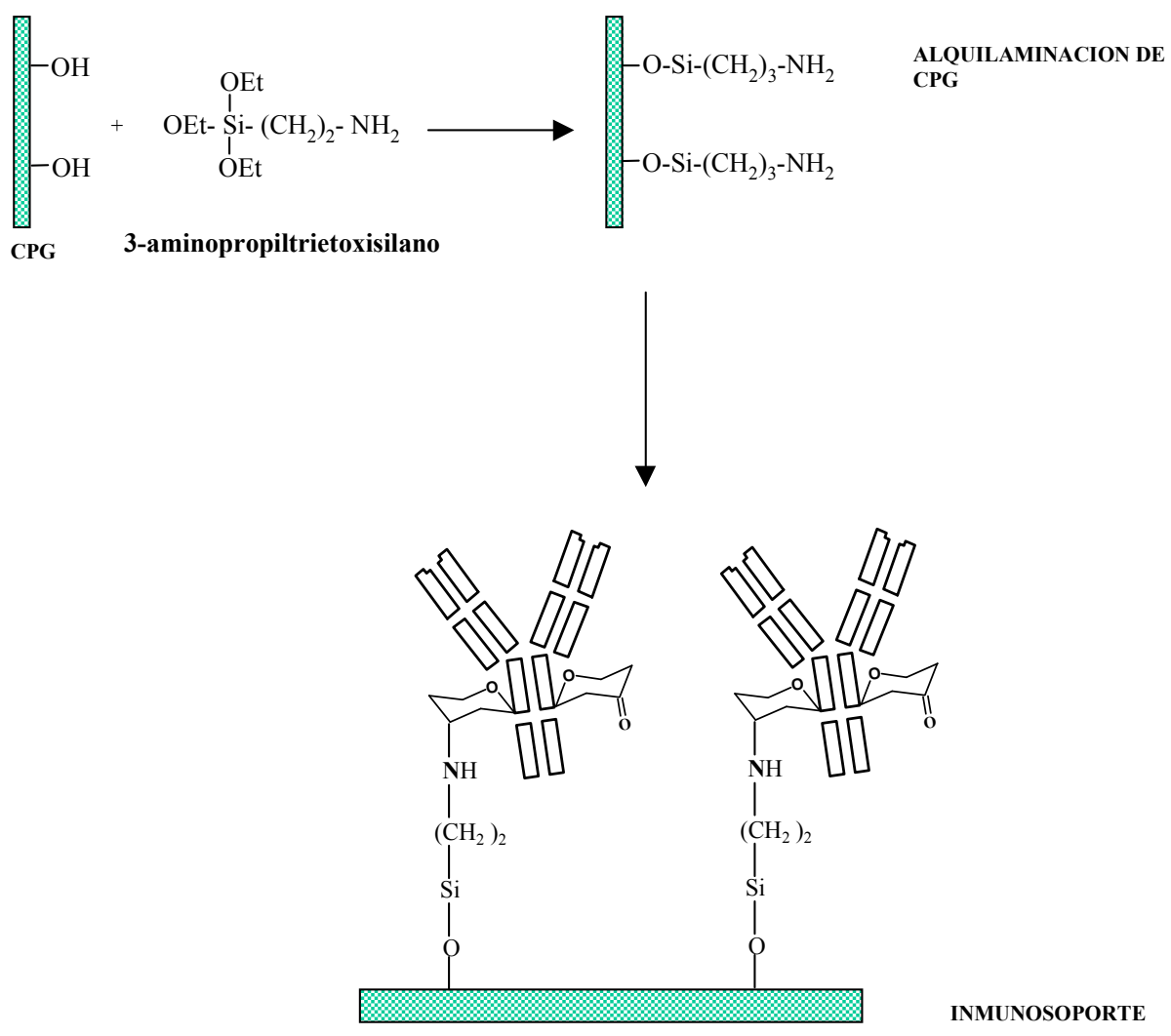

Figura 2.7. Etapas del proceso de inmovilización de anticuerpos sobre CPG

\subsubsection{Inmovilización de anticuerpos sobre gel de agarosa (GAHz)}

Se utilizó un gel comercial de agarosa, derivatizado con grupos hidrazina (GAHz), capaz de inmovilizar los anticuerpos de forma orientada y covalente. El procedimiento seguido, según las recomendaciones del fabricante, consistió básicamente en oxidar los anticuerpos con una disolución de peryodato (ver apartado 
2.6.1), de modo que los grupos aldehído generados en los anticuerpos se unan al soporte por los grupos hidrazina, formando enlaces hidrazona (Figura 2.8). Finalizado el proceso, el inmunosoporte se conserva del mismo modo que en el caso anterior.

Los inmunosoportes preparados con CPG y GAHz se utilizaron para el desarrollo de inmunosensores en formato directo.

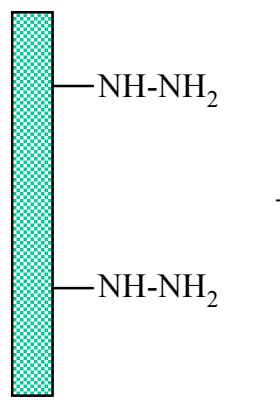

GAHz

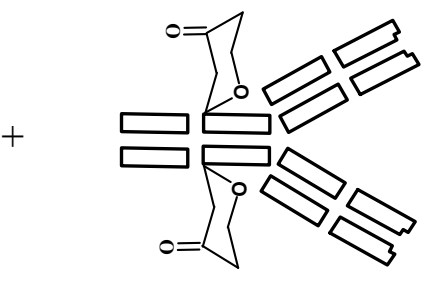

Anticuerpo oxidado

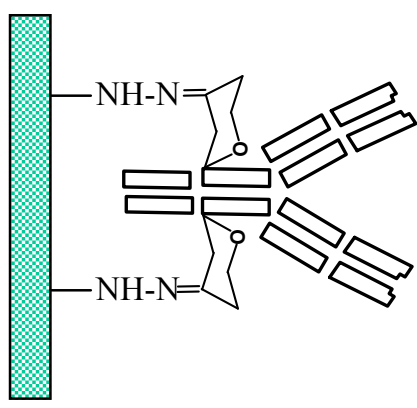

Inmunosoporte

Figura 2.8. Etapas del proceso de inmovilización de anticuerpos sobre gel de agarosa derivatizado con grupos hidrazina

\subsubsection{Inmovilización de haptenos}

La inmovilización de haptenos se lleva a cabo mediante conjugados haptenoBSA. De esta forma, la unión al soporte se realiza a través de la proteína y el hapteno permanece inalterado en todo el proceso de inmovilización. Los procedimientos de inmovilización de proteínas a soportes como CPG y geles derivatizados, están bien estudiados y caracterizados. En principio, esta vía de inmovilización de haptenos es universal, dada la posibilidad de conjugar cualquier hapteno a proteína. Además, se puede predeterminar la relación molar en los conjugados.

\subsubsection{Inmovilización sobre CPG}

Para la inmovilización de conjugados sobre CPG alquilaminado se siguió el procedimiento descrito por Masoom y Townshend (198) para la inmovilización covalente de enzimas.

Fundamentalmente, el procedimiento consiste en tratar $1 \mathrm{~g}$ de CPG alquilaminado con glutaraldehído al 2,5\% en tampón fosfato $100 \mathrm{mM}, \mathrm{pH} 7$, durante 1 hora, haciendo pasar corriente de nitrógeno los 10 primeros minutos. El soporte activado se lava con abundante agua destilada con el fin de eliminar el exceso de glutaraldehído y se incuba con $3 \mathrm{ml}$ de la disolución de conjugado hapteno-BSA (1 
$\mathrm{mg} / \mathrm{ml}$ ) durante 20 horas a temperatura ambiente. Las bases de Schiff formadas entre los grupos carbonilo del soporte y los amino libres de la BSA se estabilizan con borohidruro sódico, tal y como se ha descrito anteriormente. En estas condiciones operativas se obtuvieron rendimientos de alrededor del $85 \%$. El resto de los grupos activos del soporte son bloqueados mediante tratamiento con etanolamina/ $\mathrm{HCl}, \mathrm{pH} 8$, durante 1 hora a temperatura ambiente. Los soportes así preparados se mantienen a $4{ }^{\circ} \mathrm{C}$ en PBS con $0,02 \% \mathrm{NaN}_{3}$.

\subsubsection{Inmovilización sobre gel de agarosa derivatizado (GASc)}

En este caso se utiliza un gel de agarosa derivatizado con grupos $N$ hidroxisuccinimida, diseñado para el acoplamiento covalente de proteínas, especialmente BSA. La presencia de un brazo espaciador de 15 átomos de $\mathrm{C}$ hace suponer que los efectos estéricos sean despreciables en este tipo de soporte.

Básicamente, el proceso consiste en adicionar $3 \mathrm{ml}$ de la disolución conjugado hapteno-BSA $(1 \mathrm{mg} / \mathrm{ml})$ a $1 \mathrm{~g}$ de soporte, previamente tratado según recomendaciones del fabricante, manteniendo la mezcla en agitación a $4{ }^{\circ} \mathrm{C}$ durante 4 horas. Tras esta etapa de incubación, el gel se lava con PBS y los grupos activos restantes se bloquean con etanolamina/ $\mathrm{HCl}, \mathrm{pH} 8$, mediante tratamiento durante 1 hora a temperatura ambiente. La Figura 2.9 muestra esquemáticamente el procedimiento de inmovilización. La eficiencia de acoplamiento fue aproximadamente del $95 \%$, estimada midiendo la concentración de conjugado en el sobrenadante.

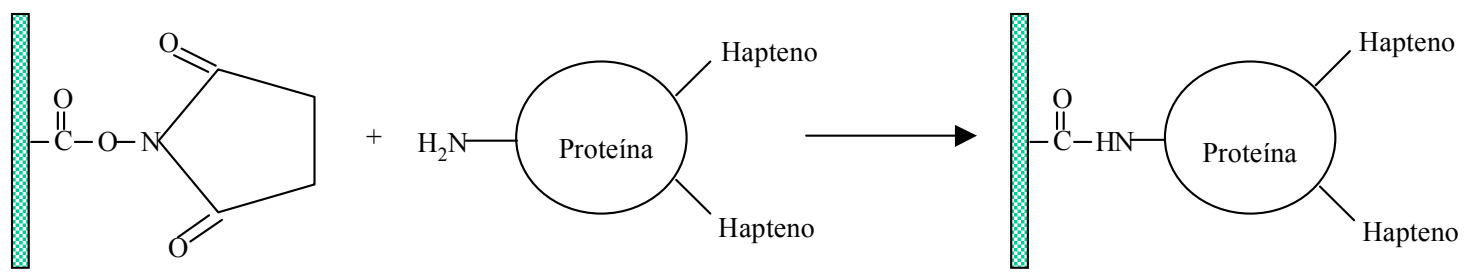

GAHSc

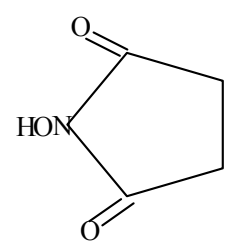

Figura 2.9. Inmovilización de conjugados hapteno-proteína sobre gel de agarosa derivatizado con grupos $N$-hidroxisuccinimida 


\subsection{PRUEBAS PRELIMINARES. SELECCIÓN DE VARIABLES}

Para el desarrollo de inmunosensores en flujo se hace necesario realizar la selección y optimización de todas las variables que intervienen en el mismo (soporte, inmunorreactivos, modo de inmovilización, formato de ensayo, condiciones de regeneración), de una forma rápida, sencilla y metódica.

Para ello se utilizó un método semicuantitativo basado en la técnica de inmunofiltración (IF). Esta metodología en batch, es capaz de simular las principales operaciones que se efectúan en el inmunosensor y ha sido aplicada con éxito en el proceso de selección de variables para el desarrollo de inmunosensores (44).

El esquema del sistema de inmunofiltración se muestra en la Figura 2.10. Este dispositivo, diseñado originalmente como una alternativa al ELISA clásico, permite realizar los mismos ensayos que se hacen en ELISA convencional, con la ventaja de que los periodos de incubación de las especies bioactivas son mucho más cortos, ya que se acelera el proceso de difusión de las especies desde el seno de la disolución hasta la interfase sólido-líquido.

Además, la inmovilización de la especie bioactiva se realiza -sobre una membrana susceptible de retener dicha molécula- durante el proceso de filtración a vacío. Las reacciones bioquímicas siguientes se realizan sobre dicha membrana, por filtración de las disoluciones que contienen los reactivos y las muestras problema. De este modo, mientras que en un ELISA clásico son necesarias varias horas para inmovilizar el inmunorreactivo sobre las paredes del pocillo, en el caso del sistema de inmunofiltración este proceso se realiza en pocos minutos. En resumen, mediante este dispositivo se puede llevar a cabo un ensayo en 2 o 3 horas, mientras que el mismo ensayo en ELISA convencional tarda un día o más, dependiendo de las características de los inmunorreactivos utilizados.

Aprovechando estas ventajas, el dispositivo de inmunofiltración se usó como herramienta para la selección de las variables que posteriormente conducirían al desarrollo de los inmunosensores. Este dispositivo y su aplicación han sido ampliamente descritos por Morais y col. $(191,199)$.

El procedimiento seguido en los ensayos de selección de variables mediante IF se resume en los siguientes pasos:

- Colocar la membrana inerte (membrana de fibra de vidrio Whatman GF/C) en el dispositivo. 
- Bloquear los puntos de unión inespecífica de la membrana por adición y posterior filtrado de $0,2 \mathrm{ml} /$ pocillo de una disolución de BSA $(25 \mathrm{~g} / \mathrm{l})$.

- Adicionar $50 \mu 1 /$ pocillo de una suspensión del inmunosorbente a ensayar (1 mg para CPG y $10 \mathrm{mg}$ para los geles).

- Añadir los reactivos en función del formato utilizado. Por ejemplo, en ensayos en formato directo, disolución de trazador enzimático y patrón o muestra. Todas estas disoluciones $(0,2 \mathrm{ml} /$ pocillo $)$ se filtran a través de la membrana y el inmunosoporte. Tras la última adición de reactivos, se procede al lavado con PBST (5 porciones de $0,2 \mathrm{ml} /$ pocillo) con el fin de eliminar las especies no unidas.

- Colocar una placa ELISA en el dispositivo para recoger el producto de la reacción enzimática y adicionar el substrato. Habitualmente se emplea la enzima HRP y como substrato OPD $(0,075 \mathrm{ml} /$ pocillo de una disolución recién preparada a $2 \mathrm{~g} / \mathrm{l}$ de OPD- $0,012 \%$ de $\mathrm{H}_{2} \mathrm{O}_{2}$ en tampón fosfato sódico 0,062 M, citrato sódico 0,025 M, pH 5,4). Tras 5 minutos de incubación, se adicionan $0,075 \mathrm{ml}$ de $\mathrm{H}_{2} \mathrm{SO}_{4} 2,5 \mathrm{M}$ para detener la reacción. La mezcla resultante se filtra y se recoge en la placa ELISA, que es leída en un lector de placas a $490 \mathrm{~nm}$.

Este procedimiento general se adapta a cada caso particular según el tipo de ensayo a realizar. Estos son básicamente, ensayos de actividad, competición, desorción y regeneración. 


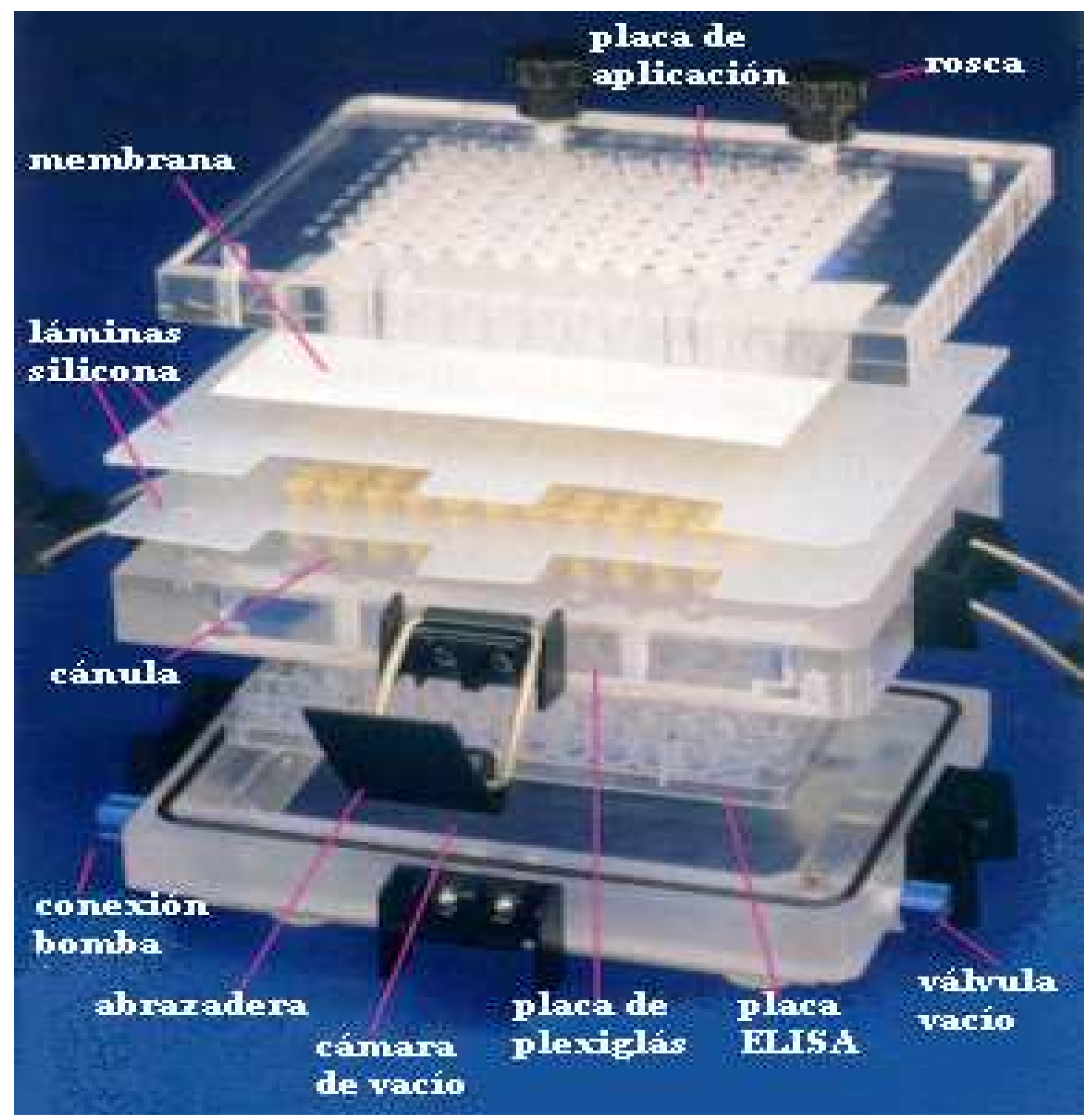

Figura 2.10. Esquema del sistema de inmunofiltración

A continuación se describen los diferentes ensayos realizados mediante el sistema de inmunofiltración.

Los ensayos de actividad se realizan con el fin de evaluar el comportamiento de los diferentes inmunorreactivos inmovilizados y optimizar las concentraciones de los restantes reactivos (e.g. concentración de trazador enzimático). En todos los casos, las señales son comparadas con las de los blancos, especialmente al estimar las correspondientes a uniones inespecíficas. Mediante este tipo de ensayo se han evaluado también los medios orgánicos de trabajo en los que se disuelven los inmunorreactivos.

Aquellas combinaciones de inmunorreactivos seleccionadas en los ensayos de actividad para cada uno de los formatos y soportes, son evaluadas -respecto a sensibilidad- mediante ensayos de competición. En estos ensayos, se establece una 
competencia entre el analito y el trazador enzimático (a la concentración seleccionada) en los formatos de anticuerpo inmovilizado, o el hapteno inmovilizado para el formato de conjugado inmovilizado. De esta manera, las condiciones que no dan lugar a una inhibición apreciable de la señal a concentraciones relativamente bajas, son descartadas para el futuro desarrollo de los inmunosensores.

Los ensayos de desorción tienen por objeto seleccionar aquellos agentes desorbentes capaces de revertir la reacción $\mathrm{Ab}-\mathrm{Ag}$, regenerando el inmunosoporte. Estos ensayos, similares a los ensayos de actividad, con la salvedad de la inclusión de una etapa adicional de desorción de los inmunocomplejos formados, previamente a la última etapa en la que se determina la actividad enzimática. La eficacia de cada desorbente se establece comparando la señal de absorbancia obtenida tras la etapa de desorción y la señal de absorbancia original obtenida cuando no se lleva a cabo dicha etapa. En la selección del agente desorbente se ha seguido el criterio de obtener una señal prácticamente similar a las señales inespecíficas (blanco). Este criterio garantiza la desorción cuantitativa.

Por último, los ensayos de regeneración consisten en la realización de varios ciclos de formación del complejo $\mathrm{Ab}$-Ag y posterior desorción con el agente más efectivo, seleccionado en los ensayos anteriores. De esta forma y para un determinado formato, puede evaluarse la reutilización de los inmunosoportes. Este estudio es crítico, ya que determina, para cada caso, la posibilidad o no de desarrollar un inmunosensor en dichas condiciones.

El desarrollo de estos ensayos previos ha permitido la selección de las variables clave para la posterior puesta a punto de los inmunosensores.

\subsection{DESCRIPCIÓN DE LOS EQUIPOS UTILIZADOS EN EL DESARROLLO DE LOS SISTEMAS SENSORES}

En el desarrollo de los inmunosensores se ha utilizado un sistema de manejo de fluidos (Figura 2.11) que consta de una válvula de pistón de $2,5 \mathrm{ml}$ de capacidad que tiene acoplada una válvula de distribución de ocho vías (módulo 50300) y una segunda válvula de distribución auxiliar (módulo 50120) de ocho vías. Todo el sistema está gobernado por un programa informático.

Los puertos de las válvulas están conectados mediante tubos de PTFE $\left(\Phi_{\mathrm{i}} 0,5 \mathrm{~mm}\right)$ a las disoluciones de los reactivos necesarios para cada uno de los ensayos 
(e.g. tampón de lavado, trazador, agente desorbente, substratos enzimáticos, muestras o patrones, etc.).

El sistema sensor propiamente dicho consiste en una minicolumna de polimetilmetacrilato, cuyas dimensiones óptimas son función del soporte y formato utilizados. En general, la longitud de la columna (4 mm de $\Phi_{\mathrm{i}}$ y $1 \mathrm{~cm}$ de $\Phi_{\mathrm{e}}$ ) oscila entre 4 y $7 \mathrm{~mm}$ de longitud.

El modo básico de operación del sistema consiste en aspirar volúmenes predeterminados de las disoluciones de reactivos y hacerlas pasar de forma secuencial a través del reactor. El sistema dispone también de una jeringuilla que permite hacer mezclas de las disoluciones si el ensayo lo requiere. Cabe destacar que dado el alto número de entradas al sistema (15 puertos), éste permite analizar de forma totalmente automática entre 6 y 7 muestras, actuando como un muestreador.

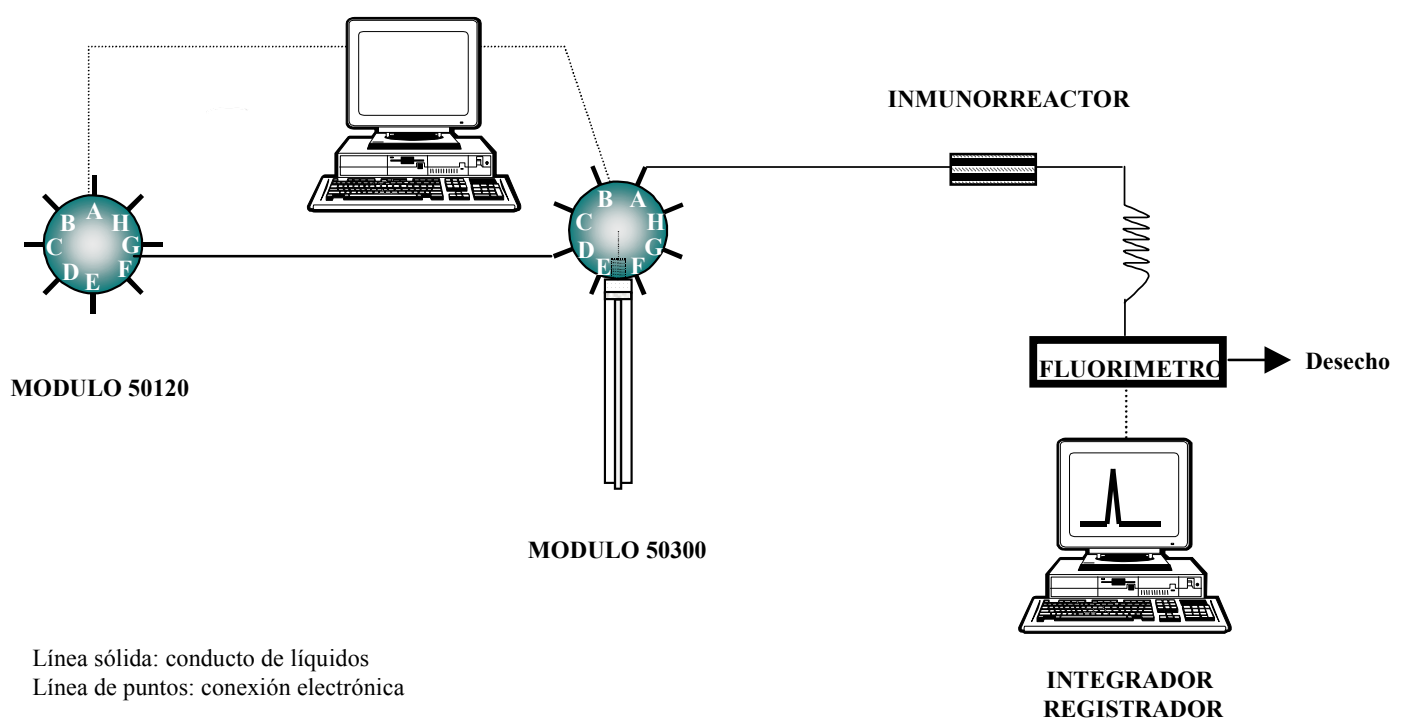

Figura 2.11. Esquema del inmunosensor

A continuación se describen los distintos protocolos desarrollados para cada formato de ensayo.

\subsubsection{Formato directo}

Este formato está basado en los fundamentos del inmunoensayo heterogéneo competitivo directo. Los soportes utilizados para inmovilizar los anticuerpos han sido CPG y gel de agarosa derivatizado con grupos hidrazina (GAHz).

El protocolo de ensayo consiste en la inyección, a través del inmunosensor, de una mezcla de trazador enzimático y disolución patrón o problema. Dicha mezcla se 
realiza -en cada ensayo- mediante la aspiración de cantidades prefijadas de ambos reactivos. Posteriormente se procede al lavado con PBST, lo que garantiza la eliminación de las especies no unidas en el sensor. A continuación, se inyecta el substrato enzimático y tras un tiempo óptimo de incubación, se inyecta el tampón de lavado, con lo que el producto de la reacción enzimática es transportado al detector, donde la señal es medida y registrada. Finalmente, el inmunosoporte es regenerado inyectando una disolución desorbente, de modo que el sistema queda preparado para la realización de un nuevo ciclo de ensayo. En la Tabla 2.1 se muestra con detalle el protocolo genérico de ensayo para este formato, cuyas etapas se esquematizan en la Figura 2.12.

\section{Tabla 2.1. Protocolo de ensayo correspondiente al formato directo}

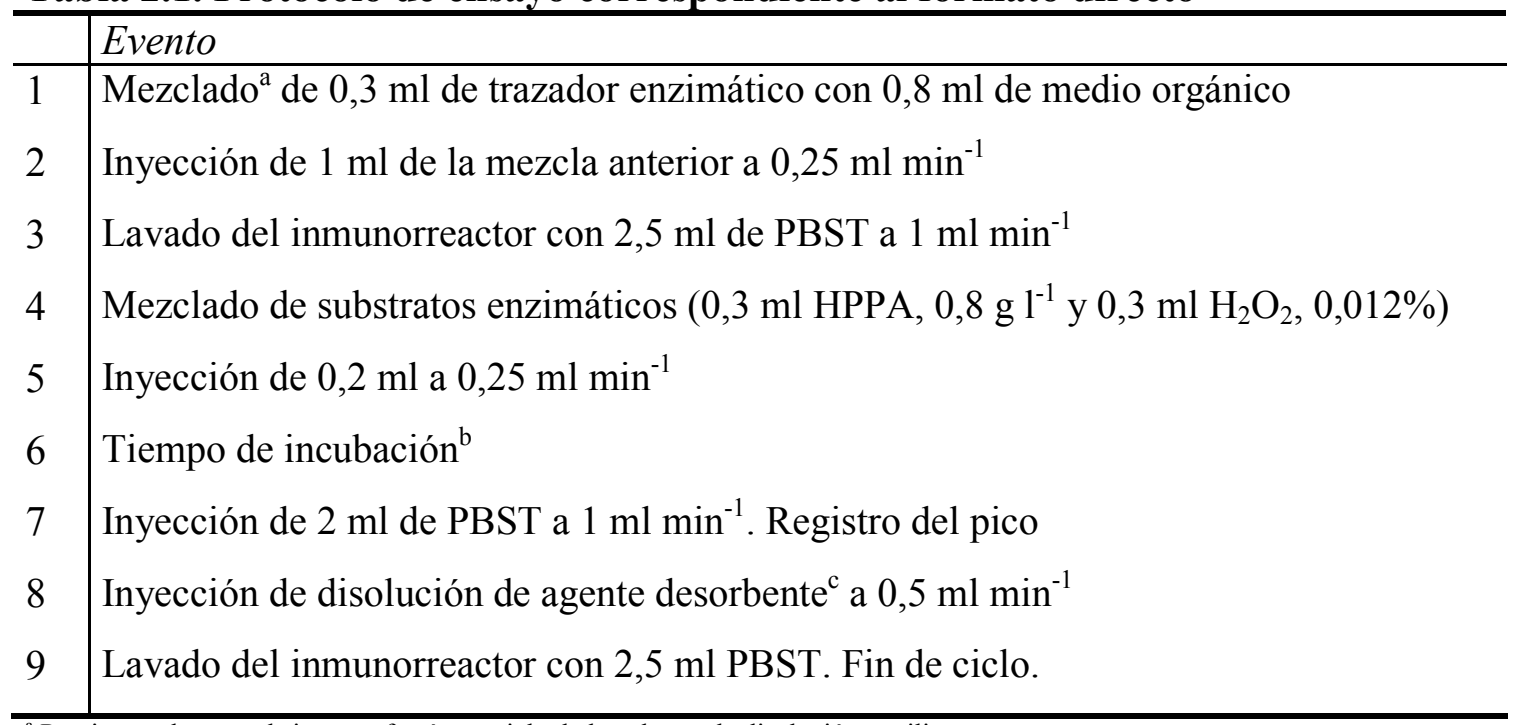

${ }^{a}$ Previo a cada paso el sistema efectúa un ciclo de lavado con la disolución a utilizar

${ }^{\mathrm{b}}$ El tiempo de incubación es variable en función del medio orgánico y de los inmunorreactivos utilizados

${ }^{\mathrm{c}}$ El volumen de agente desorbente es variable en función del medio orgánico y de los inmunorreactivos utilizados 


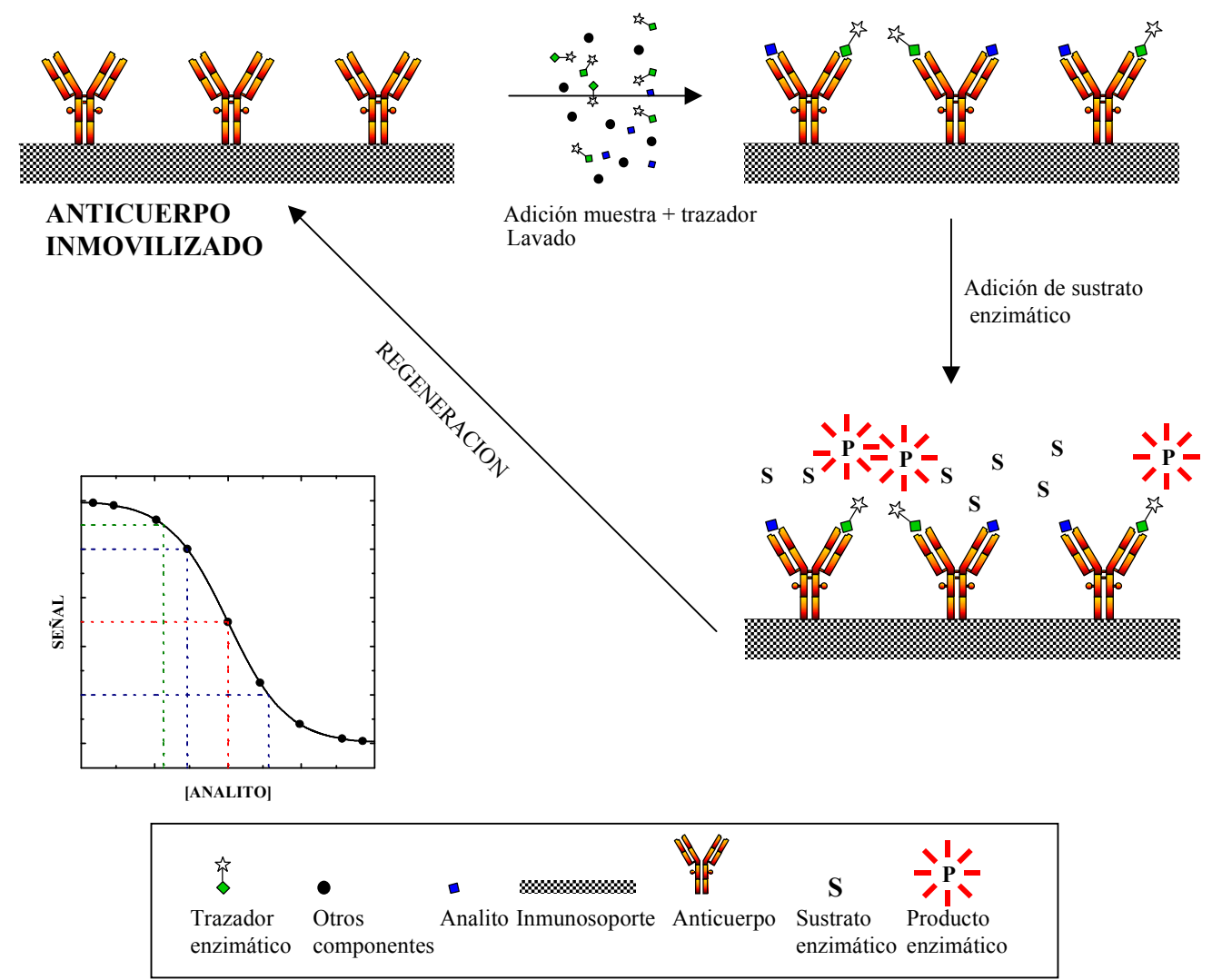

Figura 2.12. Representación de las etapas seguidas en los ensayos en formato directo

La distribución de las disoluciones de los reactivos en los distintos puertos del sistema se equematiza en la Figura 2.13.

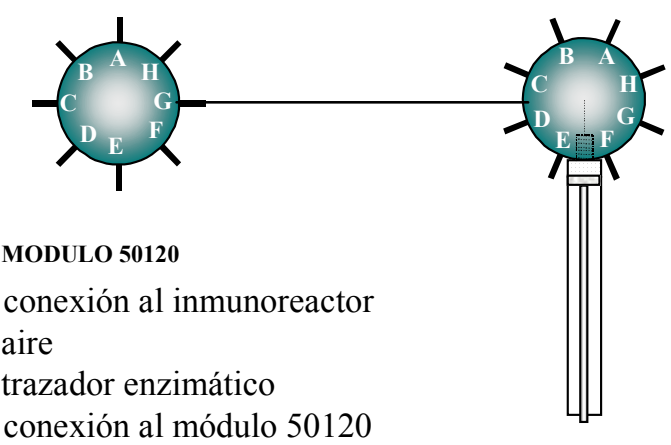

D: conexión al módulo 50120

E: tampón de lavado

$\mathrm{F}$ : disolución $\mathrm{H}_{2} \mathrm{O}_{2}$

MODULO 50300

$\mathrm{G}$ : disolución HPPA

A: agente desorbente

H: desecho

B-H: patrones o muestras

Figura 2.13. Formato directo. Conexión módulos-disoluciones

Todos los reactivos fueron disueltos en PBST, excepto los patrones y muestras que se prepararon en el medio orgánico utilizado en cada caso. 


\subsubsection{Formato indirecto}

Este formato es similar al del inmunoensayo heterogéneo competitivo indirecto. En este caso, se utiliza como reactivo inmovilizado el hapteno conjugado a BSA. Los soportes utilizados para la inmovilización de los conjugados han sido CPG y gel de agarosa derivatizado con grupos $N$-hidroxisuccinimida (GASc).

El protocolo de ensayo consiste en la inyección, a través del inmunorreactor, de una mezcla de disolución de anticuerpo específico y disolución patrón o problema. La mezcla se realiza para cada ensayo mediante la aspiración de cantidades prefijadas de ambos componentes. Posteriormente, se lava el sistema con PBST, lo que garantiza la eliminación de las especies no unidas, y se inyecta una disolución de anticuerpo secundario marcado, específico frente al primero. A continuación se inyecta el substrato enzimático cuyo producto de reacción es transportado al detector donde es medida y registrada la señal producida. Finalmente, se procede a la regeneración del sistema del modo descrito anteriormente. En la Tabla 2.2 se muestra el protocolo de ensayo seguido en este formato, cuyas etapas se esquematizan en la Figura 2.14.

Tabla 2.2. Protocolo de ensayo correspondiente al formato indirecto

\begin{tabular}{|c|c|}
\hline & Evento \\
\hline 1 & 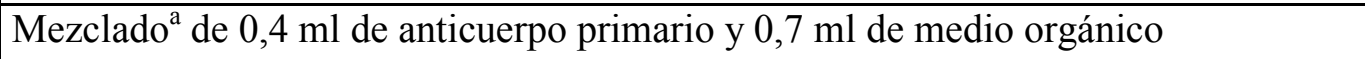 \\
\hline 2 & Inyección de $1 \mathrm{ml}$ de la mezcla anterior a $0,25 \mathrm{ml} \mathrm{min}^{-1}$ \\
\hline 3 & Lavado del inmunorreactor con $2,5 \mathrm{ml}$ de PBST \\
\hline 4 & Inyección de $0,2 \mathrm{ml}$ de anticuerpo secundario \\
\hline 5 & Lavado del inmunorreactor con $2,5 \mathrm{ml}$ de PBST \\
\hline 6 & Mezclado de substratos enzimáticos $\left(0,3 \mathrm{ml} \mathrm{HPPA}, 0,8 \mathrm{~g} \mathrm{l}^{-1}\right.$ y $\left.0,3 \mathrm{ml} \mathrm{H}_{2} \mathrm{O}_{2}, 0,012 \%\right)$ \\
\hline 7 & Inyección de $0,2 \mathrm{ml}$ de $0,25 \mathrm{ml} \mathrm{min}^{-1}$. Tiempo de incubación ${ }^{\mathrm{b}}$ \\
\hline 8 & Inyección de $2 \mathrm{ml}$ de PBST a $1 \mathrm{ml} \min ^{-1}$. Registro del pico \\
\hline 9 & Inyección de disolución de agente desorbente ${ }^{\mathrm{c}}$ a $0,5 \mathrm{ml} \mathrm{min}^{-1}$ \\
\hline 10 & Lavado del inmunorreactor con 2,5 ml PBST. Fin de ciclo. \\
\hline
\end{tabular}

${ }^{\text {a }}$ Previo a cada paso el sistema efectúa un ciclo de lavado con la disolución a utilizar

${ }^{\mathrm{b}}$ El tiempo de incubación es variable en función del medio orgánico y de los inmunorreactivos utilizados

${ }^{\mathrm{c}}$ El volumen de agente desorbente es variable en función del medio orgánico y de los inmunorreactivos utilizados 


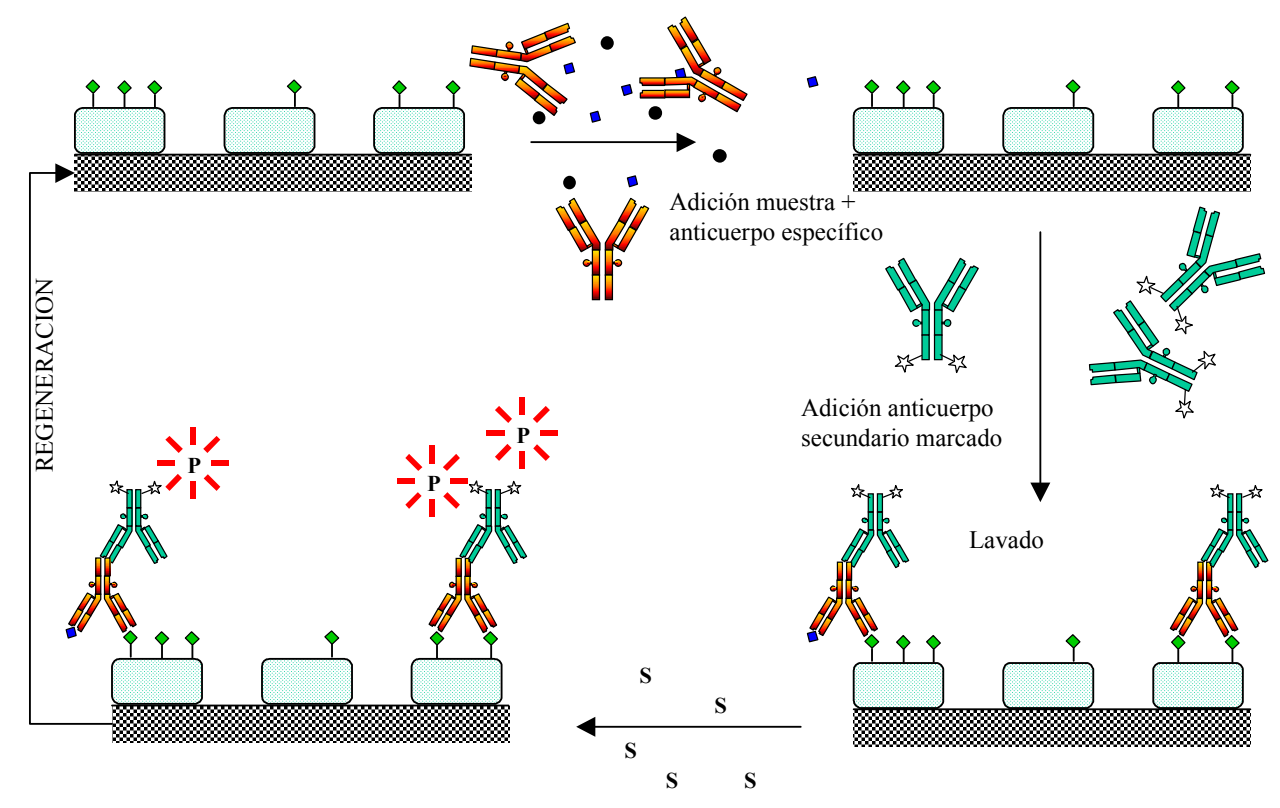

Adición sustrato enzimático

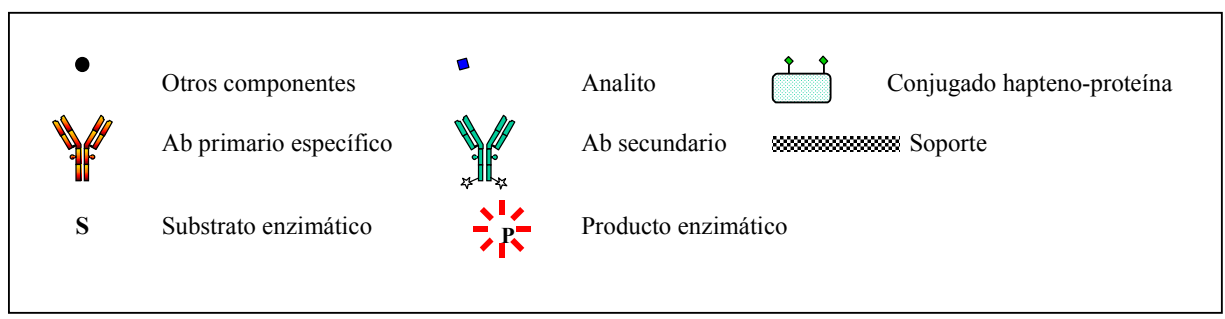

Figura 2.14. Representación de las etapas seguidas en los ensayos en formato indirecto

La Figura 2.15 muestra la distribución de las disoluciones de los reactivos en los distintos puertos del sistema.

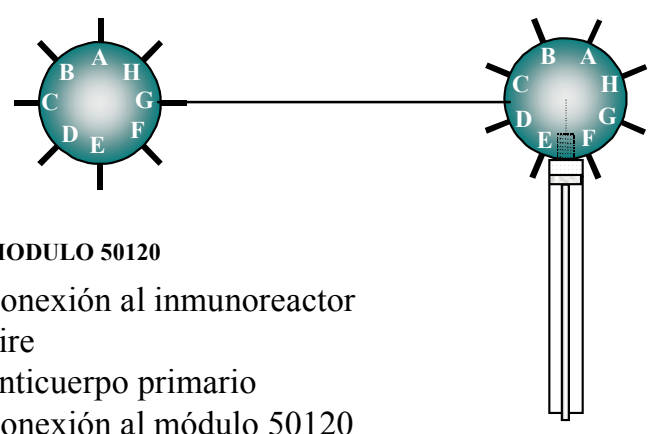

D: conexión al módulo 50120

E: tampón de lavado

MODULO 50300

F: disolución $\mathrm{H}_{2} \mathrm{O}_{2}$

G: disolución HPPA A: agente desorbente

H: desecho B: anticuerpo secundario

C-H: patrones o muestras

Figura 2.15. Formato indirecto. Conexión módulos-disoluciones 


\subsubsection{Formato de captura}

Este formato esta basado en los fundamentos del inmunoensayo heterogéneo competitivo directo. En este caso, a diferencia del formato directo, los inmunocomplejos formados en disolución son atrapados por el soporte, con lo que las reacciones de competición se realizan en disolución. El soporte utilizado es un gel polimérico derivatizado como grupos azlactona con proteína $\mathrm{A} / \mathrm{G}$ inmovilizada, capaz de unir de forma reversible y específica todas las subclases de $\operatorname{IgG}$ de ratón y conejo a través de su región Fc. De acuerdo con las instrucciones del fabricante (196), la máxima capacidad de acoplamiento se consigue utilizando tampón fosfato sódico $20 \mathrm{mM}, \mathrm{pH} \mathrm{8,0.} \mathrm{Por} \mathrm{otro}$ lado, la etapa de regeneración del soporte -que se lleva a cabo con una disolución Glicina $0,1 \mathrm{M} / \mathrm{HCl}, \mathrm{pH}$ 2,0- es simple y muy efectiva. Esta disolución permite la ruptura de las uniones Ab-proteína A/G, dejando el sensor libre para la realización de un nuevo ciclo.

Utilizando este formato se han ensayado dos tipos de protocolos: simultáneo y secuencial. El modo simultáneo consiste en efectuar la inmunorreacción en fase homogénea $y$, a continuación, hacer pasar la mezcla por el soporte de proteína $A / G$, de modo que los inmunocomplejos formados quedan retenidos. En el modo secuencial, se hace llegar al soporte la disolución de anticuerpo, y tras eliminar el exceso por lavado, se introduce en el sistema una mezcla de trazador enzimático y disolución patrón o muestra. Las mezclas se realizan en cada ensayo mediante la aspiración de cantidades prefijadas de los reactivos. A continuación, se procede al lavado con PBT, lo que garantiza la eliminación de las especies no unidas. Tras esto, se inyecta el substrato enzimático, incubándose hasta la obtención de la máxima señal. El producto de la reacción enzimática es transportado al detector -mediante inyección de tampón de lavado-, donde la señal es medida y registrada. Por último, la inyección de la disolución desorbente garantiza la ruptura de las uniones Ab-proteína A/G, dejando el sistema apto para la realización de un nuevo ciclo de ensayo. En la Tabla 2.3 se resumen los protocolos de ensayo seguidos en este formato, cuyas etapas se esquematizan en la Figura 2.16. 
Tabla 2.3. Protocolos de ensayo correspondientes al formato de captura

\begin{tabular}{|c|c|c|}
\hline & \multicolumn{2}{|l|}{ Evento } \\
\hline & Protocolo simultáneo & Protocolo secuencial \\
\hline 1 & $\begin{array}{l}\text { Mezclado a de } 0,5 \mathrm{ml} \text { de medio orgánico } \\
\text { con } 0,3 \mathrm{ml} \text { de trazador enzimático y } 0,3 \\
\mathrm{ml} \mathrm{de} \mathrm{anticuerpo} \mathrm{específico}\end{array}$ & $\begin{array}{l}\text { Inyección de } 1 \mathrm{ml} \text { de anticuerpo } \\
\text { específico a } 0,25 \mathrm{ml} \mathrm{min}^{-1}\end{array}$ \\
\hline 2 & Inyección de $1 \mathrm{ml}$ de la mezcla anterior a & Lavado inmunorreactor con $2,5 \mathrm{ml}$ de \\
\hline & & PBT \\
\hline 3 & & $\begin{array}{l}\text { Mezclado a de } 0,3 \mathrm{ml} \text { de trazador } \\
\text { enzimático con } 0,8 \mathrm{ml} \text { de medio orgánico } \\
\text { Inyección de } 1 \mathrm{ml} \text { de la mezcla anterior a } \\
0,25 \mathrm{ml} \mathrm{m^{-1 }}\end{array}$ \\
\hline 4 & \multicolumn{2}{|c|}{ Lavado del inmunorreactor con $2,5 \mathrm{ml}$ de PBT a $1 \mathrm{ml} \mathrm{min}^{-1}$} \\
\hline 5 & \multicolumn{2}{|c|}{ Mezclado de substratos enzimáticos ( $0,3 \mathrm{ml} \mathrm{HPPA}, 0,8 \mathrm{~g} \mathrm{l}^{-1}$ y $\left.0,3 \mathrm{ml} \mathrm{H}_{2} \mathrm{O}_{2}, 0,012 \%\right)$} \\
\hline 6 & \multicolumn{2}{|c|}{ Inyección de $0,2 \mathrm{ml}$ de $0,25 \mathrm{ml} \mathrm{min}^{-1}$. Tiempo de incubación ${ }^{\mathrm{b}}$} \\
\hline 7 & \multicolumn{2}{|c|}{ 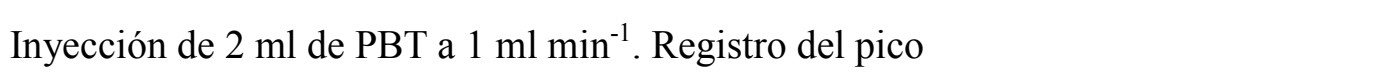 } \\
\hline 8 & \multicolumn{2}{|c|}{ Inyección de disolución de agente desorbente ${ }^{\mathrm{c}}$ a $0,5 \mathrm{ml} \mathrm{min}^{-1}$} \\
\hline 9 & \multicolumn{2}{|c|}{ Lavado del inmunorreactor con 2,5 ml PBT. Fin de ciclo. } \\
\hline
\end{tabular}

${ }^{a}$ Previo a cada paso el sistema efectúa un ciclo de lavado con la disolución a utilizar

${ }^{\mathrm{b}}$ El tiempo de incubación es variable en función del medio orgánico y de los inmunorreactivos utilizados

${ }^{c}$ El volumen de agente desorbente es variable en función del medio orgánico y de los inmunorreactivos utilizados 


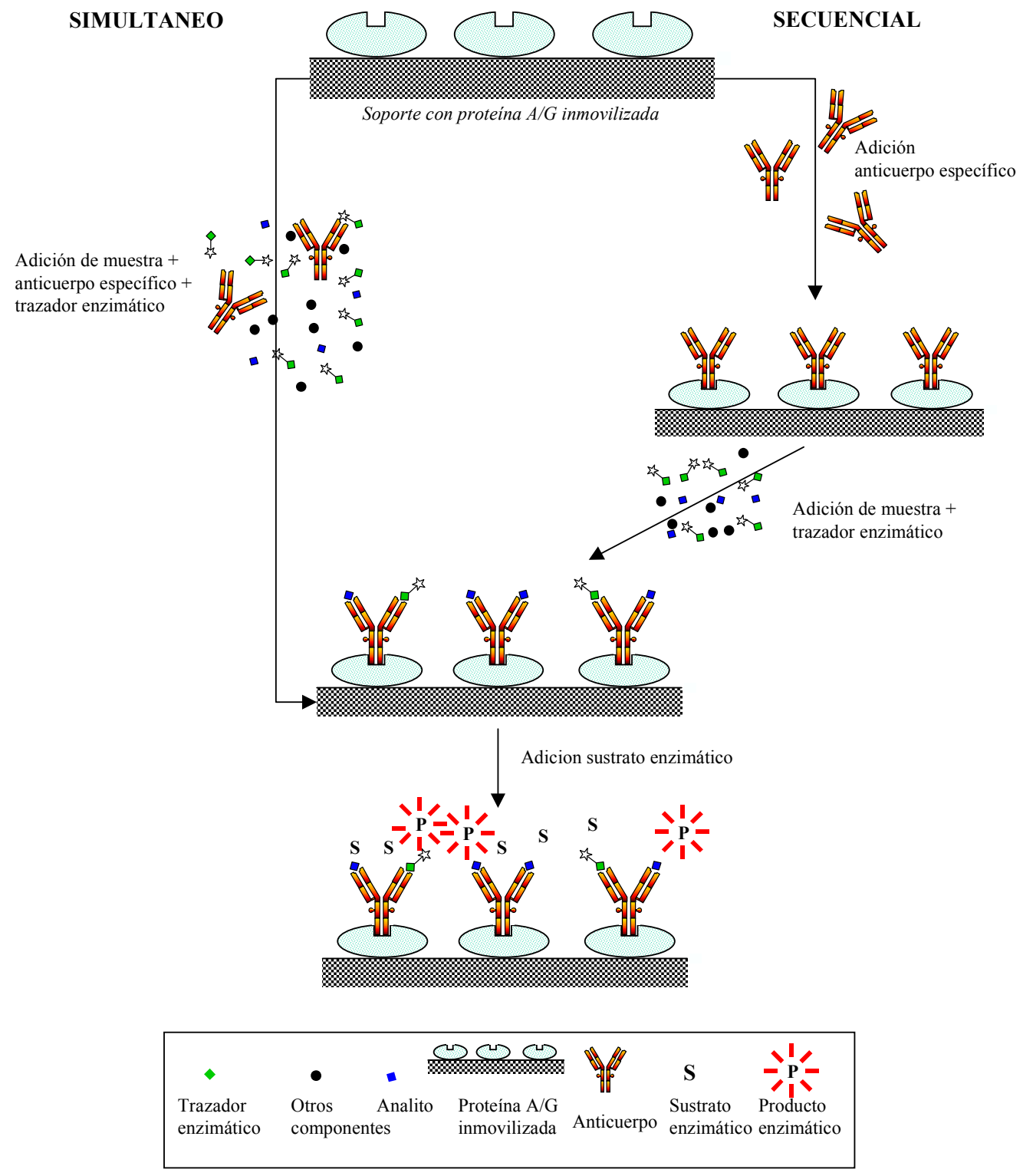

Figura 2.16. Representación de las etapas seguidas en los ensayos en formato de captura. Protocolos de ensayo simultáneo y secuencial

En la Figura 2.17 puede observarse la distribución de los reactivos en el sistema. 


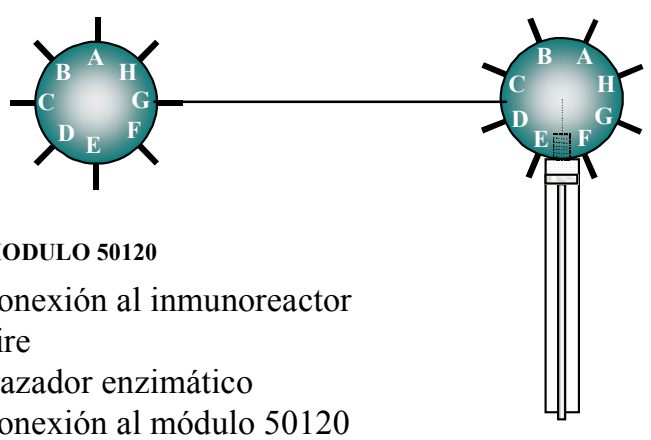
A: conexión al inmunoreactor
B: aire
C: trazador enzimático
D: conexión al módulo 50120
E: tampón de lavado
F: disolución $\mathrm{H}_{2} \mathrm{O}_{2}$
MODULO 50300
$\mathrm{G}$ : disolución HPPA
A: agente desorbente
H: desecho
$\mathrm{B}$ : anticuerpo primario
$\mathrm{C}-\mathrm{H}$ : patrones o muestras

Figura 2.17. Formato de captura. Conexión módulos-disoluciones

Todas las disoluciones fueron preparadas en PBT, excepto las muestras y patrones que fueron realizadas utilizando el medio orgánico de trabajo.

\subsection{SISTEMAS DE DETECCIÓN EMPLEADOS EN EL DESARROLLO DE LOS INMUNOSENSORES}

En este apartado se hace una breve descripción de los sistemas de detección empleados en el desarrollo de los diferentes inmunosensores.

\subsubsection{Inmunosensores con detección fluorescente}

Para el desarrollo de estos inmunosensores se utilizó, en todos los formatos, la peroxidasa del rábano picante (HRP) como enzima marcadora. Esta enzima genera un producto fluorescente $\left(\lambda_{\text {ex }} 320 \mathrm{~nm}\right.$ y $\left.\lambda_{\text {em }} 405 \mathrm{~nm}\right)$ con el substrato HPPA en presencia de $\mathrm{H}_{2} \mathrm{O}_{2}$. Este sistema de detección, ampliamente utilizado en métodos inmunoquímicos en flujo $(148,153)$ y en inmunosensores $(44)$, ha sido escogido como modelo en todos los sistemas desarrollados en esta tesis.

\subsubsection{Inmunosensores con detección fluorescente con resolución temporal}

En estos sistemas se ha empleado un complejo tetracarboxílico de terbio (III) derivado del sistema piridil bispirazol y funcionalizado como isotocianato, cuyo nombre químico es $\quad\{2-\{\mathrm{N}-\{1-\{6-\{3-\{[$ bis(carboxilatometil)amino]metil $\}-1 \mathrm{H}-$ pirazol-1-yl $\}-$ piridin-2-yl $\}$-1H-pirazol-3-ylmetil\}-N-(carboxilatometil)amino\}-6-(4-

isotiocianatobenzoil) amino]hexanoato\} terbio (III). Este compuesto, cuya síntesis y 
propiedades han sido descritas previamente (200), presenta un rendimiento cuántico del $80 \%$ y un desplazamiento de stokes de $227 \mathrm{~nm}$. En la Figura 2.18 se muestra la estructura de dicha molécula. Este complejo presenta una zona cromófora formada por la piridina y los dos pirazoles. La radiación absorbida se transfiere desde ellas al terbio, que es el que emite la señal luminiscente.

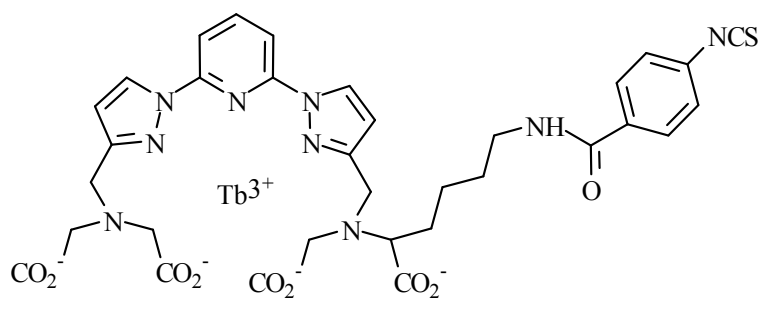

Figura 2.18. Estructura del complejo de Tb

Los espectros de emisión y excitación de dicha molécula (Figuras 2.19 y 2.20) muestran dos máximos de excitación a 267 y 318 nm y tres máximos de emisión a 545, 595 y $605 \mathrm{~nm}$. Las condiciones de trabajo utilizadas para este sistema han sido $\lambda_{\text {exc }} 318$ $\mathrm{nm}$ y $\lambda_{\text {em }} 545 \mathrm{~nm}$, con tiempo de retardo de $0,1 \mathrm{~ms}$, a pesar de que la absorción a $267 \mathrm{~nm}$ es ligeramente mayor pueden producirse interferencias debidas a las especies proteicas utilizadas en los ensayos.

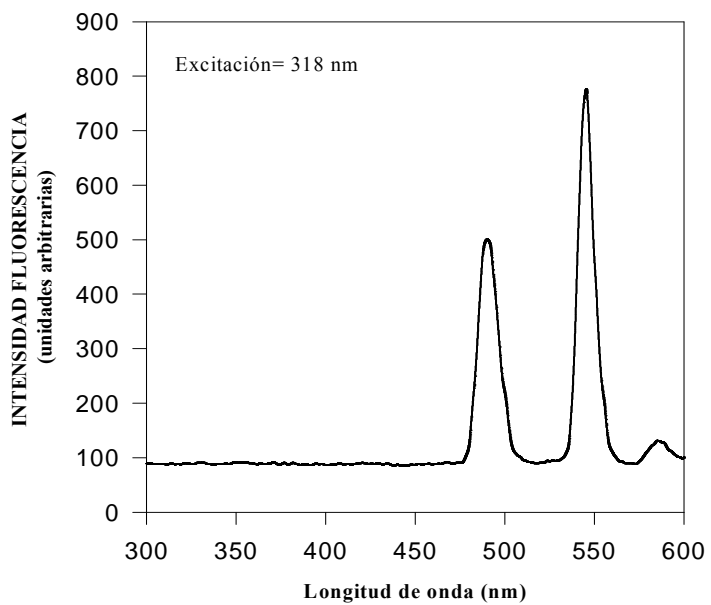


Figura 2.19. Espectro de emisión del complejo de Tb

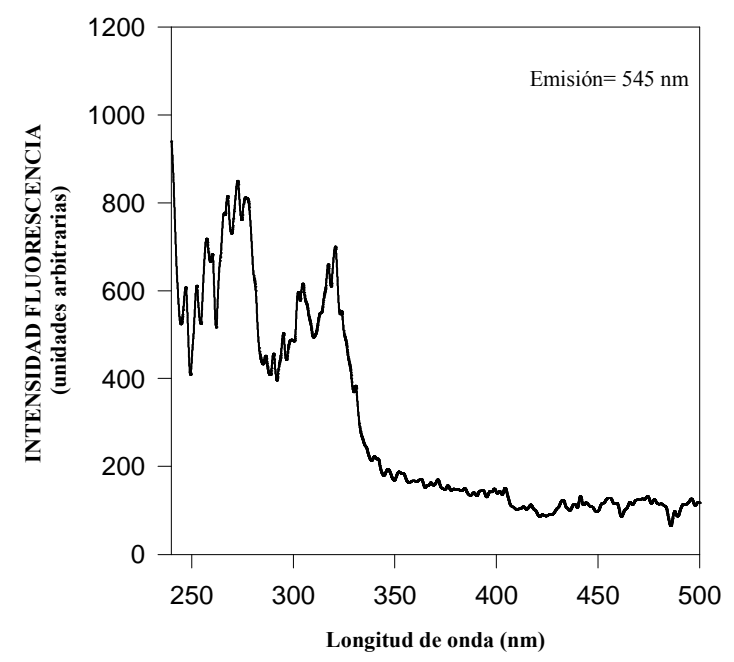

Figura 2.20. Espectro de excitación del complejo de Tb

\subsubsection{Conjugación complejo de Tb-hapteno. Formato directo}

Se pretendía poner a punto un método de conjugación general basado en la unión del grupo carboxilo libre del hapteno a una diamina que actuaría de espaciador, de modo que el grupo amino libre pudiera unirse al complejo de Tb a través de su grupo isotiocianato. Básicamente, se obtendría la siguiente molécula:

\section{HAPTENO---ESPACIADOR---COMPLEJO Tb}

Para ello se utilizó el hapteno $\mathrm{CNH}$ (sistema carbaril) activado mediante el método del anhídrido mixto y cadaverina (1,5 pentanodiamina). Este procedimiento fue infructuoso, ya que el grupo carbamato del hapteno se mostró mas reactivo frente a la diamina que el anhídrido mixto, dando lugar a 1-naftol. En la Figura 2.21 se muestran los pasos seguidos para realizar la síntesis. Si bien esta reacción de acoplamiento con proteínas es totalmente efectiva, en este caso y debido a que existen menores impedimentos estéricos para acceder al grupo carbamato, se produce la descomposición del hapteno activado. Así pues, no se han podido desarrollar inmunosensores en formato directo utilizando este marcador y sistema inmunoanalítico. 


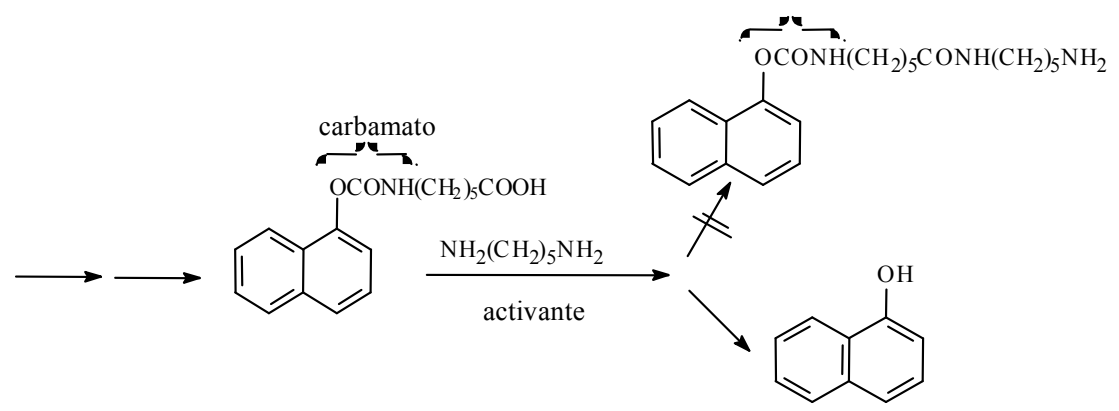

Figura 2.21. Descripción de las etapas seguidas para la funcionalización de haptenos con cadaverina

\subsubsection{Conjugación complejo de Tb-anticuerpo secundario. Formato indirecto}

Este procedimiento se basa en el método descrito por Khokhar y col. (201) para el acoplamiento del isotiocianato de rodamina a proteínas. Para ello, se disolvieron $5 \mathrm{mg}$ del complejo de $\mathrm{Tb}$ en $500 \mu \mathrm{l}$ tampón carbonato $50 \mathrm{mM}$, pH 9,6, conteniendo un $20 \%$ (v/v) de DMF y se incubaron con $2 \mathrm{mg}$ de anticuerpo secundario (anticonejo) disueltos en $500 \mu \mathrm{l}$ del mismo tampón. La reacción de acoplamiento transcurrió con ligera agitación en oscuridad durante 12 horas a $4^{\circ} \mathrm{C}$. Tras dializar el producto durante 12 horas a $4^{\circ} \mathrm{C}$-con una cambio de agua a la mitad del proceso- se comprobó la presencia del conjugado complejo de Tb-Ab secundario. Las Figuras 2.22 y 2.23 muestran los espectros de emisión y excitación de este conjugado.

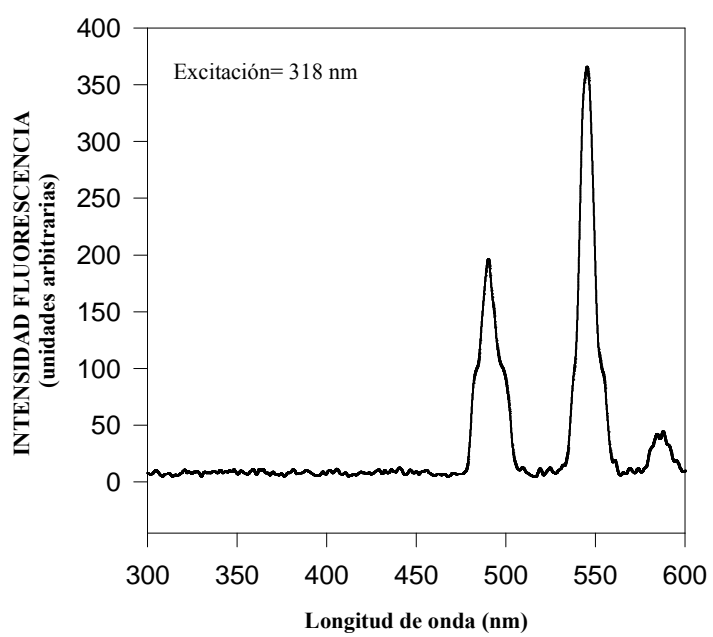


Figura 2.22. Espectro de emisión del conjugado complejo de Tb-anticuerpo secundario

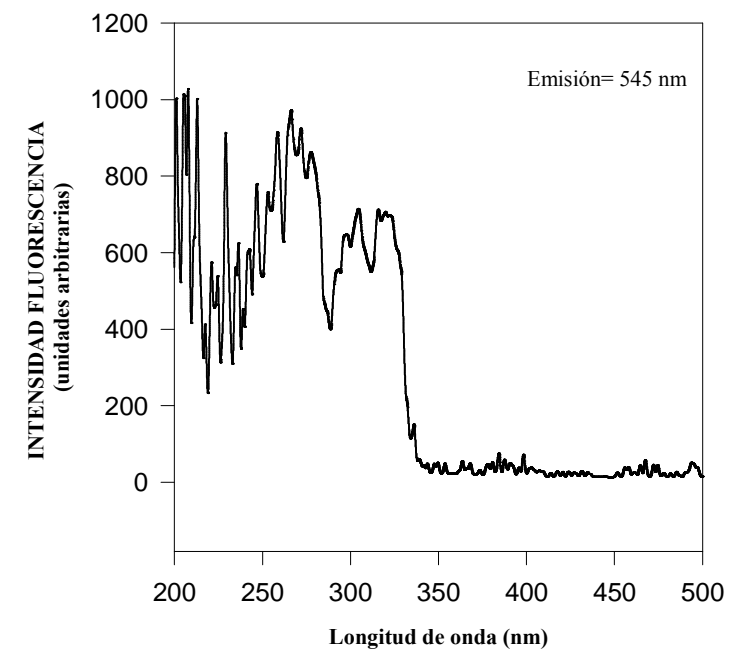

\section{Figura 2.23. Espectro de excitación del conjugado complejo de Tb-anticuerpo secundario}

Comparando estos espectros con los del complejo de $\mathrm{Tb}$ puede comprobarse que el proceso de acoplamiento no modifica el comportamiento de la molécula de $\mathrm{Tb}$ a la hora de su emisión de fluorescencia con resolución temporal.

Para realizar los ensayos utilizando formato indirecto, se situó la celda de flujo con el conjugado hapteno-BSA inmovilizado en el soporte GASc, lo más cerca posible del detector.

Básicamente, el protocolo de ensayo comprende las etapas esquematizadas en la Tabla 2.4. 
Tabla 2.4. Protocolo de ensayo correspondiente al sistema con detección fluorescente con resolución temporal

\begin{tabular}{l|l}
\hline & Evento \\
\hline 1 & Mezclado $^{\text {a }}$ de $0,3 \mathrm{ml}$ de anticuerpo primario y $0,8 \mathrm{ml}$ de medio orgánico \\
2 & Inyección de $1 \mathrm{ml}$ de la mezcla anterior a $0,25 \mathrm{ml} \mathrm{min}^{-1}$ \\
3 & Lavado del inmunorreactor con $2,5 \mathrm{ml}$ de PBST \\
4 & Inyección de $0,2 \mathrm{ml}$ de anticuerpo secundario marcado con el complejo de $\mathrm{Tb}$ \\
5 & Lavado del inmunorreactor con $2,5 \mathrm{ml}$ de PBST a $1 \mathrm{ml} \mathrm{min}{ }^{-1}$ \\
6 & Incubación durante 1 minuto. Lectura de fluorescencia con resolución temporal \\
7 & Inyección de disolución de agente desorbente ${ }^{\mathrm{b}}$ a $0,5 \mathrm{ml} \mathrm{min}^{-1}$ \\
8 & Lavado del inmunorreactor con $2,5 \mathrm{ml}$ PBST a $1 \mathrm{ml} \mathrm{min}^{-1}$. Fin de ciclo. \\
\hline $\begin{array}{l}\text { a Previo a cada paso el sistema efectúa un ciclo de lavado con la disolución a utilizar } \\
{ }^{\mathrm{b}} \text { El volumen de agente desorbente es variable en función del medio orgánico y de los inmunorreactivos utilizados }\end{array}$
\end{tabular}

En la Figura 2.24 se muestra esquemáticamente la distribución de los reactivos en el sistema.

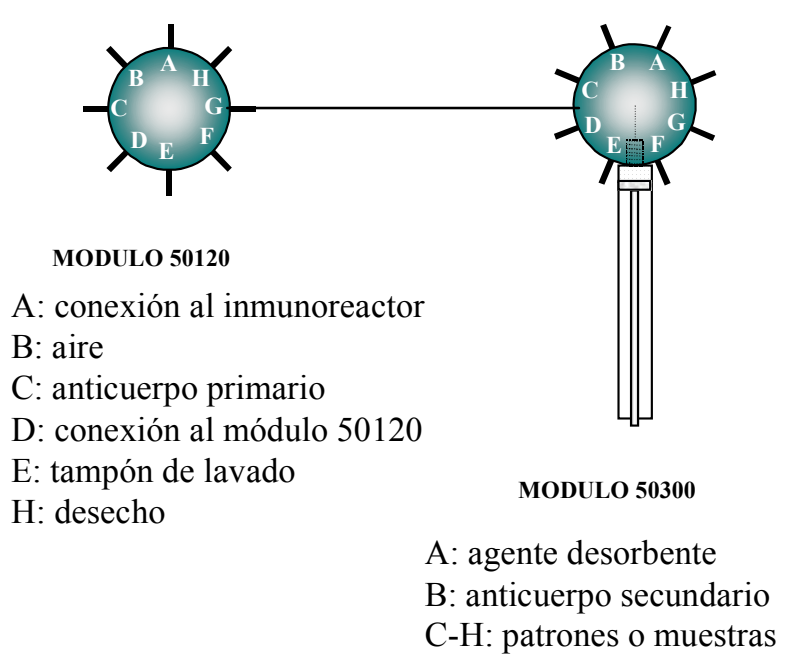

Figura 2.24. Inmunosensores con detección fluorescente con resolución temporal. Conexión módulos-disoluciones

\subsubsection{Inmunosensores con detección luminiscente}

Para el desarrollo de los inmunosensores con detección luminiscente se utilizó fosfatasa alcalina como enzima marcadora. Esta enzima es aislada a partir de la mucosa intestinal bovina o a partir de E. coli. Una unidad de actividad de esta enzima corresponde a la hidrólisis de $1 \mu \mathrm{mol}$ de $p$-nitrofenil fosfato ( $p$-NPP) por minuto. La 
disolución de substrato está compuesta por glicina $100 \mathrm{mM}, \mathrm{ZnCl}_{2} 1 \mathrm{mM}, \mathrm{MgCl}_{2} 1 \mathrm{mM}$ y $p$-NPP 6 mM, pH 10,4 o dietanolamina $1 \mathrm{M}, \mathrm{MgCl}_{2} 0,5 \mathrm{mM}$ y $p$-NPP $15 \mathrm{mM}, \mathrm{pH} 9,8$.

También se ha ensayado un substrato enzimático perteneciente a la familia de los 1,2 dioxetanos. En un trabajo reciente realizado por Adams et al. (202) se describen los fundamentos fisicoquímicos así como una perspectiva histórica del empleo de sustancias que contienen en su molécula el grupo 1,2 dioxetano y su uso como substrato quimioluminiscente de la fosfatasa alcalina. Esta familia de substratos quimioluminiscentes, entre los que destaca el denominado AMPPD: [3-(2'espiroadamantil)-4-metoxi-4-(3''-fosforiloxi)-fenil-1,2-dioxetano], recientemente sintetizado (203), emiten luz cuando son activados por la acción de la fosfatasa alcalina. Esta enzima desfosforila el dioxetano produciendo un anión fenolato con una vida media muy prolongada, lo que hace que la señal de emisión se acumule. Este hecho permite un alto tiempo de decaimiento que puede ser de varias horas. Su descomposición es la que genera la señal luminosa registrada. En resumen, estos compuestos tienen en su molécula el grupo 1,2 dioxetano, capaz de generar energía para su emisión de luz y un grupo fenol fosfato por el cual la enzima cataliza dicha reacción. Estas sustancias han sido empleadas para la determinación ultra-sensible de tirotropina, pruebas de ADN y marcadores tumorales (204), entre otras muchas aplicaciones. De hecho y utilizando estos substratos han podido detectarse concentraciones de hasta $10^{-15}$ $\mathrm{mol} / \mathrm{l}$ de fosfatasa alcalina (205). Inmovilizada en membranas, ha podido detectarse a niveles inferiores a $10^{-20} \mathrm{~mol} / \mathrm{l}(206)$.

En este trabajo se ha utilizado un dioxetano comercial denominado CDP-Star (Tropix, PE Applied Biosystems, Massachusetts, USA), cuyo nombre químico es 2cloro-5-(4-metoxisiro \{1,2-dioxetano-3,2' -(5' -cloro)-triciclo[3.3.1.1 $\left.1^{3,7}\right]$ decano $\}$-4-il)-1fenil fosfato disódico (CDP). Esta sustancia es un derivado 1,2 dioxetano aplicado en la detección de fosfatasa alcalina, libre o conjugada, tanto en disolución como en ensayos con membranas. En comparación con AMPPD presenta una cinética más rápida, lo que permite obtener la misma señal en aproximadamente la mitad de tiempo. Además muestra una mejor relación señal/ruido.

Por otro lado, pueden usarse sustancias potenciadoras que aumentan considerablemente la señal emitida. Estos productos son mezclas que pueden incrementar la señal de 10 a 500 veces y mantienen al substrato quimioluminiscente en un medio hidrofóbico, evitando así el efecto desactivador (quenching) frecuente en 
medios acuosos. En la Tabla 2.5. se recogen las sustancias comerciales empleadas en este estudio.

Tabla 2.5. Relación de las sustancias empleadas como potenciadores

\begin{tabular}{l|llc}
\hline Denominación & Nombre químico & Familia química & Máximo emisión (nm) \\
\hline Emerald II & $\begin{array}{l}\text { Cloruro de } \\
\text { poli(benziltributil)amonio } \\
\text { y fluoresceina sódica }\end{array}$ & $\begin{array}{l}\text { Homopolímero de amonio } \\
\text { cuaternario y compuesto } \\
\text { orgánico fluorescente }\end{array}$ & 542 \\
Sapphire II & $\begin{array}{l}\text { Cloruro de } \\
\text { poli(benziltributil) amonio }\end{array}$ & $\begin{array}{l}\text { Homopolímero de amonio } \\
\text { cuaternario }\end{array}$ & 463 \\
Sapphire & $\begin{array}{l}\text { Cloruro de } \\
\text { poli(benzildimetilvinilben } \\
\text { zil)amonio }\end{array}$ & $\begin{array}{l}\text { Homopolímero de amonio } \\
\text { cuaternario }\end{array}$ & 463 \\
Emerald & $\begin{array}{l}\text { Cloruro de } \\
\text { poli(benzildimetilvinilben } \\
\text { zil)amonio y fluoresceina } \\
\text { sódica }\end{array}$ & $\begin{array}{l}\text { Homopolímero de amonio } \\
\text { cuaternario y compuesto } \\
\text { orgánico fluorescente }\end{array}$ & 542 \\
\hline
\end{tabular}

Todos estos compuestos fueron suministrados por Tropix, PE Applied Biosystems, MA, USA. Las aplicaciones más importantes descritas en la bibliografía para estos potenciadores, son en ensayos tipo ELISA y en la detección de ácidos nucleicos.

\subsection{DISOLVENTES ORGÁNICOS}

La selección de los disolventes orgánicos a emplear para el desarrollo de los diferentes ensayos se ha realizado, principalmente, teniendo en cuenta los disolventes más ampliamente utilizados en los procesos de extracción de productos fitosanitarios en diferentes matrices (207-209). De acuerdo con esto, se han escogido los siguientes compuestos:

$\Rightarrow$ Disolventes miscibles en agua: metanol, acetonitrilo y acetona. Otros disolventes miscibles como tetrahidrofurano, 2-propanol y $N-N$ ' dimetilformamida, fueron escogidos como disolventes de transferencia, con el fin de compatibilizar los disolventes inmiscibles en agua con los tampones acuosos utilizados en inmunosensayo.

$\Rightarrow$ Disolventes inmiscibles en agua: hexano, acetato de etilo y diclorometano.

Algunas propiedades de estos disolventes (210) se muestran en la Tabla 2.6.

Tabla 2.6. Propiedades físico-químicas de los disolventes empleados

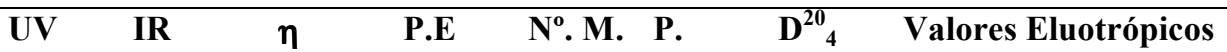




\begin{tabular}{lllllllllll} 
& $\begin{array}{l}\text { Cutoff } \\
(\mathbf{n m})\end{array}$ & $\left.\mathbf{( 2 0}{ }^{\mathbf{}} \mathbf{C}\right)$ & & $\left.\mathbf{(}^{\mathbf{o}} \mathbf{C}\right)$ & $\mathbf{( M ) *}$ & & & Alúmina & $\mathbf{C}_{\mathbf{1 8}}$ & Silica \\
\hline $\mathbf{M e O H}$ & 205 & 1,3284 & 0,55 & 64,70 & 12,00 & 5,1 & 0,792 & 0,95 & 1,0 & 0,70 \\
$\mathbf{M e C N}$ & 190 & 1,3441 & 0,38 & 81,60 & 11,17 & 5,8 & 0,782 & 0,65 & 3,1 & 0,52 \\
$\mathbf{A C T}$ & 330 & 1,3587 & 0,36 & 56,29 & 15,17 & 5,1 & 0,791 & 0,56 & 8,8 & 0,53 \\
$\mathbf{T H F}$ & 212 & 1,4072 & 0,55 & 66,00 & 17,00 & 4,0 & 0,887 & 0,45 & 3,7 & 0,53 \\
$\mathbf{I S}$ & 205 & 1,3772 & 2,40 & 82,26 & 15,00 & 3,9 & 0,785 & 0,82 & 8,3 & 0,60 \\
$\mathbf{D M F}$ & 268 & 1,4305 & 0,92 & 153,00 & 12,00 & 6,4 & 0,950 & --- & 7,6 & -- \\
$\mathbf{H X}$ & 195 & 1,3749 & 0,31 & 68,70 & 29,00 & 0,1 & 0,659 & 0,01 & --- & 0,00 \\
$\mathbf{A c E t}$ & 256 & 1,3724 & 0,45 & 77,11 & 19,00 & 4,4 & 0,901 & 0,58 & --- & 0,48 \\
$\mathbf{C H} \mathbf{C l}_{2}$ & 233 & 1,4241 & 0,44 & 39,75 & 20,00 & 3,1 & 1,325 & 0,42 & -- & 0,30
\end{tabular}

MeOH: metanol; MeCN: acetonitrilo; ACT: acetona; THF: tetrahidrofurano; IS: isopropanol; DMF: N-N' Dimetilformamida; HX: hexano; AcEt: acetato de etilo; $\mathrm{CH}_{2} \mathrm{Cl}_{2}$ : diclorometano; IR: índice de refracción; $\eta .:$ viscosidad; P.E.: punto de ebullición; $\mathrm{N}^{\circ}$.M.: número de miscibilidad; P.: polaridad; $\mathrm{D}^{20}{ }_{4}$ : densidad.

* Todos los pares de disolventes cuyo valor de M difiere en 15 unidades, son miscibles en todas las proporciones a $15^{\circ} \mathrm{C}$. Los pares cuya diferencia es 16 tienen una temperatura crítica de disolución entre $25^{\circ} \mathrm{C}$ y $75^{\circ} \mathrm{C}$. Una diferencia de 17 o superior indica la total inmiscibilidad de los disolventes o que presentan una temperatura crítica de disolución superior a $75^{\circ} \mathrm{C}(211)$.

\subsection{TRATAMIENTO DE MUESTRAS}

Las muestras reales (vegetales y aguas) fueron sometidas a un proceso de extracción de los analitos, con el extractante o eluyente escogido en cada caso particular. Las muestras vegetales fueron extraídas con disolventes orgánicos, mientras que en las muestras de agua se utilizó extracción en fase sólida.

Las muestras fueron reforzadas a varios niveles con el analito antes de proceder a su extracción. Los extractos orgánicos no analizados inmediatamente se mantuvieron a $-20{ }^{\circ} \mathrm{C}$ hasta su análisis. En todos los casos se utitilizaron muestras control no reforzadas.

\subsubsection{Muestras vegetales}

Las muestras vegetales (tomates, pimientos verdes y rojos) utilizadas, frescas y procesadas, fueron adquiridas de mercados locales. Antes de su extracción, las muestras fueron troceadas y homogeneizadas en un homogeneizador Osterizer (Milwaukee, WI), tras lo cual, porciones de las mismas fueron reforzadas a varios niveles con el analito (carbaril) y sometidas a los procedimientos de extracción descritos a continuación:

$\Rightarrow$ Procedimiento de referencia (MRS): Este protocolo de extracción es una modificación de un método multirresiduo puesto a punto para la extracción de plaguicidas de la familia de los N-metilcarbamatos (212). Básicamente, el procedimiento consistió en la adición a las muestras $(10 \mathrm{~g})$ de $20 \mathrm{ml}$ de 
acetonitrilo y $5 \mathrm{ml}$ de agua destilada. Esta mezcla fue agitada durante 10 minutos. El líquido sobrenadante fue filtrado a vacío mediante placa porosa G-3. Al líquido obtenido se le añadieron $30 \mathrm{ml}$ de agua destilada, $10 \mathrm{ml}$ de éter de petróleo y un poco de $\mathrm{NaCl}$. Esta mezcla se agitó durante 1 minuto y se decantó. La fase acuosa fue extraída con $5 \mathrm{ml}$ de éter de petróleo procediendo a una nueva decantación. La nueva fase orgánica obtenida se unió a la anterior. Este procedimiento se repitió 5 veces hasta que el último extracto etéreo no tuvo coloración. A continuación, la fase orgánica se lavó con $10 \mathrm{ml}$ de agua destilada. La nueva fase etérea se secó con $\mathrm{Na}_{2} \mathrm{SO}_{4}$ anhidro. Este extracto orgánico se llevó a sequedad en un baño termostático a $40{ }^{\circ} \mathrm{C}$ bajo corriente de nitrógeno y el residuo seco obtenido se redisolvió en $5 \mathrm{ml}$ de metanol. Esta disolución metanólica se limpió pasándola por un cartucho $\mathrm{C}_{18}$, previamente acondicionado. El extracto incoloro obtenido se diluyó al 50\% con tampón acuoso quedando listo para su posterior análisis.

$\Rightarrow$ Procedimiento de extracción directa: Básicamente, el procedimiento consistió en la adición de $10 \mathrm{ml}$ de metanol a $5 \mathrm{~g}$ de muestra vegetal y extracción durante 15 minutos con agitación intensa. El líquido sobrenadante se filtró a vacío utilizando una placa porosa G-3. El extracto obtenido se manipuló del modo indicado en el procedimiento de referencia.

\subsubsection{Muestras de agua}

En todos los casos, los analitos fueron extraídos mediante extracción en fase sólida (SPE), previo filtrado en papel Watman $n^{0} 5$ para eliminar cualquier materia en suspensión. Para tal fin se utilizaron cartuchos $\mathrm{C}_{18}$ (Waters, Milford, MA). El volumen de agua tomada en cada caso dependió del formato de ensayo utilizado.

Previamente a la extracción, los cartuchos fueron acondicionados utilizando el siguiente protocolo:

- Activación con $10 \mathrm{ml}$ de metanol

- Lavado con $10 \mathrm{ml}$ de agua destilada

- Adición de las muestras

- Lavado con $10 \mathrm{ml}$ de agua destilada

- Elución del analito retenido con $2 \mathrm{ml}$ de metanol 
Los extractos orgánicos obtenidos se diluyeron al 50\% (v/v) con el tampón de trabajo. Cuando fue necesario, éstos se almacenaron, congelados a $-20^{\circ} \mathrm{C}$, hasta su análisis.

\section{RESULTEUOSYIISOUSIÓN}

\subsection{SISTEMA MODELO. ESTUDIOS PRELIMINARES}

Para el desarrollo de las investigaciones se utilizó un sistema modelo carbarilanticarbaril, para el que se disponía de anticuerpos, tanto monoclonales como policlonales, y de trazadores enzimáticos (HRP), con el fin de obtener reglas básicas que pudieran aplicarse a otros sistemas y analitos de interés.

Además, y dado que el objetivo era desarrollar inmunosensores en flujo compatibles con medios orgánicos, se trabajó con formatos de ensayo heterogéneos competitivos y detección óptica. 


\subsection{ESTUDIO DE DISOLVENTES ORGÁNICOS}

En primer lugar se procedió a evaluar las condiciones de compatibilidad del material de trabajo con los disolventes orgánicos seleccionados (ver sección experimental).

Se observó que, en general, los disolventes puros no eran totalmente compatibles con los diferentes inmunorreactivos (precipitación por desnaturalización), disolución de soportes y materiales de trabajo: contenedores de líquidos, puntas de pipetas automáticas, etc. además, se presentaron problemas relacionados con la evaporación de disolventes.

Por ello, se realizó un estudio de miscibilidad de los disolventes seleccionados y de compatibilidad con el tampón acuoso de trabajo (PBST), preparando mezclas binarias y ternarias teóricamente compatibles con el sistema utilizado, evitando fenómenos de partición indeseables. Inicialmente, el criterio para seleccionar las mezclas, además de su miscibilidad, fue que éstas no provocaran la precipitación de los trazadores enzimáticos. Para tal fin, se adicionó el trazador CNH-HRP a una concentración de $1 \mathrm{mg} / 1$, a cada una de las mezclas obtenidas. En todos los casos, los ensayos de compatibilidad se realizaron de modo que las mezclas contuvieran el mayor porcentaje de disolvente orgánico posible. Cabe destacar que -de los disolventes escogidos- el THF y el isopropanol se utilizaron especialmente como disolventes de transferencia al tampón acuoso, debido a su miscibilidad con prácticamente cualquier disolvente polar y apolar de los recogidos en la serie eluotrópica. Los resultados de este estudio se recogen en la Tabla 3.1.

Tabla 3.1. Mezclas binarias y ternarias compatibles. Resultados expresados como porcentajes de disolvente orgánico en PBST (v/v)

\begin{tabular}{|c|c|c|c|c|c|c|c|c|c|}
\hline Mezcla & МеОН & $\mathrm{MeCN}$ & IS & THF & $\mathbf{A C}$ & HX & DC & $\mathbf{A E}$ & PBST \\
\hline M1 & 50 & & & & & & & & 50 \\
\hline M2 & & 50 & & & & & & & 50 \\
\hline M3 & & & 50 & & & & & & 50 \\
\hline M4 & & & & 50 & & & & & 50 \\
\hline M5 & & & & & 50 & & & & 50 \\
\hline M6 & & & 40 & & & 50 & & & 10 \\
\hline M7 & & & 35 & & & & & 25 & 40 \\
\hline M8 & & & 60 & & & & 25 & & 15 \\
\hline
\end{tabular}




\begin{tabular}{|c|c|c|c|c|c|c|c|c|}
\hline M9 & 25 & 25 & & & & & & 50 \\
\hline M10 & 25 & & 25 & & & & & 50 \\
\hline M11 & 25 & & & & 25 & & & 50 \\
\hline M12 & 25 & & & 25 & & & & 50 \\
\hline M13 & & 25 & & & 25 & & & 50 \\
\hline M14 & & 25 & 25 & & & & & 50 \\
\hline M15 & & 37,5 & & 37,5 & & & & 25 \\
\hline M16 & & & 25 & & 25 & & & 50 \\
\hline M17 & & & & 37,5 & 37,5 & & & 25 \\
\hline M18 & & & 37,5 & 37,5 & & & & 25 \\
\hline M19 & 30 & & & & & & 20 & 50 \\
\hline M20 & & 55 & & & & & 5 & 40 \\
\hline M21 & & & & & 40 & & 10 & 50 \\
\hline M22 & 55 & & & & & 5 & & 40 \\
\hline M23 & & & & & 55 & 5 & & 40 \\
\hline
\end{tabular}


Las mezclas miscibles con mayor porcentaje de disolvente orgánico que no precipitaron a los trazadores enzimáticos (Tabla 3.1) fueron las utilizadas posteriormente en el desarrollo de los inmunosensores.

Hay que indicar que el uso de disolventes inmiscibles en agua como hexano y diclorometano requieren un menor porcentaje de medio acuoso (PBST). En todos los casos, el isopropanol fue el disolvente de transferencia óptimo. Las mezclas binarias y ternarias de disolventes miscibles en agua fueron toleradas, en todos los casos, al $50 \%$ $\mathrm{v} / \mathrm{v}$, lo que resulta muy interesante ya que altas concentraciones de disolventes orgánicos permitirán que los factores de dilución de los extractos de las muestras sean bajos.

\subsection{ESTUDIOS PRELIMINARES: SELECCIÓN DE VARIABLES}

Dado el gran número de variables que afectan al desarrollo de los inmunosensores, se hizo necesario el empleo de una técnica de optimización rápida y sencilla. En este estudio se utilizó la técnica de inmunofiltración, que ha demostrado ser muy eficaz en la selección de variables para el desarrollo de inmunosensores en medios acuosos $(191,199)$.

Las variables estudiadas fueron las siguientes:

1. Inmunorreactivos:

1.a. Anticuerpos monoclonales: conjunto de ocho anticuerpos monoclonales frente a carbaril.

1.b. Trazadores enzimáticos: CNH-HRP, CNA-HRP y CPNU-HRP.

2. Medios orgánicos: un total de 23 mezclas orgánicas previamente seleccionadas según su miscibilidad y compatibilidad, de acuerdo a lo expuesto anteriormente.

3. Soportes: vidrio de poro controlado $(\mathrm{CPG})$ y gel de agarosa derivatizado con grupos hidrazina $(\mathrm{GAHz})$.

4. Desorbentes y condiciones de desorción más efectivas.

Es estudio se inició utilizando formato directo. Posteriormente, y a la vista de los resultados, se estudiaron otros formatos. 


\subsubsection{Ensayos de actividad}

Para conocer el efecto de las mezclas orgánicas en las propiedades de reconocimiento de los Abs, es necesario realizar ensayos de actividad con todas las combinaciones Ab-trazador, tanto homólogas como heterólogas, y soportes. Estos ensayos permiten conocer el efecto de las diferentes mezclas orgánicas compatibles sobre la actividad de los inmunosoportes constituidos por anticuerpos inmovilizados en dos soportes: GAHz y CPG.

Las señales obtenidas en los distintos medios orgánicos, fueron comparadas con las obtenidas en medio acuoso (PBST). El criterio de selección fue la obtención de una señal de absorbancia próxima a 1 a.u. En todos los casos, las señales inespecíficas, debidas a la unión del trazador enzimático a la membrana y al soporte, fueron evaluadas y utilizadas como control. En general, estas señales fueron minimizadas bloqueando los centros activos de la membrana con una proteína inerte, como por ejemplo BSA, y utilizando un tensoactivo como Tween 20 en el tampón acuoso de trabajo.

Estos ensayos permitieron seleccionar las mezclas orgánicas, soportes, Abs y trazadores que produjeron las mejores señales, y descartar aquellas que generaron señales mínimas, irreproducibles o necesitaron altas concentraciones de trazador.

Así por ejemplo, en la Figura 3.1 se muestran las señales relativas obtenidas al comparar los medios orgánicos y acuoso (PBST), utilizando GAHz como soporte, CNH-HRP como trazador y todos los anticuerpos monoclonales anticarbaril. 


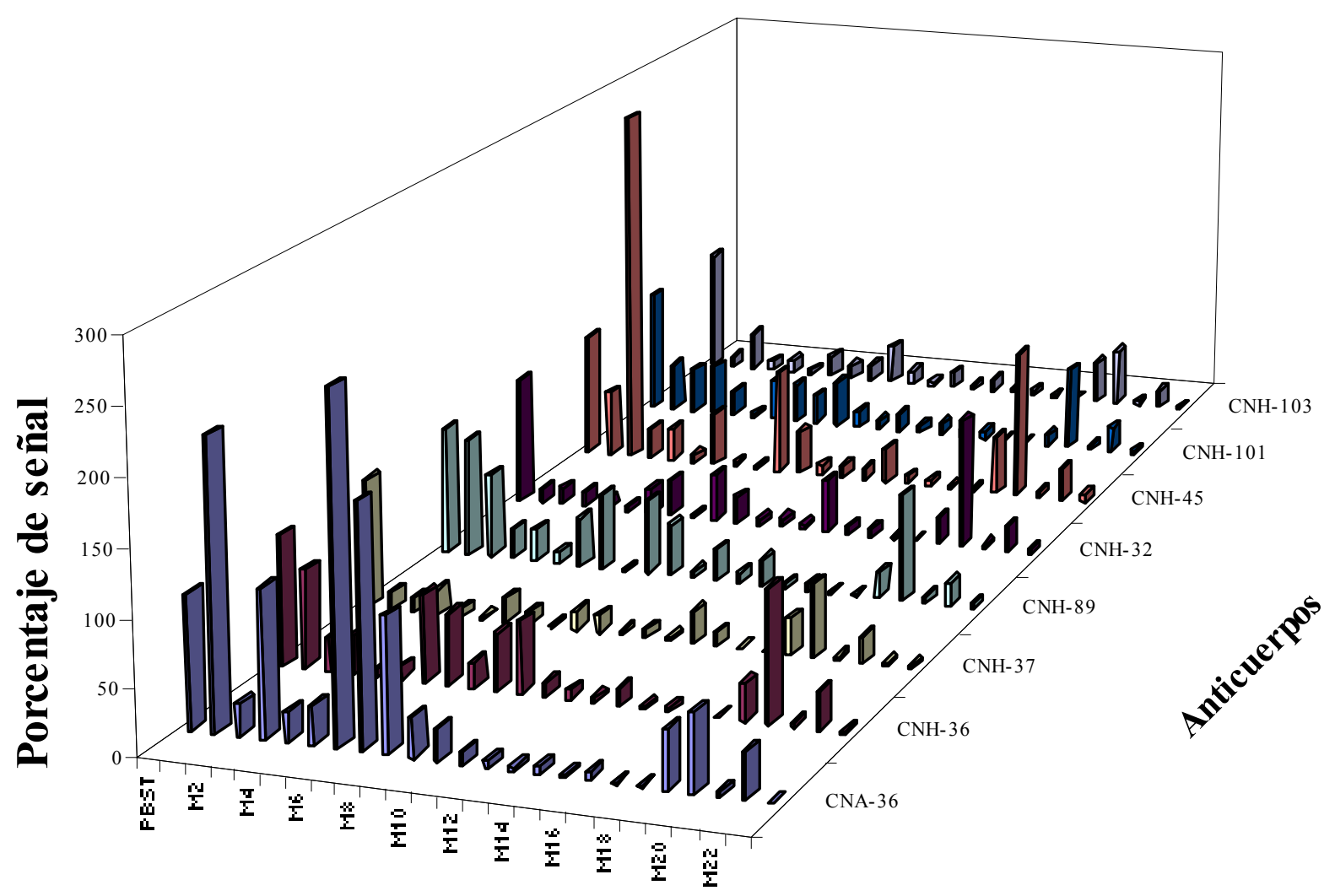

Medios orgánicos

Figura 3.1. Porcentajes de señal obtenidos mediante inmunofiltración utilizando los anticuerpos monoclonales anti-carbaril inmovilizados en GAHz. Trazador CNH-HRP y todos los medios orgánicos estudiados

Generalmente, las señales más elevadas se obtuvieron con las mezclas orgánicas que contenían disolventes miscibles en agua, excepto las que utilizan acetona y THF (M5, M11, M12, M13, M15, M16, M17, M18, M21, M23), independientemente de la mezcla orgánica, anticuerpo y trazador enzimático utilizado.

Los mismos resultados se obtuvieron en un estudio similar realizado con los anticuerpos inmovilizados en CPG, y todos los medios orgánicos y trazadores disponibles. Este comportamiento indica que la magnitud de la señal obtenida depende, principalmente, de la mezcla orgánica empleada en los ensayos.

Respecto al comportamiento de los trazadores enzimáticos, el CNA-HRP no produjo señal apreciable en ningún caso hasta una concentración de $3 \mathrm{ppm}$. A esta concentración, las señales inespecíficas debidas a la unión del trazador a la membrana y al soporte son muy importantes, por lo que fue desechado. Los trazadores CNH-HRP y 
CPNU-HRP fueron ensayados en un rango de 0,25 a 2 ppm, en función del anticuerpo y medio orgánico utilizado, ya que las señales inespecíficas eran mínimas.

Las mezclas orgánicas seleccionadas en los ensayos de actividad fueron las siguientes:

- $50 \%$ metanol (MeOH)- 50\% PBST (M1)

- $50 \%$ acetonitrilo (MeCN)- 50\% PBST (M2)

- $50 \%$ isopropanol (IS)- 50\% PBST (M3)

- $25 \% \mathrm{MeOH}-25 \% \mathrm{MeCN}-50 \%$ PBST (M9)

- $25 \% \mathrm{MeOH}-25 \%$ IS- 50\% PBST (M10)

- $25 \%$ MeCN- 25\% IS- 50\% PBST (M14)

- $25 \%$ acetato de etilo (AE)- $35 \%$ IS- $40 \%$ PBST (M7)

- $20 \%$ AE- 30\% MeOH- 50\% PBST (M19)

- $5 \%$ AE- 55\% MeCN- 40\% PBST (M20)

- $5 \%$ diclorometano (DC)- 45\% IS- 50\% PBST (M8)

- 5\% DC- 55\% MeOH- 40\% PBST (M22)

- $5 \%$ hexano (HX)- 55\% IS- 40\% PBST (M6)

Por otro lado, fueron seleccionados los anticuerpos que presentaban actividad en un mayor número de mezclas orgánicas. Estos fueron: CNA-36, CNH-36, CNH-45 y CNH-89.

En resumen, los ensayos de actividad realizados utilizando la técnica de inmunofiltración permitieron seleccionar los medios de trabajo, trazadores enzimáticos $\mathrm{y}$ anticuerpos con mejor respuesta. Todas estas condiciones fueron las utilizadas como punto de partida para el desarrollo de los inmunosensores.

\subsubsection{Ensayos de competición}

Dado que el número de variables a optimizar era todavía elevado (4 anticuerpos, 2 trazadores enzimáticos, 12 medios orgánicos y dos soportes de inmovilización), se hizo necesario acotar las condiciones finales a probar en los inmunosensores. Para tal fin y mediante la técnica de inmunofiltración, se realizaron ensayos de competición con todas las combinaciones posibles. En todos los casos se utilizaron tres valores de la curva de competición: el valor en ausencia de analito $\left(\mathrm{A}_{\max }\right)$, parámetro para el que se adoptó el criterio de que fuera como mínimo 0,6 u.a $\left(\mathrm{B}_{0}\right)$ de señal neta (restando los valores de absorbancia de las señales inespecíficas), y los valores correspondientes a 
concentraciones de carbaril de 10 y $100 \mu \mathrm{g} / \mathrm{l}$. Los ensayos se realizaron con los trazadores enzimáticos CNH-HRP y CPNU-HRP, y todos los medios orgánicos seleccionados. Los resultados obtenidos se muestran en la Tabla 3.2.

Tabla 3.2. Resultados obtenidos en los ensayos de competición mediante inmunofiltración (\%)

\begin{tabular}{|c|c|c|c|c|c|c|c|c|c|}
\hline \multirow[t]{2}{*}{ Medio } & \multirow[t]{2}{*}{ [analito] } & \multicolumn{2}{|l|}{ CNA-36 } & \multicolumn{2}{|l|}{ CNH-36 } & \multicolumn{2}{|l|}{ CNH-45 } & \multicolumn{2}{|l|}{ CNH-89 } \\
\hline & & CNH-HRP & $\begin{array}{l}\text { CPNU- } \\
\text { HRP }\end{array}$ & CNH-HRP & $\begin{array}{l}\text { CPNU- } \\
\text { HRP }\end{array}$ & CNH-HRP & $\begin{array}{l}\text { CPNU- } \\
\text { HRP }\end{array}$ & CNH-HRP & $\begin{array}{l}\text { CPNU- } \\
\text { HRP }\end{array}$ \\
\hline \multirow{4}{*}{ M1 } & 0 & 100 & 100 & 100 & 100 & 100 & 100 & 100 & 100 \\
\hline & $10 \mathrm{ppb}$ & 48 & 57 & 75 & 87 & 56 & 45 & 89 & 93 \\
\hline & $100 \mathrm{ppb}$ & 23 & 8 & 28 & 21 & 19 & 11 & 72 & 84 \\
\hline & 0 & 100 & 100 & 100 & 100 & 100 & 100 & 100 & 100 \\
\hline \multirow[t]{3}{*}{ M2 } & $10 \mathrm{ppb}$ & 69 & 62 & 92 & 89 & 55 & 32 & 100 & 98 \\
\hline & $100 \mathrm{ppb}$ & 38 & 25 & 39 & 41 & 32 & 25 & 89 & 80 \\
\hline & 0 & 100 & 100 & 100 & 100 & 100 & 100 & 100 & 100 \\
\hline \multirow[t]{3}{*}{ M3 } & $10 \mathrm{ppb}$ & 72 & 75 & 92 & 88 & 79 & 87 & 90 & 98 \\
\hline & $100 \mathrm{ppb}$ & 61 & 41 & 49 & 56 & 47 & 52 & 70 & 89 \\
\hline & 0 & 100 & 100 & 100 & 100 & 100 & 100 & 100 & 100 \\
\hline \multirow[t]{3}{*}{ M6 } & $10 \mathrm{ppb}$ & 76 & 64 & 87 & 99 & 95 & 99 & 100 & 98 \\
\hline & $100 \mathrm{ppb}$ & 60 & 48 & 78 & 87 & 65 & 89 & 90 & 99 \\
\hline & 0 & 100 & 100 & 100 & 100 & 100 & 100 & 100 & 100 \\
\hline \multirow[t]{3}{*}{ M7 } & $10 \mathrm{ppb}$ & 76 & 100 & 89 & 93 & 83 & 60 & 93 & 89 \\
\hline & $100 \mathrm{ppb}$ & 42 & 78 & 42 & 72 & 35 & 29 & 80 & 81 \\
\hline & 0 & 100 & 100 & 100 & 100 & 100 & 100 & 100 & 100 \\
\hline \multirow[t]{3}{*}{ M8 } & $10 \mathrm{ppb}$ & 89 & 92 & 100 & 95 & 80 & 93 & 100 & 99 \\
\hline & $100 \mathrm{ppb}$ & 75 & 83 & 95 & 88 & 64 & 80 & 100 & 96 \\
\hline & 0 & 100 & 100 & 100 & 100 & 100 & 100 & 100 & 100 \\
\hline \multirow[t]{3}{*}{ M9 } & $10 \mathrm{ppb}$ & 75 & 65 & 89 & 98 & 76 & 78 & 100 & 98 \\
\hline & $100 \mathrm{ppb}$ & 33 & 21 & 36 & 56 & 45 & 45 & 95 & 95 \\
\hline & 0 & 100 & 100 & 100 & 100 & 100 & 100 & 100 & 100 \\
\hline \multirow[t]{3}{*}{ M10 } & $10 \mathrm{ppb}$ & 98 & 82 & 99 & 90 & 75 & 81 & 90 & 94 \\
\hline & $100 \mathrm{ppb}$ & 45 & 38 & 52 & 37 & 49 & 39 & 85 & 84 \\
\hline & 0 & 100 & 100 & 100 & 100 & 100 & 100 & 100 & 100 \\
\hline \multirow[t]{3}{*}{ M14 } & 10 ppb & 89 & 92 & 85 & 90 & 78 & 81 & 89 & 92 \\
\hline & $100 \mathrm{ppb}$ & 55 & 41 & 71 & 59 & 65 & 70 & 85 & 74 \\
\hline & 0 & 100 & 100 & 100 & 100 & 100 & 100 & 100 & 100 \\
\hline \multirow[t]{3}{*}{ M19 } & $10 \mathrm{ppb}$ & 93 & 87 & 98 & 100 & 67 & 76 & 97 & 100 \\
\hline & $100 \mathrm{ppb}$ & 51 & 41 & 61 & 56 & 54 & 19 & 89 & 96 \\
\hline & 0 & 100 & 100 & 100 & 100 & 100 & 100 & 100 & 100 \\
\hline \multirow[t]{3}{*}{ M20 } & $10 \mathrm{ppb}$ & 95 & 83 & 100 & 91 & 97 & 99 & 99 & 96 \\
\hline & $100 \mathrm{ppb}$ & 81 & 65 & 78 & 88 & 91 & 93 & 80 & 82 \\
\hline & 0 & 100 & 100 & 100 & 100 & 100 & 100 & 100 & 100 \\
\hline \multirow[t]{2}{*}{ M22 } & $10 \mathrm{ppb}$ & 74 & 90 & 98 & 95 & 99 & 89 & 98 & 99 \\
\hline & $100 \mathrm{ppb}$ & 59 & 75 & 91 & 89 & 68 & 72 & 96 & 100 \\
\hline
\end{tabular}

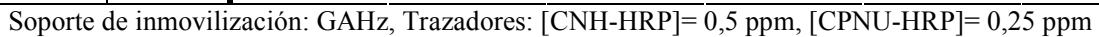

En ella se observa que el anticuerpo CNH-89 no compite en ninguno de los medios seleccionados. Este comportamiento es similar al observado para este anticuerpo en medio acuoso $(44,191)$.

Por otro lado, los anticuerpos CNA-36, CNH-36 y CNH-45 se seleccionaron para su posterior estudio en sistemas en flujo, ya que presentaban competición en la mayoría de las mezclas utilizadas. 
Respecto a los medios orgánicos, en general, la competición se vio influenciada por la polaridad de los medios de ensayo, siendo peor en las mezclas formadas por disolventes inmiscibles en agua (menor polaridad). Así pues, todas las mezclas orgánicas presentaban un comportamiento interesante para su aplicación al desarrollo de sensores.

\subsubsection{Reversibilidad de las reacciones Anticuerpo-Antígeno. Regeneración de inmunosoportes}

Un aspecto crítico a la hora de desarrollar inmunosensores es la reversibilidad de la reacción anticuerpo-antígeno (155), dado que dicha propiedad incide directamente en la reusabilidad de los sistemas desarrollados. Para que un inmunosensor pueda ser reutilizado, el inmunosoporte debe ser sometido a condiciones que rompan el inmunocomplejo formado tras cada ensayo.

Las sustancias empleadas para tal fin, deben poseer una alta concentración salina o un $\mathrm{pH}$ ácido $(\cong 2)$. A veces los propios disolventes orgánicos pueden tener este efecto. Todas estas condiciones son propias de desnaturalización de proteínas. Por ello, en mayor o menor extensión, los inmunosoportes tienen una vida limitada, ya sea por la desnaturalización de la especie inmunoactiva inmovilizada o por el propio deterioro del soporte.

En los inmunosensores, la reusabilidad viene determinada principalmente por la naturaleza de la unión inmunoquímica. De forma cualitativa, si el anticuerpo tiene una alta afinidad por el antígeno necesitará de condiciones más drásticas para romper dicha unión, por lo que los inmunosoportes tendrán una baja reusabilidad. Por el contrario, anticuerpos de muy baja afinidad requerirán condiciones de regeneración más suaves, con lo que la vida útil del inmunosensor será elevada. Como contrapartida, los sistemas basados en estos anticuerpos presentarán una baja sensibilidad. En general, se tendrá que llegar a un compromiso entre afinidad y reusabilidad de los inmunosoportes utilizados. Los problemas de regeneración serán mayores en el desarrollo de inmunosensores basados en formato directo, ya que en este caso, al estar inmovilizado el anticuerpo, es el que debe soportar los tratamientos de regeneración.

En los sistemas basados en formato indirecto estas premisas se ven suavizadas, ya que -en principio- la especie inmovilizada (conjugado hapténico) es más resistente a los desorbentes y el hapteno sólo tiene que mantener su integridad estructural para ser reconocido por el anticuerpo, que es adicionado en cada ciclo de ensayo (155). 
Los agentes desorbentes más usuales son: glicina $0,1 \mathrm{M} / \mathrm{HCl}$ a $\mathrm{pH} 2-3, \mathrm{NaSCN} 3$ $\mathrm{M}, \mathrm{H}_{3} \mathrm{PO}_{4}$ 0,1 M, pH 2,2, ácido acético 0,1 M, pH 2,8 y NaCl 5 M. Estos agentes fueron ensayados previamente utilizando la técnica de inmunofiltración (199) y posteriormente en los inmunosensores en flujo (44), evaluando su capacidad desorbente en medio acuoso. En todos los casos se comprobó que el agente más efectivo era disolución glicina $0,1 \mathrm{M} / \mathrm{HCl}, \mathrm{pH} 2$. Esta mezcla producía una rotura efectiva de las uniones $\mathrm{Ab}-\mathrm{Ag}$ con el menor volumen y tiempo de tratamiento.

Trabajando en medio orgánico y con el fin de corroborar estos resultados, se comparó el efecto de la glicina y el ácido acético 0,1 M, pH 2,8 también mediante inmunofiltración. Para realizar los ensayos se escogieron las siguientes condiciones experimentales:

- Agentes desorbentes: glicina $0,1 \mathrm{M} / \mathrm{HCl}, \mathrm{pH} 2$ y ácido acético 0,1 M, pH 2,8

- Inmunosoporte: CNH-36 inmovilizado en GAHz

- Medios orgánicos: 50\% MeOH-50\% PBST (M1, mezcla representativa de disolvente miscible) y 25\% AE-35\% IS- 40\% PBST (M7, mezcla representativa de disolvente inmiscible)

- Trazador enzimático: CNH-HRP

- Ciclos de tratamiento: máximo de 5 ciclos con el agente desorbente a ensayar

Los ensayos consistieron en realizar ciclos consecutivos de formación/desorción de los inmunocomplejos. El porcentaje de desorción fue calculado mediante la siguiente expresión:

$$
\text { Porcentaje de desorción }=\left(\mathrm{B}_{0}-\mathrm{B}\right) / \mathrm{B}_{0} \text { × } 100
$$

Donde:

$\mathrm{B}_{0}$ : señal de absorbancia sin tratamiento desorbente

B: señal de absorbancia tras cada ciclo de tratamiento con el desorbente Los resultados obtenidos en estos ensayos se muestran en la Tabla 3.3.

Tabla 3.3. Señales obtenidas tras varios ciclos de desorción*

\begin{tabular}{l|ccll}
\hline \multicolumn{2}{c}{} & \multicolumn{2}{c}{ Glicina $\mathbf{0 , 1}$ M/HCl $\mathbf{~ p H ~ 2 , 0}$} & \multicolumn{2}{c}{ Acido acético 0,1 M pH 2,8 } \\
\cline { 2 - 5 } & M1 & M7 & M1 & M7 \\
\hline 1 Ciclo & 97,1 & 97,3 & 21,6 & 16,0 \\
2 Ciclos & 98,3 & 98,1 & 38,6 & 24,7 \\
3 Ciclos & 100,0 & 99,4 & 57,5 & 45,3 \\
4 Ciclos & 100,0 & 100,0 & 78,3 & 75,1
\end{tabular}




\begin{tabular}{l|lcr}
5 Ciclos & 100,0 & 100,0 & 82,8 \\
\end{tabular}

Puede observarse que la desorción es prácticamente completa en los dos medios de ensayo utilizando glicina y un solo ciclo de tratamiento. En el caso del ácido acético, la desorción no es efectiva en ninguno de los medios, por lo que se requiere un número excesivo de ciclos de lavado (>>5) para la completa desorción.

A la vista de estos resultados, se concluye que el uso de una disolución Glicina $0,1 \mathrm{M} / \mathrm{HCl}, \mathrm{pH} 2$, permite regenerar completamente los inmunosoportes en sólo un ciclo de tratamiento.

\subsection{DESARROLLO DE INMUNOSENSORES PARA EL SISTEMA MODELO}

Todas las variables estudiadas mediante el sistema de inmunofiltración fueron trasladadas al inmunosensor para estudiar su comportamiento y obtener las condiciones finales de ensayo.

Para la puesta a punto de los inmunosensores en medios orgánicos se partió de algunas condiciones previamente optimizadas en medio acuoso (213).

Como substrato se utilizó una disolución de HPPA a 0,8 g/l, en combinación con peróxido de hidrógeno a $0,012 \%(\mathrm{v} / \mathrm{v})$. Este substrato permite efectuar la detección fluorimétrica $\left(\lambda_{\text {ex }} 320 \mathrm{~nm}\right.$ y $\lambda_{\mathrm{em}} 405 \mathrm{~nm}$ ) del producto de reacción con una sensibilidad elevada $(148,153)$.

Respecto a la densidad de inmovilización, tanto del anticuerpo como del conjugado hapténico, los criterios de selección se basaron en obtener una elevada actividad del inmunoadsorbente y máxima sensibilidad.

La geometría de los reactores fue también establecida utilizando minicolumnas de polimetacrilato de metilo, con la entrada y salida provistas de una rosca para el acoplamiento de conectores utilizados habitualmente en sistemas en flujo. El tamaño de cada reactor y por tanto el volumen de inmunosoporte a utilizar, fue optimizado de modo que se obtuviera una señal máxima con el menor volumen.

\subsubsection{Optimización del inmunosensor. Formato directo}

Para el desarrollo de los inmunosensores basados en formato directo se ensayaron todas las condiciones previamente seleccionadas mediante inmunofiltración. 
El tamaño óptimo del reactor fue el mismo (4 $\mathrm{mm}$ de longitud, $4 \mathrm{~mm}$ de diámetro interno) para ambos soportes (GAHz y CPG).

En primer lugar, se realizaron ensayos de actividad con el fin de evaluar los medios orgánicos seleccionados previamente por inmunofiltración, utilizando para ello los anticuerpos CNA-36, CNH-36 y CNH-45 inmovilizados en GAHz y el trazador CNH-HRP.

Mediante estos ensayos se optimizó también el volumen de mezcla orgánica a utilizar y el caudal de trabajo, siguiendo el criterio de alcanzar la máxima señal con la menor concentración de trazador. Se escogió 1,1 ml como volumen óptimo, de los cuales $300 \mu \mathrm{l}$ eran de trazador enzimático y $800 \mu \mathrm{l}$ de medio orgánico. El caudal de inyección fue de $0,25 \mathrm{ml} / \mathrm{min}$.

Por otro lado, se comprobó la correcta regeneración del inmunosoporte mediante la inyección del substrato enzimático tras cada ciclo analítico, evaluando así la señal residual obtenida. En todos los casos, la desorción fue total utilizando una disolución glicina $0,1 \mathrm{M} / \mathrm{HCl}$ a un $\mathrm{pH}$ comprendido entre 2,0 y 2,4. El volumen de desorbente requerido osciló entre $0,5 \mathrm{ml}$ y $2,0 \mathrm{ml}$, operando a un caudal de $0,5 \mathrm{ml} / \mathrm{min}$. En cada caso concreto, el agente desorbente fue ajustado ( $\mathrm{pH}$, volumen) para lograr una correcta desorción en las condiciones menos drásticas posibles, con el fin de alargar al máximo la vida útil del inmunosoporte.

Se comprobó que las mezclas con hexano (M6) y diclorometano (M8, M22 y M23) producían inestabilidad en la línea base, dada la alta persistencia de las mismas en el sistema. Además, causaron problemas de funcionamiento en las válvulas del módulo de manejo de fluidos, por lo que fueron descartadas. En otros casos fue necesario reducir la carga orgánica de las mezclas para obtener señales aceptables, por lo que seleccionó un nuevo grupo de medios orgánicos:

- $50 \%$ MeOH- 50\% PBST (M1)

- $50 \% \mathrm{MeCN}-50 \%$ PBST (M2)

- $\quad 25 \% \mathrm{MeCN}-75 \%$ PBST (LM2)

- $25 \% \mathrm{MeOH}-25 \% \mathrm{MeCN}-50 \%$ PBST (M9)

- $25 \% \mathrm{MeOH}-25 \%$ IS- 50\% PBST (M10)

- $25 \%$ MeCN- 25\% IS- 50\% PBST (M14)

- $10 \%$ AE- $25 \%$ IS- $65 \%$ PBST (LM7)

- $10 \%$ AE- 25\% MeOH- 65\% PBST (LM19) 
- $5 \% \mathrm{AE}-25 \% \mathrm{MeCN}-70 \%$ PBST (LM20)

Con estas mezclas se realizaron de nuevo ensayos de regeneración para los tres anticuerpos seleccionados (CNH-36, CNA-36 y CNH-45) inmovilizados en los dos soportes (CPG y GAHz), utilizando los dos trazadores enzimáticos seleccionados previamente (CNH-HRP y CPNU-HRP). Los resultados obtenidos se representan en las Figuras 3.2.1, 3.2.2 y 3.2.3. En cada una de ellas, se dan las combinaciones anticuerpotrazador-medio orgánico que presentaron señal aceptable utilizando la menor concentración posible de trazador. Esta variable se mostró muy importante, ya que altas concentraciones de trazador producían señales inespecíficas elevadas, haciendo inviable el desarrollo de los inmunosensores en dichos medios. La concentración máxima de trazador ensayada fue de $3 \mathrm{mg} / \mathrm{l}$ para CNH-HRP y $2 \mathrm{mg} / \mathrm{l}$ para CPNU-HRP. 


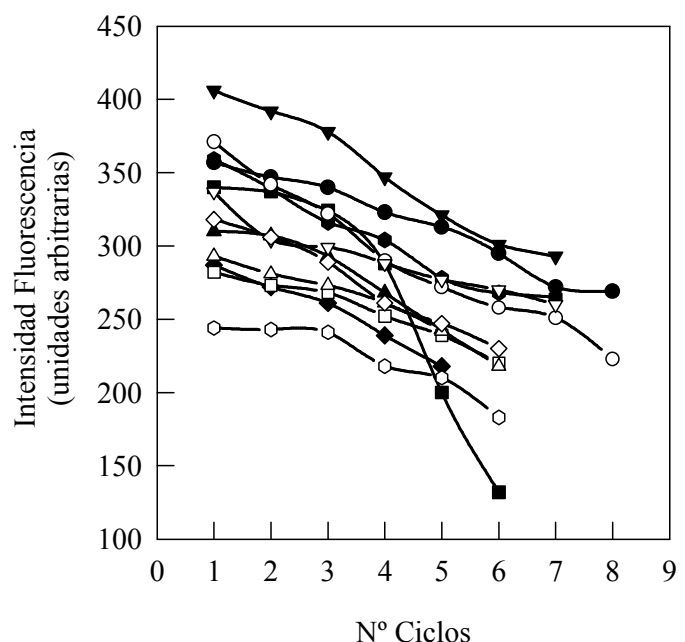

(a)

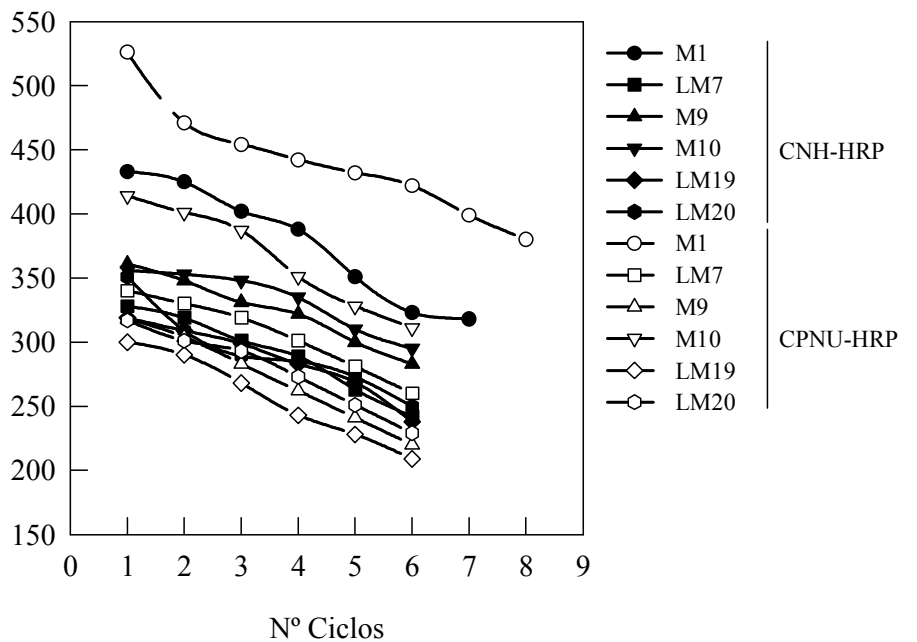

(b)

Figura 3.2.1 Señales de fluorescencia obtenidas en los ensayos de regeneración con el anticuerpo CNH 36 inmovilizado en GAHz (a) y CPG (b)

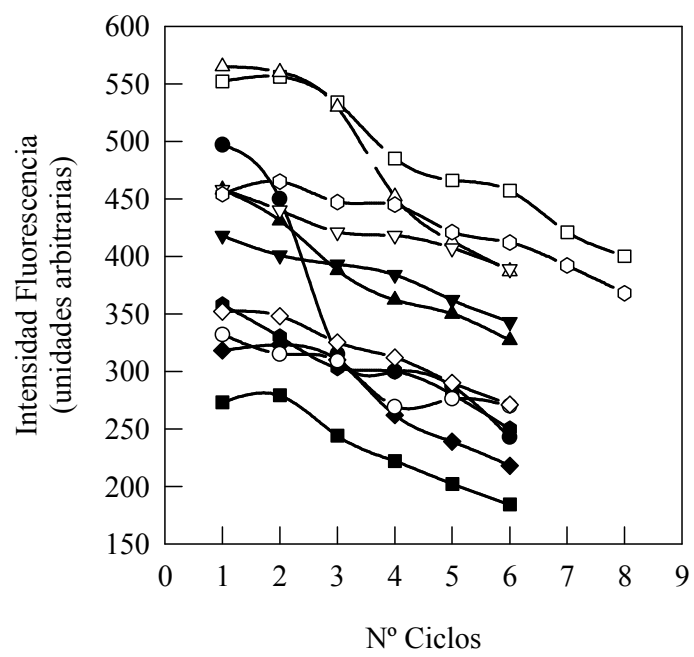

(a)

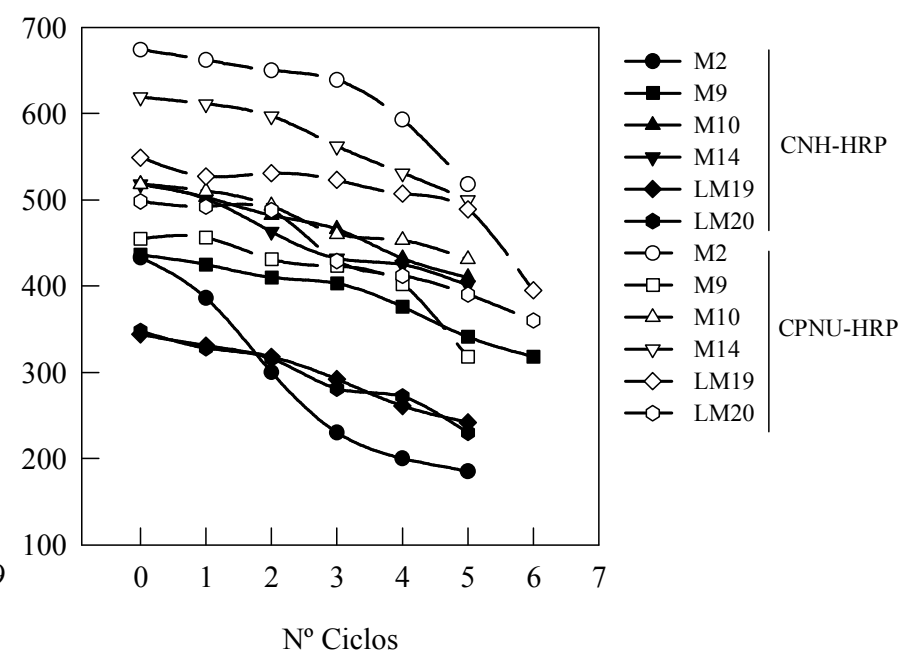

(b)

Figura 3.2.2 Señales de fluorescencia obtenidas en los ensayos de regeneración con el anticuerpo CNH 45 inmovilizado en GAHz (a) y CPG (b) 


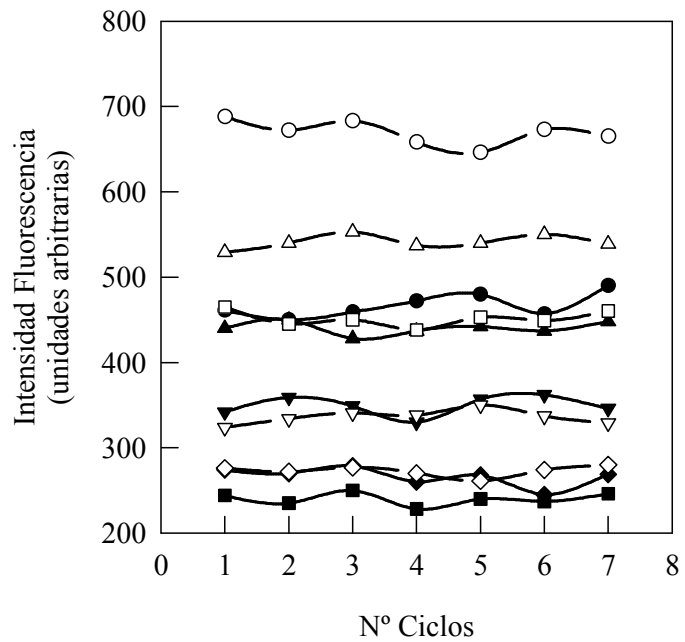

(a)

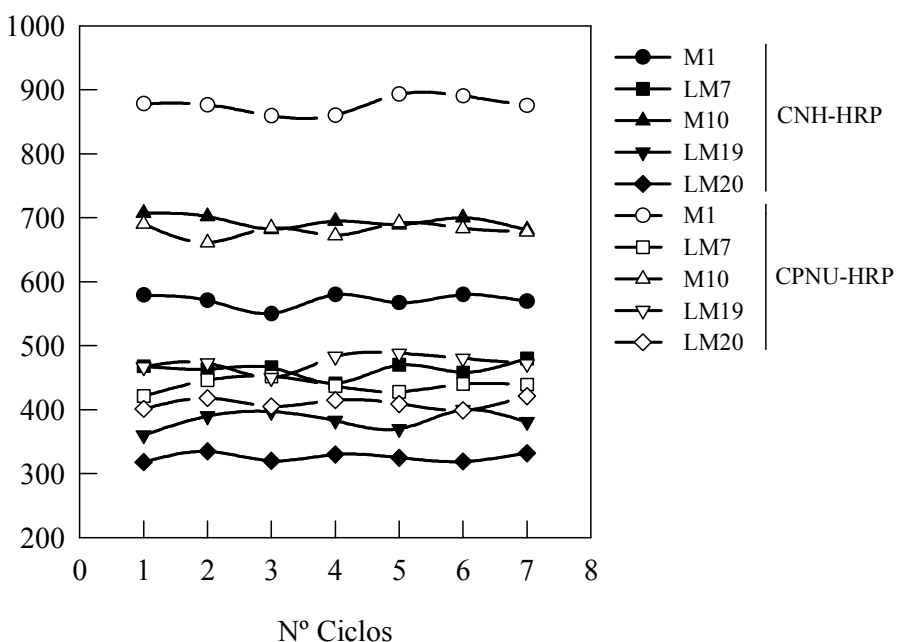

(b)

Figura 3.2.3 Señales de fluorescencia obtenidas en los ensayos de regeneración con el anticuerpo CNA 36 inmovilizado en GAHz (a) y CPG (b)

Como se aprecia en las figuras 3.2.1 y 3.2.2, los inmunosoportes preparados con los anticuerpos CNH-36 y CNH-45 no pudieron regenerarse en ninguna de las condiciones seleccionadas. Sólo el anticuerpo CNA-36 (Figura 3.2.3) proporcionó señales estables, independientemente del número de ciclos y variables ensayadas, lo que indicó la posibilidad de desarrollar inmunosensores para carbaril en este formato.

Por otro lado, puede observarse que, en general, las señales fueron más elevadas al utilizar como trazador enzimático la especie CPNU-HRP, incluso a menores concentraciones. Respecto a los soportes, en todos los casos se obtuvo más señal cuando se utilizó CPG, debido probablemente a los procesos de inmovilización seguidos en ambos casos; además, a volúmenes iguales de inmunosoporte, un sistema con CPG contiene aproximadamente 3 veces más de anticuerpo que cuando se utiliza GAHz.

En resumen, las condiciones seleccionadas como óptimas tras los ensayos de actividad y regeneración fueron:

- Anticuerpo monoclonal: CNA-36 inmovilizado en GAHz y CPG

- Trazadores enzimáticos: CNH-HRP y CPNU-HRP

- Medios orgánicos: 50\% MeOH - 50\% PBST (M1); 25\% MeOH - 25\% IS - 50\% PBST (M10); 10\%AE - 25\% MeOH - 65\% PBST (LM19); 10\% AE - 25\% IS - 65\% PBST (LM7); 5\% AE - 25\% MeCN - 70\% PBST (LM20) 
En estas condiciones se obtuvieron señales estables y una actividad (estimada en función del número de ciclos soportados) suficiente (Tabla 3.4) para garantizar la caracterización de los inmunosensores estudiados.

Tabla 3.4. Número mínimo de ciclos de regeneración efectuados con cada inmunosoporte y mezcla orgánica ensayada

\begin{tabular}{lllll}
\hline \multirow{2}{*}{ Medio orgánico } & \multicolumn{2}{c}{ GAHz } & \multirow{2}{*}{ CPG } \\
\hline & CNH-HRP & CPNU-HRP & CNH-HRP & CPNU-HRP \\
\cline { 2 - 5 } $50 \%$ MeOH-50\%PBST (M1) & 22 & 20 & 18 & 20 \\
10\%AE-25\%IS-65\%PBST (LM7) & 22 & 18 & 20 & 18 \\
10\%AE-25\%MeOH-65\%PBST (LM19) & 18 & 20 & 19 & 17 \\
$5 \%$ AE-25\%MeCN-70\%PBST (LM20) & 20 & 25 & 19 & 19 \\
25\%MeOH-25\%IS-50\% PBST (M10) & 20 & 20 & 18 & 17 \\
\hline MeOH: metanol; MeCN: acetonitrilo; IS: isopropanol; AE: acetato de etilo; PBST: PBS con 0,05\% Tween 20; MAb: CNA-36
\end{tabular}

\subsubsection{1.- Ensayos de competición en formato directo}

Los ensayos competitivos se realizaron utilizando todas las variables anteriormente seleccionadas. Las curvas de competición obtenidas se muestran en la Figura 3.3. La Tabla 3.5 recoge los valores $I_{50}$-parámetro que estima la sensibilidadpara todas las combinaciones estudiadas.

Tabla 3.5. Valores de $I_{50}(\mu \mathrm{g} / \mathrm{l})$ obtenidos en formato directo con el anticuerpo monoclonal CNA 36 inmovilizado en los dos soportes. Ensayos realizados con los trazadores y medios orgánicos seleccionados

\begin{tabular}{lllll}
\hline Medio orgánico & \multicolumn{2}{c}{ GAHz } & \multicolumn{2}{c}{ CPG } \\
\hline & CNH-HRP & CPNU-HRP & CNH-HRP & CPNU-HRP \\
\hline
\end{tabular}




$\begin{array}{llccc}\text { 50\%MeOH-50\%PBST (M1) } & 19,7 \pm 4,6 & 17,3 \pm 3,7 & 29,3 \pm 5,9 & 20,3 \pm 3,9 \\ \text { 10\%AE-25\%IS-65\%PBST (LM7) } & 90,0 \pm 20,3 & 110,3 \pm 17,9 & 63,2 \pm 17,5 & 47,8 \pm 15,8 \\ \text { 10\%AE-25\%MeOH-65\%PBST (LM19) } & 104,8 \pm 19,5 & 76,9 \pm 18,4 & 89,8 \pm 18,7 & 72,9 \pm 19,1 \\ & & & & \\ \text { 5\%AE-25\%MeCN-70\%PBST (LM20) } & 157,1 \pm 22,2 & 95,6 \pm 17,5 & 59,6 \pm 16,7 & 54,8 \pm 16,7 \\ & & 19,5 \pm 5,7 & 38,1 \pm 7,5 & 15,2 \pm 3,8\end{array}$

MeOH: metanol; MeCN: acetonitrilo; IS: isopropanol; AE: acetato de etilo; PBST: PBS con 0.05\% Tween 20. Valores expresados como media \pm desviación estándar $(\mathrm{n}=3)$

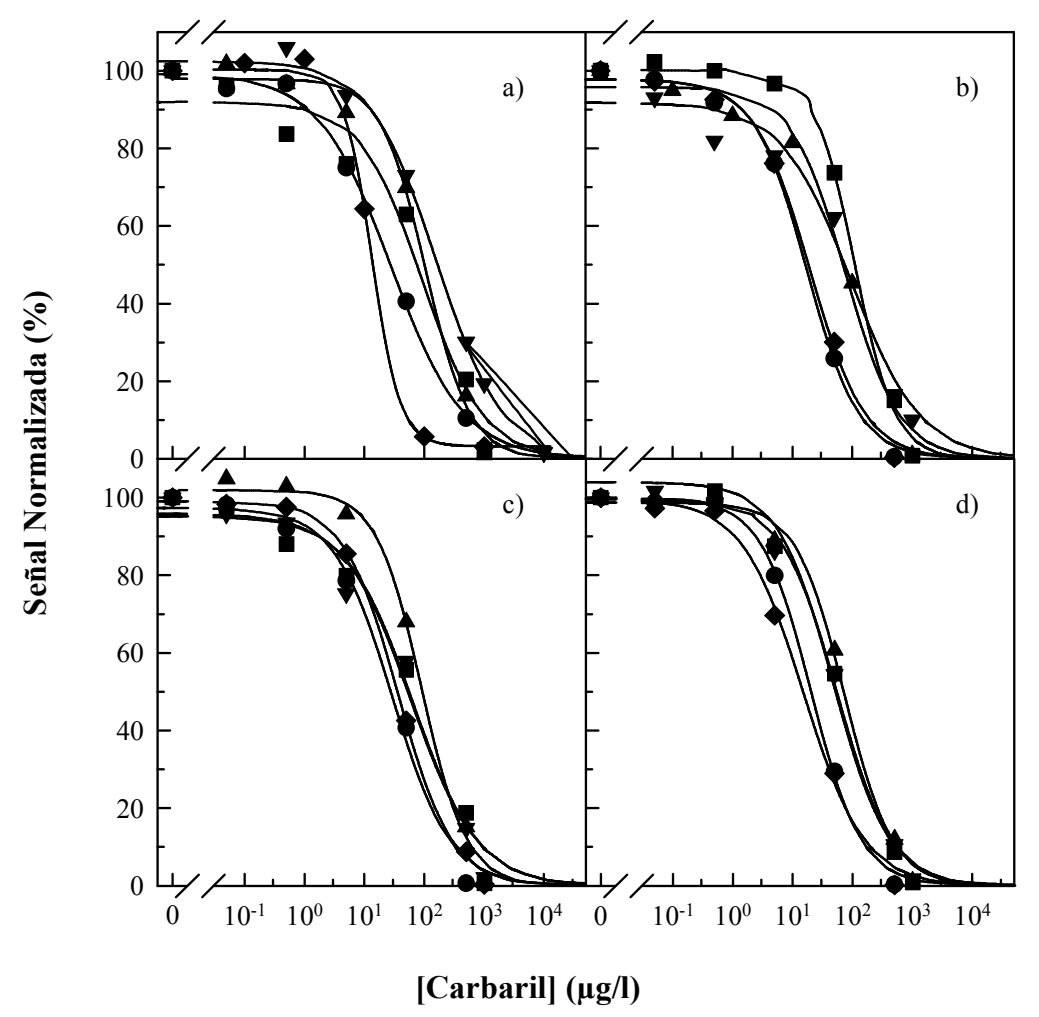

Figura 3.3. Curvas de competición obtenidas para todas las combinaciones inmunosoporte-trazador: a) anticuerpo CNA 36 inmovilizado en GAHz y CNH-HRP como trazador; b) idénticas condiciones, excepto trazador CPNU-HRP; c) CNA 36 inmovilizado en CPG y CNH-HRP como trazador; d) idénticas condiciones, excepto trazador CPNU-

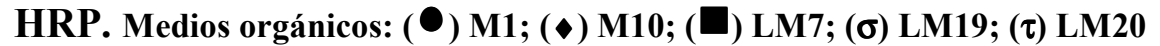

Como se aprecia en la Tabla 3.4, existen grandes diferencias de sensibilidad entre los ensayos realizados con las mezclas de disolventes miscibles (M1 y M10) y los correspondientes a los no-miscibles (LM7, LM19 y LM20). Estas diferencias pueden ser explicadas en parte, por el hecho de que el analito debe difundir desde el medio orgánico hasta los sitios de unión del anticuerpo, proceso que se hace más lento al 
disminuir la polaridad de la mezcla. Este resultado pone de manifiesto el marcado carácter hidrofílico de las interacciones inmunoquímicas estudiadas.

Por otro lado, se constata que hay una relación entre la polaridad del medio de análisis y la sensibilidad del ensayo, de modo que -en general- el sistema es más sensible al aumentar la polaridad de la mezcla orgánica.

Respecto a los soportes utilizados, el anticuerpo inmovilizado en CPG se muestra más sensible en las mezclas de disolventes apolares que inmovilizado en GAHz. Esto es debido a la menor concentración de trazador necesaria en el primer caso, lo que mejora la sensibilidad del ensayo. Con las mezclas que contienen metanol estas diferencias son menos apreciables, si bien en este medio, los ensayos más sensibles se obtienen utilizando GAHz.

Por otro lado, el trazador CPNU-HRP mejora, en general, la sensibilidad de los ensayos, debido a que se necesitan menores concentraciones para obtener señales aceptables, lo que se traduce en una mejor competición. Este efecto es más apreciable cuando se emplea como soporte CPG. El concepto homología-heterología de hapteno no es aplicable en este caso, ya que ambos trazadores son heterólogos respecto al anticuerpo utilizado en los ensayos. Cabe destacar que la sensibilidad en todos los casos es menor a la obtenida en medio acuoso, ya sea en formato ELISA $(166,168)$ o en inmunosensor (44).

El inmunosoporte fue desechado cuando: (i) existía pérdida apreciable de las propiedades hidrodinámicas del sistema; (ii) la sensibilidad del ensayo disminuía apreciablemente (aumento del valor de $\mathrm{I}_{50}$ ) y (iii) las señales absolutas caían un valor del $10 \%$ del inicial.

El anticuerpo inmovilizado en GAHz toleró hasta 95 ciclos de regeneración, llegando a 171 en el caso de utilizar CPG. Este resultado es debido a que en el caso del anticuerpo inmovilizado en CPG fue necesaria una menor concentración de trazador para obtener una señal aceptable, lo que requirió un menor volumen de disolución regenerante. Dado que esta etapa incide en la vida útil del sensor, es obvio que cuanto más suaves sean las condiciones de desorción mayor será la reusabilidad del inmunosoporte. Así pues, se concluye que el anticuerpo inmovilizado en CPG se mostró más resistente que inmovilizado en GAHz, fenómeno previamente observado (213). Este hecho también es debido a las mejores propiedades hidrodinámicas del CPG, así como al propio proceso de inmovilización del anticuerpo en ambos soportes. En el caso 
de inmovilización en CPG se forma un enlace amina, más estable que el correspondiente enlace hidrazona formado en el caso de GAHz.

Cuando el inmunosoporte no se utilizaba, era guardado en una disolución de PBS conteniendo $0,02 \%$ de $\mathrm{NaN}_{3}$ como conservante. Este hecho no evitó una caída de señal en días sucesivos, que era corregida incrementando el tiempo de incubación de los substratos enzimáticos, hecho que no modificó la sensibilidad de los ensayos.

\subsubsection{Optimización del inmunosensor. Formato indirecto}

En este formato, la cantidad de anticuerpo que se une al conjugado hapteno-BSA inmovilizado en un soporte, es medida y correlacionada con la concentración de analito utilizando un anticuerpo secundario específico frente al primero. Este principio básico implica un paso adicional en el desarrollo de los inmunosensores, lo que supone un incremento en el tiempo de ensayo.

Al igual que en el formato anterior, la selección de las condiciones se realizó mediante ensayos de actividad, bajo el criterio de obtener máxima señal con la menor concentración de inmunorreactivos. De este modo, se estableció como óptima la inyección de una mezcla de $400 \mu 1$ de disolución de anticuerpo primario diluido en PBS y $700 \mu \mathrm{l}$ de medio orgánico, a un caudal de inyección de $0,25 \mathrm{ml} / \mathrm{min}$, y $200 \mu \mathrm{l}$ de anticuerpo secundario diluido 1/5000 en PBST, al mismo caudal.

La regeneración del inmunosensor se llevó a cabo utilizando un volumen de 2,5 $\mathrm{ml}$ de una disolución glicina $0,1 \mathrm{M} / \mathrm{HCl}, \mathrm{pH} 2$, a un caudal de $0,5 \mathrm{ml} / \mathrm{min}$. En este formato de ensayo la etapa de regeneración es menos crítica, ya que la especie inmovilizada sólo tiene que ser reconocida por el anticuerpo utilizado en cada ciclo; además, dada su naturaleza, el hapteno es más estable en estas condiciones.

Cabe destacar que, en este formato, las señales inespecíficas -debidas a la unión del anticuerpo secundario al inmunosoporte- son más importantes, lo que en principio limitó las condiciones de ensayo útiles para el desarrollo de inmunosensores.

Este estudio se llevó a cabo utilizando los conjugados CNA-BSA y CNH-BSA inmovilizados en GASc y CPG, los anticuerpos CNH-36, CNH-36 y CNH-45, en los medios orgánicos seleccionados para el formato directo.

En este caso, las dimensiones del inmunorreactor escogido al utilizar GASc como soporte fueron de $7 \mathrm{~mm}$ de longitud x $4 \mathrm{~mm}$ de diámetro interno. Este reactor es considerablemente mayor al utilizado en formato directo, ya que fue necesario una mayor cantidad de inmunosoporte para obtener señales útiles. 
En el caso del soporte $\mathrm{CPG}$, las dimensiones del reactor fueron las mismas que para el formato directo, debido a que las señales inespecíficas fueron muy importantes. En este caso, solo fue posible obtener señales útiles cuando se utilizó el anticuerpo monoclonal CNH-45, el medio orgánico M1 (50\% MeOH - 50\% PBST) y el conjugado CNH-BSA como especie inmovilizada. En estas condiciones, el valor de $\mathrm{I}_{50}$ obtenido fue $34,2 \mu \mathrm{g} / 1$.

En la Tabla 3.6 se muestran los resultados de los ensayos de competición correspondientes a este formato. Las siglas N.A. (no actividad) significan que, en esas condiciones, no se obtuvieron señales útiles para realizar los ensayos de competición. Las siglas N.C (no competición) muestran aquellas situaciones en las que aunque se obtiene señal suficiente para realizar los ensayos no se produjo inhibición en la señal.

Tabla 3.6. Valores de $I_{50}(\mu \mathrm{g} / \mathrm{l})$ obtenidos en formato indirecto con los dos conjugados hapteno-proteína inmovilizados en GASc. Ensayos realizados con los anticuerpos y medios orgánicos seleccionados

\begin{tabular}{llll}
\hline Medio Orgánico & MAb & CNH-BSA & CNA-BSA \\
\hline $50 \%$ MeOH-50\%PBST (M1) & CNH-45 & $24,2 \pm 7,9$ & $24,2 \pm 7,1$ \\
& CNH-36 & N.C & $179,0 \pm 38,9$ \\
& CNA-36 & N.A & $189,0 \pm 42,9$ \\
\hline $50 \%$ MeCN-50\%PBST (M2) & CNH-45 & N.C & N.C \\
& CNH-36 & N.C & N.C
\end{tabular}




\begin{tabular}{|c|c|c|c|}
\hline & CNA-36 & N.A & N.A \\
\hline \multirow[t]{3}{*}{ 25\%MeCN-75\%PBST (LM2) } & CNH-45 & N.C & n.d \\
\hline & CNH-36 & N.C & n.d \\
\hline & CNA-36 & n.d & n.d \\
\hline \multirow[t]{3}{*}{ 25\%MeOH-75\%PBST (LM1) } & CNH-45 & n.d & n.d \\
\hline & CNH-36 & $80,4 \pm 19,5$ & $64,4 \pm 16,7$ \\
\hline & CNA-26 & N.A & $60,4 \pm 19,5$ \\
\hline \multirow[t]{3}{*}{ 25\%MeOH-25\%MeCN-50\%PBST (M9) } & CNH-45 & $46,3 \pm 6,1$ & $90,4 \pm 9,8$ \\
\hline & CNH-36 & N.C & N.A \\
\hline & CNA-36 & N.A & N.C \\
\hline \multirow[t]{3}{*}{ 25\%MeOH-25\%IS-50\%PBST (M10) } & CNH-45 & $52,2 \pm 7,5$ & $66,4 \pm 10,1$ \\
\hline & CNH-36 & $68,4 \pm 8,7$ & $170,9 \pm 20,8$ \\
\hline & CNA-36 & N.A & N.A \\
\hline \multirow[t]{3}{*}{ 10\%AE-25\%IS-65\%PBST (LM7) } & CNH-45 & N.C & $94,5 \pm 8,7$ \\
\hline & CNH-36 & N.C & N.C \\
\hline & CNA-36 & N.C & N.C \\
\hline \multirow[t]{3}{*}{ 10\%AE-25\%MeOH-65\%PBST (LM19) } & CNH-45 & $58,4 \pm 5,5$ & $110,5 \pm 9,5$ \\
\hline & CNH-36 & N.C & N.C \\
\hline & CNA-36 & N.A & N.C \\
\hline
\end{tabular}

MeOH: metanol; MeCN: acetonitrilo; IS: isopropanol; AE: acetato de etilo; PBST: PBS con 0.05\% Tween 20. n.d: no determinado. Valores expresados como media \pm desviación estándar $(n=3)$, N.A: no actividad, N.C: no competición

A la vista de estos resultados, se observa también una relación entre sensibilidad y polaridad de la mezcla orgánica, ya que en las mezclas metanólicas la sensibilidad fue superior a la obtenida con los disolventes inmiscibles. En todos los casos, la mezcla M1 fue el medio orgánico más adecuado y el anticuerpo CNH-45 produjo los ensayos más sensibles, independientemente del conjugado hapténico utilizado $\left(\mathrm{I}_{50} \cong 24 \mu \mathrm{g} / \mathrm{l}\right)$.

Es necesario señalar la influencia del formato de ensayo en el reconocimiento de anticuerpos de especies hapténicas. Así por ejemplo, el hapteno CNA -utilizado como trazador enzimático (CNA-HRP) en formato directo- es mal reconocido por el anticuerpo CNH-45 dada la falta de señal. Sin embargo, cuando esta especie está conjugada a BSA si es reconocida por dicho anticuerpo, pudiendo obtener los correspondientes inmunosensores basados en formato indirecto. Este hecho ha sido observado también por otros autores $(44,191)$. 
Respecto al protocolo de ensayo, el anticuerpo en forma nativa y el medio orgánico están en íntimo contacto durante el proceso de mezcla. Esto provoca la desnaturalización parcial de la inmunoglobulina, lo que redunda en un peor reconocimiento y por tanto, en una menor sensibilidad, efecto mucho más acusado en las mezclas que contienen disolventes inmiscibles. En formato directo, la resistencia de los anticuerpos en medios orgánicos es mayor al encontrarse inmovilizados.

Otro aspecto que influye en la baja sensibilidad obtenida en formato indirecto, es la existencia de factores estéricos que afectan al reconocimiento. En estos ensayos, el anticuerpo en disolución debe unirse al conjugado hapteno-proteína inmovilizado en el soporte, lo que supone un impedimento a la hora del reconocimiento por parte del anticuerpo, siendo necesaria una mayor concentración de esta especie para obtener suficiente señal. Este fenómeno produce una peor competición y por tanto, una menor sensibilidad.

Respecto a la vida útil de los inmunosensores, un reactor con conjugado inmovilizado en GASc pudo ser utilizado al menos 50 ciclos sin pérdida de actividad o cambios en las propiedades hidrodinámicas. Probablemente, la vida útil sea mucho mayor dado que, como especie inmovilizada, el conjugado es más estable que el anticuerpo; sin embargo, ésta no se estimó debido a la baja sensibilidad obtenida.

\subsubsection{Optimización del inmunosensor. Formato de captura}

En el formato de ensayo de captura de inmunocomplejo se utiliza el soporte azlactona-Proteína A/G. Esta proteína, como ya se ha mencionado, es capaz de unir de forma orientada y reversible inmunoglobulinas de una amplia variedad de especies.

En estos ensayos se mezcla el anticuerpo disuelto en $\mathrm{PB}$, con el trazador disuelto en PBT y el medio orgánico conteniendo el analito (o patrón), de modo que los inmunocomplejos se forman en disolución y posteriormente son fijados por el soporte. Tras un lavado con PBT, se añade el substrato enzimático con el fin de cuantificar la cantidad de trazador unida al soporte. Esta descripción genérica corresponde al protocolo de ensayo simultáneo. Utilizando este inmunosoporte, la desorción es segura y completa utilizando $2,5 \mathrm{ml}$ de una disolución glicina $0,1 \mathrm{M} / \mathrm{HCl}, \mathrm{pH} 2$.

En este formato, la cantidad de soporte (proteína A/G) no es restrictiva -dado que su finalidad es unir los complejos formados en disolución-, por lo que se utilizó un reactor de dimensiones idénticas a las del formato directo. 
Para el desarrollo de estos inmunosensores se ensayaron los mismos anticuerpos, medios orgánicos y trazadores que para el formato directo, utilizando como tampón de trabajo PB conteniendo Tween $20(0,05 \% \mathrm{v} / \mathrm{v})$ para eliminar las señales inespecíficas, según pruebas preliminares efectuadas en batch.

Respecto a la reusabilidad, el soporte pudo ser utilizado hasta 300 ciclos sin mostrar pérdida en su capacidad de reconocimiento. El reactor se guardaba en PB con $0,02 \% \mathrm{NaN}_{3}$ y el soporte era cambiado cuando mostraba impedimentos al flujo o se observaba una disminución en su actividad.

Los ensayos de actividad realizados utilizando los trazadores CNH-HRP y CPNU-HRP indicaron que el anticuerpo CNA-36 mostraba actividad en los medios orgánicos M1, LM2, LM7, M10, LM19 y LM20, mientras que los anticuerpos CNH-36 y CNH-45 sólo producían señal en los medios orgánicos conteniendo disolventes miscibles en agua (M1, LM2 y M10).

En estas condiciones, se realizaron los ensayos de competición para determinar la sensibilidad de los inmunosensores objeto de estudio. Los valores de $\mathrm{I}_{50}$ se muestran en la Tabla 3.7, en la que puede observarse de nuevo que los ensayos más sensibles se obtienen al aumentar la polaridad de la mezcla.

Tabla 3.7. Valores de $I_{50}(\mu \mathrm{g} / \mathrm{l})$ obtenidos en formato de captura con los anticuerpos monoclonales estudiados. Ensayos realizados con los trazadores y medios orgánicos seleccionados

\begin{tabular}{lllllll}
\hline $\begin{array}{l}\text { Medio } \\
\text { orgánico }\end{array}$ & \multicolumn{2}{c}{ CNA-36 } & \multicolumn{2}{c}{ CNH-36 } & \multicolumn{2}{c}{ CNH-45 } \\
\hline & CNH-HRP & CPNU-HRP & CNH-HRP & CPNU-HRP & CNH-HRP & CPNU-HRP \\
\cline { 2 - 7 } M1 & $11,9 \pm 2,3$ & $11,8 \pm 1,9$ & $32,5 \pm 4,0$ & $43,4 \pm 6,3$ & $11,1 \pm 2,3$ & $9,1 \pm 2,0$ \\
LM2 & $78,5 \pm 5,8$ & $35,4 \pm 3,8$ & $47,3 \pm 6,1$ & $71,7 \pm 6,9$ & $16,8 \pm 3,7$ & $34,2 \pm 4,3$ \\
LM7 & $49,8 \pm 4,0$ & $83,5 \pm 6,3$ & n.a & n.a & n.a & n.a \\
M10 & $14,5 \pm 2,1$ & $12,2 \pm 2,0$ & $57,4 \pm 5,9$ & $101,0 \pm 8,1$ & $21,4 \pm 5,3$ & $24,8 \pm 3,9$ \\
LM19 & $59,7 \pm 4,8$ & $58,7 \pm 5,5$ & n.a & n.a & n.a & n.a \\
LM20 & $96,3 \pm 6,9$ & $110,6 \pm 8,1$ & n.a & n.a & n.a & n.a \\
\hline
\end{tabular}

M1: 50\% MeOH (metanol)-50\% PBT; LM2: 25\% MeCN (acetonitrilo)-75\% PBT; LM7: 10\% AE (acetato de etilo)-25\% IS (isopropanol)-65\% PBT; M10: 25\% MeOH-25\% IS-50\% PBT; LM19: 10\% AE-25\% MeOH-65\% PBT; LM20: 5\% AE-25\% MeCN-70\% PBT; PBT: PB con $0.05 \%$ Tween 20; n.a: no actividad; Valores expresados como media \pm desviación estándar (n=3) 
La mejor sensibilidad se obtiene utilizando el anticuerpo $\mathrm{CNH}-45$ junto con el trazador CPNU-HRP y el medio orgánico M1 $\left(\mathrm{I}_{50}, 9,1 \mu \mathrm{g} / 1\right)$.

Respecto a los anticuerpos utilizados, el CNA-36 fue más resistente al efecto de las mezclas orgánicas, lo que parece estar relacionado con la capacidad de regeneración de este anticuerpo observada en formato directo. Por otro lado, el anticuerpo CNH-45 se mostró más sensible en los medios orgánicos en los que fue posible realizar los ensayos de competición, excepto en la mezcla M10. Este hecho concuerda con los datos obtenidos en formato indirecto, donde este anticuerpo mostró los mejores resultados. De los tres anticuerpos ensayados, el CNH-36 fue el menos resistente a los medios orgánicos investigados y produjo los ensayos menos sensibles. De hecho, en las mejores condiciones de ensayo (mezcla M1), se obtuvieron valores de $\mathrm{I}_{50} \quad 32,5$ y 43,4 $\mu \mathrm{g} / 1$ al utilizar CNH-HRP y CPNU-HRP, respectivamente.

Finalmente, se ensayó el protocolo de ensayo secuencial que, como ya se ha expuesto en la parte experimental (sección 2.8.3), consiste en la inyección del anticuerpo disuelto en PB y lavado del exceso del mismo previamente a la inyección de la mezcla de trazador enzimático y medio orgánico. En este caso, las señales obtenidas fueron muy inferiores a las alcanzadas utilizando el protocolo simultáneo. Por ejemplo, trabajando con el anticuerpo CNH-45, la mezcla M1 y el trazador CPNU-HRP, se obtuvo un valor de $\mathrm{I}_{50}$ de $20,7 \mu \mathrm{g} / \mathrm{l}$, mientras que fue de $9,1 \mu \mathrm{g} / \mathrm{l}$ en el protocolo simultáneo (Tabla 3.7). Estos resultados parecen lógicos dado que en el protocolo simultáneo todas las especies involucradas en la reacción inmunoquímica están en disolución.

Comparando los tres formatos de ensayo estudiados, se aprecia que el de captura produce los ensayos de mayor sensibilidad, debido probablemente a las condiciones en que se produce la competición. En los inmunosensores en formato directo (anticuerpos inmovilizados) la reacción de competición se produce en la superficie del inmunosoporte, lo que implica que las especies que están en disolución deben difundirse hasta los sitios de unión del anticuerpo. Los procesos de difusión son por lo general lentos -ya que están controlados por el transporte de materia desde la interfase hasta los sitios de unión- y además, pueden aparecer impedimentos estéricos e interacciones electrostáticas que dificulten dicho proceso.

En el caso de los ensayos en formato indirecto, también ocurren estos fenómenos, aunque es el anticuerpo (más voluminoso) el que debe difundirse hasta la especie inmovilizada (conjugado hapteno-proteína). 
En el caso del formato de captura, todas las especies están en disolución y la reacción inmunoquímica se produce de forma instantánea, no siendo afectada por la presencia de superficies ni por efectos de difusión. En contrapartida, las especies proteicas en forma nativa pueden desnaturalizarse en presencia de medios orgánicos con mayor facilidad que cuando se encuentran inmovilizadas (214).

\subsubsection{Recapitulación}

En la Tabla 3.8 se resumen los resultados obtenidos en las condiciones de máxima sensibilidad y carga orgánica, con los inmunosensores desarrollados para carbaril basados en anticuerpos monoclonales.

Cabe destacar que, los ensayos más sensibles se obtienen en formato de captura. En formato directo se han seleccionado dos medios orgánicos, uno correspondiente a la máxima sensibilidad y otro a la mezcla orgánica binaria con mayor porcentaje de disolvente orgánico, que será el empleado para el análisis de muestras reales. En el caso de formato indirecto para el mismo $\mathrm{Ab}$ y soporte, se han seleccionado los dos conjugados hapteno-proteína, dado que prácticamente no existen diferencias de sensibilidad.

Tabla 3.8. Resumen de las características de los inmunosensores para carbaril

FORMATO

\begin{tabular}{lll}
\hline DIRECTO INDIRECTO CAPTURA & CATO
\end{tabular}

\begin{tabular}{|c|c|c|c|c|c|c|}
\hline \multirow{4}{*}{ o } & Anticuerpo & \multicolumn{2}{|c|}{ CNA-36 } & \multicolumn{2}{|c|}{ CNH-45 } & CNH-45 \\
\hline & Trazador & CNH-HRP & & & --- & CPNU-HRP \\
\hline & Conjugado & --- & --- & $\mathrm{CNH}-\mathrm{BSA}$ & CNA-BSA & --- \\
\hline & Soporte & & $\mathrm{Hz}$ & & $\mathrm{Sc}$ & PAG \\
\hline \multicolumn{2}{|c|}{ MEDIO ORGÁNICO } & $25 \% \mathrm{MeOH}-$ & $50 \% \mathrm{MeOH}-$ & \multicolumn{2}{|c|}{$50 \% \mathrm{MeOH}-50 \% \mathrm{PBST}$} & $50 \% \mathrm{MeOH}-$ \\
\hline \multicolumn{2}{|c|}{$I_{50}(\mu \mathrm{g} / \mathrm{l})$} & 13,5 & 17,3 & 24,2 & 24,2 & 9,1 \\
\hline \multicolumn{2}{|c|}{$\mathrm{LD}(\boldsymbol{\mu g} / \mathbf{l})$} & 4,2 & 1,4 & 3,2 & 2,4 & 0,7 \\
\hline \multicolumn{2}{|c|}{ RD $(\mu g / l)$} & $6,5-31,2$ & $3,8-68,0$ & $6,8-131,7$ & $5,8-137,5$ & $2,0-44,9$ \\
\hline
\end{tabular}


GAHz: gel de agarosa con grupos hidrazina; GASc: gel de agarosa con grupos N-hidroxisuccinimida; PAG: gel de agarosa con proteina A/G inmovilizada; MeOH: metanol; IS: isopropanol; PBST: PBS con 0.05\% Tween 20; PBT: PB con 0.05\% Tween 20; LD: límite de detección; RD: rango dinámico

\subsection{ESTUDIO DE REACTIVIDAD CRUZADA}

Este estudio fue realizado utilizando los tres formatos de ensayo en las condiciones más sensibles y de máxima concentración de disolventes orgánicos.

La especificidad de los sistemas desarrollados se evaluó utilizando 1-naftol, principal metabolito del carbaril, y otros compuestos relacionados estructuralmente con éste: carbofurano, metomilo, propoxur, aldicarb y metiocarb. Los ensayos de competición realizados con estos compuestos permiten determinar el valor de $\mathrm{I}_{50}$ necesario para el cálculo de reactividad cruzada, de acuerdo a la expresión:

$$
\mathrm{RC}=\left(\mathrm{I}_{50} \text { carbaril } / \mathrm{I}_{50} \text { interferente }\right) \times 100
$$

\subsubsection{Formato directo}

Las condiciones utilizadas en los ensayos de reactividad cruzada para este formato fueron: anticuerpo monoclonal CNA-36 inmovilizado en GAHz, medio orgánico 50\% MeOH-50\% PBST (M1) y trazador enzimático CPNU-HRP.

Los resultados obtenidos se muestran en la Tabla 3.9, observándose que la reactividad cruzada es, en todos los casos, despreciable. Hay que destacar que los valores de reactividad cruzada en medio acuoso son siempre mayores a los obtenidos en medio orgánico, lo que indica que el sistema es más selectivo trabajando en dicho medio.

Tabla 3.9. Valores de reactividad cruzada (\%RC) obtenidos utilizando formato directo en las condiciones seleccionadas

\begin{tabular}{llll}
\hline COMPUESTO & $\mathbf{I}_{\mathbf{5 0}}(\mathbf{n M})$ & \multicolumn{2}{c}{ RC (\%) } \\
\hline Carbaril & 86 & 100 & $(100)^{*}$ \\
1- Naftol & 215.280 & 0,04 & $(1,06)$ \\
Metiocarb & 14.570 & 0,59 & $(5,80)$ \\
Propoxur & 40.560 & 0,21 & $(1,50)$ \\
Carbofurano & 6.460 & 1,33 & $(7,40)$
\end{tabular}




\begin{tabular}{llll} 
Aldicarb & $>4,7.10^{5}$ & $<1,8 \cdot 10^{-2}$ & $\left(<4.10^{-3}\right)$ \\
Metomilo & $>1,5.10^{4}$ & $<5,4 \cdot 10^{-1}$ & $\left(<3.10^{-3}\right)$ \\
\hline * Valores de RC obtenidos en medio acuoso & &
\end{tabular}

\subsubsection{Formato indirecto}

Al igual que en el formato anterior se operó en las condiciones de máxima sensibilidad, que en este caso fueron: conjugado CNH-BSA inmovilizado en GASc, anticuerpo CNH-45 y medio orgánico 50\%MeOH-50\%PBST (M1).

Los resultados, comparados con los obtenidos en medio acuoso (213) utilizando los mismos inmunoreactivos y soporte, se muestran en la Tabla 3.10.

Tabla 3.10. Valores de reactividad cruzada (\%RC) obtenidos utilizando formato indirecto en las condiciones seleccionadas

\begin{tabular}{llll}
\hline COMPUESTO & $\mathbf{I}_{\mathbf{5 0}}(\mathbf{n M})$ & \multicolumn{3}{c}{ RC (\%) } \\
\hline Carbaril & 120 & 100 & $(100)^{*}$ \\
1-Naftol & 197.510 & 0,06 & $(0,03)$ \\
Metiocarb & 142.390 & 0,08 & $(0,06)$ \\
Aldicarb & $>4,7.10^{5}$ & $\left\langle 2,5.10^{-2}\right.$ & $(<0,013)$ \\
Carbofurano & $>4,2.10^{5}$ & $\left\langle 2,8.10^{-2}\right.$ & $(<0,013)$ \\
Propoxur & $>9,4.10^{5}$ & $\left\langle 1,3.10^{-2}\right.$ & $(<0,005)$ \\
Metomilo & $>1,6.10^{5}$ & $\left\langle 7,5.10^{-2}\right.$ & $(<0,005)$
\end{tabular}

* Valores de RC obtenidos en medio acuoso

Se observa que los valores de RC obtenidos son despreciables $(<0,1 \%)$ en ambos medios de ensayo. Por otro lado, hay que indicar que las diferencias en selectividad encontradas entre el formato directo e indirecto son debidas, principalmente, al anticuerpo utilizado, aunque también depende del formato de ensayo.

\subsubsection{Formato de captura}

El estudio de selectividad utilizando formato de captura fue realizado, al igual que los formatos anteriores, en las condiciones de máxima sensibilidad: anticuerpo 
CNH-45, trazador CPNU-HRP y medio orgánico 50\% MeOH-50\% PBST (M1). Los valores de RC obtenidos se muestran en la Tabla 3.11.

Tabla 3.11. Valores de reactividad cruzada $(\% \mathrm{RC})$ obtenidos utilizando formato de captura en las condiciones seleccionadas

\begin{tabular}{llll}
\hline COMPUESTO & $\mathbf{I}_{\mathbf{5 0}}(\mathbf{n M})$ & \multicolumn{2}{c}{$\mathbf{R C}(\mathbf{\%})$} \\
\hline Carbaril & 45 & 0,47 & $(100)^{*}$ \\
1-Naftol & 9.540 & 0,15 & $($ n.d $)$ \\
Metiocarb & 28.920 & $<0,47$ & $(0,12)$ \\
Propoxur & $>9,4.10^{3}$ & $<0,10$ & $\left(<10^{-3}\right)$ \\
Carbofurano & $>4,2.10^{4}$ & $<9,5.10^{-3}$ & $\left(1,910^{-3}\right)$ \\
Aldicarb & $>4,7.10^{5}$ & $<2,8.10^{-2}$ & $\left(<10^{-3}\right)$ \\
Metomilo & $>1,6.10^{5}$ & & $\left(<10^{-3}\right)$ \\
\hline
\end{tabular}

* Valores obtenidos en medio acuoso utilizando el mismo anticuerpo; n.d.: no determinado

A la vista de los resultados se concluye que las interferencias son despreciables en ambos medios, aunque los valores de $\mathrm{RC}$ son superiores al trabajar en medio orgánico. Por otro lado, al comparar los resultados obtenidos en formato de captura con los del formato indirecto -que utiliza el mismo anticuerpo- puede apreciarse como influye el formato de ensayo en la selectividad del inmunosensor.

\subsection{COMPARACIÓN CON LOS SISTEMAS EN MEDIO ACUOSO}

A la hora de obtener conclusiones sobre las prestaciones de los inmunosensores en medio orgánico, es lógica la comparación con los mismos sistemas en medio acuoso. En principio, muchas son las variables que pueden relacionarse, aunque parece lógico pensar que los parámetros sensibilidad y selectividad son los mas adecuados para dicha comparación. En la Tabla 3.12 se muestran resumidos los valores de $\mathrm{I}_{50}$ obtenidos con los inmunosensores en todos los formatos estudiados, tanto en medio acuoso (213) como en el medio orgánico más sensible (50\% metanol- 50\% tampón acuoso).

Tabla 3.12. Valores de $I_{50}(\mu \mathrm{g} / \mathrm{l})$ de los inmunosensores en medio acuoso y medio orgánico para todos los formatos y soportes

\begin{tabular}{cccccccc}
\hline $\begin{array}{c}\text { Formato Directo } \\
\text { (GAHz) }\end{array}$ & \multicolumn{2}{c}{$\begin{array}{c}\text { Formato Directo } \\
\text { (CPG) }\end{array}$} & \multicolumn{2}{c}{$\begin{array}{c}\text { Formato Indirecto } \\
\text { (GASc) }\end{array}$} & Formato Captura \\
\hline Acuoso & Orgánico & Acuoso & Orgánico & Acuoso & Orgánico & Acuoso & Orgánico \\
CNA-36 & CNA-36 & CNA-36 & CNA-36 & CNH-45 & CNH-45 & CNH-36 & CNH-45 \\
\hline $0,4 \pm 0,2$ & $17,3 \pm 3,7$ & $0,3 \pm 0,1$ & $20,3 \pm 3,9$ & $1,0 \pm 0,3$ & $24,2 \pm 7,9$ & $0,1 \pm 0,008$ & $9,1 \pm 2,1$ \\
\hline
\end{tabular}


Los resultados muestran la diferencia de sensibilidad, prevista a priori, entre ambos medios. Este comportamiento puede explicarse teniendo en cuenta la desnaturalización parcial que sufren los inmunorreactivos en medio orgánico, lo que hace necesario utilizar mayores concentraciones de los mismos para conseguir una señal suficiente. Este incremento en la concentración de inmunorreactivos se traduce en una menor sensibilidad en los ensayos.

Otro aspecto a tener en cuenta es que los anticuerpos seleccionados en formato directo e indirecto son los mismos independientemente del medio de trabajo (acuoso $\mathrm{u}$ orgánico), excepto en el formato de captura. Esto podría indicar que, en principio, el medio orgánico no cambia las propiedades de reconocimiento de los anticuerpos.

Respecto a la selectividad del inmunoensayo, la Tabla 3.13 muestra los resultados de RC obtenidos en ambos medios.

Tabla 3.13. Valores comparados de RC (\%) obtenidos con los inmunosensores en medio orgánico y acuoso (condiciones de máxima sensibilidad)

\begin{tabular}{|c|c|c|c|c|c|c|c|c|}
\hline \multirow[b]{3}{*}{ Compuesto } & \multicolumn{4}{|c|}{ MEDIO ACUOSO } & \multicolumn{4}{|c|}{ MEDIO ORGANICO } \\
\hline & \multicolumn{2}{|c|}{ F.D } & \multirow{2}{*}{$\begin{array}{c}\text { F.I } \\
(\mathrm{GASc})\end{array}$} & \multirow[t]{2}{*}{ F.C* } & \multicolumn{2}{|c|}{ F.D } & \multirow{2}{*}{$\begin{array}{c}\text { F.I } \\
(\mathrm{GASc})\end{array}$} & \multirow{2}{*}{ F.C } \\
\hline & $(\mathrm{GAHz})$ & $(\mathrm{CPG})$ & & & (GAHz) & $(\mathrm{CPG})$ & & \\
\hline Carbaril & 100 & 100 & 100 & 100 & 100 & 100 & 100 & 100 \\
\hline 1-Naftol & 1,06 & 0,98 & 0,03 & $<10^{-3}$ & 0,04 & 0,05 & 0,06 & 0,47 \\
\hline Metiocarb & 5,80 & 5,58 & 0,06 & 0,45 & 0,06 & 0,05 & 0,08 & 0,15 \\
\hline Carbofurano & 7,40 & 6,80 & $<0,013$ & $1,4 \cdot 10^{-3}$ & 1,33 & 1,10 & $<3.10^{-2}$ & $<0,10$ \\
\hline Propoxur & 1,50 & 1,32 & $<0,005$ & $<10^{-3}$ & 0,21 & 0,31 & $<10^{-2}$ & $<0,47$ \\
\hline Aldicarb & $<4.10^{-3}$ & $<4.10^{-3}$ & $<0,013$ & $<10^{-3}$ & $<2.10^{-2}$ & $<3.10^{-2}$ & $<3.10^{-2}$ & $<9.10^{-3}$ \\
\hline Metomilo & $<3.10^{-3}$ & $<4.10^{-3}$ & $<0,005$ & $<10^{-3}$ & $<5.10^{-2}$ & $<4.10^{-3}$ & $<8.10^{-2}$ & $<3.10^{-2}$ \\
\hline
\end{tabular}

A la vista de estos resultados, se puede concluir que los inmunosensores en medio orgánico son, por lo general, más selectivos, dado que los valores de RC son inferiores a los obtenidos en medio acuosos. Es decir, aunque el reconocimiento del analito y los interferentes se ve disminuido en medios orgánicos, este fenómeno afecta en mayor medida a los interferentes, lo que se traduce en valores de RC más bajos (menor interferencia). 


\subsection{ANALISIS DE MUESTRAS REFORZADAS}

La última etapa en el desarrollo de los inmunosensores es comprobar que son sistemas válidos para el análisis de muestras reales, o en su defecto para muestras a las que se les adiciona el analito (muestras reforzadas).

Todos los inmunosensores desarrollados para carbaril se aplicaron en las condiciones de máxima sensibilidad. Dado que se trabaja en medios orgánicos, se hizo especial hincapié en los métodos de extracción de los analitos, siguiendo las recomendaciones dadas por los métodos oficiales de análisis. Por otro lado, se desarrollaron métodos alternativos de preparación de muestra (extracción directa con metanol, SPE con cartuchos $\mathrm{C}_{18}$ ) con la finalidad de mejorar la sensibilidad y/o reducir la duración de los análisis.

\subsubsection{Inmunosensor en formato de captura}

Basados en este formato, y dada su elevada sensibilidad y reusabilidad, se estudió la posibilidad de desarrollar un método de extracción rápido aplicable a muestras sólidas, concretamente para conservas vegetales. En todos los casos se utilizó un método de extracción multirresiduo (212) para contrastar los resultados obtenidos. Por otro lado, las muestras fortificadas se analizaron también mediante HPLC (ver materiales y métodos) con el fin de comparar los resultados con los obtenidos en los inmunosensores. Finalmente, las condiciones experimentales se aplicaron a muestras de aguas y zumos, de modo que pudieran abarcarse tanto matrices sólidas como líquidas.

\subsubsection{Análisis de vegetales frescos y procesados}

En primer lugar se evaluó la extracción directa con metanol como método rápido de preparación de muestra. Para tal fin, una serie de muestras vegetales reforzadas con carbaril a tres niveles fueron extraídas utilizando tanto un procedimiento general multirresiduo (MRS) como directamente con metanol (EDM). Los extractos obtenidos en ambos casos fueron analizados mediante el inmunosensor en las condiciones de máxima sensibilidad. En la Tabla 3.14 se muestran los resultados obtenidos.

Tabla 3.14. Determinación de carbaril en muestras vegetales mediante el inmunosensor con formato de captura. Comparación entre el método de extracción multirresiduo (MRS) y la extracción directa con metanol (EDM) 


\begin{tabular}{|c|c|c|c|c|c|c|}
\hline \multirow{3}{*}{$\begin{array}{l}\text { Nivel } \\
\text { reforzado } \\
(\mu \mathrm{g} / \mathrm{Kg})\end{array}$} & \multicolumn{6}{|c|}{ Nivel encontrado $(\mu \mathrm{g} / \mathrm{Kg})$} \\
\hline & \multicolumn{2}{|l|}{ Tomate } & \multicolumn{2}{|c|}{ Pimiento verde } & \multicolumn{2}{|c|}{ Pimiento rojo } \\
\hline & MRS & EDM & MRS & EDM & MRS & EDM \\
\hline 10 & $13,0 \pm 2,0$ & $10,8 \pm 0,6$ & $9,8 \pm 0,4$ & $7,8 \pm 2,6$ & $10,1 \pm 0,9$ & $8,2 \pm 1,0$ \\
\hline 20 & $25,0 \pm 1,4$ & $23,6 \pm 2,6$ & $21,9 \pm 3,6$ & $14,8 \pm 2,7$ & $19,6 \pm 2,3$ & $21,7 \pm 0,9$ \\
\hline 30 & $30,6 \pm 3,4$ & $34,5 \pm 1,7$ & $34,1 \pm 6,6$ & $26,2 \pm 3,1$ & $29,5 \pm 3,5$ & $26,5 \pm 2,9$ \\
\hline
\end{tabular}

Valores expresados como media \pm SD (tres determinaciones)

Además, y con el fin de evaluar la presencia de efecto matriz, se procedió al análisis de muestras sin reforzar, no observándose tal efecto en ninguno de los casos estudiados.

Cabe destacar los buenos resultados obtenidos con muestras de pimiento rojo, con valores de recuperación del 99,1\% para el método multirresiduo y 93,0\% para la extracción directa con metanol. En el caso de las muestras de tomate, la recuperación media obtenida fue de $119,0 \%$ para el método multirresiduo y $113,7 \%$ para la extracción con metanol, lo que indica que se produce una ligera sobrestimación de carbaril, independientemente del tipo de extracción utilizada. En general, en todos los casos se obtuvieron valores de recuperación próximos al $100 \%$, con un valor de RSD $\leq 19,3 \%$. Comparando ambos procedimientos de extracción, se puede concluir que la extracción directa con metanol es muy adecuada para el análisis rápido de muestras, tanto por los resultados obtenidos (exactitud, precisión y recuperación) como por el bajo consumo de disolvente orgánico.

El estudio realizado para estimar la selectividad del inmunosensor se llevó a cabo utilizando muestras de tomate reforzadas con $20 \mu \mathrm{g} / \mathrm{Kg}$ de carbaril y $200 \mu \mathrm{g} / \mathrm{Kg}$ de 1-naftol (principal interferente, con un valor de RC de 0,47\%). El porcentaje de recuperación medio obtenido fue del 104\%, lo que demostró que el 1-naftol no influyó en el resultado del análisis, incluso a una concentración 10 veces superior a la de carbaril.

Posteriormente se procedió al análisis de las muestras vegetales reforzadas y extraídas directamente con metanol, comparando los resultados con los obtenidos mediante una modificación del método ELISA puesto a punto por Abad y col. $(166,168)$, que utiliza los mismos inmunorreactivos. Como método confirmatorio, los extractos se analizaron también mediante HPLC con detección fluorescente. 
La modificación del método ELISA consistió en la introducción de metanol en el tampón acuoso de trabajo. Así pues, se realizó un estudio con el fin de determinar la concentración óptima de disolvente a utilizar. En la Figura 3.4 se muestra el efecto de la concentración de metanol en la sensibilidad del inmunoensayo en placa.

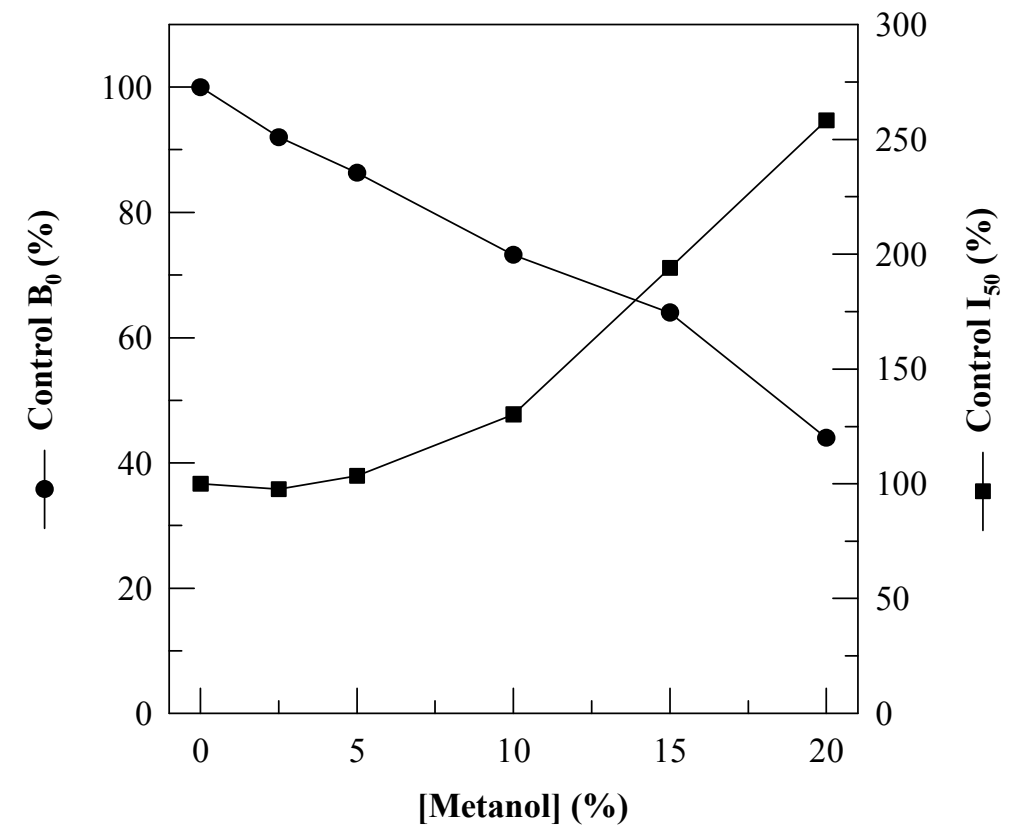

\section{Figura 3.4. Influencia de la concentración de metanol en la sensibilidad del método ELISA empleado en la determinación de carbaril}

Como se aprecia en la figura, la adición de hasta un 5\% de metanol al tampón acuoso de trabajo no influyó significativamente en la sensibilidad de la técnica ELISA, mostrando solo una ligera influencia en el valor de la señal obtenida que no impidió realizar los ensayos.

Comprobado el método de extracción directa con metanol, éste se aplicó a un conjunto de muestras vegetales -frescos y procesados-, reforzadas con carbaril a tres niveles $(50,100$ y $150 \mu \mathrm{g} / \mathrm{Kg})$. Los extractos fueron posteriormente analizados mediante las tres técnicas mencionadas (inmunosensor, ELISA y HPLC).

La Figura 3.5 muestra las curvas de calibrado obtenidas con el inmunosensor y la técnica ELISA, observándose una ligera diferencia en la sensibilidad, siendo la técnica ELISA la que mostró un menor valor de $\mathrm{I}_{50}$. 


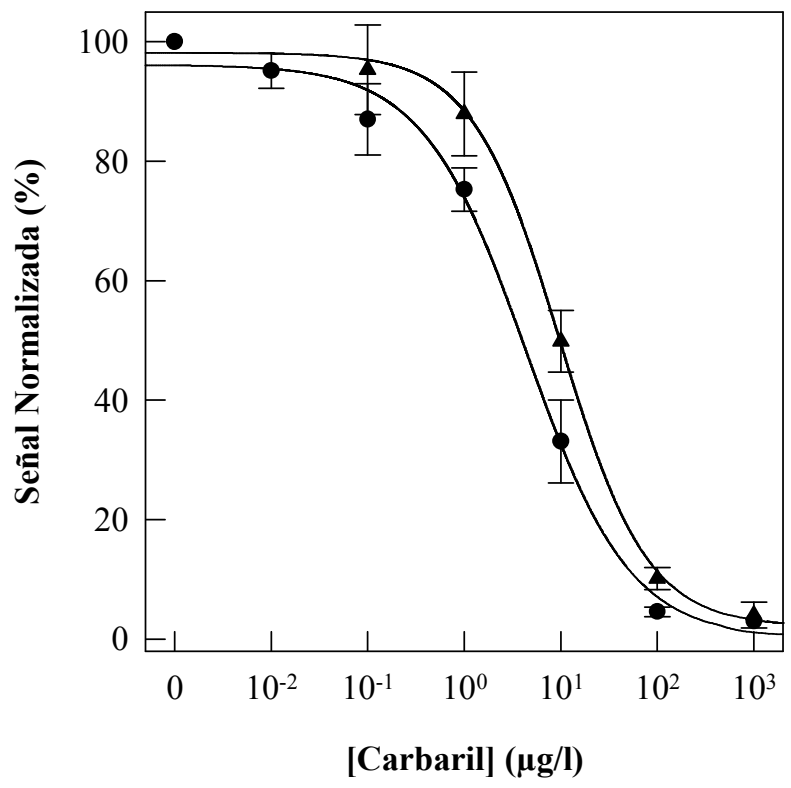

Figura 3.5. Curvas de competición normalizadas obtenidas mediante los dos métodos inmunológicos: ( $\sigma$ ) Sensor utilizando 50\% MeOH-50\% PBT como medio orgánico. ( $\lambda$ ) ELISA utilizando PBS-T con 5\% MeOH $(\mathrm{v} / \mathrm{v})$

En la Tabla 3.15 se muestran las concentraciones de carbaril así como las recuperaciones obtenidas para todas las muestras analizadas. Estos resultados demuestran la efectividad del método de extracción propuesto, dadas las buenas recuperaciones alcanzadas. Los valores medios fueron: 94,5\% con el inmunosensor, 92,5\% mediante ELISA y 89,5 por HPLC. En todos los casos, la desviación standard relativa (RSD) fue inferior al 12\%. 
Tabla 3.15. Determinación de carbaril en muestras vegetales reforzadas utilizando el inmunosensor en formato de captura. Comparación con los resultados obtenidos en ELISA y HPLC

\begin{tabular}{|c|c|c|c|c|c|c|c|}
\hline \multirow[b]{2}{*}{ Muestra } & \multirow{2}{*}{$\begin{array}{l}\text { Nivel } \\
\text { reforzado } \\
(\mu \mathrm{g} / \mathrm{Kg})\end{array}$} & \multicolumn{2}{|c|}{ Inmunosensor } & \multicolumn{2}{|l|}{ ELISA $^{1}$} & \multicolumn{2}{|l|}{ HPLC } \\
\hline & & $\begin{array}{l}\text { Nivel } \\
\text { encontrado } \\
(\mu \mathrm{g} / \mathrm{Kg})\end{array}$ & $\begin{array}{l}\mathrm{R} \\
(\%)\end{array}$ & $\begin{array}{l}\text { Nivel } \\
\text { encontrado } \\
(\mu \mathrm{g} / \mathrm{Kg})\end{array}$ & $\begin{array}{l}\mathrm{R} \\
(\%)\end{array}$ & $\begin{array}{l}\text { Nivel } \\
\text { encontrado } \\
(\mu \mathrm{g} / \mathrm{Kg})\end{array}$ & $\begin{array}{l}\mathrm{R} \\
(\%)\end{array}$ \\
\hline \multirow[t]{3}{*}{ Tomate } & 50 & $40,9 \pm 4,8$ & 81,9 & $54,7 \pm 6,9$ & 109,2 & $41,3 \pm 1,8$ & 82,6 \\
\hline & 100 & $108,1 \pm 4,3$ & 108,1 & $93,6 \pm 14,0$ & 93,6 & $87,4 \pm 4,0$ & 87,4 \\
\hline & 150 & $136,8 \pm 14,4$ & 91,2 & $135,0 \pm 7,2$ & 90,0 & $140,2 \pm 6,4$ & 93,5 \\
\hline \multirow{3}{*}{$\begin{array}{l}\text { Pimiento } \\
\text { Verde }\end{array}$} & 50 & $49,5 \pm 5,6$ & 99,1 & $44,3 \pm 2,0$ & 88,6 & $42,7 \pm 1,9$ & 85,4 \\
\hline & 100 & $115,0 \pm 13,3$ & 115,0 & $89,0 \pm 10,0$ & 89,0 & $94,7 \pm 4,3$ & 94,7 \\
\hline & 150 & $172,1 \pm 8,7$ & 114,7 & $123,4 \pm 14,8$ & 82,3 & $132,9 \pm 5,9$ & 88,6 \\
\hline \multirow{3}{*}{$\begin{array}{l}\text { Pimiento } \\
\text { Rojo }\end{array}$} & 50 & $39,5 \pm 7,2$ & 79,0 & $50,2 \pm 5,6$ & 100,4 & $44,8 \pm 2,1$ & 89,6 \\
\hline & 100 & $73,7 \pm 10,5$ & 73,7 & $82,8 \pm 14,4$ & 82,8 & $90,3 \pm 5,1$ & 90,3 \\
\hline & 150 & $132,4 \pm 14,3$ & 88,3 & $145,0 \pm 13,4$ & 96,7 & $140,1 \pm 6,8$ & 93,4 \\
\hline
\end{tabular}

${ }^{1}$ En cada placa ELISA se intercaló un calibrado en PBST con $5 \% \overline{\text { de metanol }}$

$\mathrm{R}$ : recuperación

Respecto a las matrices estudiadas, los mejores resultados se obtuvieron con las muestras de tomate, con recuperaciones de 93,7\%, 97,6\% y 87,8\% para el inmunosensor, ELISA y HPLC, respectivamente. Los valores de recuperación en pimiento (109,6\% para verde y $80,3 \%$ para rojo) fueron buenos y comparables a los obtenidos mediante ELISA (86,6\% para verde y $93,3 \%$ para rojo) y HPLC (89,5\% para verde y $91,1 \%$ para rojo).

Por otro lado, en la Figura 3.6 se muestra la correlación entre los resultados obtenidos mediante el inmunosensor y la técnica ELISA, para las tres matrices. Como se aprecia, los coeficientes de regresión (r) son superiores a 0,95 $(0,956$ para pimiento rojo, 0,988 para tomate y 0,996 para pimiento verde), con pendientes inferiores a 1,02. En dicha figura también se muestra la comparación de los resultados obtenidos con el inmunosensor y el método de referencia (HPLC). Los valores de $\mathrm{r}$ fueron 0,992, 0,998 y 0,964, para tomate, pimiento verde y pimiento rojo, respectivamente.

En resumen, se ha demostrado la posibilidad de analizar residuos de carbaril utilizando inmunosensores en flujo en medio orgánico (50\% MeOH-50\% PBT), sin más que mezclar el extracto orgánico obtenido con el tampón de trabajo. Ello permite 
simplificar la etapa de preparación de muestra respecto al método de referencia, ya que no requiere concentración ni derivatización de los extractos.

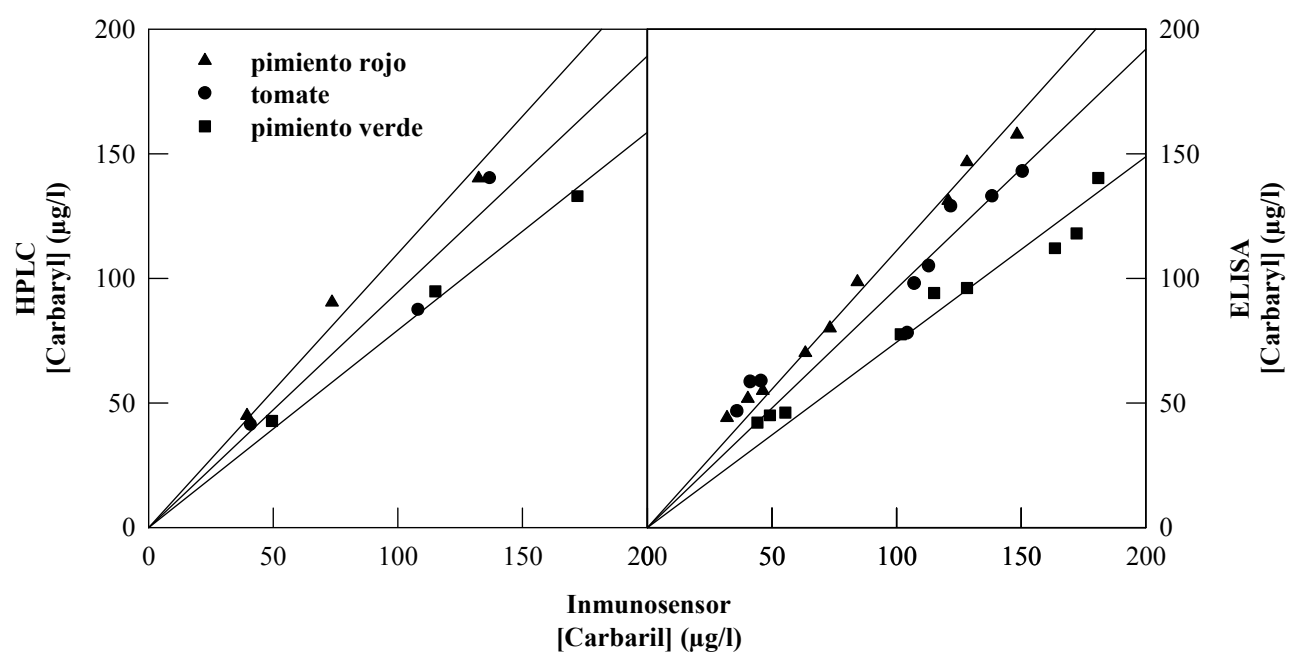

Figura 3. 6. Correlación entre los resultados obtenidos en los análisis de carbaril mediante el inmunosensor, ELISA y HPLC en muestras vegetales

\subsubsection{Análisis de muestras líquidas}

Utilizando el mismo sistema inmunoanalítico (inmunosensor en formato de captura) se procedió a analizar muestras líquidas, escogiéndose como matrices muestras comerciales de zumo de manzana y agua mineral.

La muestras de zumo de manzana se extrajeron, en primer lugar, utilizando cartuchos $\mathrm{C}_{18}$, y elución con metanol. Este procedimiento no dio buenos resultados debido a la presencia de colorantes en el extracto, por lo que no pudo ser analizado mediante el inmunosensor.

En una segunda alternativa, las muestras de zumo se extrajeron con éter de petróleo utilizando una modificación de método MRS descrito para matrices sólidas. Así, se tomaron $20 \mathrm{ml}$ de zumo reforzado con carbaril $(1,5$ y $10 \mu \mathrm{g} / \mathrm{l})$ y se añadieron 10 $\mathrm{ml}$ de éter de petróleo al que se le había adicionado un poco de $\mathrm{NaCl}$. Esta mezcla se agitó y trasvasó a un embudo de decantación. Tras la separación de fases, se recogió la fracción etérea, añadiéndose otros $5 \mathrm{ml}$ de éter de petróleo a la fase acuosa para una nueva etapa de extracción. Las fases etéreas se unieron y filtraron en presencia de $\mathrm{Na}_{2} \mathrm{SO}_{4}$ anhidro para eliminar los posibles restos de agua. El filtrado se evaporó a 
sequedad bajo corriente de $\mathrm{N}_{2}$ a una temperatura de $45{ }^{\circ} \mathrm{C}$. El residuo seco se resuspendió en metanol $(5 \mathrm{ml})$ y se diluyó al 50\% con PBT para su análisis en el inmunosensor. Los resultados obtenidos se muestran en la Tabla 3.16.

Tabla 3.16. Análisis de carbaril en muestras de zumo de manzana reforzado

\begin{tabular}{llll}
\hline $\begin{array}{l}\text { Nivel reforzado } \\
(\boldsymbol{\mu g} / \mathbf{l})\end{array}$ & $\begin{array}{l}\text { Nivel encontrado } \\
(\boldsymbol{\mu g} / \mathbf{l})\end{array}$ & $\begin{array}{l}\text { RSD } \\
(\%)\end{array}$ & $\begin{array}{l}\text { Recuperación } \\
(\%)\end{array}$ \\
\hline 0 & $<\mathrm{LOD}$ & --- & --- \\
1 & $1,4 \pm 0,2$ & 14 & 136 \\
5 & $6,4 \pm 0,8$ & 12 & 129 \\
10 & $11,9 \pm 1,2$ & 10 & 119 \\
\hline Valores expresados como media $\pm \mathrm{SD}(\mathrm{n}=3)$ & &
\end{tabular}

El análisis de una muestra de zumo sin reforzar -utilizado como controlpermitió comprobar la ausencia de falsos positivos. Los valores de recuperación obtenidos fueron ligeramente altos, indicando una sobrestimación del nivel de carbaril debido a un ligero efecto matriz. Sin embargo, el análisis de regresión lineal indicó una muy buena correlación entre el nivel de carbaril añadido y el determinado mediante el inmunosensor $(\mathrm{r}=0,9990)$. Estos datos muestran la posibilidad de aplicar el inmunosensor al análisis de carbaril en muestras de zumos, a niveles muy por debajo de los límites permitidos por la legislación (14). Hay que indicar que en manzanas y zumos los límites máximos de residuos están en el rango de $\mathrm{mg} / \mathrm{l}$, según el producto fitosanitario considerado.

En el caso de las muestras de agua mineral reforzadas con carbaril a $0,1 \mu \mathrm{g} / \mathrm{l}$ (límite máximo de residuos de plaguicidas para aguas potables admitido por la UE), y dado que el inmunosensor no detecta niveles tan bajos, fue necesario preconcentrar el analito. Para ello se realizó una extracción en fase sólida utilizando cartuchos $\mathrm{C}_{18} \mathrm{y}$ metanol como eluyente. En este formato, no fue posible el análisis del extracto metanólico, ya que al diluirlo al 50\% con PBT para su uso en el inmunosensor, se producía turbidez en las muestras, lo que impidió la aplicación de este modo de extracción. La solución de recurrir a trabajar con menor porcentaje de metanol no parecía lógica, ya que se producía la dilución de la muestra. Tampoco parecía procedente cambiar de tampón acuoso y volver a optimizar todo el ensayo, ya que este tipo de muestras pueden analizarse ventajosamente utilizando otros formatos como, por ejemplo, el directo (apartado 3.7.2.2). 


\subsubsection{Inmunosensor en formato directo}

Para el análisis de muestras reales mediante el inmunosensor basado en formato directo, se escogieron aquellas condiciones que produjeron los ensayos más sensibles ( $\mathrm{I}_{50}$ media $\left.17,3 \pm 3,7 \mu \mathrm{g} / \mathrm{l}\right)$. Estas fueron:

- Anticuerpo CNA-36 inmovilizado en GAHz

- Trazador enzimático: CPNU-HRP

- Medio orgánico de análisis: 50\% metanol-50\% PBST

Al igual que en el formato anterior, se procedió al análisis de muestras sólidas (vegetales) y líquidas (agua mineral) reforzadas con carbaril. Los procesos de extracción utilizados tenían como objetivo obtener un extracto metanólico del analito que, tras una dilución al 50\% con el tampón acuoso de trabajo (PBST), permitiera la utilización del inmunosensor.

\subsubsection{Análisis de muestras vegetales}

En este caso se utilizaron muestras de tomate y pimiento rojo en conserva y pimiento verde natural, que fueron reforzadas con carbaril a tres niveles (20, 50 y 100 $\mu \mathrm{g} / \mathrm{l})$ y extraídas directamente con metanol. En todos los casos, se utilizó como control una porción de la muestra sin reforzar para comprobar la ausencia de falsos positivos. Los resultados obtenidos se muestran en la Tabla 3.17.

A la vista de los resultados, se concluye que el inmunosensor es aplicable al análisis de muestras vegetales dada la buena correlación entre los valores añadidos de carbaril y los medidos, si bien, en general, se aprecia una ligera sobrestimación en la cantidad de analito medida. 
Tabla 3.17. Análisis de carbaril en muestras vegetales utilizando el inmunosensor en formato directo

\begin{tabular}{|c|c|c|c|c|}
\hline Matriz & $\begin{array}{l}\text { Nivel } \\
\text { reforzado } \\
(\mu \mathrm{g} / \mathrm{l}) \\
\end{array}$ & $\begin{array}{l}\text { Nivel } \\
\text { encontrado } \\
(\mu \mathrm{g} / \mathrm{l})\end{array}$ & $\begin{array}{l}\text { RSD } \\
(\%)\end{array}$ & $\begin{array}{l}\text { Recuperación } \\
(\%)\end{array}$ \\
\hline \multirow{4}{*}{$\begin{array}{l}\text { Tomate } \\
\text { conserva }\end{array}$} & 0 & $<\mathrm{LOD}$ & --- & --- \\
\hline & 20 & $25,5 \pm 2,5$ & 10 & 128 \\
\hline & 50 & $50,8 \pm 2,7$ & 5 & 104 \\
\hline & 100 & $105,2 \pm 2,8$ & 3 & 107 \\
\hline \multirow{4}{*}{$\begin{array}{l}\text { Pimiento rojo } \\
\text { conserva }\end{array}$} & 0 & $<\mathrm{LOD}$ & --- & --- \\
\hline & 50 & $54,6 \pm 3,0$ & 6 & 109 \\
\hline & 100 & $108,8 \pm 13,6$ & 12 & 109 \\
\hline & 200 & $210.7 \pm 7.4$ & 4 & 105 \\
\hline \multirow{4}{*}{$\begin{array}{l}\text { Pimiento verde } \\
\text { natural }\end{array}$} & 0 & $<$ LOD & --- & --- \\
\hline & 40 & $52,9 \pm 4,4$ & 8 & 132 \\
\hline & 100 & $105,8 \pm 5,2$ & 5 & 106 \\
\hline & 200 & $191,9 \pm 1,8$ & 1 & 96 \\
\hline
\end{tabular}

\subsubsection{Análisis de aguas}

El mismo sistema inmunoanalítico se aplicó al análisis de muestras de agua mineral comercial. En este caso, volúmenes de agua entre 200 y $250 \mathrm{ml}$ se reforzaron con carbaril y se extrajeron utilizando cartuchos $\mathrm{C}_{18}$. Los extractos orgánicos obtenidos (en metanol) se diluyeron al 50\% con PBST y se analizaron mediante el inmunosensor. En este caso, la dilución no provocó el enturbiamiento de la mezcla (extracto alcohólico-tampón acuoso), por lo que este modo de preparación de muestra pudo utilizarse sin problemas. Los resultados obtenidos al analizar los extractos se recogen en la Tabla 3.18. Al igual que en casos anteriores, se utilizó una muestra sin reforzar para la detección de falsos positivos. 
Tabla 3.18. Análisis de carbaril en muestras de agua mineral utilizando el inmunosensor en formato directo

\begin{tabular}{llll}
\hline $\begin{array}{l}\text { Nivel reforzado } \\
(\mathbf{n g} / \mathbf{l})\end{array}$ & $\begin{array}{l}\text { Nivel encontrado } \\
\text { (ng/l) }\end{array}$ & $\begin{array}{l}\text { RSD } \\
(\mathbf{\%})\end{array}$ & $\begin{array}{l}\text { Recuperación } \\
(\%)\end{array}$ \\
\hline 0 & $<$ LOD & --- & --- \\
100 & $81,2 \pm 8,9$ & 11 & 81 \\
500 & $548,5 \pm 47,4$ & 9 & 110 \\
1000 & $1090,0 \pm 80,0$ & 7 & 109 \\
\hline Valores expresados como media $\pm \mathrm{SD}(\mathrm{n}=3)$ & &
\end{tabular}

Los resultados obtenidos al analizar las muestras reforzadas indicaron que el inmunosensor determinaba carbaril en agua potable a niveles de $0,1 \mu \mathrm{g} / 1$, límite máximo de residuos de plaguicidas permitido por la legislación europea para este tipo de muestras. Los valores de recuperación estuvieron comprendidos entre el 81 y el $110 \%$. La correlación (análisis de regresión lineal) entre los niveles de carbaril añadido y los encontrados fue muy satisfactoria, con un coeficiente de regresión de 0,9997, una pendiente de 1,12 y una desviación standard relativa inferior al 11\%.

\subsubsection{Inmunosensor en formato indirecto}

Al igual que en los formatos anteriores, se escogieron aquellas condiciones que produjeron los ensayos más sensibles $\left(\mathrm{I}_{50}\right.$ media $\left.24,2 \pm 7,9 \mu \mathrm{g} / \mathrm{l}\right)$. Estas fueron:

- Anticuerpo CNH-45

- Conjugado BSA-CNH inmovilizado en GASc

- Medio orgánico de análisis: 50\% metanol-50\% PBST

Dado que los inmunosensores basados en formato indirecto mostraron la peor sensibilidad, se escogieron únicamente dos matrices -tomate en conserva y agua mineral- para comprobar las prestaciones de este formato.

Para agua mineral se tomaron cuatro alicuotas de $150 \mathrm{ml}$, tres de las cuales fueron reforzadas con carbaril y la otra se utilizó como control. El analito fue extraído en fase sólida $\left(\mathrm{C}_{18}\right)$, y los extractos metanólicos obtenidos diluidos al 50\% con PBST y analizados con el inmunosensor. En la Tabla 3.19 se muestran los resultados de dichos análisis. 
Tabla 3.19. Análisis de carbaril en agua mineral utilizando el inmunosensor en formato indirecto

\begin{tabular}{llll}
\hline $\begin{array}{l}\text { Nivel reforzado } \\
(\mathbf{n g} / \mathbf{l})\end{array}$ & $\begin{array}{l}\text { Nivel encontrado } \\
(\mathbf{n g} / \mathbf{l})\end{array}$ & $\begin{array}{l}\text { RSD } \\
(\%)\end{array}$ & $\begin{array}{l}\text { Recuperación } \\
(\%)\end{array}$ \\
\hline 0 & $<$ LOD & --- & --- \\
100 & $80,8 \pm 4,0$ & 5 & 81 \\
500 & $484,4 \pm 18,2$ & 4 & 97 \\
1000 & $1420,0 \pm 50,0$ & 3 & 142 \\
\hline Valores expresados como media \pm SD $(\mathrm{n}=3)$ & &
\end{tabular}

Estos resultados demuestran que es posible detectar residuos de carbaril a niveles de $0,1 \mu \mathrm{g} / 1$. En general, la correlación entre las cantidades de carbaril añadidas y medidas -estimada como recuperación- es aceptable (106\% en valor medio), aunque hay que señalar la sobrestimación obtenida para la muestra reforzada con $1000 \mathrm{ng} / \mathrm{l}$. Cabe destacar la excelente precisión obtenida con este sistema $(\mathrm{RSD}<5 \%)$, inferior en todos los casos a los resultados obtenidos con los otros inmunosensores para carbaril.

Respecto a la muestra de tomate en conserva, se procedió de igual forma que en casos anteriores. Los extractos metanólicos obtenidos se analizaron mediante el inmunosensor, previa dilución al 50\% con PBST. Una muestra sin reforzar fue extraída y analizada para comprobar la ausencia de falsos positivos. Los resultados obtenidos en este caso se muestran en la Tabla 3.20.

Tabla 3.20. Análisis de carbaril en muestras de tomate utilizando el inmunosensor en formato indirecto

\begin{tabular}{llll}
\hline $\begin{array}{l}\text { Nivel reforzado } \\
(\boldsymbol{\mu g} / \mathbf{l})\end{array}$ & $\begin{array}{l}\text { Nivel encontrado } \\
(\boldsymbol{\mu g} / \mathbf{l})\end{array}$ & $\begin{array}{l}\text { RSD } \\
(\mathbf{\%})\end{array}$ & $\begin{array}{l}\text { Recuperación } \\
(\mathbf{\%})\end{array}$ \\
\hline 0 & $<$ LOD & --- & -- \\
20 & $19,2 \pm 3,0$ & 16 & 96 \\
50 & $41,6 \pm 5,6$ & 13 & 83 \\
100 & $96,1 \pm 7,5$ & 8 & 96 \\
\hline
\end{tabular}

Valores expresados como media $\pm \mathrm{SD}(\mathrm{n}=3)$

Como se muestra en la tabla, el inmunosensor es adecuado para el análisis de residuos de carbaril en este tipo de matriz. Los datos de recuperación obtenidos (entre 83-96\%) muestran una muy buena correlación entre las cantidades de carbaril añadidas y las medidas con el inmunosensor. Sin embargo, la precisión alcanzada no es tan buena 
como en el caso anterior $-\mathrm{RSD}<16 \%$ frente al 5\%- y la recuperación media es ligeramente inferior $-92 \%$ frente al 106\%-.

\subsection{DESARROLLO DE INMUNOSENSORES PARA CARBARIL BASADOS EN ANTICUERPOS POLICLONALES}

Los estudios comparativos entre el comportamiento de los anticuerpos monoclonales y policlonales en medios orgánicos son muy escasos, ya que es dificil disponer de los tipos de anticuerpos y de los inmunorreactivos necesarios. En principio, cabría esperar que los dos tipos de anticuerpos soportasen por igual los medios orgánicos, ya que ambos sistemas fueron desarrollados con el fin de operar en medio acuoso.

Los objetivos a alcanzar en este apartado fueron: (i) comprobar en qué medida los anticuerpos policlonales eran compatibles con los medios orgánicos, (ii) comparar los resultados obtenidos con los dados al utilizar anticuerpos monoclonales, (iii) caracterizar los distintos tipos de inmunosensores y evaluar su aplicación al análisis de muestras reales.

Para ello, se partió de los valores de las variables previamente optimizadas en el desarrollo de inmunosensores basados en anticuerpos monoclonales, utilizando un suero policlonal anti-carbaril (R2114) y un conjunto de cinco haptenos.

\subsubsection{Desarrollo inmunosensores en formato directo}

Todas las mezclas seleccionadas para los MAbs mediante experiencias en flujo, fueron estudiadas utilizando el PAb inmovilizado en los dos soportes ensayados $(\mathrm{GAHz}$ y CPG).

El primer estudio consistió en evaluar la actividad de los inmunosoportes y sus propiedades de regeneración. Cabe destacar que el sistema fue reusable en todas las condiciones en las que se apreciaba actividad, dadas las excelentes propiedades de regeneración mostradas por este $\mathrm{Ab}$. Como agente desorbente se utilizó una disolución glicina $0,1 \mathrm{M} / \mathrm{HCl}, \mathrm{pH} 2,4$, cuyo volumen fue optimizado en cada caso para conseguir la correcta desorción, ya que este tratamiento afecta a la vida útil del sensor.

Los trazadores enzimáticos empleados en los ensayos de actividad fueron evaluados en el rango 0,3 a 2,0 mg/1 y 0,05 a $0,30 \mathrm{mg} / 1$, para el anticuerpo inmovilizado en GAHz y CPG, respectivamente. De los cinco trazadores disponibles (CNH-HRP, CPNU-HRP, CNA-HRP, H4-HRP y H5-HRP), sólo las especies CNH-HRP, CPNU- 
HRP y H4-HRP mostraron actividad. Los otros dos trazadores fueron probados hasta una concentración de 3,0 mg/l, no obteniéndose en ningún caso señal suficiente para el desarrollo de los inmunosensores. Los mejores resultados se obtuvieron con el trazador H4-HRP y la mezcla M1 (50\% metanol-50\% PBST). En este medio, los trazadores se emplearon a menor concentración, lo que indicó que M1 fue la mezcla orgánica más compatible con las interacciones inmunoquímicas estudiadas. En la Tabla 3.21 se muestran las concentraciones óptimas de trazador obtenidas en los ensayos de actividad.

Tabla 3.21. Valores óptimos de concentración de trazador H4-HRP (mg/l) obtenidos en los ensayos de actividad realizados en el medio $50 \%$ MeOH- 50\% PBST

\begin{tabular}{lll}
\hline Trazador enzimático & R2114-GAHz & R2114-CPG \\
\hline CNH-HRP & 2 & 0,3 \\
CPNU-HRP & 0,5 & 0,1 \\
CNA-HRP & $>3$ & $>3$ \\
H4-HRP & 0,3 & 0,05 \\
H5-HRP & $>3$ & $>3$ \\
\hline
\end{tabular}

Puede observarse que la concentración de trazador necesaria para obtener señales útiles fue mayor al emplear el soporte GAHz, lo que también ocurría al utilizar MAbs.

La Tabla 3.22 muestra los valores de $I_{50}(\mu \mathrm{g} / \mathrm{l})$ obtenidos para todas las combinaciones -medio orgánico/trazador/soporte- que permitieron realizar ensayos de competición.

Como se aprecia en dicha tabla, los ensayos más sensibles se obtienen con la mezcla M1, debido a la menor concentración de trazador requerida para efectuar los ensayos. 
Tabla 3.22. Valores de $I_{50}(\mu \mathrm{g} / \mathrm{l})$ obtenidos con el anticuerpo policlonal $\mathbf{R 2 1 1 4}$ inmovilizado en GAHz y CPG, trazadores y medios orgánicos seleccionados

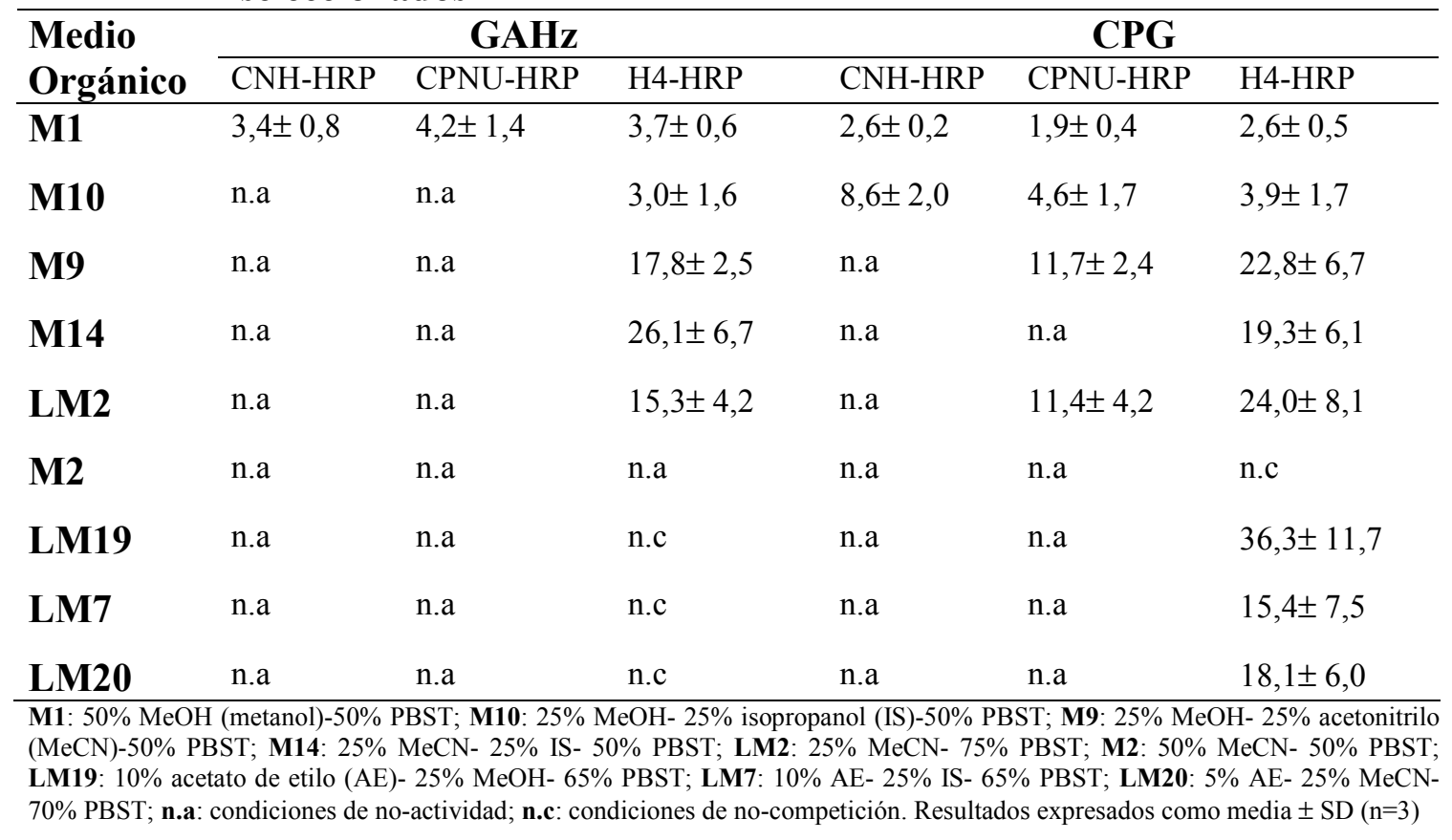

A la vista de estos resultados, parece que existe una relación entre la concentración de trazador empleada en el medio M1 y la viabilidad de los ensayos en otros medios orgánicos. Es decir, que si este valor es elevado en medio metanólico, existe poca probabilidad de desarrollar el correspondiente sensor en otros medios orgánicos menos compatibles con las interacciones inmunoquímicas estudiadas.

Según la hipótesis anterior, un anticuerpo inmovilizado en CPG necesita menor concentración de trazador que cuando se soporta en $\mathrm{GAHz}$, lo que permite desarrollar ensayos de competición en un mayor número de mezclas. Esto puede ser debido a que el anticuerpo inmovilizado en CPG es más resistente al efecto de los medios orgánicos que cuando lo está en GAHz. Del mismo modo, utilizando el trazador H4-HRP se puede trabajar con un mayor número de sistemas, dado que se requiere menor concentración, independientemente del soporte.

Al comparar los resultados obtenidos en ambos soportes, no se observan diferencias de sensibilidad apreciables. Así, utilizando CPG como soporte y la mezcla $\mathrm{M} 1$, los valores de $\mathrm{I}_{50}$ estuvieron comprendidos entre 1,9 y 2,6 $\mu \mathrm{g} / 1$ para CPNU-HRP y H4-HRP y CNH-HRP, respectivamente. Por otro lado, cuando el anticuerpo se inmovilizó en CPG, fue posible obtener curvas de inhibición en un mayor número de 
mezclas, lo que indica que el anticuerpo inmovilizado en este soporte se muestra más resistente a la acción de los medios orgánicos estudiados.

Las curvas de calibrado obtenidas con el anticuerpo policlonal inmovilizado en GAHz y CPG se muestran en las Figuras 3.7 (a y b) y 3.8 ( $a, b$ y c), respectivamente. Puede apreciarse que los medios orgánicos conteniendo metanol produjeron los ensayos más sensibles, mientras que las otras mezclas, debido al peor reconocimiento del trazador y a una mayor desnaturalización del anticuerpo inmovilizado, condujeron a ensayos menos sensibles.

Finalmente, en la Figura 3.9 se muestran las curvas de competición para el anticuerpo monoclonal CNA-36 y el policlonal R2114, correspondientes a los ensayos en las condiciones más sensibles. Como puede observarse, existe una diferencia de sensibilidad apreciable entre los ensayos efectuados con el anticuerpo monoclonal $\left(\mathrm{I}_{50}\right.$ $17,3 \mu \mathrm{g} / \mathrm{l})$ y el policlonal $\left(\mathrm{I}_{50} 1,9 \mu \mathrm{g} / \mathrm{l}\right)$.

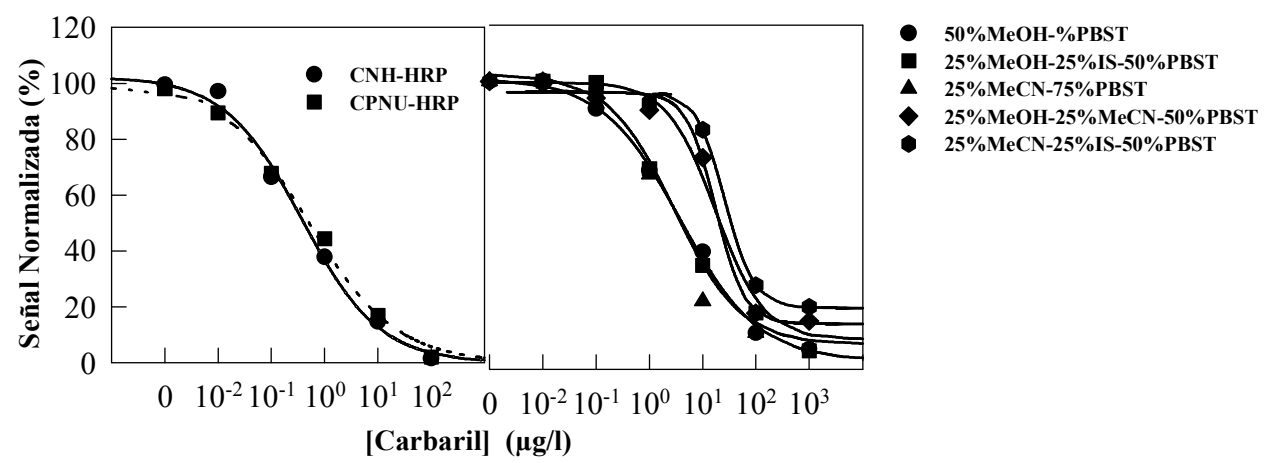

Figura 3.7. Curvas de calibrado obtenidas con el anticuerpo policlonal R2114: a) Inmovilizado en GAHZ con los trazadores CNH-HRP y CPNUHRP en el medio 50\% MeOH-50\% PBST; b) Inmovilizado en CPG con el trazador H4-HRP y los medios orgánicos seleccionados 


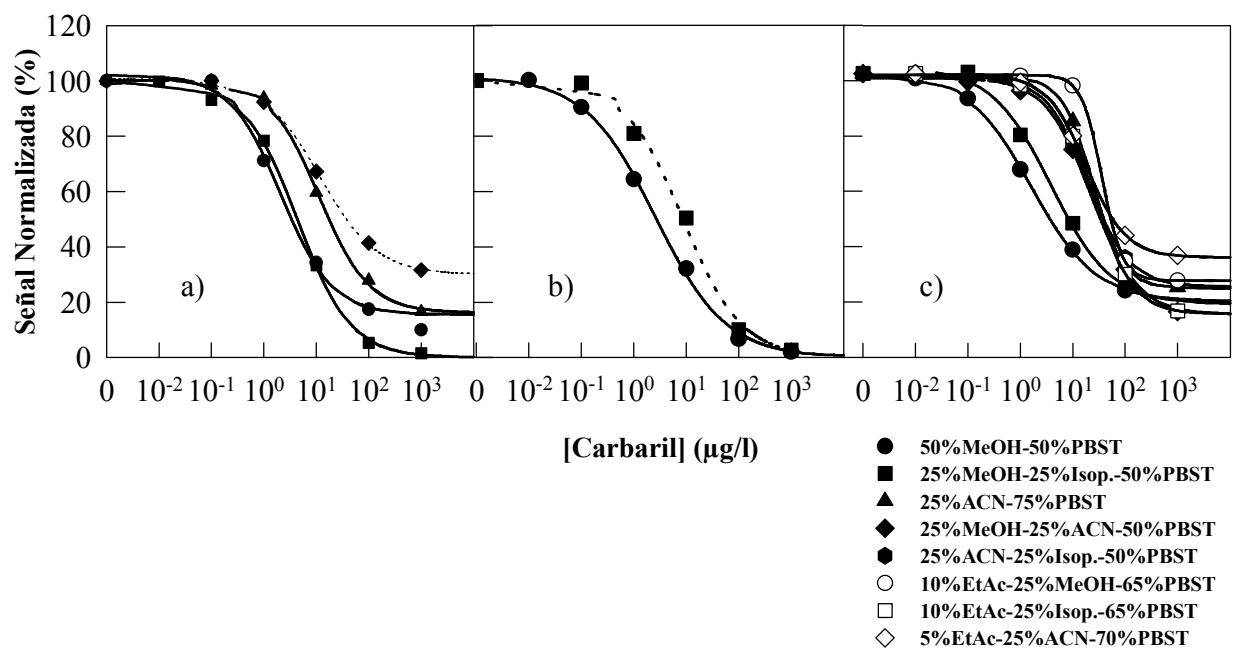

Figura 3.8. Curvas de calibrado obtenidas con el anticuerpo policlonal R2114 inmovilizado en CPG con los trazadores CPNU-HRP (a); CNH-HRP (b); H4-HRP (c) y los medios orgánicos seleccionados

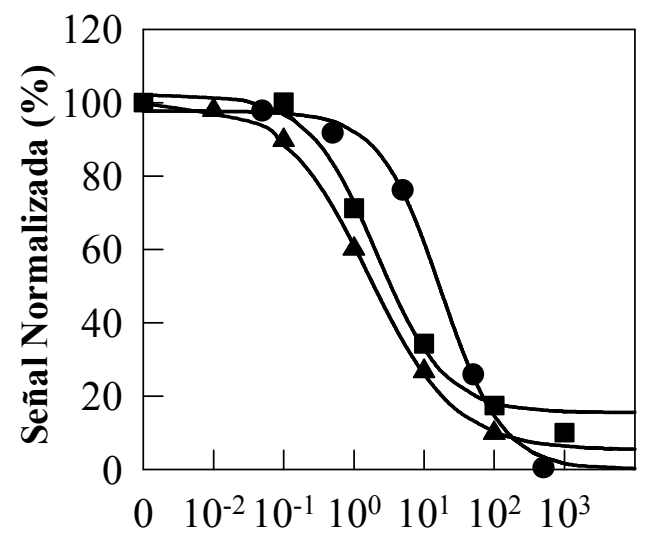

CNA-36 en GAHz; CPNU-HRP

口 R2114 en CPG; CPNU-HRP

$\triangle \quad$ R2114 en CPG; H4-HRP

[Carbaril] $(\mu \mathrm{g} / \mathrm{l})$

Figura 3.9. Comparación de las curvas de calibrado obtenidas en el medio M1 utilizando las condiciones más sensibles

\subsubsection{Desarrollo de inmunosensores en formato indirecto}

Para el desarrollo de los inmunosensores basados en este formato, se utilizaron las mismas condiciones encontradas como óptimas en el desarrollo de los inmunosensores basados en anticuerpos monoclonales. Para dicho estudio se utilizó el 
anticuerpo policlonal R2114, los haptenos CNA, CNH, H4 y H5 conjugados a BSA y los soportes GASc y CPG.

Los ensayos de actividad indicaron que sólo la mezcla 50\% MeOH- 50\% PBST y el soporte GASc daban señales útiles. En las restantes condiciones probadas no se obtuvieron señales suficientes para realizar los ensayos de competición, lo que pone de manifiesto la menor resistencia del anticuerpo policlonal en forma nativa a los diferentes medios orgánicos, comparada con los anticuerpos monoclonales. Este hecho, unido a los inconvenientes presentados por este formato de ensayo (menor reconocimiento por impedimento estérico y una alta concentración de inmunorreactivos), dio lugar a ensayos con menor sensibilidad que cuando se utilizó formato directo. Los valores de $\mathrm{I}_{50}$ obtenidos para los conjugados CNA-BSA y H5-BSA fueron 36,2 $\mu \mathrm{g} / 1$ y 26,1 $\mu \mathrm{g} / 1$, respectivamente. En los restantes casos no se observó competición.

Finalmente, hay que indicar que los ensayos de competición mostraron una baja sensibilidad y un menor rango dinámico comparados con los obtenidos con los anticuerpos monoclonales. Además, las curvas de competición estuvieron mal definidas como se muestra en la Figura 3.10.

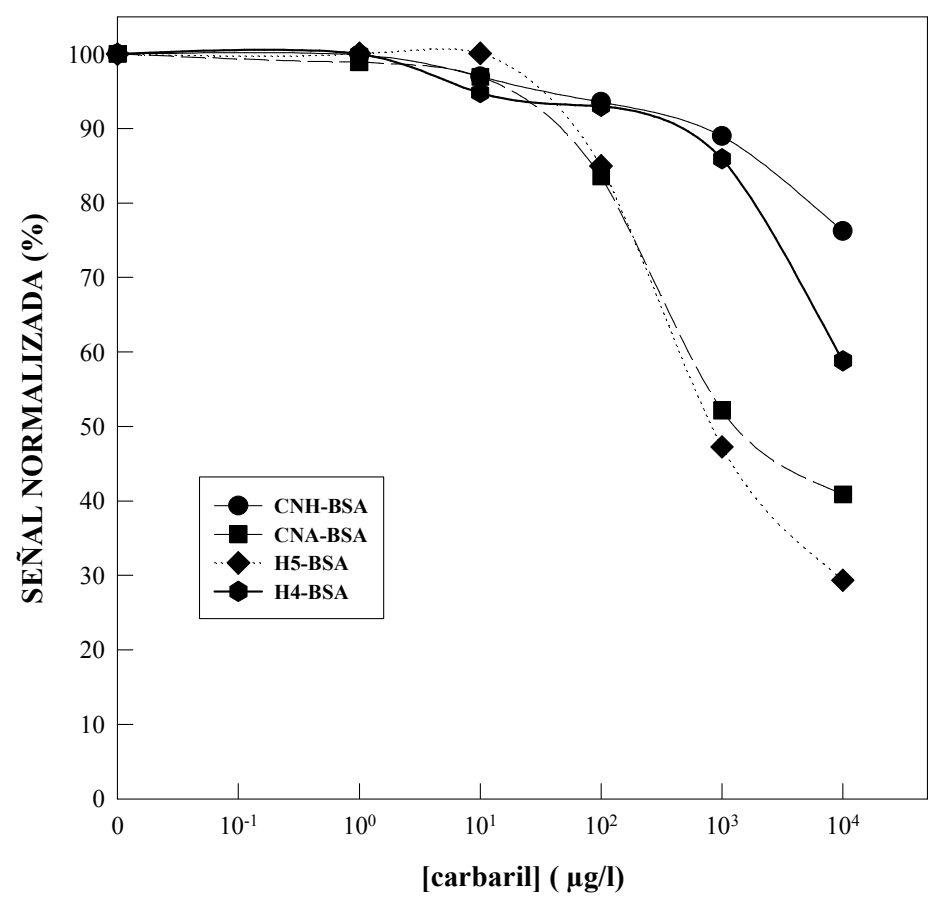

Figura 3.10. Curvas de calibrado obtenidas con el anticuerpo R2114 en formato indirecto. Soporte: GASc 


\subsubsection{Desarrollo de inmunosensores en formato de captura}

Para el desarrollo de estos inmunosensores fueron utilizadas las condiciones optimizadas para el formato directo. El protocolo de ensayo empleado fue el simultáneo, ya que en los estudios realizados con MAbs el protocolo secuencial mostró una menor actividad y sensibilidad.

Los ensayos de actividad indicaron que el trazador H4-HRP manifestaba actividad en todos los medios orgánicos ensayados, mientras que los trazadores $\mathrm{CNH}-$ HRP y CPNU-HRP sólo pudieron ser utilizados en las mezclas a base de metanol. Este hecho pone nuevamente de manifiesto que el anticuerpo policlonal en su forma nativa se muestra menos resistente a los medios orgánicos que los anticuerpos monoclonales estudiados. Cabe recordar que en el protocolo de ensayo simultáneo, al igual que en el formato indirecto, el anticuerpo en forma nativa se mezcla íntimamente con los medios orgánicos, por lo que los efectos desnaturalizantes son más acusados que en formato directo.

En la Tabla 3.23 se muestran los resultados obtenidos en los ensayos de competición, en todas las condiciones compatibles.

Tabla 3.23. Valores de $I_{50}(\mu \mathrm{g} / \mathrm{l})$ obtenidos con el anticuerpo policlonal $R 2114$ en formato de captura

\begin{tabular}{llll}
\hline Medio orgánico & CNH-HRP & CPNU-HRP & H4-HRP \\
\hline 50\% MeOH-50\%PBT (M1) & $2,0 \pm 0,2$ & $3,4 \pm 0,5$ & $1,8 \pm 0,2$ \\
25\%MeOH-25\%IS-50\%PBT (M10) & $2,2 \pm 0,2$ & n.c & $1,4 \pm 0,2$ \\
25\%MeOH-25\%MeCN-50\%PBT (M9) & n.a & n.c & $9,0 \pm 1,6$ \\
25\%MeCN-25\%IS-50\%PBT (M14) & n.a & n.c & $8,3 \pm 1,5$ \\
25\%MeCN-75\%PBT (LM2) & n.a & n.c & $5,1 \pm 2,1$ \\
$50 \% \mathrm{MeCN}-50 \%$ PBT (M2) & n.a & n.c & n.c \\
10\%AE-25\%MeOH-65\%PBT (LM19) & n.a & n.c & $13,6 \pm 4,0$ \\
$10 \% A E-25 \%$ IS-65\%PBT (LM7) & n.a & n.c & $10,1 \pm 3,7$ \\
$5 \%$ AE-25\%MeCN-70\%PBT (LM20) & n.a & n.c & n.c
\end{tabular}

MeOH: metanol; MeCN: acetonitrilo; IS: isopropanol; AE: acetato de etilo; PBT: PB con 0.05\% Tween 20. n.a. No actividad; n.c. No competición. Valores expresados como media \pm desviación estándar $(\mathrm{n}=3)$ 
A la vista de los resultados, la mezcla orgánica M10 mostró la máxima sensibilidad $\left(\mathrm{I}_{50}, 1,4 \mu \mathrm{g} / \mathrm{l}\right)$ con el trazador H4-HRP, aunque la mezcla M1 mostró competición con los tres trazadores estudiados, obteniéndose una sensibilidad similar, con valores de $\mathrm{I}_{50}$ comprendidos entre 1,8 y $3,4 \mu \mathrm{g} / 1$. Por otro lado, cabe destacar que la mezcla LM2, medio con mayor contenido en tampón acuoso, no produjo los ensayos más sensibles y sólo mostró competición con el trazador H4-HRP, demostrando que el acetonitrilo es el disolvente orgánico más pernicioso para las interacciones inmunoquímicas estudiadas. Por otro lado, se aprecia de nuevo la relación entre sensibilidad del ensayo y polaridad del medio orgánico de trabajo, de modo que el ensayo es más sensible a medida que crece la polaridad de la mezcla orgánica utilizada.

Finalmente, al comparar los valores de $\mathrm{I}_{50}$ obtenidos con el anticuerpo policlonal y con los monoclonales, se pone de manifiesto la gran diferencia de sensibilidad que existe en función del tipo de anticuerpo utilizado en el desarrollo de los inmunosensores para carbaril.

\subsubsection{Recapitulación}

A continuación se resumen los resultados (Tabla 3.24) obtenidos con los inmunosensores para carbaril basados en anticuerpo policlonal, que dan lugar a las mejores prestaciones.

Tabla 3.24. Resumen de las características de los inmunosensores desarrollados para carbaril con en el anticuerpo policlonal $\mathbf{R 2 1 1 4}$

\section{FORMATO}

\begin{tabular}{lll}
\hline DIRECTO & CAPTURA & INDIRECTO
\end{tabular}

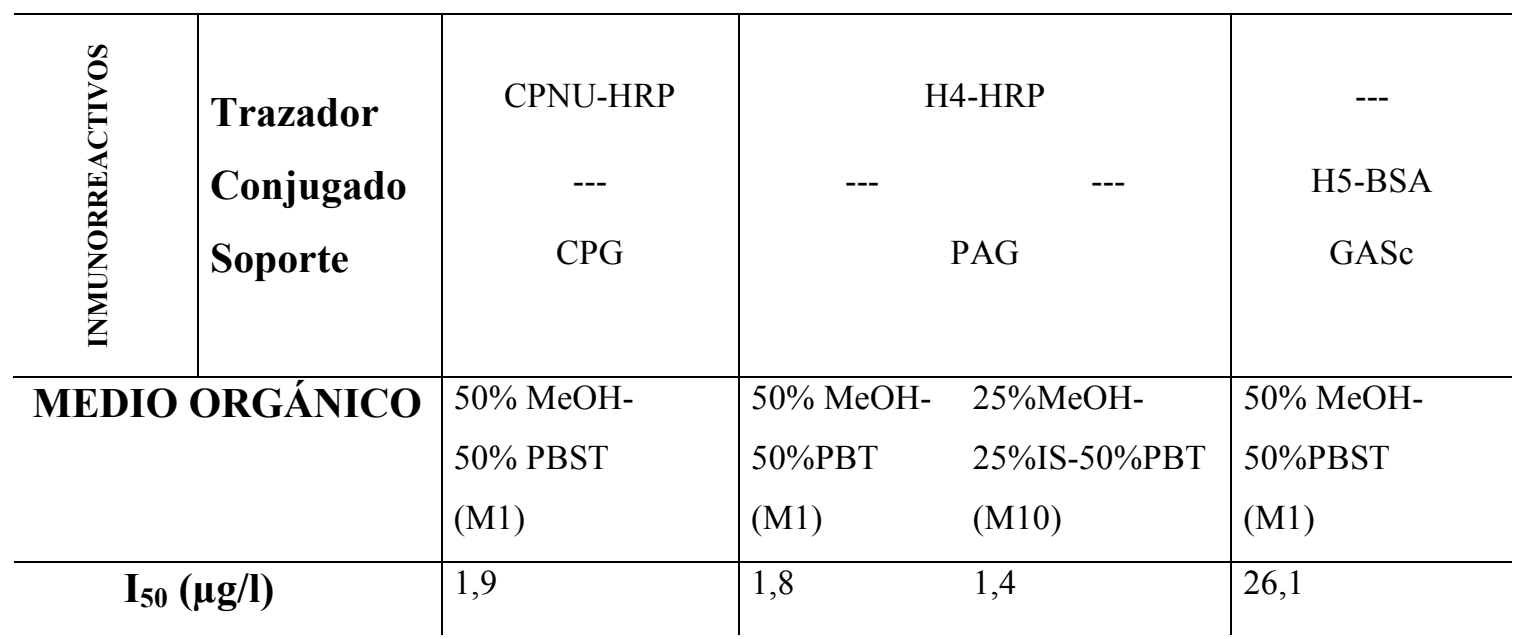




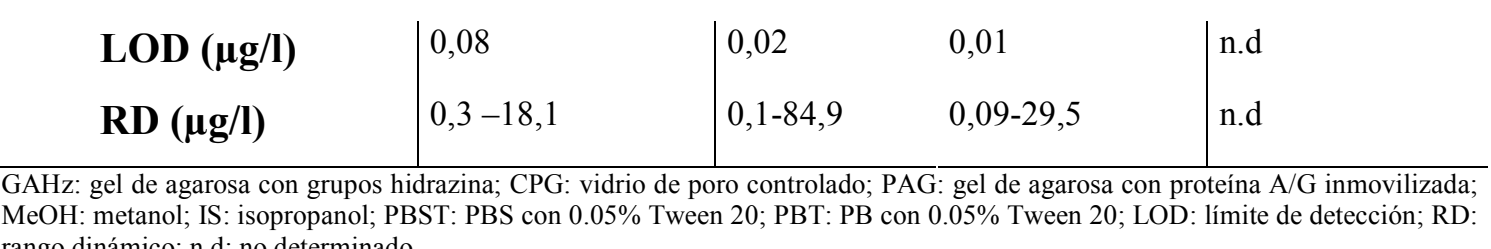
rango dinámico; n.d: no determinado

En formato de captura aparecen dos medios orgánicos: una mezcla ternaria correspondiente a la máxima sensibilidad (mezcla M10) y el otro que corresponde a la mezcla orgánica binaria con mayor porcentaje de disolvente orgánico. Este último será el utilizado para el análisis de muestras reales, dada su gran sensibilidad y fácil manipulación.

\subsection{ESTUDIO DE REACTIVIDAD CRUZADA}

Los ensayos de reactividad cruzada se realizaron -al igual que en los casos anteriores- para estimar la selectividad de los inmunosensores desarrollados, utilizando como interferentes los mismos compuestos que en el caso de los anticuerpos monoclonales. Para cada uno de los formatos ensayados, los ensayos se realizaron en las condiciones de máxima sensibilidad y mayor porcentaje de disolvente orgánico.

\subsubsection{Formato directo}

En la Tabla 3.25 se muestran los valores de $\mathrm{I}_{50} \mathrm{y}$ reactividad cruzada (\%RC) obtenidos en todos los ensayos realizados, incluyendo los obtenidos mediante la técnica ELISA (46). Estos ensayos se efectuaron, para cada inmunosoporte, en las condiciones óptimas previamente establecidas.

Tabla 3.25. Valores de reactividad cruzada (\%RC) obtenidos con el anticuerpo R2114 inmovilizado en GAHZ y CPG. Comparación con ELISA

\begin{tabular}{|c|c|c|c|c|c|c|c|c|c|}
\hline \multirow[t]{3}{*}{ Compuesto } & \multicolumn{4}{|c|}{$\mathbf{I}_{50}(\mathrm{nM})$} & \multicolumn{4}{|c|}{ RC (\%) } & \multirow{2}{*}{$\begin{array}{l}\text { RC (\%) } \\
\text { ELISA }\end{array}$} \\
\hline & \multicolumn{2}{|c|}{$\mathrm{GAHz}$} & \multicolumn{2}{|c|}{$\mathrm{CPG}$} & \multicolumn{2}{|c|}{ GAHz } & \multicolumn{2}{|c|}{$\mathrm{CPG}$} & \\
\hline & $\begin{array}{l}\text { CNH- } \\
\text { HRP }\end{array}$ & $\begin{array}{l}\text { H4- } \\
\text { HRP }\end{array}$ & $\begin{array}{l}\text { CPNU- } \\
\text { HRP }\end{array}$ & $\begin{array}{l}\text { H4- } \\
\text { HRP }\end{array}$ & $\begin{array}{l}\text { CNH- } \\
\text { HRP }\end{array}$ & $\begin{array}{l}\text { H4- } \\
\text { HRP }\end{array}$ & $\begin{array}{l}\text { CPNU- } \\
\text { HRP }\end{array}$ & $\begin{array}{l}\text { CNH- } \\
\text { HRP }\end{array}$ & \\
\hline Carbaril & 17,1 & 18,2 & 9,5 & 13,2 & 100 & 100 & 100 & 100 & 100 \\
\hline 1-Naftol & $210^{4}$ & $310^{4}$ & $710^{4}$ & $210^{4}$ & 0,077 & 0,070 & 0,014 & 0,063 & $<0,001$ \\
\hline Propoxur & $>910^{4}$ & $>910^{4}$ & $>210^{5}$ & $>910^{4}$ & $<0,018$ & $<0,019$ & $<0,004$ & $<0,01$ & 4,2 \\
\hline Carbofurano & $>410^{4}$ & $>410^{4}$ & $>410^{4}$ & $>410^{4}$ & $<0,040$ & $<0,043$ & $<0,002$ & $<0,03$ & 3,0 \\
\hline Metiocarb & $410^{4}$ & $210^{4}$ & $310^{4}$ & $110^{4}$ & 0,041 & 0,114 & 0,036 & 0,09 & n.d \\
\hline
\end{tabular}




\begin{tabular}{llllll|llll|l} 
Metomilo & $>210^{5}$ & $>210^{5}$ & $>210^{5}$ & $>210^{5}$ & $<0,011$ & $<0,011$ & $<0,006$ & $<810^{-3}$ & n.d \\
Aldicarb & $>510^{5}$ & $>510^{5}$ & $>510^{5}$ & $>510^{5}$ & $<0,003$ & $<0,003$ & $<0,002$ & $<310^{-3}$ & 4,2 \\
\hline
\end{tabular}

Como puede apreciarse, los valores de RC en el medio M1 son sensiblemente inferiores a los obtenidos en ELISA (medio acuoso), lo que indica que el inmunosensor en medio orgánico es más selectivo. Por otro lado, se aprecia que el soporte de inmovilización no influye en la especificidad del ensayo, afirmación lógica dado que en estos métodos el factor determinante de la selectividad es el anticuerpo utilizado. En cualquier caso, las interferencias son despreciables debido a los bajos valores de RC obtenidos.

Comparando los resultados con los obtenidos al utilizar el anticuerpo monoclonal CNA-36 en formato directo (Tabla 3.9), puede apreciarse que, en general, el anticuerpo policlonal se muestra más selectivo en este formato. De hecho, cuatro compuestos (1-naftol, metiocarb, propoxur y carbofurano) presentaron curvas de competición completas, mientras que con el anticuerpo policlonal tan sólo dos de ellos permiten definir las curvas (1-naftol y metiocarb).

\subsubsection{Formato indirecto}

En este formato, la baja sensibilidad obtenida en los ensayos (curvas de competición mal definidas) impidió llevar a cabo los ensayos de reactividad cruzada.

\subsubsection{Formato de captura}

Para este estudio se utilizó el suero R2114, la mezcla 50\% MeOH- 50\% PBT y el trazador H4- HRP. Los valores de $\mathrm{I}_{50}$ y RC obtenidos se muestran en la Tabla 3.26.

Tabla 3.26. Valores de reactividad cruzada $(\% \mathrm{RC})$ obtenidos en formato de captura

\begin{tabular}{lll}
\hline \multicolumn{1}{c}{ COMPUESTO } & $\mathbf{I}_{\mathbf{5 0}}(\mathbf{n M})$ & $\mathbf{R C}(\%)$ \\
\hline Carbaril & $8,8 \pm 0,9$ & 100 \\
1-Naftol & 7.020 & 0,13 \\
Metiocarb & 19.250 & 0,05 \\
Propoxur & 36.770 & 0,02 \\
Carbofurano & $>42.060$ & $<0,02$
\end{tabular}




\begin{tabular}{lll} 
Aldicarb & $>47.340$ & $<0,02$ \\
Metomilo & $>159.790$ & $<610^{-3}$ \\
\hline Anticuerpo R2114, trazador H4-HRP
\end{tabular}

Como se aprecia en dicha tabla, los valores de RC son despreciables en todos casos, lo que indica que los compuestos estudiados no presentan interferencias en la determinación de carbaril utilizando este inmunosensor.

Comparando estos resultados con los valores de RC obtenidos con el anticuerpo monoclonal CNH-45 (Tabla 3.11), se aprecia que, en general, el suero policlonal es más selectivo.

\subsection{ANÁLISIS DE MUESTRAS REALES}

Al igual que en el caso de MAbs, la aplicación de los inmunosensores desarrollados con el PAb al análisis de muestras reales supone la conclusión del desarrollo y caracterización de estos sistemas como herramientas eficaces de análisis. Por lo general, esta etapa se ha realizado sobre muestras reales reforzadas con el analito de interés, de modo que pueda demostrarse la aplicabilidad de estos sistemas para el análisis de productos fitosanitarios.

Los inmunosensores se aplicaron en las condiciones de máxima sensibilidad utilizando el medio orgánico M1 (50\% metanol-50\% tampón). Así pues, este medio definió los métodos de extracción a utilizar. En general, las muestras sólidas se extrajeron directamente con metanol dada la efectividad de este procedimiento. Por otro lado, las muestras de agua se extrajeron en fase sólida con cartuchos $\mathrm{C}_{18} \mathrm{y}$ fueron eluidas posteriormente con metanol.

En todos los casos se empleó formato de captura, dado que estos inmunosensores mostraron la máxima sensibilidad y reusabilidad. En este formato, las mejores prestaciones fueron obtenidas con el trazador H4-HRP y 50\% MeOH-50\% PBT como medio orgánico de ensayo.

\subsubsection{Vegetales frescos y procesados}

Al igual que en los ensayos anteriores, se utilizaron muestras comerciales (pimiento verde natural y tomate y pimiento rojo en conserva) reforzadas con carbaril a tres niveles. En todos los casos se utilizó una muestra sin reforzar para la detección de posibles falsos positivos. Las muestras fueron extraídas con metanol y los extractos 
orgánicos obtenidos analizados mediante el inmunosensor, tras su acondicionamiento con PBT para obtener el medio orgánico de trabajo (50\% MeOH-50\% PBT). En la Tabla 3.27, se muestran los resultados obtenidos en dicho estudio.

Tabla 3.27. Determinación de carbaril en muestras vegetales utilizando el inmunosensor en formato de captura

\begin{tabular}{lllll}
\hline MUESTRA & $\begin{array}{l}\text { Nivel reforzado } \\
(\boldsymbol{\mu g} / \mathbf{l})\end{array}$ & $\begin{array}{l}\text { Nivel encontrado } \\
(\boldsymbol{\mu g} / \mathbf{l})\end{array}$ & $\begin{array}{l}\text { RSD } \\
(\%)\end{array}$ & $\begin{array}{l}\text { Recuperación } \\
(\mathbf{\%})\end{array}$ \\
\hline $\begin{array}{l}\text { Pimiento verde } \\
\text { Natural }\end{array}$ & 0 & $<\mathrm{LOD}$ & --- & --- \\
& 10 & $9,2 \pm 1,5$ & 16 & 93 \\
& 40 & $40,6 \pm 5,9$ & 15 & 102 \\
\hline Tomate conserva & 0 & $115,8 \pm 7,8$ & 7 & 116 \\
& 100 & $<\mathrm{LOD}$ & --- & --- \\
& 40 & $11,4 \pm 1,7$ & 15 & 114 \\
& 100 & $44,5 \pm 4,8$ & 11 & 112 \\
\hline Pimiento rojo & 0 & $101,8 \pm 9,7$ & 10 & 102 \\
Conserva & 10 & $<\mathrm{LOD}$ & --- & --- \\
& 40 & $8,1 \pm 1,4$ & 17 & 81 \\
\hline
\end{tabular}

Valores expresados como media \pm desviación estándar $(\mathrm{n}=3)$

Los resultados muestran una buena correlación entre las cantidades de carbaril adicionado a las muestras y las determinadas mediante el inmunosensor. Para las muestras de pimiento verde natural, la recuperación -estimada como valor medio- fue del $104 \%$. Para tomate y pimiento rojo en conserva este valor fue $109 \%$ y $108 \%$, respectivamente. Puede apreciarse que, en general, existe una ligera tendencia a sobrestimar la cantidad de carbaril (valores de recuperación superiores al 100\%). Por otro lado cabe destacar la excelente precisión obtenida en las medidas, con valores de RSD entre el 6 y el 17\%.

Así pues, se ha demostrado la posibilidad de utilizar anticuerpos policlonales para determinar residuos de carbaril en muestras vegetales, extraídas en medio orgánico utilizando un método rápido. 


\subsubsection{Aguas}

La determinación de carbaril en aguas de origen natural se realizó con el mismo sistema inmunoanalítico utilizado para vegetales. En este caso, se analizaron aguas procedentes de la albufera de Valencia y otras tomadas en diferentes puntos del río Llobregat seleccionados por la empresa AGBAR (Aguas de Barcelona S.A).

\subsubsection{Análisis de agua procedente de la Albufera}

En este caso, las muestras de agua fueron previamente filtradas (Watman $n^{\circ} 5$ ) para eliminar la materia en suspensión. Diferentes alicuotas de las muestras $(80 \mathrm{ml})$ reforzadas con carbaril a tres niveles, fueron extraídas utilizando cartuchos $\mathrm{C}_{18}$. Una muestra sin reforzar se utilizó para controlar la ausencia de falsos positivos. Los extractos orgánicos obtenidos se diluyeron al 50\% con el tampón acuoso de trabajo (PBT) y fueron analizados con el inmunosensor. Los resultados obtenidos se muestran en la Tabla 3.28.

Tabla 3.28. Análisis de carbaril en muestras de agua de la albufera

\begin{tabular}{llll}
\hline $\begin{array}{l}\text { Nivel reforzado } \\
\text { (ng/l) }\end{array}$ & $\begin{array}{l}\text { Nivel encontrado } \\
\text { (ng/l) }\end{array}$ & $\begin{array}{l}\text { RSD } \\
(\%)\end{array}$ & $\begin{array}{l}\text { Recuperación } \\
(\%)\end{array}$ \\
\hline 0 & $<$ LOD & --- & --- \\
50 & $54,3 \pm 7,9$ & 15 & 109 \\
100 & $88,5 \pm 11,4$ & 13 & 88 \\
500 & $496,0 \pm 46,7$ & 9 & 99 \\
\hline
\end{tabular}

El análisis de los controles mostró la ausencia de falsos positivos, dado que los valores obtenidos fueron inferiores al límite de detección del ensayo. En general, la correlación entre las cantidades de carbaril añadidas y las medidas con el inmunosensor fue muy buena (valor medio de recuperación 99\%). La precisión fue aceptable, obteniéndose valores de RSD comprendidos entre el 9\% y el 15\%. Finalmente, cabe destacar que el inmunosensor desarrollado permite la determinación de carbaril a concentraciones inferiores a $0,1 \mu \mathrm{g} / 1$, nivel máximo permitido por la legislación para este tipo de muestras. 


\subsubsection{Agua procedente del Río Llobregat}

Las muestras utilizadas en este caso procedían de las estaciones de muestreo de Can Carné, Sallent, Sant Joan Despí, Pont Molins, Pont Vilamare, Anoia, Can Burés y Prese Cairat. De cada uno de los puntos se tomaron dos submuestras, una utilizada como control (sin reforzar) y la otra reforzada con carbaril a una concentración de 100 $\mathrm{ng} / \mathrm{l}$. Todas las muestras fueron previamente filtradas con un filtro Watman $\mathrm{n}^{\mathrm{a}} 5 \mathrm{y}$ sometidas a extracción en fase sólida con cartuchos $\mathrm{C}_{18}$. Los extractos metanólicos obtenidos se diluyeron al 50\% con el tampón acuoso de trabajo y se analizaron mediante el inmunosensor. Los resultados obtenidos se muestran en la Tabla 3.29.

Tabla 3.29. Análisis de carbaril en muestras de agua del Río Llobregat reforzadas

\begin{tabular}{|c|c|c|c|}
\hline $\begin{array}{l}\text { PUNTO DE } \\
\text { MUESTREO }\end{array}$ & $\begin{array}{l}\text { Nivel encontrado } \\
\text { (ng/l) }\end{array}$ & $\begin{array}{l}\text { RSD } \\
(\%)\end{array}$ & $\begin{array}{l}\text { Recuperación } \\
(\%)\end{array}$ \\
\hline Anoia & $100,8 \pm 7,1$ & 7 & 101 \\
\hline Can Burés & $105,1 \pm 3,8$ & 4 & 105 \\
\hline Can Carné & $91,3 \pm 5,1$ & 6 & 91 \\
\hline Pont Molins & $98,1 \pm 6,2$ & 6 & 98 \\
\hline Pont Vilamare & $99,7 \pm 5,9$ & 6 & 100 \\
\hline Prese Cairat & $107,6 \pm 4,4$ & 4 & 108 \\
\hline Sallent & $92,2 \pm 3,4$ & 4 & 92 \\
\hline S. Joan Despí & $93,1 \pm 4,6$ & 5 & 93 \\
\hline
\end{tabular}

Valores expresados como media \pm desviación estándar $(n=3)$

Se observa que, en todos los casos, las recuperaciones son excelentes, oscilando entre el 91\% y 108\% (promedio 99\%). Por otro lado, la precisión obtenida fue también elevada, variando entre el 4\% y el 7\% (RSD medio 5,25\%). Las muestras sin reforzar estuvieron por debajo del límite de detección del ensayo, lo que confirmó la ausencia de falsos positivos. 


\subsection{DESARROLLO DE INMUNOSENSORES PARA 1-NAFTOL}

Después de desarrollar los inmunosensores para el sistema modelo, que permitió establecer una serie de variables básicas en este tipo de sistemas, se abordó el desarrollo de inmunosensores para el análisis de otros analitos, tomando como punto de partida los datos disponibles. En primer lugar se escogió el 1-naftol, principal metabolito del carbaril, con el fin de completar el estudio.

Para el desarrollo de los inmunosensores para 1-naftol se disponía de un conjunto de tres anticuerpos policlonales denominados 3898, 3905 y 3907 y del hapteno 2b (ácido [(5-hidroxi 2-naftilenil) oxi) acético), previamente caracterizados mediante ensayos realizados en formato ELISA (174).

Utilizando estos inmunorreactivos y partiendo de los conocimientos adquiridos en el desarrollo de los inmunosensores para carbaril, se procedió a la puesta a punto y evaluación de los sistemas para 1-naftol.

\subsubsection{Desarrollo de inmunosensores en formato directo}

Estos inmunosensores fueron desarrollados utilizando las mejores condiciones seleccionadas, que fueron básicamente las siguientes:

- Anticuerpo policlonal: 3907, seleccionado en ELISA (174) por su buena sensibilidad y menor reactividad cruzada frente a carbaril.

- Soporte de inmovilización: CPG, ya que mostró mejores prestaciones que GAHz.

- Medio orgánico de análisis: 50\% MeOH-50\% PBST, mezcla de mayor sensibilidad en todos los sistemas desarrollados.

- Trazador enzimático: $2 b-H R P$

El primer estudio consistió en realizar ensayos de actividad con los inmunorreactivos seleccionados, con el fin de establecer la concentración óptima de trazador $(0,1 \mathrm{mg} / \mathrm{l})$, así como las condiciones de desorción. El tratamiento de desorción más efectivo consistió en utilizar $2,5 \mathrm{ml}$ de disolución glicina $0,1 \mathrm{M} / \mathrm{HCl}, \mathrm{pH} 2$. Cabe destacar que estas condiciones de desorción fueron más drásticas que las necesarias en otros inmunosensores desarrollados en este formato.

Posteriormente, se realizaron ensayos de regeneración con el fin de estimar la posibilidad de realizar ciclos consecutivos sin pérdida de actividad del inmunorreactor. Dichos ensayos se realizaron en medio acuoso (tampón PBST) y en el medio orgánico 
escogido (50\%MeOH-50\%PBST). En la Tabla 3.30 se muestran los porcentajes de señal obtenidos tras cada ciclo de ensayo en ambos medios de trabajo.

Tabla 3.30. Porcentaje de señal normalizada obtenidas tras cada ciclo de regeneración

\begin{tabular}{lllllllll}
\hline & \multicolumn{7}{c}{$\mathbf{N}^{\mathbf{0}}$ CICLO } \\
\cline { 2 - 8 } MEDIO ENSAYO & 1 & 2 & 3 & 4 & 5 & 6 & --- & 10 \\
\hline PBST & 100 & 95,9 & 81,7 & 71,5 & 69,3 & 63,9 & --- & 60,2 \\
$50 \% \mathrm{MeOH}-50 \%$ PBST & 100 & 95,1 & 88,2 & 77,3 & 68,5 & 62,1 & --- & 59,4 \\
\hline
\end{tabular}

Como puede apreciarse, el anticuerpo no puede ser reutilizado dada la caída de señal mostrada tras cada ciclo de regeneración. Este comportamiento es similar en los dos medios de ensayo, lo que indica que la desnaturalización del anticuerpo inmovilizado se debe a las drásticas condiciones de regeneración del inmunosoporte. Este hecho impidió la puesta a punto de un inmunosensor para 1-naftol en formato directo.

\subsubsection{Desarrollo de inmunosensores en formato indirecto}

Para el desarrollo de estos inmunosensores se escogieron las condiciones en las que el formato indirecto (ELISA) mostró, a priori, las mejores prestaciones. Por tanto, en este caso se utilizó el conjugado 2b-BSA inmovilizado en GASc y el suero 3907.

Los ensayos de actividad realizados no mostraron un rango de señal útil para la realización de los ensayos de competición en el medio orgánico seleccionado (50\% $\mathrm{MeOH}-50 \%$ PBST). Solo en medio acuoso se obtuvo señal suficiente para realizar los ensayos de competición, si bien la sensibilidad ( $\left.\mathrm{I}_{50} 1065,6 \mu \mathrm{g} / \mathrm{l}\right)$ era muy inferior a la de otros sistemas estudiados. Así pues, tampoco fue posible desarrollar un inmunosensor en formato indirecto capaz de realizar ensayos para 1-naftol en medio orgánico.

\subsubsection{Desarrollo de inmunosensores en formato de captura}

El desarrollo de inmunosensores para 1-naftol en formato de captura, se abordó primero en medio acuoso con el fin de conocer las prestaciones de este sistema inmunoanalítico. En primer lugar se utilizó el anticuerpo 3907, seleccionado como óptimo en los ensayos ELISA; posteriormente, los resultados obtenidos se aplicaron a los otros anticuerpos disponibles. En todos los casos, los ensayos se llevaron a cabo en modo simultáneo. 
Considerando los resultados obtenidos previamente, tanto en ELISA (174) como con los inmunosensores (formato directo e indirecto), podemos indicar que para 1naftol, la afinidad del Ab por el analito es muy inferior a la observada en el caso del carbaril, lo que implica utilizar altas concentraciones de inmunorreactivos para realizar los ensayos. Por tanto, dado que en este formato la cantidad de soporte utilizado (proteína $\mathrm{A} / \mathrm{G}$ inmovilizada) no es limitante, su cantidad no debe ser restrictiva, de modo que sea capaz de unir todos los inmunocomplejos formados en disolución. Los ensayos de actividad realizados utilizando un reactor de dimensiones similares a las empleadas usualmente en este formato no fueron satisfactorias, por lo que se optó por trabajar con un reactor de mayores dimensiones, aproximadamente el doble $(7 \mathrm{~mm}$ de longitud, $4 \mathrm{~mm}$ de diámetro interno). Con este reactor, los ensayos de actividad se llevaron a cabo utilizando disoluciones de Ab comprendidas entre 1/5.000 y 1/20.000 y concentraciones de trazador enzimático en el rango de 0,25 a 2,0 mg/l. La desorción fue completa utilizando disolución glicina $0,1 \mathrm{M} / \mathrm{HCl}, \mathrm{pH} 2$, como es usual en este formato de ensayo.

Como medio acuoso se utilizó el tampón de unión definido para este tipo de soporte (PB). Optimizadas las concentraciones de inmunorreactivos (dilución 1/10.000 para los tres anticuerpos y trazador a $1 \mathrm{mg} / 1$ con el Ab 3907 y a $2 \mathrm{mg} / 1$ para los otros dos Abs), se realizaron los ensayos de competición, observándose un efecto anómalo: la señal obtenida aumentaba al hacerlo la concentración de analito utilizada. Fenómeno previamente descrito para sistemas en medio acuoso (213). Este hecho podía atribuirse a la presencia de uniones inespecíficas, dado que los controles de desorción fueron correctos. Así pues, y con el fin de corregir este efecto, se ensayó la adición de Tween 20 al tampón acuoso de trabajo. En la Tabla 3.31 se muestran los valores de $I_{50}$ obtenidos utilizando diferentes concentraciones de Tween $20(0,01$ a $0,05 \% \mathrm{v} / \mathrm{v})$, para los tres anticuerpos disponibles.

Tabla 3.31. Valores de $I_{50}(\mu \mathrm{g} / \mathrm{l})$ obtenidos en medio acuoso con el inmunosensor para 1-Naftol en formato de captura

\begin{tabular}{llll} 
& \multicolumn{3}{c}{ Anticuerpos } \\
\cline { 2 - 4 } Medios de ensayo & 3898 & 3905 & 3907
\end{tabular}




\begin{tabular}{llll}
\hline PB-0.05\% Tw (PBT) & $1165 \pm 146$ & $1045,4 \pm 113,3$ & $796,3 \pm 80,2$ \\
PB-0.025\% Tw & $597,6 \pm 85,4$ & $1127,5 \pm 146,0$ & $106,6 \pm 13,9$ \\
PB-0.01 Tw & n.a & n.a & $430,6 \pm 27,6$ \\
\hline
\end{tabular}

Tw: Tween 20; n.a: no actividad; Valores expresados como media \pm desviación estándar ( $\mathrm{n}=3$ )

PB: tampón $20 \mathrm{mM}$ fosfato sódico, $\mathrm{pH} 8$

Como puede observarse, el porcentaje de Tween 20 influye significativamente en la sensibilidad de los ensayos. Los mejores resultados se obtuvieron con el anticuerpo 3907. El ensayo más sensible se obtuvo con el tampón PB conteniendo $0,025 \%$ de Tween 20, alcanzándose valores de $\mathrm{I}_{50}$ similares a los obtenidos en ensayos ELISA (106,6 $\mu \mathrm{g} / 1$ con el inmunosensor y $72 \mu \mathrm{g} / 1$ en microplaca) con el mismo anticuerpo.

Posteriormente, y dada la baja sensibilidad obtenida en medio acuoso, se estudió el comportamiento de los inmunosensores desarrollados con los tres Abs se aplicaron en los diferentes medios orgánicos, con el fin de seleccionar las mejores mezclas. La Tabla 3.32. muestra los resultados obtenidos. El medio orgánico M1 dio lugar a los ensayos más sensibles, por lo que se estudió el efecto de la concentración del tensoactivo en dicha mezcla (M1').

Tabla 3.32. Valores de $I_{50}(\mu \mathrm{g} / \mathrm{l})$ obtenidos en medio orgánico con el inmunosensor para 1-Naftol en formato de captura

\begin{tabular}{llll}
\hline \multirow{2}{*}{ Medios orgánicos } & \multicolumn{3}{c}{ Anticuerpos } \\
\cline { 2 - 4 } & 3898 & 3905 & 3907 \\
\hline $50 \% \mathrm{MeOH}-50 \%$ PBT (M1) & $1176,5 \pm 266,8$ & $1380,9 \pm 194,7$ & $781,9 \pm 88,3$ \\
$50 \% \mathrm{MeOH} 50 \%$ PB-0.025 Tw 20 (M1') & n.a & n.a & $1448,6 \pm 145,9$ \\
$50 \%$ MeCN-50\%PBT (M2) & n.a & n.a & $>9992$ \\
$25 \% \mathrm{MeCN}-75 \%$ PBT (LM2) & n.a & n.a & $>9992$ \\
$25 \% \mathrm{MeOH}-25 \%$ IS-50\%PBT (M10) & n.a & n.a & $>9992$ \\
$10 \% \mathrm{AE}-25 \% \mathrm{MeOH}-65 \% \mathrm{PBT}(\mathrm{LM} 19)$ & n.a & n.a & $1211,0 \pm 135,8$
\end{tabular}

MeOH: metanol; MeCN: acetonitrilo; IS: isopropanol; AE: acetato de etilo; Tw. Tween 20; n.a: no actividad. Valores expresados como media \pm desviación estándar $(n=3)$

El efecto del Tween 20 en medio metanólico es contrario al presentado en los ensayos en medio acuoso utilizando el Ab 3907. Concentraciones de Tween de 0,025\% (v/v) doblan el valor de $\mathrm{I}_{50}$ obtenido en PBT (Tween 0,05\% v/v). En los otros casos, no se obtiene señal suficiente para completar los ensayos de competición. 
Respecto a los anticuerpos, los mejores resultados fueron obtenidos con el suero 3907, al igual que ocurría en los formatos ELISA y en los sistemas en medio acuoso.

En la Figura 3.11 se muestran las curvas de competición obtenidas con el anticuerpo 3907 en todos los medios de ensayo (acuosos y orgánicos). Cabe destacar que los medios con acetonitrilo mostraron prácticamente las mismas curvas de inhibición (M2 y LM2)
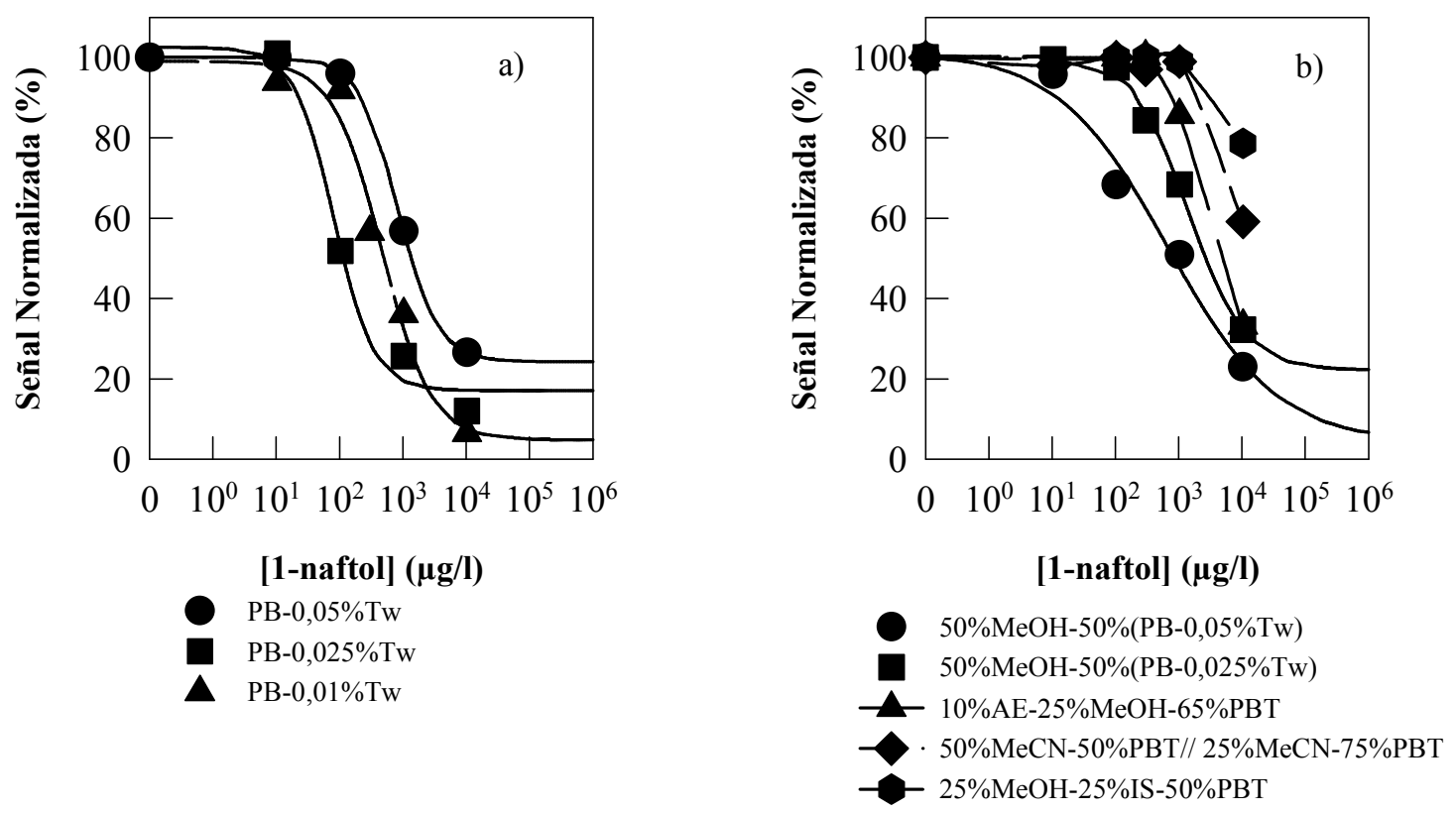

a) Figura 3.11. Curvas de competición obtenidas con el anticuerpo 3907 en el formato de captura en los medios de ensayo estudiados: a) acuosos; b) orgánicos

En la Figura 3.12, se comparan las curvas de calibrado obtenidas en el medio acuoso y orgánico más sensible. 


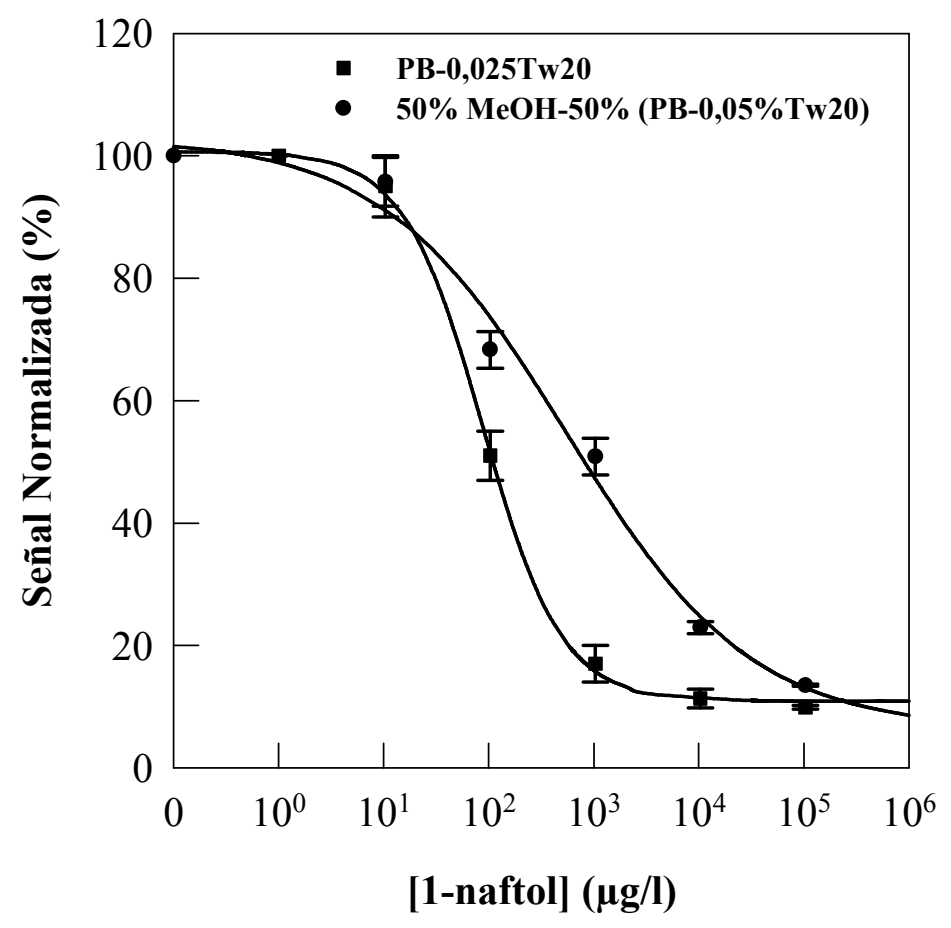

Figura 3.12. Comparación de las curvas de calibrado obtenidas en medio acuoso y orgánico en las condiciones de máxima sensibilidad

\subsubsection{Recapitulación}

La Tabla 3.33 resume las condiciones de máxima sensibilidad obtenidas en el desarrollo de los inmunosensores para 1-naftol. 
Tabla 3.33. Resumen de las características de los inmunosensores desarrollados para 1-naftol

FORMATO CAPTURA

\begin{tabular}{|c|c|c|c|}
\hline 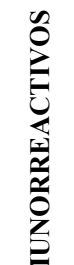 & $\begin{array}{l}\text { Trazador } \\
\text { Anticuerpo } \\
\text { Soporte }\end{array}$ & \multicolumn{2}{|c|}{$\begin{array}{c}\text { 2b-HRP } \\
3907 \\
\text { PAG }\end{array}$} \\
\hline \multicolumn{2}{|c|}{ MEDIO ENSAYO } & PB- $0,025 \%$ Tween 20 & $\begin{array}{l}50 \% \mathrm{MeOH}-50 \% \text { PBT } \\
\text { (M1) }\end{array}$ \\
\hline \multicolumn{2}{|c|}{$I_{50}(\mu \mathrm{g} / \mathrm{l})$} & 106,6 & 781,9 \\
\hline \multicolumn{2}{|c|}{ LOD $(\mu \mathrm{g} / \mathrm{l})$} & 15,1 & 11,1 \\
\hline \multicolumn{2}{|c|}{ RD $(\mu \mathrm{g} / \mathrm{l})$} & $29,8-541,0$ & $49,4-16376,8$ \\
\hline
\end{tabular}

PAG: gel de agarosa con proteína A/G inmovilizada; MeOH: metanol; PBT: PB con 0,05\% Tween 20; LOD: límite de detección; $\mathrm{RD}$ : rango dinámico; $\mathrm{PB}$ : tampón $20 \mathrm{mM}$ fosfato sódico, $\mathrm{pH} 8$

\subsection{ESTUDIO DE REACTIVIDAD CRUZADA}

La selectividad de los inmunosensores desarrollados se determinó utilizando como interferentes una serie de plaguicidas de la familia de los N-metilcarbamatos con similitud estructural con el 1-naftol: carbaril, propoxur, metiocarb y carbofurano. Las condiciones de trabajo escogidas fueron las de máxima sensibilidad, tanto en medio acuoso como orgánico. Así, se utilizó el anticuerpo 3907 y como medios de ensayo, el tampón acuoso PB-0,025\% Tween 20 y la mezcla orgánica 50\% MeOH-50\% PBT. La Tabla 3.34 recoge los valores de $\mathrm{I}_{50}$ y reactividad cruzada obtenidos para cada compuesto estudiado.

Tabla 3.34. Valores de reactividad cruzada (\%RC) obtenidos en medio acuoso y orgánico con el inmunosensor en formato de captura

\begin{tabular}{lllll}
\hline \multirow{2}{*}{ Compuesto } & \multicolumn{2}{c}{ PB-0,025\% Tween 20 } & \multicolumn{1}{c}{$\mathbf{5 0 \%}$ MeOH- 50\% PBT } \\
\cline { 2 - 5 } & $\mathrm{I}_{50}(\mu \mathrm{M})$ & $\mathrm{RC}(\%)$ & $\mathrm{I}_{50}(\mu \mathrm{M})$ & $\mathrm{RC}(\%)$ \\
\hline 1-Naftol & $0,74 \pm 0,09$ & 100 & $5,43 \pm 0,61$ & 100 \\
Carbaril & 140,2 & 0,53 & $>497,3$ & $<0,15$ \\
Propuxur & $>478,3$ & $<0,15$ & $>478,3$ & $<0,15$ \\
Metiocarb & $>444,1$ & $<0,16$ & $>444,1$ & $<0,16$ \\
Carbofurano & $>452,3$ & $<0,16$ & $>452,3$ & $<0,16$ \\
\hline
\end{tabular}

Como puede apreciarse, los valores de reactividad cruzada son despreciables en los dos medios de ensayo para todos los compuestos investigados. Sólo el carbaril 
(precursor del 1-naftol) muestra alguna interferencia $(<1 \%)$ en medio acuoso, tal y como ocurría en los ensayos de caracterización en ELISA. Esta elevada selectividad permite realizar tanto el análisis de 1-naftol como estudiar la degradación del carbaril.

Nuevamente se observa que los inmunosensores en medios orgánicos son menos sensibles que sus homólogos en medios acuosos, pero más selectivos.

\subsection{ANÁlisis DE MUESTRAS DE AGUAS NATURALES. ESTUdiOS DE PRECONCENTRACIÓN}

Con el fin de caracterizar los inmunosensores desarrollados, éstos fueron aplicados a la determinación de 1-naftol en un conjunto de muestras de agua procedentes del río Llobregat (Barcelona). Las condiciones de ensayo utilizadas fueron: anticuerpo 3907 y 50\%MeOH-50\% PBT como medio de análisis.

De cada una de las muestras se tomaron dos fracciones de $50 \mathrm{ml}$. Una fracción fue reforzada con 1-naftol a $40 \mu \mathrm{g} / 1$ y la otra se utilizó como control. Todas las muestras fueron extraídas en fase sólida, diluyendo los extractos al 50\% con PBT para su análisis. En todos los casos se obtuvo un factor de preconcentración de 33,4. Los resultados de los análisis se muestran en la Tabla 3.35.

Tabla 3.35. Análisis de 1-naftol en muestras de agua reforzadas $(40 \mu \mathrm{g} / \mathrm{l})$

\begin{tabular}{llll}
\hline Puntos muestreo & $\begin{array}{l}\text { Nivel encontrado } \\
(\boldsymbol{\mu g} / \mathbf{l})\end{array}$ & $\begin{array}{l}\text { RSD } \\
(\%)\end{array}$ & $\begin{array}{l}\text { Recuperación } \\
(\%)\end{array}$ \\
\hline Anoia & $40,4 \pm 6,5$ & 16 & 101 \\
Can Burés & $44,9 \pm 0,7$ & 2 & 112 \\
Can Carmé & $36,1 \pm 3,3$ & 9 & 90 \\
Pont de Molins & $43,4 \pm 3,6$ & 8 & 108 \\
Pont de Vilamare & $41,2 \pm 0,7$ & 2 & 103 \\
Prese Cairat & $45,1 \pm 7,5$ & 17 & 113 \\
Sallent & $50,3 \pm 1,7$ & 3 & 126 \\
Sant Joan Despí & $37,3 \pm 2,7$ & 7 & 93 \\
\hline
\end{tabular}

En todos los casos, el análisis de las muestras de agua sin reforzar indicó la ausencia de falsos positivos así como de efecto matriz. La correlación entre las cantidades de 1-naftol añadidas y encontradas fue aceptable, observándose una ligera 
sobrestimación del analito -valores de recuperación comprendidos entre 90 y 113\%, con un valor medio de 106\%-. La precisión de las medidas -expresadas como RSD (\%)- fue aceptable, estando comprendidas entre el 2 y el 17\%. Estos datos demuestran nuevamente la viabilidad práctica de los inmunosensores desarrollados en medios orgánicos.

Por otro lado, dado que los inmunosensores desarrollados para 1-naftol presentaban muy baja sensibilidad tanto en medio acuoso como en orgánico, se pensó en la posibilidad de preconcentrar el analito con el fin de disminuir los límites de detección. Para este propósito, una muestra de agua destilada fue reforzada con 1-naftol a $50 \mu \mathrm{g} / \mathrm{l}$, tomándose diferentes volúmenes $(50$ a $700 \mathrm{ml})$ que fueron extraídos utilizando cartuchos $\mathrm{C}_{18}$. Los extractos orgánicos obtenidos fueron analizados mediante el inmunosensor, consiguiéndose factores de preconcentración que oscilaron entre 33,4 y 280 , en función del volumen de muestra utilizado. Los valores de recuperación obtenidos para cada volumen ensayado se muestran en la Figura 3.13.

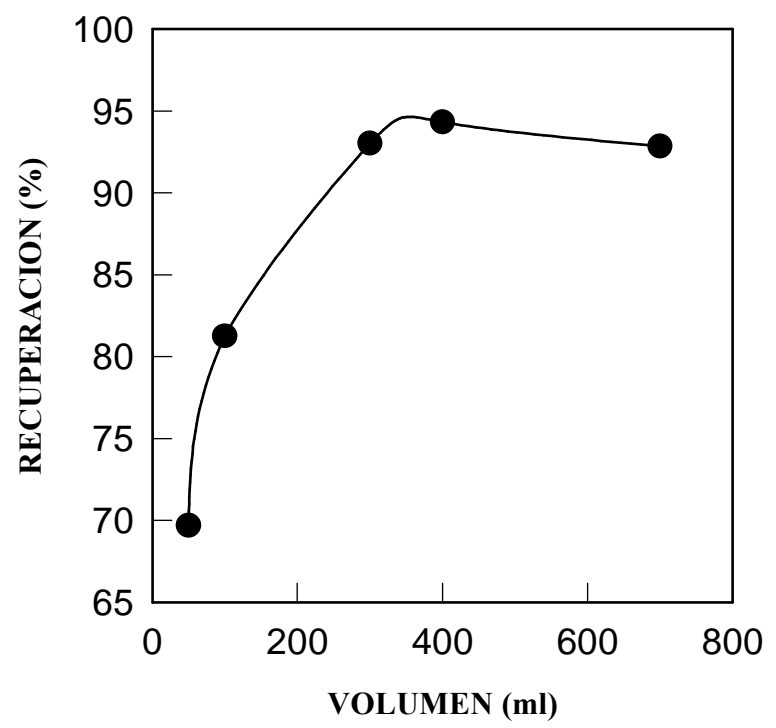

Figura 3.13. Curva de preconcentración para 1-naftol

Como se aprecia en dicha figura, para este nivel de dopaje, los mejores resultados (recuperación $>90 \%$ ) se obtuvieron al utilizar volúmenes de muestra elevados $(>300 \mathrm{ml})$, ya que las concentraciones ensayadas eran similares al valor de $\mathrm{I}_{50}$ del inmunosensor. En resumen, para un analito como 1-naftol y con un anticuerpo poco 
sensible, la etapa de preconcentración se ha mostrado muy efectiva, mejorando notablemente las prestaciones del método inmunoquímico.

\subsection{DESARROLLO DE INMUNOSENSORES PARA IRGAROL 1051}

Para el desarrollo de estos inmunosensores se utilizaron las condiciones seleccionadas como óptimas a lo largo del desarrollo experimental. Los inmunorreactivos estudiados en cada uno de los formatos fueron los seleccionados previamente mediante ensayos de inmunofiltración, basados en pruebas de actividad y competición con todas las combinaciones anticuerpo/trazador enzimático. Estos inmunorreactivos fueron: los anticuerpos policlonales R-15 y R-16 y los haptenos 4a, 4b, 4d y 4e (ver materiales y métodos). Las combinaciones óptimas fueron: anticuerpo R-15/trazador 4d-HRP y anticuerpo R-16/trazadores 4a-HRP, 4b-HRP y 4e-HRP.

\subsubsection{Desarrollo de inmunosensores en formato de captura}

Este fue el primer formato de ensayo utilizado, dado que en todos los casos anteriores mostró las mejores prestaciones. A partir de las combinaciones antes señaladas y mediante ensayos de actividad, se obtuvieron las concentraciones óptimas de inmunorreactivos en los medios orgánicos seleccionados como óptimos para los estudios con carbaril. Los dos anticuerpos (R15 y R16) fueron utilizados a una concentración de $2 \mathrm{mg} / 1$ de proteína, mientras que los trazadores enzimáticos fueron utilizados en un rango de concentración dependiente del medio orgánico ensayado, de modo que hubo que disminuir la concentración a medida que la polaridad de la mezcla aumentaba. En la Tabla 3.36 se resumen los valores obtenidos.

Posteriormente, se realizaron ensayos de competición en una serie de medios orgánicos con el fin de conocer su efecto sobre la sensibilidad. Como en todos los sensores de captura de inmunocomplejo, la desorción se llevó a cabo mediante la inyección de 2,5 ml de disolución glicina $0,1 \mathrm{M} / \mathrm{HCl}, \mathrm{pH} 2$.

Tabla 3.36. Rango óptimo de concentración de los trazadores en formato de captura

\begin{tabular}{lc}
\hline Trazador & $\begin{array}{c}\text { Rango de concentración } \\
(\mathbf{m g} / \mathbf{l})\end{array}$ \\
\hline 4a-HRP & $0,25-1,00$ \\
4b-HRP & $0,25-1,00$ \\
\hline
\end{tabular}




\begin{tabular}{ll}
\hline 4d-HRP & $1,00-1,50$ \\
4e-HRP & $0,25-0,75$ \\
\hline
\end{tabular}

En la Tabla 3.37 se muestran los valores de $I_{50}(\mu \mathrm{g} / 1)$ obtenidos en todas las condiciones estudiadas.

Tabla 3.37. Valores de $I_{50}(\mu g / l)$ obtenidos con el inmunosensor para Irgarol 1051 en formato de captura

\begin{tabular}{lllll}
\hline \multirow{2}{*}{ Medio orgánico } & \multicolumn{3}{c}{ R-15 } & \multicolumn{2}{c}{ R-16 } \\
\cline { 2 - 5 } & 4d-HRP & 4a-HRP & 4b-HRP & 4e-HRP \\
\hline $50 \%$ MeOH-50\% PBT (M1) & $0,8 \pm 0,2$ & $1,3 \pm 0,7$ & $2,6 \pm 0,9$ & $1,0 \pm 0,2$ \\
$25 \%$ MeOH-25\% IS-50\% PBT (M10) & $2,2 \pm 0,9$ & $1,5 \pm 0,9$ & n.a & $4,1 \pm 1,2$ \\
$25 \%$ MeOH-25\% MeCN-50\% PBT (M9) & $6,2 \pm 1,5$ & $1,5 \pm 0,6$ & n.a & $3,1 \pm 1,2$ \\
$50 \%$ MeCN-50\% PBT (M2) & n.c & n.c & n.a & n.a \\
$25 \%$ MeCN-75\% PBT (LM2) & $2,3 \pm 0,8$ & $1,1 \pm 0,5$ & n.c & $2,0 \pm 0,8$ \\
$10 \%$ AE- 25\% IS- 65\% PBT (LM7) & n.c & $8,4 \pm 2,4$ & n.c & n.a \\
$10 \%$ AE- 25\% MeOH- 65\% PBT (LM19) & n.c & $3,1 \pm 1,1$ & n.c & n.a \\
$5 \%$ AE- 25\% MeCN- 70\% PBT (LM20) & n.c & $2,5 \pm 1,0$ & n.c & n.a \\
\hline
\end{tabular}

MeOH: metanol, IS: Isopropanol, MeCN: acetonitrilo, AE: acetato de etilo, PBT: tampón fosfato $20 \mathrm{mM}$, pH 8, con 0,05\% Tween 20, n.a: condiciones de no actividad, n.c: condiciones de no competición. Valores expresados como media \pm desviación estándar $(\mathrm{n}=3)$

Como se aprecia en dicha tabla, la mezcla con 50\% metanol es la que dio lugar a los ensayos más sensibles, al igual que ocurrió en todos los sistemas anteriormente desarrollados. Así mismo, el acetonitrilo sólo pudo ser utilizado al 25\% (M9 y LM2) ya que porcentajes mayores no condujeron a resultados positivos, bien por falta de señal o por ausencia de competición (M2). Además, la mezcla M14 (25\% MeCN- 25\% IS- 50\% PBT) no se incluyó debido a que en los casos precedentes no supuso una mejora en la sensibilidad respecto a las otras mezclas con acetonitrilo (M2 y LM2).

En general, tal y como ocurría en los inmunosensores desarrollados para los analitos carbaril y 1-naftol, la sensibilidad aumenta paralelamente a la polaridad del medio de ensayo. La combinación Ab/trazador que dio lugar a competición en un mayor número de mezclas fue R16/4a-HRP.

La sensibilidad fue, en todos los casos, menor a la obtenida utilizando los mismos inmunorreactivos en medio acuoso $\left(\mathrm{I}_{50} 0,05 \mu \mathrm{g} / \mathrm{l}\right)(187)$. A modo de ejemplo, en 
la Figura 3.14 se muestran las curvas de competición normalizadas, obtenidas en las condiciones de máxima sensibilidad (R-15 /4d-HRP) en medio orgánico (M1, M10, M9 y LM2) y acuoso. En ella puede apreciarse la dependencia entre el medio de ensayo y la sensibilidad alcanzada. Finalmente, se estimó la reproducibilidad de los resultados a partir de las señales obtenidas en días consecutivos, analizando un patrón de $1 \mu \mathrm{g} / \mathrm{l}$. El coeficiente de variación obtenido fue inferior al $6 \%(n=8)$.

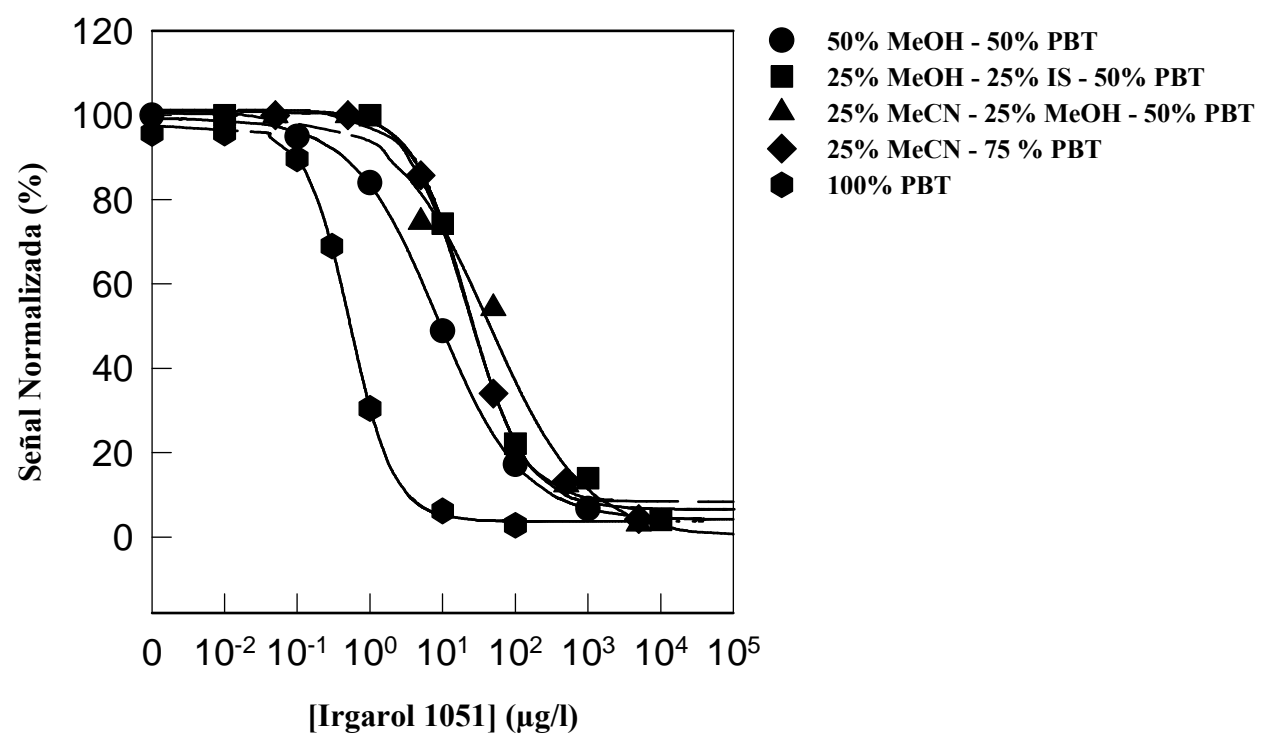

Figura 3.14. Curvas de competición normalizadas para Irgarol 1051 obtenidas en formato de captura (R-15 /4d-HRP)

\subsubsection{Desarrollo de inmunosensores en formato directo}

Para este estudio fueron escogidos los anticuerpos policlonales inmovilizados en $\mathrm{CPG}$, dado que este soporte mostró mejores prestaciones que GAHz.

En primer lugar, y mediante ensayos de actividad, se investigó el comportamiento de los trazadores en cada medio orgánico, según las combinaciones $\mathrm{Ab} /$ trazador mencionadas para el formato de captura. En la Tabla 3.38 se muestra el rango de concentraciones ensayado para cada uno de los trazadores enzimáticos empleados. El valor óptimo depende de la mezcla orgánica utilizada. 
Tabla 3.38. Rango óptimo de concentración de los trazadores en formato directo

\begin{tabular}{lc}
\hline Trazador & $\begin{array}{c}\text { Rango de concentraciones } \\
(\mathbf{m g} / \mathbf{l})\end{array}$ \\
\hline 4a-HRP & $0,10-0,80$ \\
4b-HRP & $0,25-1,00$ \\
4d-HRP & $0,12-1,25$ \\
4e-HRP & $0,10-1,00$ \\
\hline
\end{tabular}

En todos los casos, la mezcla conteniendo 50\% metanol fue el medio más compatible con las interacciones estudiadas. Nuevamente pudo observarse que, al disminuir la polaridad del medio de ensayo, la cantidad de trazador requerida fue mayor. Así, mientras que con la mezcla M1 la concentración necesaria de cualquiera de los trazadores fue la más baja del rango, para las mezclas con acetato de etilo (LM7, LM19 y LM20) estas concentraciones fueron las máximas. Cabe destacar que las concentraciones de trazador utilizadas en formato directo fueron inferiores a las del formato de captura, excepto para el trazador $4 b-H R P$ que fueron idénticas.

Como es usual en este formato de ensayo, como agente desorbente se utilizó una disolución glicina $0,1 \mathrm{M} / \mathrm{HCl}, \mathrm{pH} 2,4$. El volumen de desorbente fue optimizado en cada caso hasta conseguir la regeneración total del inmunorreactor en el mínimo tiempo de tratamiento, oscilando entre 0,25 y $1 \mathrm{ml}$ para las mezclas de metanol y las de acetato de etilo, respectivamente. Establecidas las condiciones previas, se procedió a la realización de los ensayos de competición en todos los medios orgánicos seleccionados. En la Tabla 3.39 se dan los valores de $\mathrm{I}_{50}(\mu \mathrm{g} / \mathrm{l})$ obtenidos con todas las combinaciones anticuerpo/trazador seleccionadas, en función del medio orgánico de ensayo.

Tabla 3.39. Valores de $I_{50}(\mu \mathrm{g} / \mathrm{l})$ obtenidos con el inmunosensor para Irgarol 1051 en formato directo. Anticuerpos inmovilizados en CPG

\begin{tabular}{lllll}
\hline \multirow{2}{*}{ Medio orgánico } & \multicolumn{3}{c}{ R-15 } & \multicolumn{3}{c}{ R-16 } \\
\cline { 2 - 5 } & 4d-HRP & 4a-HRP & 4b-HRP & 4e-HRP \\
\hline $50 \%$ MeOH-50\% PBST (M1) & $1,2 \pm 0,1$ & $1,2 \pm 0,1$ & $1,3 \pm 0,2$ & $2,1 \pm 0,2$ \\
$25 \%$ MeOH- 25\% IS- 50\% PBST (M10) & $8,4 \pm 1,2$ & $4,7 \pm 1,3$ & $9,9 \pm 2,3$ & $14,0 \pm 1,0$ \\
$25 \%$ MeOH-25\% MeCN- 50\% PBST (M9) & $8,0 \pm 0,7$ & $8,6 \pm 1,2$ & $4,7 \pm 0,2$ & $4,5 \pm 0,5$ \\
$50 \%$ MeCN-50\% PBST (M2) & n.c & n.c & n.c & n.c \\
$25 \%$ MeCN-75\% PBST (LM2) & $1,9 \pm 0,6$ & $1,5 \pm 0,3$ & $3,8 \pm 0,7$ & $2,5 \pm 0,1$
\end{tabular}




$\begin{array}{lllll}10 \% \text { AE- 25\% IS- 65\% PBST (LM7) } & \text { n.c } & 9,9 \pm 0,2 & \text { n.c } & 12,0 \pm 2,2 \\ 10 \% \text { AE- 25\% MeOH- 65\% PBST (LM19) } & 10,4 \pm 1,8 & 5,9 \pm 0,9 & \text { n.c } & 7,2 \pm 0,4 \\ 5 \% \text { AE- 25\% MeCN- 70\% PBST (LM20) } & \text { n.c } & 6,5 \pm 0,2 & \text { n.c } & 4,7 \pm 0,5\end{array}$

MeOH: metanol, IS: Isopropanol, MeCN: acetonitrilo, AE: acetato de etilo, PBST: tampón PBS con 0,05\% Tween 20, n.c: condiciones de no competición. Valores expresados como media \pm desviación estándar $(\mathrm{n}=3)$

A diferencia de lo que ocurre en formato de captura, el valor de $\mathrm{I}_{50}$ obtenido al utilizar la combinación R16/4e-HRP con la mezcla M1 $(2,1 \mu \mathrm{g} / \mathrm{l})$ es superior al alcanzado con R15/4d-HRP y la mezcla LM2 (1,9 $\mu \mathrm{g} / 1)$, lo que pone de manifiesto la influencia del formato de ensayo en la sensibilidad.

Cabe resaltar que fue posible realizar ensayos de competición en un mayor número de medios orgánicos, lo que corrobora el hecho de la mayor estabilidad del anticuerpo cuando está inmovilizado (formato directo) que cuando está en forma nativa (formato de captura). Además, la sensibilidad en el primer caso es ligeramente menor dado que la reacción inmunoquímica en disolución es más favorable, si bien existen excepciones (los ensayos con R-16/4a-HRP y 4b-HRP con la mezcla M1, se muestran más sensibles en formato directo (Tabla 3.39) que en formato de captura (Tabla 3.37), lo que corrobora la influencia del formato de ensayo en la sensibilidad obtenida. También se vuelve a observar la relación entre sensibilidad y polaridad del medio de ensayo, puesta de manifiesto en todos los sistemas hasta ahora desarrollados.

Finalmente, cabe resaltar que los resultados obtenidos en formato directo (Tabla 3.39) son más precisos que los obtenidos en el formato de captura (Tabla 3.37).

\subsubsection{Desarrollo de inmunosensores en formato indirecto}

En el desarrollo de estos sistemas se tuvo en cuenta que, en todos los casos, este formato de ensayo mostraba los peores resultados. Por tanto, se escogieron las condiciones de máxima sensibilidad correspondientes a los formatos anteriores: la mezcla 50\% metanol- 50\% PBST como medio de ensayo y los conjugados 4a-BSA, 4dBSA y 4e-BSA inmovilizados en GASc. También se realizaron ensayos en medio acuoso (PBST) con el fin de poder realizar comparaciones.

Mediante ensayos de actividad se obtuvieron las concentraciones óptimas de inmunorreactivos. La regeneración del inmunosensor se realizó con 2,5 $\mathrm{ml}$ de una disolución glicina $0,1 \mathrm{M} / \mathrm{HCl}, \mathrm{pH} 2$, como es usual en este formato de ensayo. El anticuerpo secundario fue utilizado a una dilución 1/5.000 y los anticuerpos específicos (R-15 y R-16) en un rango de concentraciones de 1-5 mg/l, dependiendo del conjugado 
y medio de ensayo utilizado. En la Tabla 3.40 , se muestran los valores de $I_{50}(\mu \mathrm{g} / \mathrm{l})$ obtenidos al realizar los ensayos de competición en las condiciones óptimas.

Tabla 3.40. Valores de $I_{50}(\mu \mathrm{g} / \mathrm{l})$ obtenidos con el inmunosensor para Irgarol 1051 en formato indirecto

\begin{tabular}{|c|c|c|c|c|}
\hline \multirow[b]{2}{*}{$\mathbf{A b}$} & \multirow[b]{2}{*}{ Medio de ensayo } & \multicolumn{3}{|c|}{ Conjugados hapteno-proteína } \\
\hline & & 4a-BSA & 4d-BSA & 4e-BSA \\
\hline \multirow{3}{*}{$\mathrm{R}-15$} & PBST & $2,2 \pm 0,4$ & $5,7 \pm 1,2$ & $2,3 \pm 0,5$ \\
\hline & $50 \% \mathrm{MeOH}-50 \% \mathrm{PBST}$ & $17,9 \pm 6,4$ & $17,3 \pm 3,9$ & $19,8 \pm 3,1$ \\
\hline & PBST & $2,5 \pm 0,4$ & $4,2 \pm 0,6$ & $4,2 \pm 1,0$ \\
\hline $\mathrm{R}-16$ & $50 \% \mathrm{MeOH}-50 \%$ PBST & $16,7 \pm 2,5$ & $19,3 \pm 2,7$ & $18,9 \pm 1,5$ \\
\hline
\end{tabular}

MeOH: metanol, PBST: tampón PBS con $0.05 \%$ tween 20. Valores expresados como media \pm desviación estándar $(\mathrm{n}=3)$

Como se aprecia en dicha tabla, existen diferencias apreciables en la sensibilidad del ensayo desarrollado en medio acuoso y en medio orgánico. Por otro lado, estas diferencias son menos acusadas en el medio orgánico estudiado, independientemente de la combinación Ab/conjugado. En medio acuoso el ensayo más sensible se obtuvo con la combinación R15/4a-BSA $(2,2 \mu \mathrm{g} / \mathrm{l})$ mientras que en medio orgánico fue R16/4a$\operatorname{BSA}(16,7 \mu \mathrm{g} / 1)$.

Cabe destacar que la sensibilidad en este formato de ensayo es claramente inferior a la obtenida en los formatos de ensayo anteriormente estudiados. Por tanto, se demuestra de nuevo la influencia del formato de ensayo en la sensibilidad obtenida. Finalmente, se confirma una vez más el importante efecto del medio de ensayo en las interacciones inmunoquímicas, siendo apreciables las diferencias de sensibilidad entre el medio acuoso y orgánico.

\subsubsection{Recapitulación}

A continuación se resumen (Tabla 3.41) los resultados obtenidos en el desarrollo de los inmunosensores para Irgarol 1051 en medio orgánico. Las condiciones mostradas corresponden a las situaciones de máxima sensibilidad. En formato directo se incluyen los dos trazadores que dan lugar a ensayos con igual sensibilidad. 
Tabla 3.41. Resumen de las características de los inmunosensores desarrollados para Irgarol 1051

FORMATO

\begin{tabular}{lll}
\hline DIRECTO & CAPTURA & INDIRECTO
\end{tabular}

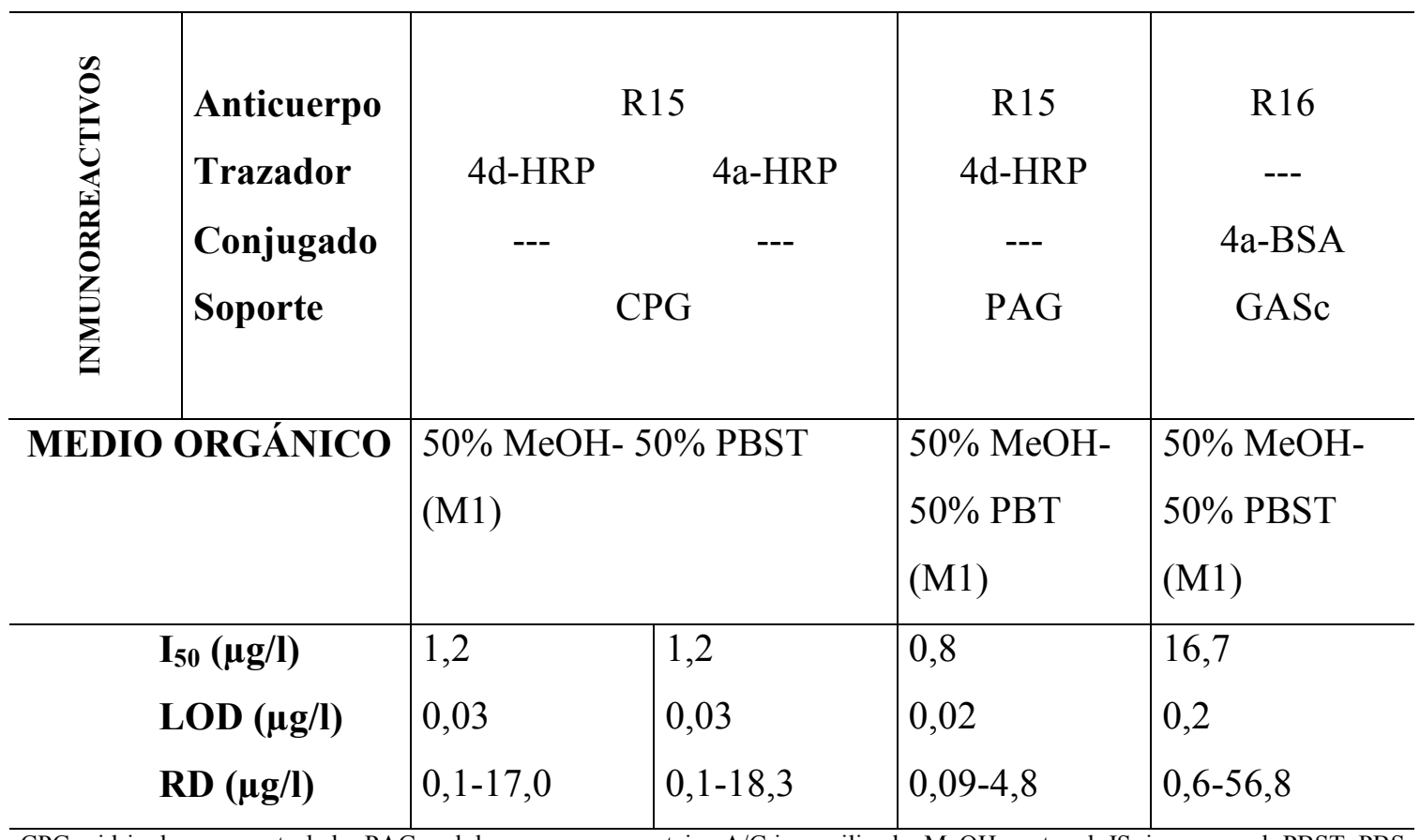

CPG: vidrio de poro controlado; PAG: gel de agarosa con proteina $\mathrm{A} / \mathrm{G}$ inmovilizada; $\mathrm{MeOH}$ : metanol; IS: isopropanol; PBST: PBS con $0.05 \%$ Tween 20; PBT: PB con $0.05 \%$ Tween 20; LOD: límite de detección; RD: rango dinámico

Como se aprecia en dicha tabla, las mejores prestaciones se obtienen en los inmunosensores basados en formato de captura.

\subsection{ESTUDIO DE REACTIVIDAD CRUZADA}

Para determinar la selectividad de los inmunosensores desarrollados para Irgarol 1051 se realizaron ensayos de competición con una serie de compuestos de la familia de las s-triazinas. Los valores de reactividad cruzada fueron expresados como relación porcentual entre los valores de $\mathrm{I}_{50}$ obtenidos para el Irgarol 1051 y los distintos interferentes. El medio orgánico de ensayo en todos los casos fue 50\% metanol-50\% tampón acuoso, dado que esta mezcla produjo los ensayos de máxima sensibilidad. En los dos formatos que proporcionaron mayor sensibilidad (captura y directo), los ensayos se realizaron utilizando los dos anticuerpos (R15 y R16), dado que la diferencia de sensibilidad entre ensayos era mínima. Los resultados obtenidos se muestran en la Tabla 3.42. En ella se han incluido, además, los valores de RC obtenidos en medio acuosos con el inmunosensor en formato de captura, dado que este formato produjo las mejores prestaciones 
Tabla 3.42. Valores de reactividad cruzada (\%RC) obtenidos con los inmunosensores para Irgarol 1051

\begin{tabular}{llllll}
\hline & \multicolumn{5}{c}{ Reactividad cruzada (\% RC) } \\
\cline { 2 - 6 } Compuesto & \multicolumn{3}{c}{ Formato Captura } & \multicolumn{3}{c}{ Formato Directo } \\
\cline { 2 - 6 } & R-15/4d-HRP & R-16/ 4e-HRP & R-15/ acuoso* & R-15/ 4d-HRP & R-16/ 4a-HRP \\
\hline Irgarol 1051 & 100,00 & 100,00 & 100,00 & 100,00 & 100,00 \\
Terbumeton & 32,80 & 1,22 & 132,00 & 32,02 & 1,02 \\
Terbutrin & 10,70 & 5,93 & 59,10 & 4,60 & 2,25 \\
Terbutilazina & 7,80 & 2,03 & 33,10 & 7,06 & 4,94 \\
Cianazina & 1,80 & 0,20 & 15,10 & 3,13 & 5,23 \\
Prometrin & 1,40 & 20,19 & 14,30 & 2,64 & 25,01 \\
Ametrin & 1,00 & 10,61 & 7,30 & 2,04 & 6,03 \\
Propazina & 0,47 & 30,00 & 3,80 & 0,47 & 34,84 \\
Atrazina & 0,07 & 2,02 & 1,60 & 0,39 & 1,83 \\
Dietilatrazina & 0,05 & 0,59 & 0,70 & 0,09 & 0,23 \\
Simazina & $<0,06$ & 0,68 & 0,20 & $<0,02$ & 0,47 \\
Deisopropilatrazina & $<0,01$ & $<0,02$ & 0,03 & $<0,07$ & $<0,07$ \\
\hline
\end{tabular}

Todos los ensayos se realizaron en medio orgánico 50\% metanol- 50\% tampón acuoso, excepto el ensayo en medio acuoso.

* Datos correspondientes a formato de captura en medio acuoso con el trazador 4d-HRP, en las condiciones de máxima sensibilidad (187)

Cabe destacar que, en principio, los valores de reactividad cruzada mostrados por un mismo anticuerpo fueron independientes del formato de ensayo utilizado. Así, el terbumeton es el mayor interferente para el $\mathrm{Ab}$ R-15 en los dos formatos, y los compuestos propazina, prometrin y ametrin lo son para el Ab R-16, siendo la propazina el interferente más destacado. Al utilizar formato de captura, también se presentan diferencias de reactividad cruzada entre el medio acuoso y el orgánico, de modo que se puede afirmar que, en todos los casos, el inmunosensor en medio orgánico es más selectivo que el equivalente sistema en medio acuoso, cuya selectividad es similar a la obtenida en ELISA (188).

Por otro lado, también se observan diferencias de selectividad en función del anticuerpo utilizado. Así, e independientemente del formato de ensayo, los valores de $\mathrm{RC}$ proporcionados por el Ab R15 son, en general, inferiores a los obtenidos con el $\mathrm{Ab}$ R16. Respecto al anticuerpo R-15 cabe señalar que las mayores interferencias las producen las especies que contienen el grupo tertbutilo en su molécula (terbutilazina, terbutrin y terbumeton), siendo el más destacado el terbumeton, dado que el hapteno 
inmunizante en la obtención del suero contenía dicho grupo. Para el resto de sustancias estudiadas las interferencias son mínimas, con valores de RC inferiores al 5\%.

\subsection{ANÁLISIS DE IRGAROL 1051 EN MUESTRAS DE AGUA}

Como en todos los sistemas desarrollados, la aplicación de los inmunosensores al análisis de muestras reales -tanto nativas como reforzadas- constituye el objetivo último a evaluar. Este caso presenta un interés especial, dado que este alguicida es de aplicación reciente y por tanto, poco conocido en comparación con los productos fitosanitarios estudiados hasta ahora, donde se dispone de varias técnicas analíticas para su determinación. El uso de Irgarol 1051 en pinturas marinas representa una contaminación potencial en todo tipo de aguas (saladas y dulces). Por tanto, el inmunosensor desarrollado fue aplicado al análisis de ambos tipos de muestras.

Para realizar los análisis se utilizó el sistema con mejores prestaciones analíticas: formato de captura, anticuerpo R-15 y trazador enzimático 4d-HRP. En todos los casos, el medio orgánico de ensayo fue 50\% metanol-50\% PBT.

En todas las muestras, el analito fue extraído utilizando cartuchos $\mathrm{C}_{18}$. Los resultados de los análisis de Irgarol 1051 en medio orgánico se muestran en las Tablas 3.43 y 3.44, comparándolos con los obtenidos en medio acuoso (187). El sistema acuoso fue validado previamente mediante ELISA y HPLC -utilizando extracción en fase sólida con detección espectrofotométrica (SPE-LC-DAD)-.

Tabla 3.43. Análisis de Irgarol 1051 en muestras de agua dulce

\begin{tabular}{|c|c|c|c|}
\hline \multirow[b]{2}{*}{ Muestra } & \multirow{2}{*}{$\begin{array}{l}\text { Nivel reforzado } \\
(\mu \mathrm{g} / \mathrm{l})\end{array}$} & \multicolumn{2}{|c|}{ Nivel encontrado $(\mu \mathrm{g} / \mathrm{l})$} \\
\hline & & Sensor acuoso & Sensor orgánico \\
\hline \multirow[t]{3}{*}{ Albufera de Valencia } & 0,00 & $0,041 \pm 0,003$ & $0,048 \pm 0,004$ \\
\hline & 0,05 & $0,087 \pm 0,007$ & $0,103 \pm 0,006$ \\
\hline & 0,10 & $0,132 \pm 0,007$ & $0,156 \pm 0,001$ \\
\hline \multirow[t]{2}{*}{ Río Júcar } & 0,00 & $0,072 \pm 0,003$ & $0,088 \pm 0,012$ \\
\hline & 0,05 & $0,138 \pm 0,014$ & $0,146 \pm 0,012$ \\
\hline
\end{tabular}

Como se aprecia en la Tabla 3.43, los análisis de agua dulce indicaron la presencia de Irgarol 1051 a niveles inferiores a $0,1 \mu \mathrm{g} / 1$, lo que significó que existía una ligera contaminación de la Albufera y del río Júcar en los puntos de muestreo (nivel 0 
de adición de analito). Estos resultados son lógicos, ya que las dos zonas de muestreo son zona de paso y atraque de embarcaciones menores, especialmente de recreo.

Tabla 3.44. Análisis de Irgarol 1051 en muestras de agua marina

\begin{tabular}{|c|c|c|c|}
\hline \multirow[b]{2}{*}{ Muestra } & \multirow{2}{*}{$\begin{array}{ll}\text { Nivel reforzado } \\
(\mu \mathrm{g} / \mathrm{l})\end{array}$} & \multicolumn{2}{|c|}{ Nivel encontrado $(\mu \mathrm{g} / \mathrm{l})$} \\
\hline & & Sensor acuoso* & Sensor orgánico \\
\hline \multirow[t]{4}{*}{ Playa de Malvarrosa } & 0,00 & $<$ LOD & $<\mathrm{LOD}$ \\
\hline & 0,05 & $0,046 \pm 0,004$ & $0,049 \pm 0,001$ \\
\hline & 0,10 & $0,091 \pm 0,004$ & $0,108 \pm 0,010$ \\
\hline & 0,50 & $0,477 \pm 0,008^{a}$ & $0,500 \pm 0,070$ \\
\hline \multirow[t]{4}{*}{ Playa de Cullera } & 0,00 & $<\mathrm{LOD}$ & $<\mathrm{LOD}$ \\
\hline & 0,05 & $0,057 \pm 0,014$ & $0,040 \pm 0,003$ \\
\hline & 0,10 & $0,093 \pm 0,005$ & $0,107 \pm 0,003$ \\
\hline & 0,50 & $0,690 \pm 0,030^{\mathrm{a}}$ & $0,750 \pm 0,060$ \\
\hline
\end{tabular}

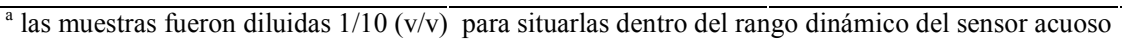

Por el contrario, no se detectó Irgarol 1051 en las muestras de agua marina analizadas (Tabla 3.44). En todos los casos, las recuperaciones obtenidas utilizando muestras reforzadas a diferentes niveles fueron excelentes ( 80 a 108\%). Sólo se observó una ligera sobrestimación del alguicida en la muestra procedente de Cullera reforzada al mayor nivel. Por otro lado, cabe destacar la excelente correlación que existe entre los resultados obtenidos con ambos tipos de inmunosensor $(r=0,9988)$, lo que demuestra la posibilidad de analizar Irgarol 1051 en aguas utilizando los inmunosensores desarrollados. Hay que indicar que en medio acuoso la curva de calibrado se realizó en agua marina artificial, debido al efecto matriz causado por la alta concentración salina de este tipo de muestras, lo que supuso la obtención de señales absolutas mucho más elevadas que las correspondientes al medio acuoso tamponado (187). En medio orgánico esto no fue necesario, dado que el proceso previo de extracción eliminó el problema (186).

\subsection{RECAPITULACIÓN}

Los estudios realizados han permitido desarrollar inmunosensores para diferentes analitos, capaces de trabajar en altas concentraciones de medio orgánico. En 
todos los casos, se han utilizado los mismos formatos de ensayo, enzima marcadora y sistema de detección. Además, se ha hecho especial hincapié en el tratamiento de muestra, proponiendo métodos de extracción rápidos y utilizando la extracción en fase sólida para mejorar los límites de detección dados los elevados factores de preconcentración conseguidos. A la vista de los resultados obtenidos y de los inconvenientes presentados, parece lógico ampliar la metodología de ensayo a fin de mejorar sus prestaciones.

Respecto a los formatos de ensayo, el indirecto mostró una menor sensibilidad, debido en parte a impedimentos estéricos. Este hecho está en contraposición con lo que ocurre en los ensayos ELISA, donde este formato es el escogido en la mayoría de las ocasiones. Los formatos de ensayo más adecuados para la determinación de los plaguicidas estudiados son, en primer lugar, el de captura de inmunocomplejo -que mostró las mejores prestaciones respecto a sensibilidad, reusabilidad y aplicabilidad- y en menor medida, el directo.

Por otro lado, el sistema de marcaje con HRP influye y limita el desarrollo de los inmunosensores en medios orgánicos. En este sentido, se plantearon las siguientes cuestiones: ¿es posible mejorar las prestaciones analíticas de los sistemas desarrollados mediante otros sistemas de marcaje y detección?, o en su defecto ¿es posible utilizar medios con mayor carga orgánica?.

\subsection{SISTEMAS DE DETECCIÓN ALTERNATIVOS}

En este apartado se pretendía poner a punto inmunosensores basados en sistemas de marcaje y detección alternativos a la fluorescencia de la reacción HPPA/HRP, con altas tolerancias a medios orgánicos y que requiriesen técnicas de detección más sensibles. Así pues, se ensayaron dos tipos de marcaje: un marcador de Tb (III) para lecturas en fluorescencia con resolución temporal y la enzima fosfatasa alcalina utilizando un substrato quimioluminiscente de la familia de 1,2-dioxetanos. Ambas técnicas de marcaje/detección son potencialmente más sensibles que la utilizada anteriormente, lo que - a priori- permitía suponer que los inmunosensores desarrollados utilizando estos sistemas presentarían una mayor sensibilidad y compatibilidad en medios con mayor carga orgánica. 


\subsubsection{Detección basada en fluorescencia con resolución temporal}

Para el desarrollo de estos sistemas se utilizó un complejo de Tb (ver sección experimental) capaz de ser detectado mediante fluorescencia con resolución temporal, que en principio tendría la ventaja de eliminar o disminuir las señales de fondo provocadas por la presencia de sustancias fluorescentes. Por otro lado, los efectos de los medios orgánicos en trazadores de este tipo serían despreciables. En primer lugar no son proteínas y por lo tanto están menos sometidas a la acción desnaturalizante del medio orgánico. Además, la señal obtenida podría ser superior, ya que, por regla general, los medios orgánicos favorecen la fluorescencia debido a la inhibición de fenómenos de desactivación (quenching).

Dado que en los experimentos realizados no fue posible marcar el hapteno con el complejo $\mathrm{Tb}$, el desarrollo de inmunosensores en formato directo fue inviable, según se describió en la sección experimental. La alternativa consistió en la formación de conjugados complejo Tb-anticuerpo secundario (formato indirecto), ya que la metodología de acoplamiento de grupos $-\mathrm{SCN}$ del complejo de $\mathrm{Tb}$ a grupos libres $-\mathrm{NH}_{2}$ del anticuerpo está bien resuelta (201). Por otro lado, estos ensayos no requieren estudiar el efecto de los medios orgánicos sobre el conjugado $\mathrm{Ab}_{2}-\mathrm{Tb}$, ya que en formato indirecto esta especie no está en contacto con dichos medios.

Dado que el anticuerpo secundario utilizado fue un anticuerpo monoclonal de ratón anticonejo, los inmunosensores desarrollados utilizando este modo de detección fueron los correspondientes a los sistemas basados en anticuerpos policlonales: carbaril, 1-naftol e irgarol 1051.

En estos ensayos el inmunosoporte se colocó en la celda de flujo del fluorímetro, de modo que la fluorescencia leída se correspondiera con la cantidad de marcador (Tb) unida al inmunosoporte a través del anticuerpo primario específico y no se produjesen pérdidas de señal en el proceso de transporte al detector. Así pues, la medida de la actividad del trazador se efectuó sobre la superficie del inmunosoporte sólido, lugar donde ocurre la competición, a diferencia de los trazadores enzimáticos que -salvo excepciones- generan un producto de reacción en fase líquida.

Tras eliminar el exceso de conjugado $\mathrm{Ab}_{2}-\mathrm{Tb}$, el protocolo de ensayo incluía una etapa de incubación ( 1 minuto) en la propia celda de flujo. La regeneración del inmunosoporte se efectuó mediante lavado con $2,5 \mathrm{ml}$ de una disolución glicina $0,1 \mathrm{M} / \mathrm{HCl}, \mathrm{pH} 2$. 
En todos los casos, la señal inespecífica debida a la especie $A_{2}-T b$ y la señal del conjugado de $\mathrm{Tb}$ unido al anticuerpo específico se evaluó mediante ensayos de actividad. Una vez definidas las concentraciones de los inmunorreactivos se procedió a realizar los ensayos de competición con el fin de determinar la sensibilidad de los inmunosensores desarrollados para cada uno de los analitos estudiados.

\subsubsection{Inmunosensores para la determinación de carbaril}

Para el desarrollo de estos inmunosensores fueron utilizados los siguientes inmunorreactivos: anticuerpo específico R2114; soporte GASc y conjugados inmovilizados CNA-BSA, CNH-BSA, H4-BSA y H5-BSA

Los resultados de los ensayos de actividad y competición indicaron que la dilución del anticuerpo R2114 debía oscilar entre 1/5.000 y 1/10.000, y la del conjugado $\mathrm{Ab}_{2}-\mathrm{Tb}$ entre $1 / 500$ y $1 / 2.000$, en función del rango de señal obtenida en cada caso y bajo el criterio de utilizar las menores concentraciones posibles.

Los medios de ensayo probados fueron PBST como medio acuoso y la mezcla $50 \%$ MeOH-50\% PBST como medio orgánico. Los resultados obtenidos en los ensayos de competición -comparados con los del marcador enzimático HRP- se muestran en la Tabla 3.45.

Tabla 3.45. Valores de $I_{50}(\mu \mathrm{g} / \mathrm{l})$ obtenidos en formato indirecto con el conjugado $\mathrm{Ab}_{2}$-Tb y con el conjugado enzimático $\mathrm{Ab}_{2}$-HRP. Sistema Carbaril

\begin{tabular}{llllll}
\hline \multirow{2}{*}{ Conjugado } & & \multicolumn{4}{c}{ Conjugado hapteno-proteína } \\
\cline { 3 - 6 } & & CNH-BSA & CNA-BSA & H4-BSA & H5-BSA \\
\hline ENZIMÁTICO & ACUOSO & n.c & $7,7 \pm 1,8$ & n.c & $0,8 \pm 0,3$ \\
$\mathrm{Ab}_{2}$-HRP & ORGÁNICO & n.c & $36,2 \pm 3,5$ & n.c & $26,1 \pm 4,7$ \\
& & & & & \\
TIEMPO & ACUOSO & n.c & $1,9 \pm 0,8$ & n.c & $1,0 \pm 0,4$ \\
RESUELTO & ORGÁNICO & n.c & $5,7 \pm 2,5$ & n.c & $6,3 \pm 0,8$ \\
$\mathrm{Ab}_{2}$-Tb & &
\end{tabular}

Acuoso: PBST; Orgánico: 50\% MeOH-50\% PBST; n.c: condiciones de no-competición; valores expresados como media \pm desviación estándar $(\mathrm{n}=3)$

Como se aprecia en dicha tabla, existe una clara mejora en la sensibilidad al utilizar el conjugado $\mathrm{Ab}_{2}-\mathrm{Tb}$ (sistema de detección fluorescente con resolución temporal), aunque en medio acuoso y con el conjugado H5-BSA la sensibilidad obtenida fue similar. Los ensayos más sensibles, en tiempo resuelto, se obtuvieron con el conjugado H5-BSA $(1,0 \mu \mathrm{g} / \mathrm{l})$ y con CNA-BSA $(5,7 \mu \mathrm{g} / \mathrm{l})$ en medio acuoso y medio 
orgánico, respectivamente. En principio, esta mejora en la sensibilidad puede ser explicada si tenemos en cuenta que la cantidad de inmunosoporte era aproximadamente tres veces inferior (capacidad de la celda de flujo) a la utilizada en el caso del conjugado enzimático. Esta reducción en la concentración de inmunorreactivo inmovilizado fue debida a dos causas: la alta sensibilidad del sistema de detección empleado y la ausencia de señales de fondo. Por otro lado, vuelve a mostrarse la diferencia de sensibilidad entre el medio acuoso y el medio orgánico, aunque esta diferencia es menos apreciable al utilizar el conjugado de $\mathrm{Tb}$.

Finalmente, se evaluó la reproducibilidad de las señales obtenidas mediante la realización de una serie de ciclos sucesivos en ambos medios de ensayo. Para ello se utilizó el anticuerpo R2114 y el conjugado H5-BSA inmovilizado en GASc, obteniéndose coeficientes de variación del $4.0 \%$ y $5.1 \%(n=9)$ en medio acuoso y orgánico, respectivamente.

\subsubsection{Inmunosensores para la determinación de 1-naftol}

Los inmunorreactivos utilizados para el desarrollo de estos sistemas fueron: el anticuerpo policlonal 3907 y el conjugado 2b-BSA inmovilizado en GASc. Estas especies produjeron los ensayos más sensibles en ELISA (174) y en los inmunosensores enzimáticos desarrollados previamente.

Mediante ensayos de actividad se establecieron los rangos óptimos de concentración de inmunorreactivos, situándose entre 1/1.000 y 1/2.000 para el anticuerpo 3907, y entre 1/500 y 1/1.000 para el anticuerpo secundario marcado con el complejo de $\mathrm{Tb}$.

En la Tabla 3.46 se muestran los valores de $\mathrm{I}_{50}$ obtenidos en medio acuoso (PBST) y orgánico (50\% MeOH-50\% PBST) para el conjugado objeto de estudio, comparándolos con los valores alcanzados al utilizar el conjugado enzimático.

Tabla 3.46. Valores de $I_{50}(\mu \mathrm{g} / \mathrm{l})$ obtenidos en formato indirecto con el conjugado $A b_{2}-T b$ y con el conjugado enzimático $A b_{2}$-HRP. Sistema 1-Naftol 
Como se aprecia en dicha tabla, con los dos conjugados -enzimático y de $\mathrm{Tb}$ sólo pudieron realizarse los ensayos de competición en medio acuoso. Hay que hacer notar que la sensibilidad mejoró ligeramente al utilizar el complejo de Tb, alcanzándose valores similares a los obtenidos en microplaca (174). Así pues, los resultados obtenidos impidieron el desarrollo de sensores en medio orgánico para este analito.

\subsubsection{Inmunosensores para la determinación de Irgarol 1051}

Para la puesta a punto de estos inmunosensores se utilizaron los mismos inmunorreactivos que en los sistemas enzimáticos previamente desarrollados. Estas especies fueron: los anticuerpos policlonales R-15 y R-16 y los conjugados 4a-BSA, 4dBSA y 4e-BSA inmovilizados en GASc.

Las concentraciones de anticuerpos en ensayos de actividad variaron entre 3,5-6 ppm y 3-5 ppm para los anticuerpos R-15 y R-16, respectivamente. El anticuerpo secundario marcado con el complejo de Tb fue utilizado a una dilución 1/1.000 en todos los casos.

En la Tabla 3.47 se muestran los valores de $I_{50}$ para todas las combinaciones ensayadas, así como los valores de sensibilidad obtenidos con el conjugado enzimático. Los medios de ensayo, como en casos anteriores, fueron PBST (acuoso) y 50\% $\mathrm{MeOH}-$ $50 \%$ PBST (orgánico).

Tabla 3.47. Valores de $I_{50}(\mu \mathrm{g} / \mathrm{l})$ obtenidos en formato indirecto con el conjugado $\mathrm{Ab}_{2}$-Tb y con el conjugado enzimático $\mathrm{Ab}_{2}$-HRP. Sistema Irgarol 1051 Conjugado hapteno-proteína

\begin{tabular}{|c|c|c|c|c|c|}
\hline $\mathbf{A b}$ & Conjugado & & 4a-BSA & 4d-BSA & 4e-BSA \\
\hline \multirow[t]{4}{*}{$\mathrm{R}-15$} & \multirow{2}{*}{$\begin{array}{l}\text { ENZIMÁTICO } \\
\mathrm{Ab}_{2} \text {-HRP }\end{array}$} & ACUOSO & $2,2 \pm 0,4$ & $5,7 \pm 1,2$ & $2,3 \pm 0,5$ \\
\hline & & ORGÁNICO & $17,9 \pm 6,4$ & $17,3 \pm 3,9$ & $19,8 \pm 3,1$ \\
\hline & \multirow{2}{*}{$\begin{array}{l}\text { TIEMPO } \\
\text { RESUELTO } \\
\mathrm{Ab}_{2}-\mathrm{Tb}\end{array}$} & ACUOSO & $0,5 \pm 0,2$ & $0,8 \pm 0,2$ & $0,8 \pm 0,3$ \\
\hline & & ORGÁNICO & $2,3 \pm 0,8$ & $2,5 \pm 0,8$ & $3,1 \pm 0,9$ \\
\hline \multirow[t]{3}{*}{ R-16 } & \multirow{2}{*}{$\begin{array}{l}\text { ENZIMÁTICO } \\
\mathrm{Ab}_{2} \text {-HRP }\end{array}$} & ACUOSO & $2,5 \pm 0,4$ & $4,2 \pm 0,6$ & $4,2 \pm 1,0$ \\
\hline & & ORGÁNICO & $16,7 \pm 2,5$ & $19,3 \pm 2,7$ & $18,9 \pm 1,5$ \\
\hline & TIEMPO & ACUOSO & $0,6 \pm 0,1$ & $0,4 \pm 0,1$ & $0,8 \pm 0,3$ \\
\hline
\end{tabular}




\begin{tabular}{ccrc}
$\begin{array}{l}\text { RESUELTO ORGÁNICO } \\
\mathrm{Ab}_{2} \text {-Tb }\end{array}$ & $1,4 \pm 0,05$ & $2,0 \pm 0,1$ & $1,8 \pm 0,07$ \\
\hline Valores expresados como media \pm desviación estándar $(\mathrm{n}=3)$ &
\end{tabular}

A la vista de estos resultados se aprecia la mejora importante de sensibilidad obtenida con el empleo del sistema de detección fluorescente con resolución temporal, frente al fluorescente/enzimático. Se observan también diferencias de sensibilidad entre el medio acuoso y orgánico, de modo que la influencia del medio de ensayo es independiente del sistema de detección empleado. Esto parece lógico, dado que en la reacción inmunoquímica no interviene el modo de detección utilizado y si el medio en el que ésta se realiza. Por último, cabe destacar que en el sistema de detección en tiempo resuelto las diferencias de sensibilidad para cada uno de los conjugados haptenoproteína son poco apreciables, siendo éstas más significativas en el sistema enzimático. Las condiciones que dieron los ensayos más sensibles con el sistema de detección fluorescente con resolución temporal fueron: R16/4d-BSA $(0,4 \mu \mathrm{g} / \mathrm{l})$ y R16/4a-BSA $(1,4 \mu \mathrm{g} / \mathrm{l})$ para medio acuoso y orgánico, respectivamente. Para los ensayos enzimáticos, las condiciones de máxima sensibilidad fueron: R15/4a-BSA $(2,2 \mu \mathrm{g} / 1)$ y R16/4a-BSA $(16,7 \mu \mathrm{g} / \mathrm{l})$ para medio acuoso y orgánico, respectivamente. Hay que indicar que las diferencias de sensibilidad son pequeñas entre conjugados, para un mismo anticuerpo y medio de ensayo.

\subsubsection{Estudio de estabilidad del conjugado $\mathrm{Ab}_{2}$-complejo de $\mathrm{Tb}$}

Uno de los aspectos a tener en cuenta en el desarrollo de inmunosensores es el estudio de la estabilidad de los inmunorreactivos utilizados. En este tipo de sistemas, la especie $\mathrm{Ab}_{2}$-complejo de $\mathrm{Tb}$ es una de las más interesantes, por lo que la viabilidad de los inmunosensores se debe, en parte, a su estabilidad.

Para realizar este estudio se utilizó el sistema Irgarol 1051 y el anticuerpo policlonal R16 a una concentración de $4 \mathrm{ppm}$. La disolución $\mathrm{Ab}_{2}$-complejo de $\mathrm{Tb}$ a una dilución 1/1.000, fue conservada a temperatura ambiente y comparada con una disolución preparada diariamente. En todos los casos, se utilizó PBST como medio de trabajo. En la Figura 3.15, se muestra la evolución de la señal obtenida en los ensayos en función del envejecimiento del reactivo $\mathrm{Ab}_{2}-\mathrm{Tb}$.

Como se aprecia, la señal va disminuyendo a lo largo de los días, lo que indica que la estabilidad del conjugado en disolución decrece paulatinamente hasta un valor 
cercano a la señal inespecífica. Aparentemente, esta especie es estable tan sólo durante los dos primeros días de ensayo.
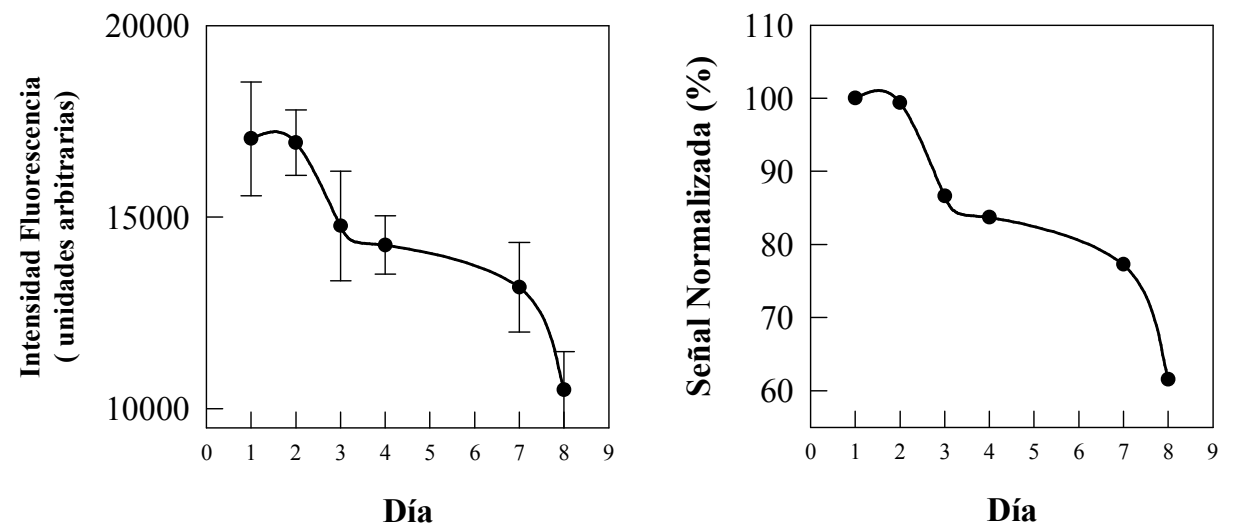

Figura 3.15. Evolución de la señal obtenida con el conjugado $\mathrm{Ab}_{2}$-Tb en función del
tiempo (sin estabilizante)

Con el fin de incrementar la estabilidad de la especie $\mathrm{Ab}_{2}-\mathrm{Tb}$ se utilizaron proteínas inertes como las empleadas usualmente en la estabilización de inmunorreactivos en disolución $(215,216)$. En este caso se adicionó ovoalbúmina (OVA) al 0,5\% (v/v) y seroalbúmina bovina (BSA) al 1\% (v/v). En la Figura 3.16 se muestra la evolución de la señal en el tiempo. 

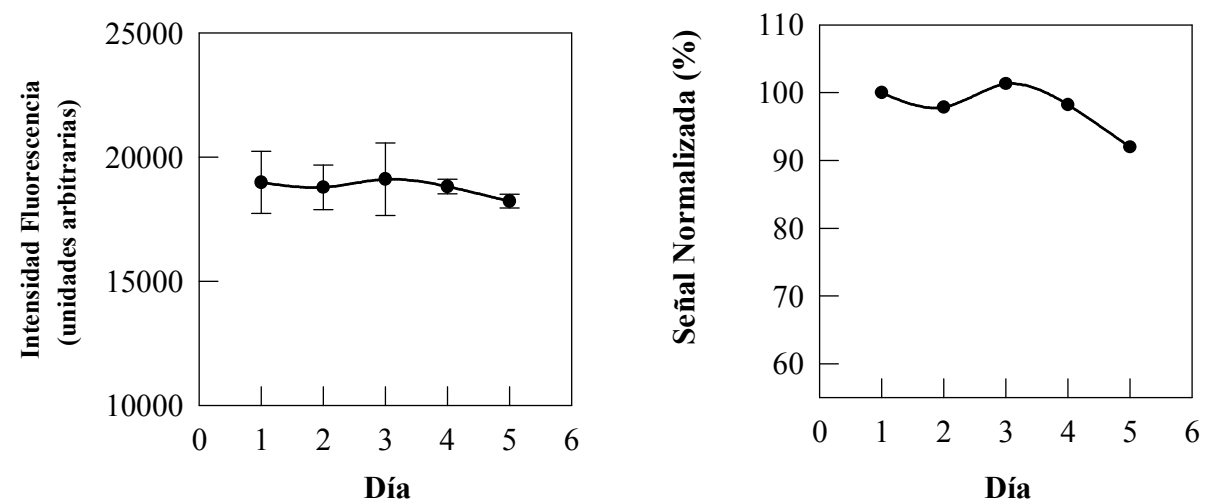

a)
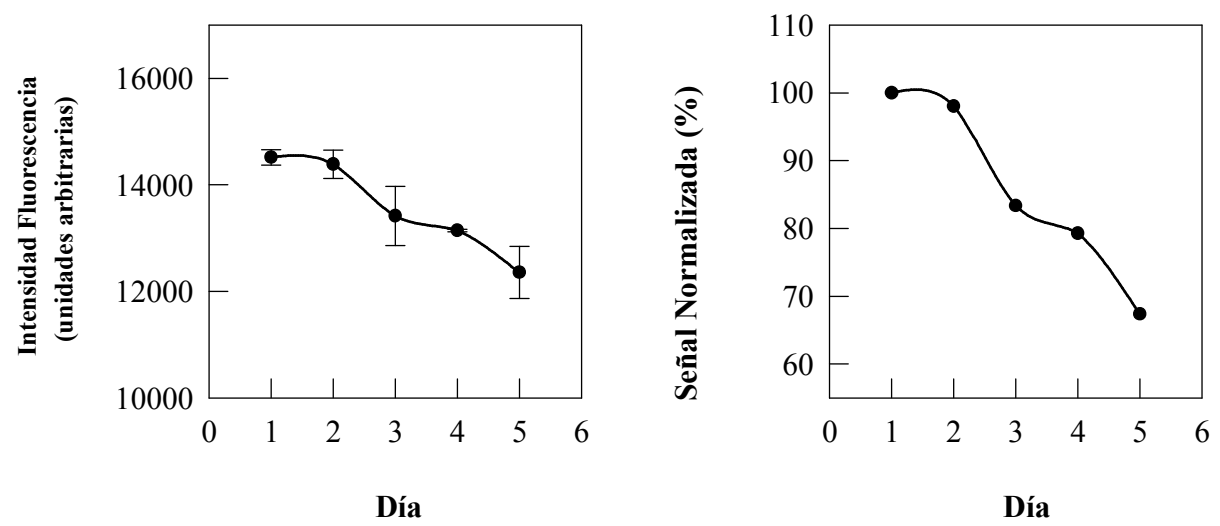

b)

Figura 3.16. Evolución de la señal obtenida con el conjugado $\mathrm{Ab}_{2}$-Tb en presencia de proteínas inertes; a) BSA (1\%); b) OVA (0,5\%)

Como se aprecia en la Figura 3.15a, la adición de BSA resultó una buena estrategia, ya que la señal se mantuvo estable durante 5 días consecutivos. Sin embargo, la adición de OVA (Figura 3.15b) como estabilizante del conjugado $\mathrm{Ab}_{2}$-complejo de $\mathrm{Tb}$ no fue efectiva, observándose ya el quinto día una caída en la señal, más pronunciada que cuando no se añade dicha proteína (Figura 3.15). Así pues, y aunque el resultado en la estabilización no es totalmente satisfactorio, si indica un camino a seguir.

\subsubsection{Inmunosensores basados en detección luminiscente}

En el desarrollo de estos sistemas se empleó como marcador la enzima fosfatasa alcalina (AP), que en presencia de compuestos de la familia de los 1,2 dioxetanos, produce señales luminiscentes (202). 
El analito escogido fue el carbaril, para el cual se disponía de anticuerpos monoclonales y policlonales. Los haptenos $\mathrm{H} 4$ y $\mathrm{CNH}$ utilizados en este estudio fueron acoplados a AP mediante una modificación del método del éster activo (46). En todos los casos se utilizó el formato de captura de inmunocomplejo -dado que éste resultó ser el ensayo más sensible, como se ha demostrado anteriormente-, el tampón trizma base 0,05M, $\mathrm{NaCl}$ 0,138M y KCl 0,027M, pH 8 (tampón TBS) como medio de trabajo y el substrato enzimático luminiscente CDP Star (ver sección experimental) disuelto en tampón dietanolamina $0,1 \mathrm{M}, \mathrm{MgCl}_{2} 1 \mathrm{mM}$, ajustado a $\mathrm{pH} 9$ con $\mathrm{HCl}$ concentrado (tampón de substrato, TS).

En primer lugar se procedió a optimizar el tiempo de incubación del substrato enzimático, para lo cual se partió de las condiciones recomendadas por el fabricante (217), utilizando el anticuerpo policlonal R2114 a una dilución 1/20.000, correspondiente a la concentración empleada en el marcaje con HRP. Dicho factor es crítico, ya que se persigue obtener la máxima señal posible evitando la desactivación del producto enzimático con propiedades luminiscentes.

En la Figura 3.17 se muestra la evolución de la señal obtenida en función del tiempo de incubación del substrato enzimático. El estudio se realizó en medio acuoso (TBS) empleando como trazador enzimático el conjugado H4-AP.

En dicha figura, el primer punto corresponde a ausencia de incubación y el tiempo transcurrido es el tiempo muerto empleado en el lavado del sistema. Por otro lado, la máxima señal se obtiene a los 4 minutos de incubación, lo que indica el elevado tiempo de decaimiento del producto luminiscente (217).

Optimizado el tiempo de incubación del substrato enzimático y mediante ensayos de actividad, se seleccionaron las concentraciones de trazador enzimático y anticuerpo que produjeron la mejor relación señal/ruido con la mínima concentración posible de inmunorreactivos. 


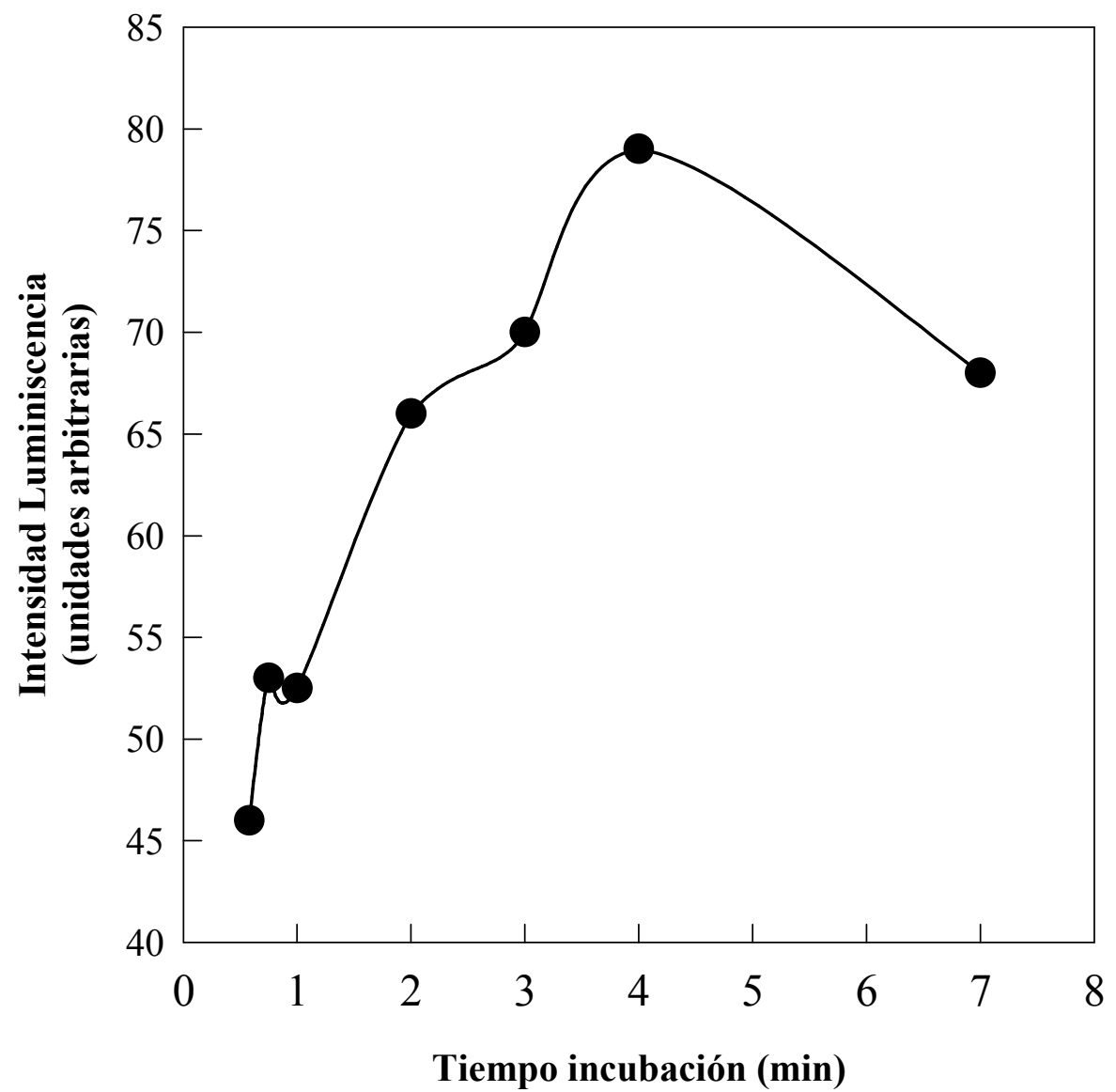

Figura 3.17. Evolución temporal de la señal obtenida con el substrato CDP Star

Trabajando en medio acuoso (TBS), se encontraron como óptimas las siguientes condiciones: $[\mathrm{R} 2114]=1 / 160.000 ;[\mathrm{H} 4-\mathrm{HRP}]=1,2.10^{-3} \mathrm{ppm} ;[$ CDP Star $]=0,1 \mathrm{mM}$.

En los ensayos de competición realizados con estas concentraciones, se obtuvo un valor de $\mathrm{I}_{50}$ de 58,2 $\pm 10,3 \mathrm{ng} / \mathrm{l}$. Este valor fue ostensiblemente menor a los obtenidos con el marcador enzimático HRP, debido a la alta sensibilidad de la reacción enzimática utilizada, lo que permitió reducir el consumo de inmunorreactivos de forma considerable.

Por otro lado, la introducción del Tween 20 en el tampón acuoso de trabajo (TBS con $0,05 \%$ Tw 20) disminuyó la sensibilidad, obteniéndose un valor de $\mathrm{I}_{50}=5,09$ $\pm 1,15 \mu \mathrm{g} / \mathrm{l}$. Este efecto indica que el tensoactivo dificulta el proceso de unión Ag-Ab, 
hecho constatado por la necesidad de emplear el trazador enzimático aproximadamente tres veces más concentrado.

Respecto al estudio en medios orgánicos, los ensayos de actividad mostraron que las señales obtenidas eran apreciablemente superiores, con lo que las concentraciones de inmunorreactivos tuvieron que ser disminuidas. Manteniendo la concentración del anticuerpo R2114, el trazador enzimático pudo utilizarse en el rango de $6.10^{-4}-1,2.10^{-3}$ $\mathrm{mg} / 1$ y el substrato enzimático entre $0,05-0,1 \mathrm{mM}$. En la Tabla 3.48 se muestran los valores de $\mathrm{I}_{50}$ obtenidos en todos los medios orgánicos ensayados, apreciándose que la sensibilidad es significativamente mayor a la obtenida con el sistema HRP (Tabla 3.23), aunque disminuye al aumentar la carga orgánica. Así por ejemplo, para el sistema enzimático en la mezcla con $50 \%$ de metanol se obtuvo un valor de $\mathrm{I}_{50}$ de 1,8 frente a $0,27 \mu \mathrm{g} / 1$ con detección luminiscente; en la mezcla con 10\% de acetato de etilo (LM19) se obtuvo un valor $\mathrm{I}_{50}$ de 13,6 frente a $1,41 \mu \mathrm{g} / 1$ alcanzado con detección luminiscente.

Por otro lado, fue posible utilizar medios con alta carga orgánica, incluso $100 \%$ $\mathrm{MeOH}$, lo que implica disolver directamente el analito en el disolvente orgánico. Respecto a sensibilidad, ésta disminuye al aumentar el porcentaje de metanol en el medio de ensayo. Se aprecia que el acetonitrilo fue el disolvente más incompatible con las interacciones inmunoquímicas estudiadas, con un alto poder desnaturalizante de proteínas. Así, se obtuvo una $\mathrm{I}_{50}$ de $30,2 \mu \mathrm{g} / \mathrm{l}$ en la mezcla con $50 \% \mathrm{MeCN}$, mientras que este valor fue de $0,27 \mu \mathrm{g} / 1$ en la mezcla con $50 \% \mathrm{MeOH}$.

En las mezclas orgánicas que utilizan acetato de etilo como disolvente inmiscible en agua, el efecto de la polaridad del medio en la sensibilidad se hizo más apreciable, de modo que al aumentar el porcentaje de disolvente orgánico aumentó el valor de $\mathrm{I}_{50}$ hasta las condiciones de no-competición (desde $1,4 \mu \mathrm{g} / 1$ hasta valores mayores a $100 \mu \mathrm{g} / \mathrm{l})$. Sin embargo, cabe destacar que la sensibilidad obtenida con mezclas orgánicas como metanol puro y acetato de etilo es superior (valores de $\mathrm{I}_{50}$ inferiores) a la alcanzada con el sistema HRP. Esta posibilidad abre la alternativa de emplear disolventes inmiscibles en agua en los métodos inmunoquímicos, con prestaciones analíticas aceptables. Finalmente, con la mezcla metanol-isopropanol se obtuvo una sensibilidad similar a la del medio más sensible -que además coincide con la mezcla orgánica seleccionada en todos los sistemas desarrollados hasta ahora-, lo que supone ampliar el campo analítico del inmunoensayo en medios orgánicos ( $\mathrm{I}_{50}$ 0,27 con $50 \% \mathrm{MeOH}$ y 0,28 con $25 \% \mathrm{MeOH} / 25 \%$ IS). 
Tabla 3.48. Valores de $I_{50}(\mu \mathrm{g} / \mathrm{l})$ obtenidos en formato de captura con detección luminiscente

\begin{tabular}{ll}
\hline Medio orgánico & $\mathbf{I}_{\mathbf{5 0}}(\boldsymbol{\mu} \mathbf{g} / \mathbf{l})$ \\
\hline $50 \%$ MeOH-50\% TBS & $0,27 \pm 0,05$ \\
$75 \%$ MeOH-25\% TBS & $0,56 \pm 0,10$ \\
$90 \% \mathrm{MeOH}-10 \%$ TBS & $0,70 \pm 77,81$ \\
$100 \% \mathrm{MeOH}$ & $7,45 \pm 1,13$ \\
$50 \% \mathrm{MeCN}-50 \%$ TBS & $30,15 \pm 5,32$ \\
$25 \% \mathrm{MeOH}-25 \%$ IS- $50 \%$ TBS & $0,28 \pm 0,08$ \\
$10 \%$ AE-25\% MeOH- 65\% TBS & $1,41 \pm 0,21$ \\
$20 \%$ AE-30\% MeOH- 50\% TBS & $5,53 \pm 1,04$ \\
$30 \%$ AE- 40\% MeOH- 30\% TBS & $>100$ \\
$60 \%$ AE- $40 \%$ MeOH & n.c
\end{tabular}

MeOH: metanol; IS: isopropanol; MeCN: acetonitrilo; AE: acetato de etilo; n.c: no-competición. Valores expresados como media \pm desviación estándar $(\mathrm{n}=3)$

Todos estos ensayos pudieron llevarse a cabo dadas las excelentes prestaciones de la reacción enzimática utilizada, lo que permitió reducir las concentraciones de inmunorreactivos y detectar un menor número de uniones Ag-Ab, a pesar de emplear condiciones drásticas tanto con disolventes miscibles en agua (metanol) como con inmiscibles (acetato de etilo).

\subsubsection{Estudio de sustancias potenciadoras de la reacción de detección quimioluminiscente}

El substrato CDP puede aumentar sus prestaciones en presencia de disoluciones potenciadoras de señal (217), sobre todo en aplicaciones en placa. Según recomendaciones del fabricante, estas sustancias deben ser empleadas a una dilución 1/10 respecto a la concentración de substrato enzimático. Las características de estas sustancias han sido descritas en la sección experimental.

El primer estudio consistió en establecer cual de los potenciadores disponibles (Emerald, Sapphire, Emerald II y Sapphire II) era más efectivo. Para tal fin se empleó una placa ELISA especial para lecturas luminiscentes, en la que se añadió una cantidad fija de trazador enzimático (H4-AP) en cada pocillo y las disoluciones de substrato enzimático y potenciador. En todos los casos, se evaluaron las señales de fondo obtenidas, ya que estas especies presentan por sí mismas altos valores de señal. En las 
Figuras 3.18 y 3.19 se muestran los valores de señal obtenidos en presencia de la enzima AP para los cuatro productos ensayados y de sus respectivos blancos.

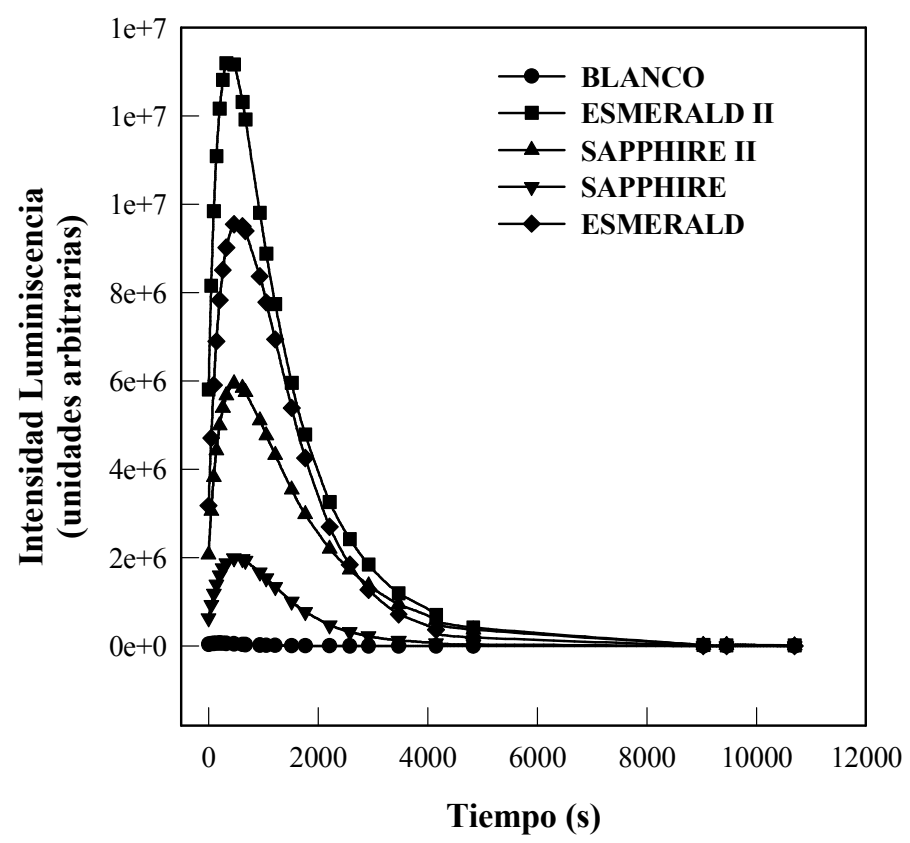

Figura 3.18. Valores obtenidos con el substrato CDP-Star en presencia de potenciadores 


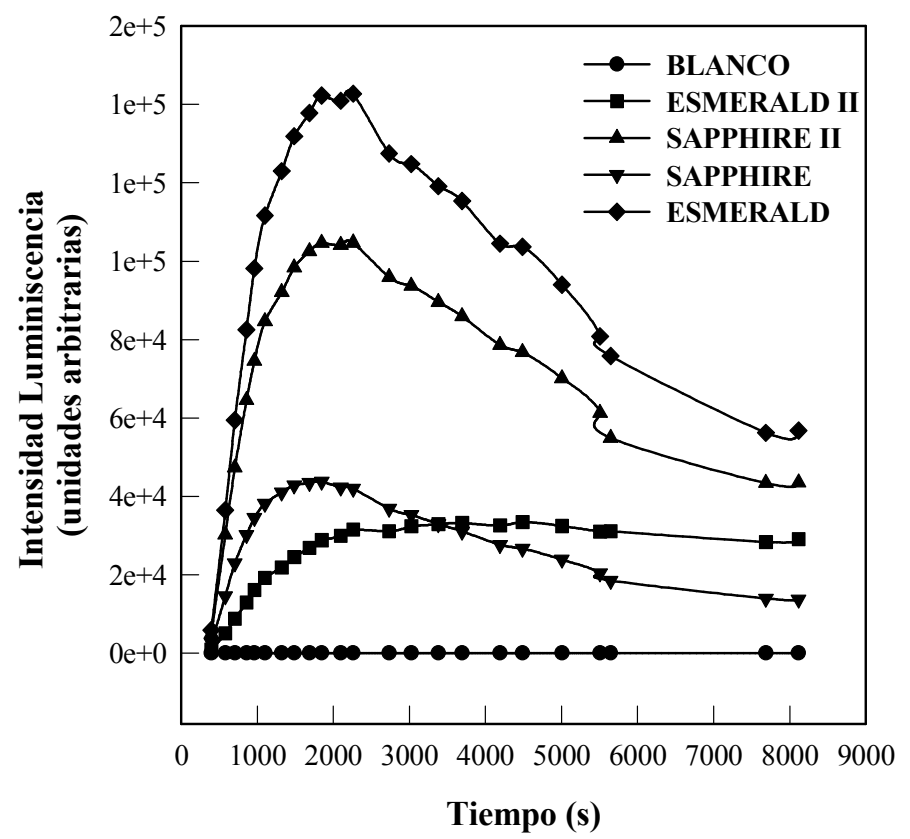

Figura 3.19. Señales de blanco debidas a los potenciadores

En ellas se aprecia que la sustancia Emerald II fue la más efectiva, con un incremento neto de señal de aproximadamente cuatro veces, por lo que fue la especie escogida para los ensayos en flujo.

Utilizando la especie Emerald II y el medio de ensayo 50\% metanol- 50\% TBS, se procedió a estudiar el efecto del potenciador en la sensibilidad. Debido a las elevadas señales de fondo obtenidas se hizo necesario diluir tanto el substrato enzimático como el potenciador. En la Tabla 3.49 se muestra la intensidad de luminiscencia obtenida al introducir en el sistema una mezcla substrato/potenciador en ausencia de trazador enzimático (señales blanco).

Tabla 3.49. Intensidad de luminiscencia para distintas concentraciones del potenciador Emerald II 


\begin{tabular}{cc}
\hline [Emerald II] & Intensidad (unidades arbitrarias) \\
\hline $1 / 40$ & 1472 \\
$1 / 80$ & 1391 \\
$1 / 160$ & 633 \\
$1 / 320$ & 213 \\
$1 / 640$ & 176 \\
\hline
\end{tabular}

Se observa que las señales de fondo de este potenciador son apreciables, por lo que se escogió una dilución de 1/640 de modo que fueran mínimas, utilizando una concentración 0,025 $\mathrm{mM}$ de substrato CDP. Con estas condiciones, los ensayos de competición realizados en el medio orgánico utilizado dieron una $\mathrm{I}_{50}$ de $0,22 \pm 0,09$, lo que puso de manifiesto que la adición de potenciadores no producía una mejora clara en la sensibilidad $(0,27 \pm 0,05)$. Este comportamiento fue debido a que no fue posible disminuir la concentración de inmunorreactivos. Así pues, se descartó el uso de estas sustancias, dado que introducían una complicación en el sistema y aumentaban el tiempo de ensayo, sin mejorar considerablemente la sensibilidad.

Finalmente, se emplearon las mejores condiciones (que no incluyeron potenciador) para desarrollar inmunosensores basados en anticuerpos monoclonales. Para tal fin, se escogieron aquellas condiciones que produjeron los ensayos más sensibles al utilizar la enzima HRP como sistema de marcaje (anticuerpo monoclonal CNH-45 en formato de captura de inmunocomplejo y trazador enzimático CNH-AP). La Tabla 3.50 muestra los valores de $\mathrm{I}_{50}$ obtenidos en diferentes medios.

Tabla 3.50. Valores de $I_{50}(\mu \mathrm{g} / \mathrm{l})$ obtenidos con el anticuerpo monoclonal CNH-45. Detección luminiscente

\begin{tabular}{ll}
\hline Medio ensayo & $\mathbf{I}_{\mathbf{5 0}}(\boldsymbol{\mu g} / \mathbf{l})$ \\
\hline TBS & $0,85 \pm 0,11$ \\
$50 \% \mathrm{MeOH}-50 \% \mathrm{TBS}$ & $3,98 \pm 1,25$ \\
$100 \% \mathrm{MeOH}$ & $19,95 \pm 5,22$ \\
$20 \% \mathrm{AE}-30 \% \mathrm{MeOH}-50 \% \mathrm{TBS}$ & $42,10 \pm 6,58$
\end{tabular}

MeOH: metanol; AE: acetato de etilo. Valores expresados como media \pm desviación estándar

A la vista de los resultados obtenidos se demuestra la posibilidad de ampliar el uso de esta reacción de detección a otros sistemas estudiados. Por otro lado, el comportamiento mostrado es similar al obtenido con el anticuerpo policlonal, así como 
las conclusiones obtenidas en dicho estudio. Además, este sistema de detección vuelve a confirmar las diferencias de sensibilidad obtenidas entre ambos tipos de anticuerpos; así por ejemplo, el valor de $\mathrm{I}_{50}$ obtenido para carbaril en el medio $50 \% \mathrm{MeOH}-50 \% \mathrm{TBS}$ fue de $3,98 \mu \mathrm{g} / 1$ frente a $0,27 \mu \mathrm{g} / 1$ obtenido con el anticuerpo policlonal.

\subsubsection{Estudio de la estabilidad del substrato enzimático}

Dada la importancia que tiene la estabilidad de los reactivos implicados en el desarrollo de los inmunosensores, se hace necesario estudiar el comportamiento de dichas especies a lo largo del tiempo y en condiciones ambientales. De hecho, la estabilidad del substrato enzimático utilizado en la reacción de detección es fundamental para la adecuada estabilidad de la señal.

En el estudio realizado, diferentes disoluciones de substrato enzimático $(0,1$ $\mathrm{mM}$ ) fueron acondicionadas con cantidades crecientes de $\mathrm{NaN}_{3}$ en el rango de $0-0,5 \%$ v/v y conservadas a temperatura ambiente. Empleando como trazador enzimático la especie H4-AP se realizaron ensayos en placa ELISA a lo largo del tiempo. Los resultados obtenidos (Figura 3.20) muestran la evolución temporal de las señales para las distintas disoluciones de substrato enzimático estudiadas.

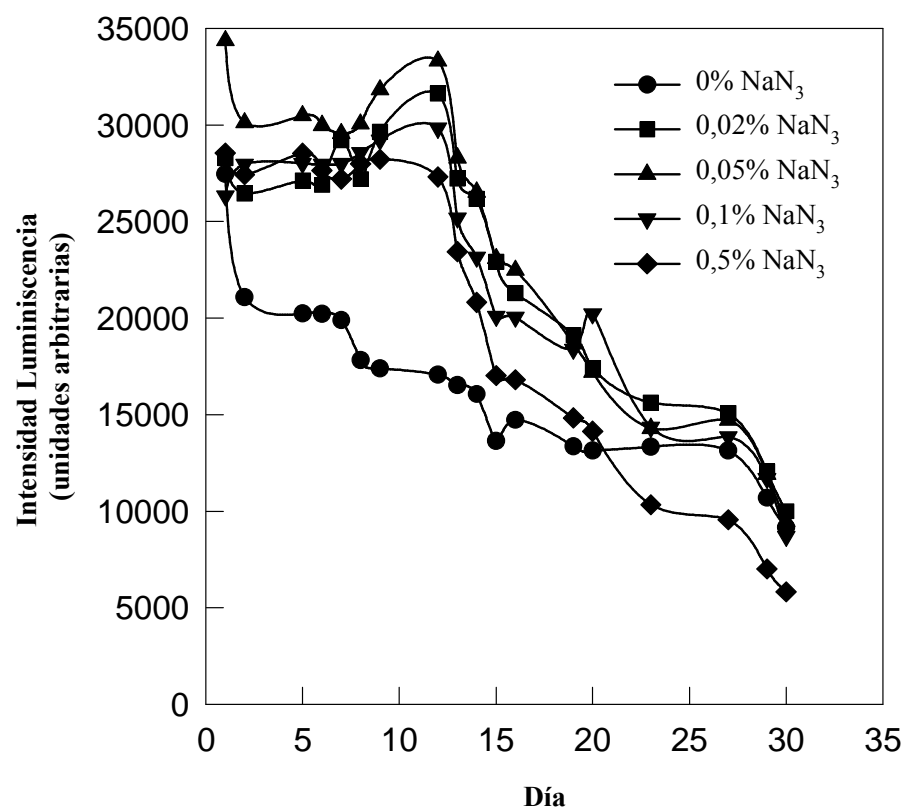

Figura 3.20. Estabilidad del substrato enzimático con el tiempo. Influencia de la adición de estabilizante 
Como se aprecia en dicha figura, porcentajes de $\mathrm{NaN}_{3}$ superiores a $0,05 \%$ mantienen la actividad del substrato enzimático al menos durante 13 días consecutivos. La ausencia de azida sódica provoca una pérdida en la señal, lo que indica una ligera degradación del substrato en condiciones ambientales. Por otro lado, la intensidad de luminiscencia a tiempo cero es igual o ligeramente superior al utilizar disoluciones sin y con azida, independientemente del porcentaje adicionado.

3.18.2.3. Efecto de los medios orgánicos sobre la actividad de la fosfatasa alcalina $(A P)$

A la hora de discernir sobre la buena sensibilidad obtenida con el sistema AP, incluso en medios con altos porcentajes de disolventes orgánicos, es preciso estudiar si los resultados son debidos a la mayor resistencia de la enzima, a la naturaleza del substrato enzimático o a ambos. Para ello se investigó como afectaba el medio orgánico a la actividad de la enzima marcadora. Así pues, a cada pocillo de una placa ELISA se añadieron $70 \mu \mathrm{l}$ de medio orgánico y $40 \mu \mathrm{l}$ de trazador enzimático (H4-AP) a 0,2 mg/l, y se incubaron entre 5-10 minutos antes de leer la señal. Estas condiciones son similares a las utilizadas en los sistemas sensores. En la Figura 3.21 se representan los porcentajes de señal obtenidos con cada uno de los medios estudiados, tomando como referencia los valores estimados en medio acuoso (TBS).

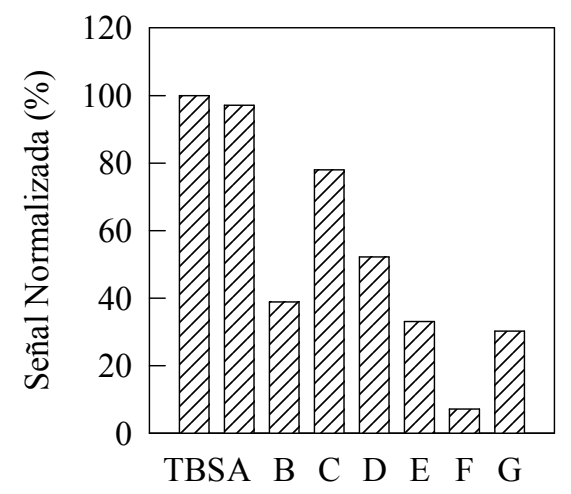

TBS: tampón acuoso, $\mathrm{pH}=8$

A: $50 \%$ Metanol- $50 \%$ TBS

B: $100 \%$ Metanol

C: $10 \%$ Acetato de etilo- $25 \%$ Metanol- $65 \%$ TBS

D: $20 \%$ Acetato de etilo- $30 \%$ Metanol- $50 \%$ TBS

E: $30 \%$ Acetato de etilo- $40 \%$ Metanol- 30\% TBS

F: $60 \%$ Acetato de etilo- $40 \%$ Metanol

G: $50 \%$ Acetonitrilo- $50 \%$ TBS

Figura 3.21. Efecto del medio orgánico ensayado en la actividad de la fosfatasa alcalina 
Como se aprecia en dicha figura, la mezcla 50\% metanol-50\% TBS (A) es el medio menos pernicioso para la enzima AP. Al aumentar el porcentaje de metanol en el medio de ensayo la señal obtenida es menor (B), debido a la importante desnaturalización de la proteína. En las mezclas con acetato de etilo, las señales disminuyen también a medida que aumenta el porcentaje de este disolvente en el medio de ensayo, alcanzándose un mínimo del $8 \%$ en el medio más perjudicial para la enzima (F, 60\% Acetato de etilo-40\% metanol). La mezcla con acetonitrilo al 50\% (G) -por su marcado carácter desnaturalizante de proteínas- tampoco dio resultados satisfactorios, obteniéndose valores de señal equivalentes a los de la mezcla con un $70 \%$ de carga orgánica (E) que incluye un 30\% de acetato de etilo.

A la vista de estos resultados se concluye que el substrato CDP permite detectar una baja actividad de la enzima, lo que repercute muy favorablemente en la sensibilidad. Además, es posible utilizar altos porcentajes de disolventes orgánicos, incluso de disolventes inmiscibles en agua, muy superiores a los utilizados con el sistema HRP.

\subsubsection{Análisis de muestras reales}

Para este estudio se escogió el anticuerpo policlonal R2114, el trazador H4-AP y la mezcla $20 \%$ acetato de etilo- $30 \%$ metanol- $50 \%$ TBS como medio de ensayo, con el fin de obtener los extractos orgánicos en un medio distinto al utilizado hasta ahora (metanol) y ampliar así la metodología de tratamiento de muestra. Las muestras de agua fueron tomadas por la empresa Aguas de Barcelona (AGBAR) en distintos puntos del río Llobregat. Paralelamente, se analizó una muestra de agua mineral. En todos los casos se tomaron alicuotas de $165 \mathrm{ml}$ de agua que fueron reforzadas con $100 \mathrm{ng} / \mathrm{l} \mathrm{de}$ carbaril y sometidas a extracción en fase sólida (SPE) utilizando cartuchos $\mathrm{C}_{18}$. El extracto obtenido en acetato de etilo-metanol (40/60), fue diluido con tampón TBS. De igual forma fueron tratadas muestras sin reforzar, con el fin de comprobar la presencia de falsos positivos y estimar el efecto matriz. En la Tabla 3.51 se muestran los valores obtenidos en el análisis mediante el inmunosensor.

Tabla 3.51. Resultados del análisis de muestras de agua reforzadas con carbaril (100 ng/l)

\begin{tabular}{llcc}
\hline Muestra & $\begin{array}{l}\text { Nivel encontrado } \\
(\mathbf{n g} / \mathbf{l})\end{array}$ & $\begin{array}{l}\text { RSD } \\
(\mathbf{\%})\end{array}$ & $\begin{array}{c}\text { Recuperación } \\
(\mathbf{\%})\end{array}$ \\
\hline Agua mineral & $98,3 \pm 12,1$ & 12 & 98
\end{tabular}




$\begin{array}{llcl}\text { Anoia } & 94,4 \pm 11,0 & 12 & 94 \\ \text { Can Carné } & 83,6 \pm 11,3 & 14 & 84 \\ \text { Pont Molins } & 81,4 \pm 5,7 & 7 & 81 \\ \text { Pont Vilamare } & 95,7 \pm 5,2 & 5 & 96 \\ \text { Prese Cairat } & 81,3 \pm 3,3 & 4 & 81 \\ \text { Sallent } & 82,2 \pm 3,4 & 4 & 82 \\ \text { S. Joan Despí } & 92,4 \pm 10,0 & 11 & 92 \\ \text { Valores expresados como media } \pm \text { desviación estándar (n=3) } & & \end{array}$

Los resultados obtenidos indican que el inmunosensor basado en detección quimioluminiscente es aplicable a la determinación de carbaril en muestras de agua, a niveles inferiores al LMR (100 ng/l) establecido para aguas de consumo humano. Los datos de recuperación obtenidos estuvieron comprendidos entre 81 y $98 \%$, lo que demostró la excelente correlación entre los niveles de carbaril añadido y encontrado. Finalmente, los valores de RSD (4-14\%) mostraron una precisión aceptable de las medidas realizadas. Cabe destacar, que el uso de la mezcla con acetato de etilo como medio de extracción y ensayo no influyó significativamente en los resultados obtenidos, ya que en el análisis de estas muestras con el sistema enzimático (Tabla 3.29) se obtuvieron recuperaciones entre el 91 y 108\%, y valores de RSD comprendidos entre 4 y $7 \%$. 


\section{CONCLUSIONES}

De acuerdo a los objetivos marcados en el presente trabajo experimental se obtuvieron las siguientes conclusiones:

- Se ha demostrado la posibilidad real de aplicar métodos inmunoquímicos en distintos medios orgánicos relacionados con los procedimientos de extracción de plaguicidas. Este hecho ha conducido al desarrollo de inmunosensores capaces de trabajar con altas concentraciones de disolventes orgánicos, resultados inviables en los ensayos en placa convencionales.

- Estos sistemas han supuesto la posibilidad da analizar muestras extraídas según los métodos oficiales. En este sentido se han puesto a punto protocolos de inmunoensayo para el análisis de muestras de agua y muestras de vegetales.

- Por otro lado, se han puesto a punto métodos de extracción rápidos para el análisis de plaguicidas mediante los inmunosensores. Este hecho redunda en un ahorro en tiempo y consumo de disolventes necesarios para en la preparación de las muestras.

- Se han obtenido y aportado datos acerca del efecto de los medios orgánicos sobre la sensibilidad y selectividad de los ensayos inmunoquímicos. Así, se ha comprobado que los ensayos en medios orgánicos presentan una menor sensibilidad que en medio acuoso existiendo una relación directa entre la polaridad del medio orgánico de ensayo y sensibilidad obtenida. Por el contrario, los ensayos en medios orgánicos se muestran más selectivos al presentar valores de reactividad cruzada inferiores a los obtenidos en medios acuosos.

- Por otro lado, se ha evidenciado la enorme importancia de la técnica de detección empleada en las prestaciones de los inmunosensores. De este modo, técnicas de detección más sensibles (fluorescencia con resolución temporal y quimioluminiscencia) que la habitual (fluorescencia) permitieron mejorar la sensibilidad de los ensayos. Esto fue posible ya que estas técnicas permitieron determinar un menor número de interacciones inmunoquímicas con la mejora ostensible en sensibilidad respecto al marcaje enzimático convencional y detección fluorimétrica. Por otro lado, este hecho permitió utilizar mayores porcentajes de disolventes orgánicos en estos sistemas.

- Respecto a cuestiones prácticas se obtuvieron las siguientes conclusiones: 
- Los soportes rígidos basados en sílice como el CPG presentaron mejores prestaciones analíticas en los sistemas basados en anticuerpo inmovilizado que los soportes tipo gel.

- Los sistemas basados en el formato indirecto (conjugado inmovilizado) presentaron las peores prestaciones en todos los sistemas estudiados.

- El formato de captura de inmunocomplejo resultó ser el más eficaz a la hora de desarrollar este tipo de sistemas. Este protocolo de ensayo permitió obviar la regeneración de los inmunosoportes, aspecto crítico en el desarrollo de los inmunosensores en flujo.

- Respecto a los inmunorreactivos utilizados, los anticuerpos policlonales mostraron una mayor sensibilidad que los correspondientes anticuerpos monoclonales sin presentar unos valores de reactividad cruzada que requirieran en ningún caso inclinarse por el segundo tipo de anticuerpos. Este último punto no es definitivo y debería ser estudiado con otros anticuerpos tanto monoclonales como policlonales. 


\section{CONOLUSIONHS}

Las conclusiones obtenidas en el presente trabajo experimental, son las siguientes:

- Se ha demostrado la posibilidad real de desarrollar métodos inmunoquímicos en distintos medios orgánicos utilizados en los procedimientos de extracción de plaguicidas. Este hecho ha conducido al desarrollo de inmunosensores capaces de trabajar con altas concentraciones de disolventes orgánicos, resultados inviables en otros formatos de ensayo.

- Los resultados obtenidos indican, por un lado, que se pueden utilizar concentraciones de incluso el 100\% de algunos disolventes, especialmente metanol. En este disolvente, que sustituye en muchos casos al agua, los anticuerpos mostraron un comportamiento francamente bueno.

Por otro lado, se han podido utilizar disolventes apolares o inmiscibles en agua, como acetato de etilo, en concentraciones relativamente elevadas (20\%). Ello ha permitido el análisis directo de extractos obtenidos en dicho disolvente. Además, se ha observado que disolventes como la acetona o el tetrahidrofurano desnaturalizan los inmunorreactivos proteicos, no pudiendo utilizarse en ningún caso.

El isopropanol se ha mostrado muy útil como disolvente de transferencia para la preparación de mezclas ternarias formadas por disolventes no miscibles en agua. Además, es de resaltar que ninguna de las mezclas de disolventes finalmente ensayadas atacó los componentes base del sistema analítico utilizado. 
- La metodología desarrollada permite analizar muestras extraídas según los métodos oficiales. En este sentido, se han puesto a punto protocolos de inmunoensayo para el análisis de muestras de agua y vegetales.

- Por otro lado, se han estudiado métodos de extracción rápidos alternativos a los multirresiduo para la determinación de plaguicidas mediante inmunosensores. Estos métodos permiten reducir tanto el consumo de disolventes necesarios para la preparación de las muestras como el tiempo de análisis.

- Se han aportado datos acerca del efecto de los medios orgánicos sobre la sensibilidad y selectividad de los ensayos inmunoquímicos. Así, se ha comprobado que los ensayos en medios orgánicos presentan menor sensibilidad que en medio acuoso, existiendo una relación directa entre la polaridad del medio orgánico de ensayo y sensibilidad obtenida. Por el contrario, los ensayos en medios orgánicos se muestran más selectivos, presentando valores de reactividad cruzada inferiores a los obtenidos en medio acuoso.

- Se ha evidenciado la enorme importancia que tiene el marcaje y el modo de detección en las prestaciones de los inmunosensores. Así, técnicas de detección más sensibles (fluorescencia con resolución temporal y quimioluminiscencia) que la habitual (fluorescencia), permitieron mejorar la sensibilidad de los ensayos al determinar un menor número de interacciones inmunoquímicas. Por otro lado, este hecho permitió utilizar mayores porcentajes de disolvente orgánico en estos sistemas.

- Los datos obtenidos mediante inmunofiltración fueron clave en la selección previa de las variables necesarias para la puesta a punto -de modo sistemático- de los inmunosensores en flujo. 
Respecto a cuestiones prácticas se obtuvieron las siguientes conclusiones:

- Los soportes siliceos rígidos como el CPG presentaron mejores prestaciones analíticas que los soportes tipo gel en los sistemas basados en anticuerpos inmovilizados.

- Los sistemas basados en formato indirecto (conjugado inmovilizado) presentaron las peores prestaciones en todos los sistemas estudiados.

- El formato de captura de inmunocomplejo resultó ser el más efectivo a la hora de desarrollar este tipo de sistemas. Este protocolo de ensayo obvia la regeneración del inmunosoporte, aspecto crítico en el desarrollo de inmunosensores en flujo.

- Los resultados preliminares obtenidos para carbaril indican que los anticuerpos policlonales muestran mayor sensibilidad que los monoclonales, mientras que la reactividad cruzada es similar en ambos casos. Esta conclusión no es definitiva, por lo que deberán estudiarse otros sistemas, utilizando anticuerpos monoclonales y policlonales.

- Finalmente, los sensores puestos a punto son potencialmente aplicables a la determinación directa de analitos en matrices no acuosas como por ejemplo, aceites y grasas comestibles o gasolinas. 


\section{Bibliosmafía}

1. Primo, E.; Carrasco, J.M. (1990) Plaguicidas y fitorreguladores. En “Química Agrícola 2". Editorial Alhambra Universidad, Madrid, pp1-26.

2. Consejería de Sanidad y Consumo. Generalitat Valenciana (1993) Plaguicidas Agrícolas: Vigilancia Sanitaria. Monografías Sanitarias Serie E, nº 13.

3. Tomlin, C. (Ed.) (1994) The Pesticide Manual. The British Crop Protection Council: The Bath Press, Bath, UK., $10^{\text {th }}$ Edition.

4. Ekström, G.; Akerblom, M. (1990) Pesticide management in food and water safety: international contributions and national approaches. Rev. Environ. Contamin. Toxicol., 114, 23-55.

5. Worldwatch Institute (1994) La situación del Mundo en 1994. Emecé, Centro de Investigaciones para la Paz, Madrid.

6. OMS (1990) Public Health Impact of Pesticides used in Agriculture. Organización Mundial de la Salud, Ginebra, Suiza.

7. Agg Ba, A.R.; Zabel, T.F. (1990) Red list substances. Selection and monitoring. J. Inst. Water Environ. Manag., 4 (1), 44-50.

8. Clower, M. (1991) Pesticide residues in food-United States Food and Drug Administration's program for immunoassay. En "Immunoassays for Trace Chemical Analysis”. M. Vanderlaan; L.H. Stanker; B.E. Watkins; D.W. Roberts (Eds.). ACS Symposium Series 451. American Chemical Society, Washington, DC, pp 49-58.

9. Zehnder, G. (1994). Integrated pest management in vegetales. Food Rev. Int., 10, 119-134.

10. Directiva 76/895/CEE del Consejo, de 3 de Marzo de 1976. Diario Oficial de las Comunidades Europeas, Bruselas, Bélgica.

11. Directiva 90/642/CEE del Consejo, de 27 de Noviembre de 1990. Diario Oficial de las Comunidades Europeas, Bruselas, Bélgica. 
12. Directiva 93/58/CEE del Consejo, de 29 de Junio de 1993. Diario Oficial de las Comunidades Europeas, Bruselas, Bélgica.

13. Directiva 94/30/CEE del Consejo, de 23 de Junio de 1994. Diario Oficial de las Comunidades Europeas, Bruselas, Bélgica.

14. Brotons, M. (1995) La nueva legislación española sobre LMRs de plaguicidas en productos vegetales. En "Tercer Seminario Internacional sobre Residuos de Plaguicidas". A. Valverde; A.R. Fernández-Alba (Eds.). Instituto de Estudios Alimentarios, Universidad de Almería, Coexpal, Almería, pp 13-34.

15. Neidert, E.; Saschenbrecker, P.W. (1996) Ocurrence of pesticide residues in selected agricultural food commodities available in Canada. J. AOAC Int., 79 (2), 549566.

16. Roy, R.R.; Wilson, P.; Laski, R.R.; Roberts, J.I.; Weishaar, J.A.; Bong, R.L.; Yees, N.J. (1997) Monitoring of domestic and imported apples and rice by the US Food and Drugs Administration pesticide program. J. AOAC. Int., 80 (4), 883 894.

17. Ministerio de Agricultura, Pesca y Alimentación (1996) Informe Anual del Programa Nacional de Vigilancia de Residuos de Productos Fitosanitarios en Origen. Subdirección General de Sanidad Vegetal, Madrid.

18. Christiansen, A.L.; Holen, B.; Otlo, A.; Varran, G.T. (1998) Norwegian Monitoring of Pesticide Residues in Fruit and Vegetables. $2^{\text {nd }}$ European Pesticide Residues Workshop, Almería, España, 24-27 Mayo.

19. Poulsen, M.E.; Granby, K.; Büchert, A.; Lund, M.E.; Andersen, J.H. (1998) The Danish monitoring of Pesticide Residues in Fruit and Vegetables '97. $2^{\text {nd }}$ European Pesticide Residues Workshop, Almería, España, 24-27 Mayo.

20. Consejo de las Comunidades Europeas (1980) Directiva del Consejo de 15 de Julio Relativa a la Calidad de las Aguas Destinadas al Consumo Humano (80/778/CEE). Diario Oficial CE, 11-29.

21. Sawyer, L.D.; McMahon, B.M.; Newsome, W.M.; Parker, G.A. (1990) Pesticide and Industrial Chemical Residues. AOAC, $15^{\text {th }}$ Edition.

22. EPA Methods (1988) Methods for the determination of organic compounds in drinking waters. EPA-600/4-88/039.

23. Thurman, E.M.; Snavely, K. (2000) Advances in solid-phase extraction disks for environmental chemistry. Trends Anal. Chem., 19 (1), 18-26. 
24. Steward, M.; Male, D. (1989) Immunological techniques. En "Immunology". I. Roitt; J. Brostoff; D. Male (Eds.). Churchil Livingstone, Middlesex House, Londres.

25. Hammock, B.D.; Mumma, R.O. (1980) Potencial of immunochemical technology for pesticide analysis. En "Recent Advances in Pesticide Analytical Technology". J.R.J. Harvey; G. Zweig (Eds.). ACS Symposium Series 136, American Chemical Society, Washington, DC, $321 \mathrm{pp}$.

26. Niessner, R. (1993) Immunoassays in environmental analytical chemistry: some thoughts on trend and status. Anal. Methods Instrum., 1 (3), 1334-1344.

27. Rittenburg, J.H. (Ed.) (1990) Development and Application of Immunoassay for Food Analysis. Elsevier Science Publishing Ltd, Essex, UK.

28. Van Emon, J.; Mumma, R.O. (Eds.) (1990) Immunochemical Methods for Environmental Analysis. ACS Symposium Series 442, American Chemical Society, Washington, DC.

29. Marco, M.P.; Gee, S.G.; Hammock, B.D. (1995) Immunochemical techniques for environmental analysis II. Antibody production and immunoassay development. Trends Anal. Chem., 14 (8), 415-425.

30. Köhler, G.; Milstein, C. (1975) Continuous cultures of fused cells secreting antibody of predefined specificity. Nature, 256, 495-497.

31. Van Emon, J.M.; Gerlach, C.L. (1995) A status report on field-portable immunoassay. Environ. Sci. Technol., 29, 312A-317A.

32. Silva Nunes, G.; Toscano, I. A.; Barceló, D. (1998) Analysis of pesticides in food and environmental samples by enzyme-linked immunosorbent assays. Trends Anal. Chem., 17 (2), 79-87.

33. Colbert, D.L.; Coxon, R.E. (1988) Paraquat mesured in serum with the Abbott TDx. Clin. Chem., 34 (9), 1948-1949.

34. Eremin, S.E. (1995) Polarization fluoroimmunoassay for rapid, specific detection of pesticides. En "Immunoanalysis of Agrochemical. Emerging Technologies". J.O. Nelson; A.E. Karn; R.B. Wong (Eds.). ACS Symposium Series 586, American Chemical Society, Washington, DC, pp 223-234.

35. Ballesteros, B.; Marco, M.P. (1998) Basic principles of the use of immunoaffinity chromatography for environmental analysis. Food Technol. Biotechnol., 36 (2), 145-155. 
36. Rule, G.S.; Mordehai, A.V.; Henion, J. (1994) Determination of carbofuran by online immunoaffinity chromatography with coupled-column liquid chromatography-mass spectrometry. Anal Chem., 6 (2), 230-235.

37. Rodbard, D.; Frazier, G.R. (1975) Statistical analysis of radioligand assay data. Methods Enzymol., 37, 2-22.

38. Raab. G.M. (1983) Comparison of a logistic and mass-action curve for radioimmunoassay data. Clin. Chem., 29, 1757-1761.

39. Hock, B. (1997) Antibodies for immunosensors. A review. Anal. Chim. Acta, 347 (1-2), 177-186.

40. Van Emon, J.M.; López-Avila, V. (1992) Immunochemical methods for environmental analysis. Anal. Chem., 64, 79-88.

41. Marx, A.; Giersh, T.; Hock, B. (1995) Immunoaffinity chromatography of striazines. Anal. Lett., 28, 267-272.

42. Pichon, V.; Chen, L.; Hennion, M.C. (1995) On line preconcentration and liquidchromatographic analysis of phenylurea pesticides in environmental water using a silica-based immunosorbent. Anal. Chim. Acta, 311 (3), 429-436.

43. Wittman, C.; Hock, B. (1993) Analysis of atrazine residues in food by an enzyme immunoassay. J. Agric. Food Chem., 41 (9), 1421-1425.

44. González-Martínez, M.A.; Morais, S.; Puchades, R.; Maquieira, A.; Abad, A.; Montoya, A. (1997) Monoclonal antibody-based flow-through immunosensor for analysis of carbaryl. Anal. Chem., 69, 2812-2818.

45. López-Avila, V. (1999) Sample preparation for environmental analysis. Crit. Rev. Anal. Chem., 29 (3), 195-230.

46. Marco, M.P.; Gee, S.G.; Cheng, H.M.; Liang, Z.Y.; Hammock, B.D. (1993) Development of an enzyme-linked immunosorbent assay for carbaryl. J. Agric. Food Chem., 41, 423-430.

47. Jourdan, S.W.; Scutellaro, A.M.; Hayes. M.C.; Herzog, D.P. (1996) Adapting immunoassays to analysis of food samples. En "Immunoassay of Insecticides, Fungicides and Pesticides”. R.C. Beieu; R.H. Stanker (Eds.). ACS Symposium Series 621, American Chemical Society, Washington, DC, pp 17-28.

48. Stanker, L.H.; Bigbee, C.; Van Emon, J.; Watkins, B.; Jensen, R.H.; Morris, C.; Vanderland, M. (1989) An immunoassay for pyrethroids: detection of permethrin in meat. J. Agric. Food Chem., 37 (3), 834-839. 
49. Wigfield, Y.Y.; Grant, R. (1992) Evaluation of an immunoassay kit for the detection of certain organochlorine (cyclodiene) pesticide residues in apple, tomato and lettuce. Bull. Environ. Contam. Toxicol., 49, 342-347.

50. Oubiña, A.; Puig, D.; Gascón, J.; Barceló, D. (1997) Determination of pentachlorophenol in certified waste-water, soil samples and industrial effluents using ELISA and liquid-solid extraction followed by liquid chromatography. Anal. Chim. Acta, 346 (1), 49-59.

51. Abad, A.; Moreno, M.J.; Montoya, A. (1997) A monoclonal immunoassay for carbofuran and its application to the analysis of fruit juices. Anal. Chim. Acta, 347 (1-2), 103-110.

52. Mercader, J.V.; Montoya, A. (1997) A monoclonal antibody-based ELISA for the analysis of azinphos-methyl in fruit juices. Anal. Chim. Acta, 347 (1-2), 95-101.

53. Skerritt, J.H.; Hill, A.S.; Beasley, H.L.; Edward, S.L.; McAdam, D.P. (1992) Enzyme-linked immunosorbent assay for quantitation of organophosphate pesticides: fenitrotion, chlorpyrifos-methyl, and pirimiphos-methyl in wheat grain and flour-milling fractions. J. AOAC Int., 75 (3), 519-528.

54. Hardy, C.L.; Hurburgh, C.R. (1994) Immunoassay detection of herbicide residues in corn. Cereal Chemistry, 71 (2), 107-111.

55. Brandon, D.L.; Binder, R.G.; Bates, A.M.; Montagne, W.C. (1992) Monoclonal antibody-based ELISA for thiabendazole in liver. J. Agric. Food Chem., 40, 1722-1731.

56. Busway, R.J.; Kugabalasooriar, J.; Perkins, L.B.; Harrison, R.O.; Young, B.E.S.; Fergusson, B.S. (1992) Determination of methyl 2-benzimidazolecarbamate in blueberries by competitive inhibition enzyme immunoassay. J. AOAC Int., 75, 323-327.

57. Van Emon, J.; Seiber, J.; Hammock, B. (1987) Application of an ELISA to determine paraquat residues in milk, beef and potatoes. Bull. Environ. Contam. Toxicol., 39 (3), 490-497.

58. Newsome, W.H.; Collins, P.G. (1990) Determination of ioprodione, vinclozolin and procymidone as the heptafluorobutyramides of 3,5 dichloroaniline. Int. J. Environ. Anal. Chem., 38 (4), 489-494.

59. Lawruk, T.S.; Gueco, A.M.; Jourdan, S.W.; Scutellaro, A.M.; Fleeker, J.R.; Herzog, D.P.; Rubio, F.M. (1995) Determination of chlorothalonil in water and 
agricultural products by a magnetic particle-based enzyme immunoassay. $J$. Agric. Food Chem., 43 (5), 1413-1419.

60. Fernandez-Alba, A.; Valverde, A.; Agüera, A.; Contreras, N.; Rodriguez, D. (1995) Determination of procymidone in vegetables by a commercial competitive inhibition enzyme immunoassay. Anal. Chim. Acta, 311 (3), 371-376.

61. Williams, K.J.; Thorpe, S.A.; Reynolds, S.L. (1996) The use of ELISA for the determination of pesticide residues in food. Int. J. Environ. Anal. Chem., 65, 149-152.

62. Staearman, G.K.; Wells, M.J.M.; Adkinsson, S.M.; Ridgill, T.E. (1995) Supercritical-fluid extraction coupled with enzyme immunoassay analysis of soil herbicides. Analyst, 120 (10), 2617-2621.

63. Richman, S.J.; Karthikeyan, S.; Bennett, D.A.; Chung, A.C.; Lee; S.M. (1996) Lowlevel immunoassay screen for 2,4-dichlorophenoxiacetic acid in apples, grapes, potatoes and oranges. Circumventing matrix effects. J. Agric. Food Chem., 44 (9), 2924-2929.

64. Gascón, J.; Salau, J.S.; Oubiña, A.; Barceló, D. (1998) Monitoring of organonitrogen pesticide in the Ebro River. Preliminary loading estimates. Analyst, 123 (5), 941-945.

65. Velasco-Arjona; A.; Manclús, J.J.; Montoya. A.; Luque de Castro, M.D. (1997) Robotic sample pretreatment immunoassay determination of chlorpyrifos metabolite (TCP) in soil and fruit. Talanta, 45 (2), 371-377.

66. Matthews, W.A.; Haverly, M. (1995) Assesment of prototype ELISA test for the detection of pesticide residues on grain. Food Agric. Immunol., 7 (2), 153-162.

67. Lavin, L.; Young, B.S.; Splittler, T.B. (1996) Analysis of benomyl residues in commodities by enzyme immunoassay: extraction, conversion, and highperformance liquid chromatography validations. En "Immunoassay of Insecticides, Fungicides and Pesticides”. R.C. Beieu, R.H. Stanker (Eds.). ACS Symposium Series 621, American Chemical Society, Washington, DC, pp 150166.

68. Mei, J.V.; Yin, C.; Carpino, L.A.; Fergusson, B.S. (1991) Hapten synthesis and development of immunoassay for methoprene. J. Agric. Food Chem., 39, 20832090.

69. Heckman; R.A.; Ferguson, B.S.; Fan, T.S.; Mei, J.V.; Yin, C.; Conner, M.; Addington, V.W.; Benezet, H.J. (1992) Validation of an enzyme immunoassay 
for analysis of methoprene residues on tobacco. J. Agric. Food Chem., 40 (12), 2530-2532.

70. Anis, N.A.; Eldefrawi, M.E.; Wong, R.B. (1993) Reusable fiber optic immunosensor for rapid detection of imazethapyr herbicide. J. Agric. Food Chem., 41 (5), 843-848.

71. Assil, H.I.; Sporns, P. (1991) ELISA and HPLC methods for analysis of fumagillin and its decomposition products in honey. J. Agric. Food Chem., 39 (12), 22062213.

72. Hill, A.S.; Beasley, H.L.; McAdam, D.P.; Skerritt, J.H. (1992) Monoclonal and polyclonal antibodies to the organophosphate fenitrothion. 2. Antibody specificity and assay performance. J. Agric. Food Chem., 40 (8), 1471-1474.

73. Schlaeppi, J.; Moser, H.; Ramsteiner, K. (1991) Determination of metolachor by competitive enzyme immunoassay using a specific monoclonal antibody. $J$. Agric. Food Chem., 39 (8), 1533-1536.

74. Lucas, A.D.; Schneider, P.; Harrison, R.O.; Seiber, J.N.; Hammock, B.D.; Biggar, J.M.; Rolston, D.E. (1992) Determination of atrazine and simazine in water and soil using polyclonal and monoclonal antibodies in ELISAs. Food Agric. Immunol., 3 (3-4), 155-167.

75. Thurman, E.M.; Meyer, M.; Pomes, M.; Perry, C.A.; Schwab, A.P. (1990) ELISA compared with GC-mass spectrometry for the determination of triazine herbicides in water. Anal. Chem., 62 (18), 2043-2048.

76. Cairoli, S.; Arnoldi, A.; Pagani, S. (1996) Enzyme-linked immunosorbent assay for the quantitation of the fungicide tetraconazole in fruits and fruit juices. J. Agric. Food Chem., 44, 3849-3854.

77. Waters, L.C.; Smith, R.R.; Stewart, J.H.; Jenkins, R.A. (1994) Evaluation of 2 field screening test for the detection of PCBs in soil by immunoassay. J. AOAC Int., 77 (6), 1664-1671.

78. Aga, A.S.; Thurman, E.M. (1993) Coupling solid-phase extraction and enzymelinked immunosorbent assay for ultra-trace determination of herbicides in pristine water. Anal. Chem., 65 (20), 2894-2898.

79. Aga, D.S.; Thurman, E.M.; Pomes, M.L. (1994) Determination of alachlor and its sulfonic acid metabolite in water by solid phase extraction and ELISA. Anal. Chem., 66 (9), 1495-1499. 
80. Plhak, L.; Sporns, P. (1992) Enzyme immunoassay for potato glycoalkaloids. $J$. Agric. Food Chem., 40 (12), 2533-2540.

81. Fan, Z.; Bushway, R.J. (1997) Determination of diazinon in fruits and vetables by ELISA. Food Technol. Biotechnol., 35 (3), 205-208.

82. Gee, S.J.; Hammock, B.D.; Van Emon, J.M. (1994) A User's Guide to Environmental Immunochemical Analysis. EPA7540/R-94/509.

83. ISO/CD15089 (1997) Water Quality: Guideline for Selective Immunoassays for the Determination of Plant Treatment and Pesticide Agents. ISO/TC/47/ Sc.2, N ${ }^{o}$ $352,13 \mathrm{pp}$.

84. Gabaldón, J.A.; Maquieira, A.; Puchades, R. (1999) Current trend in immunoassaybased kits for pesticide analysis. Crit. Rev. Food Sci. Nutr., 39 (6), 519-538.

85. Stocklein, W.; Scheller, F.W.; Abuknesha, R. (1995) Effects of organic solvents on semicontinuous immunochemical detection of coumarin derivatives. Sensors and Actuators B, 24-25, 80-84.

86. Wang, J.; Lin, Y. (1993) On line organic-phase enzyme detector. Anal. Chim. Acta, 271 (1), 53-59.

87. Iwuoha, E.I.; Adeyoju, O.; Dempsey, E.; Smyth, M.R.; Liu, J.; Wang, J. (1995) Investigation of the effects of polar organic solvents on the activity of tyrosinase entrapped in a poly(estersulphonic acid) polymer. Biosens. Bioelectron., 10, 661-667.

88. Campanella, L.; Fortuney, A.; Sammartino, M.P.; Tomassetti, M. (1994) Tyrosinase biosensor response as a function of physical properties of organic solvents. Talanta, 41, 1397-1404.

89. Iwuoha, E.I.; Smyth, M.R.; Lyons, M.E.G. (1997) Organic phase enzyme electrodes: kinetics and analytical applications. Biosens. Bioelectron., 12 (1), 5375.

90. Lu, B.; Iwuoha, E.I.; Smyth, M.R.; O'Kennedy, R (1997) Effects of acetonitrile on horseradish peroxidase (HRP)-anti HRP antibody interaction. Biosens. Bioelectron., 12 (7), 619-625.

91. Braco, L. (1995) Biocatalysis and biorecognition in nonaqueous media. Some perspectives in analytical biochemistry. Mikrochim. Acta, 120, 231-242.

92. Klibanov, A.M. (1999) Activating enzymes in nonaqueous media. $C \& E N, \mathbf{3 0}, 52$.

93. Aston, J.P.; Hitchings, E.J.; Ball, R.L.; Weeks, I.; Woodhead, J.S. (1997) Water immiscible solvent based immunoassay. J. Immunoassay, 18 (3), 235-246. 
94. Klibanov, A.M. (1989) Enzymatic catalysis in anhydrous organic solvents. Trends Biochem. Sci., 14, 141-144.

95. Khmelnitsky, Y.L.; Levashov, A.V.; Klyachko, N.L.; Martinek, K. (1995) Engineering biocatalytic system in organic media with low water content. Enzyme Microb. Technol., 10, 716-724.

96. Faber, K. (Ed.) (1999) Special techniques. En "Biotransformations in Organic Chemistry”. Springer, Verlag Berlin, Germany, pp 334-384.

97. Russell, A.J.; Trudel, L.J.; Skipper, P.L.; Groopman, J.D.; Tannenbaum, S.R.; Klibanov, A.M. (1989) Antibody-antigen binding in organic solvents. Bioch. Bioph. Res. Comm., 158 (1), 80-85.

98. Weetall, H.H. (1991) Antibodies in water immiscible solvents. Immobilized antibodies in hexane. J. Immunol. Methods, 136, 139-142.

99. Giraudi, G.; Baggiani, C. (1993) Solvent effects on testosterone-antitestosterone interaction. Biochim. Biophys. Acta, 1157, 211-216.

100. Hedenfalk, M.; Adlercreutz, P.; Mattiasson, B. (1997) Modulation of the measuring range of a radioimmunoassay using an organic water two phase system. Anal. Chim. Acta, 341 (2-3), 269-274.

101. Gee, S.J.; Miyamoto, T.; Goodrow, M.H.; Busler, D.; Hammock, B.D. (1988) Development of an ELISA for the analysis of the thiocarbamate herbicide molinate. J. Agric. Food Chem., 36, 863-870.

102. Stocklein, W.; Gebbert, A.; Schmid, R.D. (1990) Binding of triazine herbicides to antibodies in anhydrous organic solvents. Anal. Lett., 23 (8), 1465-1476.

103. Stocklein, W.; Warsinke, A.; Scheller, F.W. (1997) Organic solvent modified enzyme-linked immunoassay for the detection of triazine herbicides. En "Immunochemical Technology for Environmental Applications". D.S. Aga; E.E. Thurman (Eds.). ACS Symposium Series 657, American Chemical Society, Washington, DC, pp 373-381.

104. Nugent, P. (1992) En "Emergin Strategies for Pesticide Analysis". T. Cairus; J. Sherma (Eds.). CRC Press, Boca Ratón, Florida, 247 pp.

105. Schneider, P.; Hammock, B.D. (1992) Influence of the ELISA format and the hapten enzyme conjugate on the sensitivity of an immunoassay for s-triazine herbicide using monoclonal antibodies. J. Agric. Food Chem., 40, 525-530.

106. Hill, A.S.; Mei, J.U.; Yin, C.; Fergusson, B.S.; Skerritt, J.H. (1991) Determination of the insect growth regulator methoprene in wheat grain and 
milling fractions using an enzyme immunoassay. J. Agric. Food Chem., 39, 1882-1886.

107. Beckeit, H.K.; Lucas, A.D.; Szurdoki, F.; Gee, S.J.; Hammock, B.D. (1993) An enzyme immunoassay for the environmental monitoring of the herbicide bromacil. J. Agric. Food Chem., 41, 2220-2227.

108. Wittmann, C.; Hock, B. (1994) Development of an enzyme immunoassay for the analysis of the atrazine metabolite hidroxiatrazine. Acta Hydrochim. Hidrobiol., $22(2), 60-69$.

109. Schmidt, D.J.; Clarkson, C.E.; Swanson, T.A.; Egger, M.L.; Carlson, R.E.; Van Emon, J.M.; Karn, A.E. (1990) Monoclonal antibodies for IA of avermectins. $J$. Agric. Food Chem., 38 (8), 1763-1770.

110. Sasaki, S.; Tokitsu, Y.; Ikebukuro, K.; Yokoyama, K.; Masuda, Y.; Karube, I. (1997) Biosensing of a herbicide using a chemically modified antibody in organic solvent. Anal. Lett., 30 (3), 429-443.

111. Fukal, L.; Reisnerova, H. (1989) Effect of organic solvent concentration on RIA of aflatoxin B1. J. Radioanal. Nucl. Chem., 132 (2), 315-319.

112. Matsura, S.; Hamano, Y.; Kita, H.; Takagaki, Y. (1993) Preparation of mouse monoclonal antibodies to okadaic acid and their binding activity in organic solvents. J. Biochem., 114, 273-278.

113. Matsura, S.; Hamano, Y.; Kita, H.; Takagaki, Y. (1994) Specificity of mouse monoclonal anti-okadaic acid antibodies to okadaic acid and its analogs among diarrhetic shellfish toxins. Biosci. Biotech. Biochem., 58 (8), 1471-1475.

114. Kabanov, A.V.; Khrutskaya, M.M.; Eremin, S.A.; Klyachko, N.L.; Levashov, A.V. (1989) New way in homogeneous immunoassay: reversed micellar systems as a medium for analysis. Anal. Biochem., 181 (1), 145-148.

115. Groome, N.P.; Vacher, M.; Nicot, C.; Waks, M. (1990) Antigen-antibody binding in reverse micelles-interaction of monoclonal-antibodies with a Myelin basic-protein peptide. Biochem. Int., 21 (1), 1-7.

116. Matveeva, E.G.; Melik-Nubarov, N.S.; Miethe, P.; Levashov, A.V. (1996) Antigen-antibody interactions in the reverse micellar system:quenching of the fluorescence of fluorescein-labeled atrazine by antibodies against atrazine. Anal. Biochem., 234, 13-21.

117. Francis, J.M.; Craston, D.H. (1994) Immunoassay for parathion without its prior removal from solution in hexane. Analyst, 119, 1801-1808. 
118. Setford, S.J (2000) Immunosensing in organic and mixed aqueous-organic phase environments. Trends Anal. Chem., 19 (5), 330-339.

119. Gramatica, P.; Navas, N.; Todeschini, R. (1999). Classification of organic solvents and modelling of their physico-chemical properties by chemometric methods using different sets of molecular descriptors. Trends Anal. Chem., 18 (7), 461-470.

120. De Juan, A.; Fonrodona,G.; Casassas, E. (1997) Solvent classification based no solvatochromic parameters: a comparison with the Snyder approach. Trends Anal. Chem., 16 (1), 52-59.

121. Reichardt, C. (Ed.) (1988) Solvent and Solvent Effects in Organic Chemistry. $\mathrm{VCH}$, Weinheim, Germany.

122. Kamlet, M.J.; Abboud, J.L.M.; Taft, R.W. (1981) Progress in Physical Organic Chemistry. Vol. 13. R.W. Taft (Ed.). Interscience, New York.

123. Marqués, I.; Fonrodona, G.; Butí, S.; Barbosa, J. (1999) Solvent effects on mobile phases used in liquid chromatography: factor analysis applied to protonation equilibria and solvatochromic parameters. Trends Anal. Chem., 18 (7), 472-480.

124. Barbosa, J.; Marqués, I.; Barrón, D.; Sanz-Nebot, V. (1999) The application of factor analysis to solvatochromic parameters and $\mathrm{pHs}$ values for the standardization of potenciometric sensors in mobile phases used in liquid chromatography. Trends Anal. Chem., 18 (8), 543-551.

125. Brink, L.E.S.; Tramper, J. (1985) Optimization of organic solvents in multiphase biocatalysis. Biotechnol. Bioeng., 27, 1258-1269.

126. Connors, K.A. (1990) Chemical kinetics. The Study of Reactions Rates in Solution. VCH Plublishers, New York, pp 385-462.

127. Skládal, P. (1999) Effect of methanol on the interaction of monoclonal antibody with free and immobilized atrazine studied using the resonant mirror-based biosensor. Biosens. Bioelectron., 14, 257-263.

128. Marco, M.P.; Gee, S.; Hammock, B.D. (1995) Immunochemical techniques for environmental analysis I. Immunosensors. Trends Anal. Chem., 14 (7), 341-349.

129. Khomutov, S.M.; Zherdev, A.V.; Dzantiev, B.B.; Reshetilov, A.N. (1994) Immunodetection of herbicide 2,4-dichlorophenoxyacetic acid by field effect transistor-based biosensors. Anal. Lett., 27 (14), 2983-2995. 
130. Durst, R.A.; Siebert, S.T.A.; Roberts, M.A.; Larsson-Kovach, I.M.; Reeves, S.G. (1992) $2^{\text {nd }}$ Bioelectroanalytical Symposium. Matrafured, Budapest, Akademiai Kiado, Budapest.

131. Nunes, G.S.; Barceló, D. (1998) Electrochemical biosensors for pesticide determination. Analusis, 26 (6), M156-M159.

132. Trojanowicz, M.; Hitchman, M.L. (1996) Determination of pesticides using electrochemical biosensors. Trends Anal. Chem., 15 (1), 38-45.

133. Suleiman, A.A.; Guilbault, G.G. (1994) Recent developments in piezoelectric immunosensors. A review. Analyst, 119 (11), 2279-2282.

134. Guilbault, G.G.; Hock, B.; Schmid, R.D. (1992) A piezoelectric immunobiosensor for atrazine in drinking water. Biosens. Bioelectron., 7 (6), 411-419.

135. Minunni, M.; Skládal, P.; Mascini, M. (1994) A piezoelectric quartz-crystal biosensor as a direct affinity sensor. Anal. Lett., 27 (8), 1475-1487.

136. Minunni, M.; Mascini, M. (1993) Detection of pesticide in drinking water using real-time bioespecific interaction analysis (Bia). Anal. Lett., 26 (7), 1441-1460.

137. Kooyman, R.P.H.; Lechucha, L.M. (1997) Immunosensors based on total internal reflectance. En "Handbook of Biosensors and Electronic Noses". Medicine, Food and the Environment. E. Kress-Rogers (Ed.). CRC Press, Boca Ratón, FL, pp 169-196.

138. Oroszlan, P.; Duveneck, G.L.; Ehrat, M.; Widmer, H.M. (1993) Fiberoptic atrazine immunosensor. Sensors and Actuators B, 11 (1-3), 301-305.

139. Oroszlan, P.; Thommen, C.; Wehrli, M.; Ehrat, M. (1993) Automated optical sensing system for biochemical assays: a challenge for ELISA?. Anal. Methods Instrum., 1, 43-51.

140. Bier, F.F.; Jockers, R.; Schmid, R.D. (1994) Integrated optical immunosensor for s-triazine determination: regeneration, calibration and limitations. Analyst, 119, $437-445$.

141. Lim, C.S.; Miller, J.N.; Bridges, J.W. (1980) Automation of an energy-transfer immunoassay (for albumin) by using stopped-flow injection analysis with merging zones. Anal. Chim. Acta, 114, 183-189.

142. Valcárcel, M.; Luque de Castro, M.D. (1987) Flow Injection Analysis. Principles and Applications. Ellis Horwood Ltd., Chichester, UK. 
143. Pollema, C.H.; Ruzicka, J.; Christian, G.D.; Lernmark, A. (1992) Sequentialinjection immunoanalysis utilizing immunomagnetic beads. Anal. Chem., 64 (13), 1356-1361.

144. Puchades, R.; Maquieira, A. (1996) Recent developments in flow injection immunoanalysis. Crit. Rev. Anal. Chem., 26 (4), 195-218.

145. Gübitz, G.; Shellum, C. (1993) Flow-injection immunoassays. Anal. Chim. Acta, 283 (1), 421-428.

146. Vo-Dihn, T.; Tromberg, B.; Griffin, G.D.; Ambrose, K.R.; Sepaniak, M.J.; Gardenhire, E.M. (1987) Antibody-based fibre optics biosensors for the carcinogen benzopyrene. Appl. Spectrosc., 41 (5), 735-738.

147. Schmid, R.D. (Ed.) (1991) Flow Injection Analysis Based on Enzymes or Antibodies. GBF Monographs vol. 14, VCH, Weinheim, Germany.

148. Krämer, P.; Schmid, R. (1991) Flow Injection Immunoanalysis (FIIA)- a new immunoassay format for the determination of pesticides in water. Biosens. Bioelectron., 6, 239-243.

149. Brecht, A.; Piehler, J.; Lang, G.; Gauglitz, G. (1995) A direct optical immunosensor for atrazine detection. Anal. Chim. Acta, 311 (3), 289-299.

150. Lu, B.; Smyth, M.R.; O’Kennedy, R. (1996) Oriented immobilization of antibodies and its applications in immunoassays and immunosensors. Analyst, 121 (3), 29R-32R.

151. Tijssen, P. (1985) En "Practice and Theory of Enzyme Immunoassays". R.H. Burdon; P.H. Knippenberg (Eds.). Laboratory Techniques in Biochemistry and Molecular Biology, vol. 15, Elsevier, Amsterdam, The Netherlands.

152. Pollema, C.H.; Ruzicka, J. (1994) Flow injection renewable surface immunoassay: a new approach to immunoanalysis with fluorescence detection. Anal. Chem., 66 (11), 1825-1831.

153. Wittman, C.; Schmid, R.D. (1994) Development and application of an automated quasi-continuous immunoflow injection system to the analysis of pesticide residues in water and soil. J. Agric. Food Chem., 42, 1041-1047.

154. Mohan, S.B.; Lyddiatt, A. (1997) Recent develpoments in affinity separation technologies. En “Affinity Separations. A Practical Approach”. P. Matejtsschuk (Ed.). Oxford University Press, Inc., Nueva York, pp 1-38. 
155. González-Martínez, M.A.; Puchades, R.; Maquieira, A. (1997) Reversibility in heterogeneous flow immunosensing and related techniques. A brief overview. Food Technol. Biotechnol., 35 (3), 193-204.

156. Mattiasson, B.; Hakanson, H. (1992) Immunochemically based assays for process control. Adv. Biochem. Eng. Biotechnol., 46, 81-102.

157. Moye, H.A.; Scherer, S.J.; St. John, P.A. (1977) Dynamic fluorogenic labeling of pesticides for high performance liquid chromatography: detection of $\mathrm{N}$ methylcarbamates with o-phthaldahyde. Anal. Lett., 10, 1049-1073.

158. Simon, V.A.; Pearson, K.S.; Taylor, A. (1993) Determination of Nmethylcarbamates and N-methylcarbamoyloximes in water by high-performance liquid chromatography with the use of fluorescence detection and a single ophthalaldehyde post-column reaction. J. Chromatogr., 643, 317-320.

159. Chiba, M. (1981) Rapid colorimetric method for the analysis of carbaryl spray deposits on fruit tree foliage J. Agric. Food Chem., 29, 118-121.

160. Espinosa-Mansilla, A.; Salinas, F.; Zamoro, A. (1994) Simultaneous determination of chlorpirifos and carbaryl by differential degradation using diode-array spectrophotometry optimized by partial least squares. Analyst, 119 (6), 1183-1188.

161. Sancenón, J.F.; de la Guardia, M. (1992) Micellar enhanced flow injection fluorimetric determination of carbaryl and 1-naphthol. Quím. Anal., 11, 285-297.

162. Gallignani, M.; Garriges, S.; Martínez-Vado, A.; de la Guardia, M. (1993) Determination of carbaryl in pesticide formulations by Fourier-transform infrared spectrometry with flow-analysis. Analyst, 118 (8), 1043-1048.

163. Kumaran, S.; Tran-Minh, C. (1992) Determination of organophosphorous and carbamate insecticides by flow injection analysis. Anal. Biochem., 200 (1), 187194.

164. Argauer, R.J.; Brown, R.T. (1994) Detection of carbofuran and other carbamates using cholinesterase inhibition with $\mathrm{N}$-methylindoxylacetate as substrate. $J$. Agric. Food Chem., 42 (9), 1920-1924.

165. Marco, M.P.; Chirón, S.; Gascón, J.; Hammock, B.D.; Barceló, D. (1995) Validation of two immunoassay methods for environmental monitoring of carbaryl and 1-naphthol in ground water samples. Anal. Chim. Acta, 311 (3), 319-329. 
166. Abad, A.; Montoya, A. (1994) Production of monoclonal antibodies for carbaryl from a hapten preserving the carbamate group. J. Agric. Food Chem., 42 (8), 1818-1823.

167. Abad, A.; Montoya, A. (1995) Application of monoclonal antibody-based ELISA to the determination of carbaryl in apple and grape juices. Anal. Chim. Acta, 311 (3), 365-370.

168. Abad, A.; Primo, J.; Montoya, A. (1997) Development of an enzyme-linked immunosorbent assay to carbaryl. 1. Antibody production from several haptens and characterization in different immunoassay formats. J. Agric. Food Chem., 45 (4), 1486-1494.

169. Abad, A.; Montoya, A. (1997) Development of an enzyme-linked immunosorbent assay to carbaryl. 2. Assay optimization and application to the analysis of water samples. J. Agric. Food Chem., 45 (4), 1495-1501.

170. Megharaj, M.; Rao, A.P.; Rao, A.S.; Venkasteswarlu, K. (1990) Interaction effects of carbaryl and its hydrolysis product -1-naphthol- towards 3 isolates of microalgae from rice soil. Agric. Ecosyst. Environ., 31 (4), 293-300.

171. De Berardinis, M.Jr.; Wargin, W.A. (1982) High performance liquid chromatography determination of carbaryl and 1-naphthol in biological fluids. $J$. Chromatogr., 246 (1), 89-94.

172. García-Sánchez, F.; Cruces-Blanco, C. (1987) Isodifferential derivative spectrophotometric assay of the carbamate pesticide carbaryl and its metabolite in biological fluids and commercial formulations. Int. J. Environ. Anal. Chem., 31 (1), 23-40.

173. Sancenón, J.; Carrión, J.L.; de la Guardia, M. (1989) Fluorimetric determination of carbaryl in micellar media. Talanta, 36 (12), 1165-1169.

174. Krämer, P.; Marco, M.P.; Hammock, B.D. (1994) Development of a selective enzyme-linked immunosorbent assay for 1-naphthol -the major metabolite of carbaryl (1-naphthyl N-methylcarbamate). J. Agric. Food Chem., 42 (4), 934943.

175. Bryan, G.W.; Gibbs, P.E. (1991) Impact of low concentrations tributyltin (TBT) on marine organism. A review. En "Metal Ecotoxicology: Concepts and Applications". M.C. Newman; A.W. Mcintsoh (Eds.). Lewis, Chelsea, MI, pp 323-361. 
176. European Union (1989) Journal Officiel des Communites Europeennes, pp 1923.

177. Holt, J.S. (1993) Mechanisms and agronomic aspects of herbicide resistance. Ann. Rev. Plant Physiol. Plant Mol. Biol., 44, 203-229.

178. Dahl, B.; Blank, H. (1996) Toxic effects of the antifouling agent Irgarol 1051 on periphyton communities in coastal water microcosms. Mar. Pollut. Bull., 32, 342-350.

179. Ciba Geigy (1995) Irgarol 1051 in antifouling paints. Technical Information Bulletin, Ciba Geigy, Basel, Switzerland.

180. Gough, M.A.; Fothergill, J.; Hendrie, J.D. (1994) A survey of southern england coastal waters for the s-triazine antifouling compound Irgarol 1051. Mar. Pollut. Bull., 28, 613-620.

181. Zhou, J.L.; Fileman, T.W.; Evans, S.; Donkin, P.; Mantouran, R.F.C.; Rowland, S.J. (1996) Seasonal distribution of dissolved pesticides and polynuclear aromatic hydrocarbons in the Humber estuary and Humber coastal zone. Mar. Pollut. Bull., 32, 599-608.

182. Ferrer, I.; Ballesteros, B.; Marco, M.P.; Barceló, D. (1997) Pilot survey for the determination of the antifouling agent Irgarol 1051 in enclosed sea water samples by a direct enzyme-linked-immunosorbent assay and solid-phaseextraction followed by LC-DAD detection. Environ. Sci. Technol., 31, 35303538 .

183. Tolosa, I.; Readman, J.W.; Blaevoet, A.; Ghilini, S.; Bartocci, J.; Horvat, M. (1996) Contamination of Mediterranean (Côte d'Azur) coastal waters by organotins and Irgarol 1051 used in antifouling paints. Mar. Pollut. Bull., 32, 335-341.

184. Readman, J.W.; Kwong, L.L.; Grondin, D.; Bartocci, J.; Villeneuve, J.P.; Mee, L.D. (1993) Coastal water contamination from a triazine herbicide used in antifouling paints. Environ. Sci. Technol., 27, 1940-1942.

185. Toth, S.; Becker Van Slooten, K.; Spack, L.; de Alencastro, L.F.; Tarradellas, J. (1996) Irgarol 1051, an antifouling compound in fresh-water, sediment and biota of Lake Geneva. Bull. Environ. Contam. Toxicol., 57 (3), 426-433.

186. Penalva, J.; González-Martínez, M.A.; Puchades, R.; Maquieira, A.; Marco, M.P.; Barceló, D. (1999) Immunosensor for trace determination of Irgarol 1051 in seawater using organic media. Anal. Chim. Acta, 387 (3), 227-233. 
187. González-Martínez, M.A.; Penalva, J.; Puchades, R.; Maquieira, A.; Ballesteros, B.; Marco, M.P.; Barceló, D. (1998) An immunosensor for the automatic determination of the antifouling agent Irgarol 1051 in natural waters. Environ. Sci. Technol., 32, 3442-3447.

188. Ballesteros, B.; Barceló, D.; Camps, F.; Marco, M.P. (1997) Preparation of antisera and development of a direct enzyme-linked immunosorbent assay for the determination of the antifouling agent Irgarol 1051. Anal. Chim. Acta, 347 (1-2), 139-147.

189. Ballesteros, B.; Barceló, D.; Sánchez-Baeza, F.; Camps, F.; Marco, M.P. (1998) Influence of the hapten desing on the development of a competitive ELISA for the determination of the antifouling agent Irgarol 1051 at trace levels. Anal. Chem., 70 (19), 4004-4010.

190. Gascón, J.; Oubiña, A.; Ballesteros, B.; Barceló, D.; Camps, F.; Marco, M.P.; González-Martínez, M.A.; Morais, S.; Puchades, R.; Maquieira, A. (1997) Development of a highly sensitive enzyme-linked immunosorbent assay for atrazine. Performance evaluation by flow injection immunoassay. Anal. Chim. Acta, 347 (1-2), 149-162.

191. Morais, S.; González-Martínez, M.A.; Puchades, R.; Maquieira, A.; Abad, A.; Montoya, A (1997) Rapid screening of immunoreagents for carbaryl immunosensor development. En "Immunochemical Technology for Environmental Applications". D.S. Aga; E.M. Thurman (Eds.). ACS Symposium Series 657, American Chemical Society, Washington, DC, pp 106116.

192. Rajkowski, K.M.; Cittanova, N.; Desfosses, B.; Jayle, M.F. (1977) The conjugation of testosterone with horseradish peroxidase and a sensitive enzyme assay for the conjugate. Steroids, 29, 701-713.

193. Erlanger, B.F. (1980) The preparation of antigenic hapten-carrier conjugates: a survey. Methods Enzymol., 70, 85-104.

194. Bauminger, S.; Wilchek, M. (1980) The use of carbodiimides in the preparation of immunizing conjugates. Methods Enzymol.,70, 151-159.

195. Langone, J.J.; Van Vunakis, H. (1982) Radioimmunoassay of nicotine, cotinine and $\gamma$-3-(-piridyl)- $\gamma$-oxo-N-methylbutyramide. Methods Enzymol.,84, 628-640.

196. Pierce Chemical Company (1993) Instructions 0497, Rockford, IL. 
197. Wilson, M.B.; Nakane, P.K (1978) En "Immunofluorescence and Related Staining Techniques”. W. Knapp; H. Holubar; G. Wick (Eds.). Elsevier/NorthHolland, Amsterdam, pp 215-224.

198. Masoom, M.; Townshend, A. (1984) Determination of glucose in blood by FIA and an immobilized glucose oxidase column. Anal. Chim. Acta, 166, 111-118.

199. Morais, S.; González-Martínez, M.A.; Puchades, R.; Maquieira, A.; Abad, A.; Montoya, A. (1996) A screening method for reagent selection to develop flowimmunoassays. Book of Abstracs, $211^{\text {th }}$ ACS National Meeting, New Orleans, LA, March 24-28, vol 36 (1), ENVR-102 Publisher, American Chemical Society, Washington, pp 136-138.

200. Takalo, H.; Mukkala, V.M.; Merio, L.; Rodriguez-Ubis, J.C.; Juanes, O.; Brunet, E. (1997) Development of luminiscent Terbium (III) chelates for protein labeling-effect of triplet-state energy-level. Helv. Chim. Acta, 80 (2), 372-387.

201. Khokhar, M.Y.; Miller, J.N.; Seare, N.J. (1994) Heterogeneous fluorescence immunoassays using flow-injection analysis with protein $\mathrm{G}$ solid-phase reactors. Anal. Chim. Acta, 290 (1), 154-158.

202. Adam, W.; Reinhardt, D.; Saha-Moller, C.R. (1996) From the firefly bioluminiscence to the dioxetane-based (AMPPD) chemiluminiscence immunoassay: a retroanalysis. Analyst, 121, 1527-1531.

203. Bronstein, I.; Voyta, J.C.; Edwards, B. (1989) A comparison of chemiluminescent and colorimetric substrates in a hepatitis B virus DNA hybridization assay. Anal. Biochem., 180, 95-98.

204. Nishizono, Y.; Iida, S.; Suzuki, N.; Kawada, H.; Murakami, H.; Ashihara, Y.; Okada, M. (1991) Rapid and sensitive chemiluminescent enzyme immunoassay for measuring tumour markers. Clin. Chem., 37 (9), 1527-1531.

205. Bronstein, I.; Edwards, B.; Voyta, J.C. (1989) 1,2-Dioxetanes: novel chemiluminiscent enzyme substrates. Applications to immunoassays. En "Proc. Vth Int. Symp. On Biolum. And Chemilum.”. N. Pazzagli; E. Cadenas; L.J. Kricka; A. Roda; P. Stanley (Eds.). Chichester, Wiley, UK., pp 99-111.

206. Bronstein, I.; Voyta, J.C.; Thorpe, G.H.; Kricka, L.J.; Amstrong, R. (1989) Chemiluminiscent assay of alkaline phosphatase applied in an ultrasensitive enzyme immunoassay of thyrotrophin. Clin. Chem., 35 (7) 1441-1447.

207. Sherma, J. (1995) Pesticides. Anal. Chem.,67 (12), 1R-20R. 
208. Sawyer, L.D.; McMahon, B.M.; Newsome, W.M.; Parker, G.A. (1990) Pesticide and Industrial Chemical Residues. AOAC, $15^{\text {th }}$ Edition.

209. Moye, H. (Ed.) (1990) Analysis of Pesticide Residues. Reprint ed. Malabar. Florida, USA, 247 pp.

210. Seaver, C.; Przybytek, J. (1995) Solvent selection, Part II-physical properties. LC-GC Int., 8 (4), 190-195.

211. Bidlingmeyer, B.A. (1992) Practical HPLC Methodology. John Wiley and sons. New York, USA, 245 pp.

212. Ting, K.C.; Kho, P.K.; Musselman, A.S.; Root, G.A.; Tichelaar, G.A. (1984) High performance liquid chromatographic method for determination of six Nmethylcarbamates in vegetables and fruits. Bull. Environ. Contam. Toxicol., 33, 538-547.

213. González-Martínez, M.A. (1998) Desarrollo de inmunosensores en flujo aplicados a la determinación de residuos de plaguicidas. Tesis Doctoral, Universidad Politécnica de Valencia, Valencia, 223 pp.

214. Borman, S. (1992) Immobilized enzymes act in organic solvents. $C \& E N N e w s$, 13, 5-6.

215. Bjarnason, B.; Bousios, N.; Eremin, S.; Johansson, G. (1997) Flow-injection enzyme immunoassay of atrazine herbicide in water. Anal. Chim. Acta, 347 (12), 111-120.

216. González-Martínez, M.A.; Puchades, R.; Maquieira, A. (1999) On line immunoanalysis for environmental pollutants: from batch assays to automated sensors. Trends Anal. Chem., 18 (3), 204-218.

217. Tropix, PE Applied Biosystems. CDP-Star chemiluminiscent substrate for alkaline phosphatase. Technical Information Bulletin, MA, USA. 


\section{ARTICULOS RELACIONADOS CON LA TESIS DOCTORAL}

1.- González-Martínez, M.A.; Penalva, J.; Puchades, R.; Maquieira, A.; Ballesteros, B.; Marco, M.P.; Barceló, D. (1998) An immunosensor for the automatic determination of the antifouling agent Irgarol 1051 in natural waters. Environ. Sci. Technol., 32, 3442-3447.

2.- Penalva, J.; González-Martínez, M.A.; Puchades, R.; Maquieira, A.; Marco, M.P.; Barceló, D. (1999) Immunosensor for trace determination of Irgarol 1051 in seawater using organic media. Anal. Chim. Acta, 387, 227-233.

3.- Penalva, J.; Puchades, R.; Maquieira, A. (1999) Analytical properties of immunosensors working in organic media. Anal. Chem., 71, 3862-3872.

4.- $\quad$ Penalva, J.; Gabaldón, J.A.; Maquieira, A.; Puchades, R. (2000) Determination of carbaryl in vegetables using an immunosensor working in organic media. Food Agric. Immunol., 12, 101-114.

5.- $\quad$ Penalva, J.; Puchades, R.; Maquieira, A.; Gee, S,G.; Hammock, B.D. (2000) Development of immunosensors for the analysis of 1-naphthol in organic media. Biosens. Bioelectron., 15, 99-106.

6.- González-Martínez, M.A.; Penalva, J.; Rodriguez-Ubis, J.C.; Brunet, E.; Maquieira, A.; Puchades, R. (2006) Immunosensors for pollutants working in organic media. Study of performances of different tracers with luminiscent detection. Anal. Bioanal. Chem.,384, 1540-1547. 